Dissertation zur Erlangung des philosophischen Doktorgrades an der philosophischen Fakultät der Georg-August-Universität

\title{
Hörerverhalten in Zweiergesprächen von Deutschen und Japanern
}

Eine kontrastive Studie zu Regularitäten und Funktionen von verbalen Hörersignalen

Vorgelegt von:

Masumi Morita

aus

Ise, Japan

Berichterstatter: Prof. Dr. Dieter Cherubim

Mitberichterstatter: Prof. Dr. Claus Fischer

Göttingen 2001 


\section{Vorwort}

Diese Arbeit ist von Herrn Professor Dr. Cherubim betreut worden. An dieser Stelle möchte ich ihm für seine sowohl wissenschaftliche als auch persönliche Unterstützung herzlich danken. Mein Dank geht auch an Herrn Dr. Stefan Goes, der in der Endzeit meiner Dissertation stets mit seinem Rat zur Verfügung stand und mich vor allem bei strukturellen und konzeptionellen Fragen bekräftigt hat. Außerdem bin ich Herrn Professor Dr. Fischer zu Dank verpflichtet, es übernahm, der die vorliegende Doktorarbeit als Ko-Referent zu begutachten. Für Hilfe beim Korrekturlesen danke ich Herrn Stephan Müller, Frau Elke Brünning, Frau Christine Zahnt und Frau Antje Wendtland. Vor allem hat Herr Stephan Müller mich nicht nur fachlich, sondern auch „seelisch“ und „moralisch“ unterstützt. Ohne seine Hilfe wäre diese Arbeit nicht zustande gekommen.

$\mathrm{Zu}$ danken habe ich auch Herrn Akio Morita (der ehemalige Präsident der Firma Sony) und der Heinrich-Böll-Stiftung, die durch die Gewährung des Studien- und Promotionsstipendium mein Studium in Göttingen finanziert haben. Ein besonderes Dank gilt meinen Eltern, die mit mir sehr nachsichtig und großzügig waren und mir den langjährigen Aufenthalt im Ausland ermöglicht haben.

Nicht zuletzt möchte ich mich bei meinen Gesprächsteilnehmern, die sich für die Gesprächsaufnahme zur Verfügung gestellt haben und den Freunden und Bekannten, die ich hier nicht namentlich erwähnen konnte, bedanken, denn auch ohne ihren Beistand wäre diese Arbeit nicht realisiert worden.

Bonn, im Januar 2003 


\section{Inhaltsverzeichnis}

1 Einleitung 1

2 Forschungsüberblick 4

2.1 Kurzer Abriß der Geschichte der Hörerverhaltensforschung 4

2.2 Forschungen über Hörersignale in intrakulturellen Gesprächen 11

2.2.1 Zu Auffassungen und Klassifikationsmodellen von Hörersignalen und die prozentuale Verteilung der Typen von Hörersignalen 12

2.2.2 $\mathrm{Zu}$ einzelnen Formen der Hörersignale 17

2.2.3 Zur Gesamtfrequenz der Hörersignale pro Minute und pro Silbe 18

2.2.4 Zu Positionen und Positionsmerkmalen mit hoher und niedriger Frequenz von Hörersignalen

2.2.5 Forschungen zu Funktionen und Effekten von Hörersignalen 27

\subsection{Forschungen über Hörerverhalten im Kulturvergleich und} in interkulturellen Gesprächen 41

2.4 Zusammenfassung und Überlegungen für die empirischen Untersuchungen_48

3 Methodische Überlegungen für den empirischen Teil und die Beschreibung des

Datenmaterials 52

3.1 Methodische Überlegungen 52

3.1.1 Zur Bestimmung von Analyseaspekten und von Analysekategorien 52

3.1.2 Quantitative und qualitative Aspekte dieser Arbeit 52

3.1.3 Zur Problematik der Analyse der fremdsprachlichen Daten 53

3.1.4 Kontrastives Vorgehen 53

3.1.5 Die konkrete methodische Vorgehensweise 54

\subsection{Zum Datenmaterial____ 55}

3.2.1 Beschreibung des Datenmaterials und der Erhebungssituation _ـ 55

3.2.2 Das Beobachterparadoxon___ 59

3.2.3 Die Repräsentativität der Daten und die Generalisierbarkeit der Ergebnisse_60

3.2.4 Das Transkriptions- und Notationssystem dieser Arbeit 61 
4.1 Die Bestimmung und die Klassifikation der Hörersignale __ 64

4.1.1 Die Bestimmung von Hörerverhalten ___ 64

4.1.2 Die Klassifikation sprachlicher und nichtsprachlicher Hörersignale ___ 65

4.1.3 Definition verbaler Hörersignale___ 66

4.2 Formen der verbalen Hörersignale ___ 68

4.2.1 Die Beschreibung der Typen der Hörersignale und die prozentuale Verteilung der Typen im Deutschen 68

4.2.2 Die Beschreibung der Typen der Hörersignale und die prozentuale Verteilung der Typen in den japanischen Daten ___ 83

4.2.3 Zusammenfassung___ 91

4.3 Positionen der Hörersignale___ 95

4.3.1 Die Positionen der Hörersignale in den deutschen Daten ___ 95

4.3.2 Die Positionen der Hörersignale in den japanischen Daten __ 110

4.3.3 Zusammenfassung___ 132

4.4 Die Frequenz der Hörersignale in Abhängigkeit von Merkmalen von

Satzenden___ 137

4.4.1 Die Frequenz der Hörersignale in Abhängigkeit von Merkmalen von Satzenden in den deutschen Daten 137

4.4.2 Die Frequenz der Hörersignale in Abhängigkeit von Merkmalen von Sätzen in den japanischen Daten __ 149

4.4.3 Zusammenfassung___ 168

4.5 Funktionen von Hörersignalen _ 173

4.5.1 Vorbemerkungen zu Funktionen von Hörersignalen im Gespräch___ 173

4.5.2 Funktionen von Hörersignalen in den deutsche Daten _ 176

4.5.3 Funktionen von Hörersignalen in den japanischen Daten___ 199

4.5.4 Zusammenfassung___ 226

5 Zusammenfassung und Schlußbemerkung ___ 236

6 Literatur _ 255 


\section{Verzeichnis der Abkürzungen}

Adj. Adjektive

Adv. Adverbalsatz

AK ausgeklammerte Phrase

Att. Attributivsatz

Advst. Adversativsatz

BN Bezugsnomen

EL einleitende Satzelemente

ES einfacher, erweiterter sowie gleichkoordinierter Satz

ETC Etceteraformeln

EẄ̈ Ein-Wort-Äußerung

FM Formalnomen

HV Hilfsverb

HS Hauptsatz

KF Kurformen

kjPP konjunktionale Postposition

KKF Kombinierte Kurzformen

Konj. Konjunktion

LK Linke Klammer

MF Mittelfeld

N Normen

NF Nachfeld

Neg. Negation

Obj. Objekt oder Objektsatz

Obj.PP Objekt-Postposition

PP Postposition

RK Rechte Klammer

Suj. Subjekt

Suj.PP Subjekt-Postposition

slPP satzletzte Postposition

sIV satzletztes Verb

sIW satzletztes Inhaltswort

SNS sonstige Satzelemente 


$\begin{array}{ll}\text { SS } & \text { Sprechersignale } \\ \text { SVO } & \text { Verbzweitstellung } \\ \text { SOV } & \text { Verbletztstellung } \\ \text { V } & \text { Verb } \\ \text { VE } & \text { Verbergänzung } \\ \text { VF } & \text { Vorfeld } \\ \text { Vte } & \text { Verbform: Verbstamm }+\mathrm{i}+\text { te } \\ \text { Vru } & \text { Verbform: Verbstamm }+\mathrm{u} / \mathrm{ru} \\ \text { VVF } & \text { Vorvorfeld }\end{array}$




\section{Einleitung}

In der vorliegenden Arbeit befasse ich mich mit Hörerverhalten in Zweiergesprächen von deutschen und japanischen Studenten. Dabei dienen acht selbst aufgenommene Gespräche als Untersuchungsmaterial. Mein Ziel ist es, Höreraktivitäten unter einigen Aspekten (Formen, Positionen und Funktionen usw.) zu analysieren und systematisch auffindbare Regularitäten, die sich in meinen Daten finden lassen, aufzuzeigen. Die Ergebnisse der deutschen sowie der japanischen Daten werden dann miteinander verglichen und linguistisch, „datenimmanent“ und ggf. kulturell erklärt.

Einige Beweggründe für dieses Thema sind folgende: Zum einen lag es mir lange Zeit am Herzen, Gesprächsverhalten von Deutschen und Japanern zu erforschen und Ähnlichkeiten und Unterschiede wissenschaftlich herauszuarbeiten. Das beruht auf meinem langjährigen Aufenthalt in Deutschland. Als Ausländerin dachte ich oft über Kulturunterschiede zwischen Deutschland und Japan nach; es ist nicht zu verleugnen, daß „deutsche“ und ,japanische“ Kommunikationskonventionen sowie ihnen zugrunde liegende kulturelle Werte in vielerlei Hinsicht voneinander abweichen; das Aufeinanderprallen beider Kulturen verursachten in einer deutsch-japanischen Begegnung den Gesprächspartnern beider Länder gelegentlich Unsicherheiten oder sogar Unannehmlichkeiten. Kulturelle Differenzen zwischen beiden Ländern im kommunikativen Verhalten lassen sich auf verschiedenen linguistischen Ebenen (sprachlicher, Sprachverwendungs- und Gesprächsverhaltensebene) finden. ${ }^{1}$ Einer dieser Verhaltensaspekte ist der Hörerverhaltensstil, auf den in einigen Publikationen eingegangen wird. ${ }^{2}$ Als problematisch gilt z.B., daß hai (ja) von japanischen Hörern für deutsche Sprecher oft nicht eindeutig interpretierbar ist, nämlich ob es sich gerade um ein Verstehenssignal, ein Zustimmungssignal oder eine sonstige Mitteilung handelt; ${ }^{3}$ außerdem empfinden Deutsche

\footnotetext{
${ }^{1}$ Mae (1985), v. Helmolt (1993), Sugitani (1994) listen verschiedene Bereiche auf, in denen Verhaltensweisen von Deutschen und Japanern „kritische Differenzen“ aufzeigen. So unterscheiden sich z.B. Kommunikationsstile beider Länder in bezug auf Direktheit, Fragehandlung, Hörerverhalten, Entschuldigungsverhalten, Begründungsart, Argumentationsschemata usw.

2 Sawada (1991), v. Helmolt (1993), Takayama-Wichter (1981), Sugitani (1994) usw. Nach Takayama-Wichter verwenden japanische Deutschlerner $j a$ als Antwort auf richtig, vage, falsch oder nicht verstandene Fragen des Sprechers oder als Täuschungsmanöver des Nichtzuhörens (1981, S. 279).

${ }^{3}$ Einige Deutsche, die viel mit Japanern Kontakt haben, machen die Erfahrung, daß Japaner zwar auf eine indirekte Frage, die als Aufforderung gemeint ist, mit hai reagieren, aber trotzdem der Aufforderung nicht nachkommen; dabei meinen Japaner mit hai oft nur soviel wie: „Ja, ich habe dich verstanden“, „,ich überlege noch“. Takayama-Wichter (1981, S. 278) stellt in ihrer Analyse fest, daß japanische Deutschlerner beim Gebrauch von $j a$ ihre eigenkulturellen Verwendungen von hai übertragen. Außerdem geben Japaner, die nicht ausreichend Deutsch können, nach fast jeder Phrase ja von sich. Das kann meines Erachtens als Ausdruck der Aufnahme der syntaktisch zusammengehörigen Lautketten angesehen werden.
} 
die allzu häufige Hörerrückmeldung der Japaner eher als störend denn als aufmerksam oder unterstützend. Andererseits werden Japaner, wenn sie sich mit Deutschen unterhalten, oft dadurch verunsichert, daß sie von deutschen Hörern wenig verbale Signale erhalten. Hinsichtlich der Unterschiede im Stil des Hörerverhaltens zwischen beiden Kulturen hielt ich es für sinnvoll, anhand von einigen Gesprächsdaten gewisse systematische Tendenzen im Hörerverhalten von „Deutschen“ und „Japanern“ ausfindig zu machen, um diese wissenschaftlich dokumentieren und erklären zu können.

Außerdem war es bei der Entscheidung für den Untersuchungsgegenstand dieser Arbeit maßgeblich, daß es im deutschsprachigen Raum kaum umfangreiche Untersuchungen über das Thema Hörerverhalten gibt. Dies ist zum Teil darauf zurückzuführen, daß die Rolle des Hörers, der in einer face-to-face-Kommunikation eine große Rolle spielt, im Westen lange Zeit verkannt blieb; der Hörer galt als passiver Empfänger der Mitteilung des Sprechers, der allein den aktiven Part in der Kommunikation übernimmt und das Gespräch gestaltet. Aus diesem und dem o.a. Grund entschied ich mich, mich mit diesem bis jetzt noch wenig bekannten Teilgebiet zu befassen und einen Beitrag für die Erforschung des Gesprächsverhaltens zu leisten.

Im Vergleich zu Deutschland wird in Japan über Hörerverhalten bereits seit 20 Jahren geforscht; viele Forscher widmeten sich diesem Phänomen und publizierten zahlreiche interessante Studien. Die Relevanz der Hörerrolle in der japanischen Kultur ist auch darin ersichtlich, daß das Japanische unter dem Oberbegriff aizuchi („Gegenhammerschlag“ des Partners) ${ }^{4}$ eine Reihe von Wörtern und Sätzen besitzt, die oft im Gespräch als Feedbacks zum Einsatz kommen; dieses Wort wurde sogar in die japanische Linguistik als Fachterminus eingeführt.

Die divergierende Interessen- und Forschungslage in Deutschland und in Japan in bezug auf diesen Arbeitsbereich kann zum Teil dadurch erklärt werden, daß in beiden Ländern der Hörer und seine Tätigkeiten in der Kommunikation kulturell unterschiedlich bewertet wurden. In Deutschland liegt die kulturelle Betonung eher auf dem Akt des Sprechens; man muß, so war mein erster Eindruck, zu allem einen eigenen Kommentar bzw. seine Meinung abgeben

\footnotetext{
${ }^{4}$ „aizuchi“ bedeutet (wörtlich übersetzt) den Gegenschlag oder den Erwiderungsschlag, den der zweite Schmied mit dem Hammer schlägt, nachdem der erste Schmied geschlagen hat.
} 
und darf die Dinge niemals kommentarlos an- oder hinnehmen. Es zählt nur das, was explizit geäußert wird; hinter dem Schweigen ist nichts Gescheites verborgen. Wer nur zuhört und ständig mit dem Kopf nickt, hat keine Meinung - er kann also nicht denken; so könnte zum Beispiel der ,gute“ Zuhörer unter Umständen als dumm abgestempelt werden. Hingegen ist in Japan das Zuhören wichtiger als das Sprechen; viel Reden ist dort sogar verpönt, weil kuchi wa wazawai no moto (viel reden bringt Unheil) und stört die Harmonie zwischen Menschen. Daher präferiert man in Japan zur Vermeidung von Konflikten einen indirekten, viel implizierenden Redestil. Demnach muß der Zuhörer imstande sein, feinste und subtilste Signale des Sprechers wahrzunehmen und richtig zu interpretieren und darüber hinaus aus Teilinformationen, die er vom Sprecher aufnimmt, zu einem Ganzen zu ergänzen. Aufgrund solcher kommunikativen Leistung wird ein Hörer mit guter Befähigung in der japanischen Gesellschaft hochgeschätzt.

Das Ziel der vorliegenden Arbeit, die linguistisch verankert ist, besteht nicht in erster Linie darin, Unterschiede im Hörerverhalten zwischen beiden Sprachgruppen mit kulturellen Wertvorstellungen in den Zusammenhang zu bringen. Nichtsdestotrotz ist hier natürlich anzumerken, daß Hörerverhalten wie anderes Gesprächsverhalten ein kulturspezifisches Verhaltensmuster darstellt, dem gewisse kulturelle Werte zugrunde liegen. Dies ist auch wiederum ein Grund, weswegen manche Verhaltensmuster, die in einem Land als angemessen betrachtet werden, für Mitglieder einer anderen Kultur oft schlecht erlernbar sind und mißverstanden werden können.

Im folgenden Kapitel wird ausführlich auf die Forschungslage dieses Themas eingegangen. Aus den Befunden der Forschungsliteratur werden die Thesen für diese Arbeit abgeleitet; im Anschluß daran werden im Kapitel 3 die methodischen Grundlagen dieser Arbeit vorgestellt und begründet. Ferner werden die konkreten Analyseschritte für den empirischen Teil dargelegt. Im Kapitel 4 werden Höreraktivitäten nach Formen, Positionen und Funktionen quantitativ oder qualitativ untersucht. Im Kapitel 5, dem letzten Kapitel dieser Arbeit, werden die Ergebnisse des Kapitels 4 in bezug auf Unterschiede und Ähnlichkeiten zwischen den deutschen und den japanischen Daten zusammengefaßt und kritisch gewürdigt. 


\section{Forschungsüberblick}

\subsection{Kurzer Abriß der Geschichte der Hörerverhaltensforschung}

Bis zu 50er Jahren fand das Thema Hörerverhalten ein kaum allgemeines wissenschaftliches Interesse. ${ }^{5}$ Das lag zum Teil daran, daß die Leistung des Hörers in der Kommunikation nicht richtig anerkannt wurde; so wurde der Hörer z.B. in dem damals gängigen Kommunikationsmodell, das in der Informationstheorie entwickelt wurde, nur als passiver Empfänger und Dekodierer der Sprechermitteilung angesehen, und zugleich wurde der interpersonale Bezug zwischen den Kommunizierenden, somit der aktive Anteil des Hörers am Kommunikationsprozeß, ignoriert.

Ähnlich wie in der Kommunikationstheorie vertrat auch die in der Linguistik entwickelte Sprechakttheorie die sprecherorientierte Sichtweise. Sie ließ ebenso hörerseitige Einflüsse auf den Sprecher bei der Ausführung von sprachlichen Handlungen außer acht und befaßte sich nur mit Sprecherintentionen und den Gelingungsbedingungen ohne einen Hörerbezug. ${ }^{6}$

Das Forschungsinteresse am Hörerverhalten wuchs in den USA erst nach den 50er Jahren bei Forschern verschiedener Fachbereiche, die sich mit sozialer Interaktion beschäftigten. ${ }^{7}$ C. C. Fries (1951) z.B. war einer der ersten, der in jener Zeit auf die Signale des Hörers wie yeah, good, I know usw. aufmerksam wurde und ihnen den Namen ,signals of continued attention“ verlieh. ${ }^{8}$ Auch in Japan gab es vereinzelt Aufsätze über Ausdrücke der Erwiderung, „ôtô hyôgen“. 9

Ab den 60er Jahren gewann der Teilaspekt der sozialen Interaktion, also die Höreraktivitäten, immer mehr Bedeutung in der amerikanischen Interaktionsforschung. ${ }^{10}$ Die Forscher dieser Richtung waren sich der aktiven Rolle des Hörers im Kommunikationsprozeß bewußt und

\footnotetext{
${ }^{5}$ Es sei angemerkt, daß der Hörer schon lange eine wissenschaftliche Kategorie gewesen ist: Henne (1978, S. 122) referiert z.B. auf Bühler (1927), der bereits die verstehende, mitfühlende, gesprächssteuernde Rolle des Hörers erkannte.

6 Einer der Hauptvertreter der Sprechakttheorie, Searle (1971), beschreibt ausführlich sprecherseitige Bedingungen bei einigen Sprechakten.

${ }^{7}$ Nach W. Schmidt wurden bereits in den 50er und 60er Jahren zahlreiche Studien im Bereich der Psychologie über Aufgaben und Leistungen des Zuhörens veröffentlicht, die jetzt aber keine Verbreitung mehr finden (W. Schmidt 1999, S. 57).

${ }^{8}$ A. Blau liefert eine Auflistung von verschiedenen Bezeichnungen für Höreraktivitäten in den USA (1986, S. 7).

${ }^{9}$ Sugito (1989, S. 48) gibt zwei Autoren an: Ikegami (1952) und Miyachi (1959).

${ }_{10}$ Gemeint sind hier Wissenschaftler verschiedener Fachrichtungen, die sich mit der sozialen Interaktion beschäftigten: Hall (1969), Kendon (1967), Dittman/Llewellyn (1968) usw.
} 
machten folglich auch Höreraktivitäten zum Gegenstand der Untersuchung. Ihr Interesse galt z.B. dem Zusammenspiel der beiden Gesprächspartner oder den Effekten des Hörerverhaltens auf den Sprecher bzw. das Sprecherverhalten. ${ }^{11}$ Von den Publikationen in den 60er Jahren werden vor allem Kendon (1967), Dittman/Llewellyn (1968) und Hall (1969) in den späteren Arbeiten $\mathrm{zu}$ diesem Themenbereich oft zitiert. ${ }^{12}$

Kendon (1967) untersuchte das Blickverhalten der Gesprächspartner während der Kommunikation und zeigte, daß das Blickverhalten, wie die Blickbewegung zum anderen hin oder die Abwendung des Blicks vom Gegenüber, eine den Turnwechsel regulierende oder eine Hörerreaktion evozierende Funktion ausüben kann. Bei Dittman/Llewellyn (1968) hingegen bildeten die verbale Hörerreaktion und das Kopfnicken den Untersuchungsgegenstand. Anhand statistischer Berechnungen stellten sie fest, daß in fast der Hälfte der Fälle beide Typen zusammen auftreten, wobei Kopfnicken häufiger der verbalen Reaktion vorausgeht. Hall (1969) gilt als einer der ersten, die die Aufmerksamkeit für Kulturunterschiede im Hörerverhalten und die daraus resultierenden kommunikativen Probleme in interethnischen Gesprächssituationen geweckt haben.

In den 70er Jahren erlebte die Erforschung der Höreraktivitäten in den USA den ersten größeren Aufschwung. Eine Reihe von wegweisenden, zu weiteren Untersuchungen anregenden Arbeiten wurden in den 70er Jahren veröffentlicht.

Der Aufsatz von Yngve (1970) stellt eine der ersten linguistischen Studien über Hörerverhalten dar. Yngve führte den Fachbegriff „back channel“ ein, mit dem er kurze verbale Äußerungen des Hörers wie yes, uh uhu, oh, I believe it usw., die „out of turn“ sind, bezeichnete. $^{13}$ In seinem Aufsatz traf Yngve hinsichtlich der Formen, Positionen und Funktionen von „back channel“-Äußerungen und Kopfnicken interessante Feststellungen, die er anhand von Analysen von Zweiergesprächen herausfand. Er erkannte, daß die Plazierung von „back channel“-Äußerungen eine gewisse Systematik aufweist: Sie stehen nämlich oft nach einer ,pitch pause“, ${ }^{14}$ sind aber manchmal überlappt mit der Sprecheräußerung plaziert. Kopfnicken kann verbale Höreräußerungen begleiten, aber auch ohne sie auftreten. Aus

\footnotetext{
${ }^{11}$ Siehe Erickson 1988, S. 297-298.

${ }^{12} \mathrm{Im}$ Kapitel 2.2.4.1 werde ich auf sie eingehen.

${ }^{13}$ Yngve 1970, S. 574.

${ }^{14}$ Vgl. Yngve 1970, S. 574.
} 
funktionaler Sicht können beide Typen von Hörersignalen nach Yngve Aufmerksamkeit, Verstehen oder Zustimmung des Hörers ausdrücken. ${ }^{15}$

Nach Yngve veröffentlichten Duncan (1972, 1973, 1974) und Duncan/Fiske (1977) eine Reihe von quantitativen Studien über die Sprecher-Hörer-Koordination von verbalen und nonverbalen Aktivitäten. Ein Verdienst Duncans liegt darin, daß er einige Klassen von Hörersignalen erstellt hat, die für Forscher über Höreraktivitäten als Ausgangsbasis bei der Bestimmung von Hörersignalen dienen können. Duncans Arbeiten, die in den späteren Kapiteln dieser Arbeit vorgestellt und verwendet werden, können als Standardbeiträge zur statistisch verankerten Erforschung des Hörerverhaltens betrachtet werden und haben weitere quantitative Untersuchungen in verschiedenen Ländern (z.B. in Deutschland und Japan) angeregt. ${ }^{16}$

Neben Yngve und Duncan begann in den 70er Jahren auch Forscher in der ethnomethodologischen Konversationsanalyse damit, sich zunehmend der Interaktion zwischen dem Sprecher und dem Hörer zu widmen (Schegloff 1982, Jefferson 1984, Goodwin 1981, 1984, 1986, Erickson 1988, Miller 1991 usw.). Schegloff (1982) wendete sich gegen die begriffliche Zweiteilung des Gesprächs in Turn und „back channel“, die Yngve (1970) vornahm. Schegloff ging davon aus, daß die Konversation nur durch interaktionales „accomplishment“ oder „achievement“ zwischen dem Sprecher und dem Hörer zustande kommt, daß der Sprecherturn, vor allem der „Multi-Turn“, ein Produkt des Vollzugs der gegenseitigen Kooperation zwischen den Gesprächspartnern darstellt. ${ }^{17}$ Daher sollen Höreraktivitäten nur im Zusammenhang mit der Sprecheräußerung, vor allem mit der Turnorganisation analysiert und charakterisiert werden. ${ }^{18}$ Diesem Prinzip folgend arbeiteten Vertreter der ethnomethodologischen Konversationsanalyse nicht quantitativ, sondern nur qualitativ mit diesem Phänomen und führten exemplarisch vor, wie einzelne verbale und nonverbale Aktivitäten der Gesprächspartner einander bedingen und beeinflussen und in welchem Maße der Verlauf der Rede des Sprechers vom Verhalten des Hörers beeinträchtigt werden kann. ${ }^{19}$ Außer einigen Aufsätzen, die theoretische Überlegungen über Funktionen

\footnotetext{
${ }^{15}$ Vgl. Yngve 1970, S. 574.

${ }^{16}$ Viele Arbeiten über Höreraktivitäten wurden mehr oder minder von Duncan angeregt: Maynard (1986), White (1989), Wahmhoff/Wenzel (1979), Willkop (1988), Sawada (1991) usw.

${ }^{17}$ Schgloff 1982, S. 73.

${ }^{18}$ Vgl. Schegloff 1982, S. 74.

${ }^{19}$ Dazu Erickson 1988.
} 
einiger Höreräußerungen wie yeah, $u h$ huh, $m m ~ h m$ beinhalten, wurden in der ethnomethodologischen Konversationsanalyse eine Reihe von rein qualitativen Arbeiten wie die von Schenkein (1972), Heath (1984), Goodwin (1981, 1984), Heritage (1984) usw. veröffentlicht.

In Deutschland gab es vor den 70er Jahren kaum Publikationen über das Thema Höreraktivitäten, obwohl sich etwa in den 60er Jahren die Forschungsrichtung der „Gesprochenen Sprache“ (GS) immer mehr herauszubilden begann. Man kann sagen, daß Hörerverhalten als ein Teilaspekt der GS-Forschung erst dann Fuß faßte, als die GSForschung in den 70er Jahren zunehmend unter dem Einfluß der amerikanischen ethnomethodologischen Konversationsanalyse stand und sich deren thematischer Schwerpunkt von der Syntax zum Gesprächsverhalten verschoben hatte. ${ }^{20}$

So finden sich seit den 70er Jahren immer wieder Studien, die sich mit Höreraktivitäten befassen. $^{21}$ Schank/Schoenenthal (1976) stellen einige Merkmale (Formen, Positionen und Funktionen) der Hörersignale anhand von prägnanten Beispielen anschaulich dar. Henne (1978) und Henne/Rehbock (1982), bei denen Hörersignale „Hörerrückmeldungen“ genannt werden, liefern einen guten Forschungsüberblick über Höreraktivitäten und bieten dabei einige Anhaltspunkte an, nach denen man Hörersignale charakterisieren und erforschen kann.

Wahmhoff/Wenzel (1979) und Sawada führen eine umfassende Analyse der Hörersignale (1991) durch. In ihren Studien werden Hörersignale in Beratungsgesprächen hinsichtlich ihrer Form, Position und Funktion quantitativ untersucht.

Von C. Schmidt (1986) stammt eine interessante Studie über geschlechtsspezifisches Hörerverhalten bei Männern und Frauen, in der die Häufigkeit verschiedener Typen von Hörersignalen in Männer- und Frauengesprächen quantitativ ermittelt wird, und die Ergebnisse miteinander verglichen werden. Ein signifikanter Unterschied zwischen den beiden Datentypen besteht vor allem in der Frequenz der Hörersignale: Frauen senden nämlich eindeutig mehr turninterne Hörersignale als Männer. Daraus wurde der Schluß

\footnotetext{
20 Die Beschreibung erfolgt in Anlehnung an den Artikel „Gesprochene Sprache“ im Lexikon der germanistischen Linguistik 1980, S. 314-318.

${ }^{21}$ Wahmhoff/Wenzel (1979), Barba (1988), Willkop (1988), Hartung (1998) usw.
} 
gezogen, daß Frauen in der Hörerrolle kooperativer, aktiver und unterstützender sind als Männer. ${ }^{22}$

Über die Funktionen von Hörersignalen gibt es eine Reihe von relevanten Publikationen. Außer Henne (1978) beschäftigt sich Rath (1979) relativ früh mit einigen Partikeln wie uhmhm, ja usw., die häufig als Hörersignale verwendet werden. Basierend auf empirischen Daten sieht Rath die Funktion der Hörersignale in ihrer pragmatisch-kommunikativen Kraft darin, die Teilnahme am Kommunikationsprozeß zu bezeugen und das Gespräch zu steuern. In Anlehnung an Rath teilt Bublitz (1980) Hörersignale nach ihren Funktionen in nicht (gesprächs)steuernde und (gesprächs)steuernde Typen ein.

Außer relativ theoretischen Arbeiten sind auch einige empirische Studien zur Funktion von Hörersignalen zu finden. Quasthoff $(1981,1986)$ analysiert Funktionen der Hörersignale in der alltäglichen Erzählung und stellt fest, daß sie eine erzählhemmende oder erzählfördernde Wirkung auf den Sprecher ausüben können. Barba (1988) zeigt anhand von Interviews, daß Hörersignale, die generell Aufmerksamkeit anzeigen, darüber hinaus noch als Verstehensund Fortsetzungssignal fungieren oder diverse Einstellungen (Zustimmung, Ironie, Staunen usw.) kundgeben können. Das Ironiepotential von Hörersignalen wird von Hartung (1998) in seiner qualitativen Analyse einiger Mehr-Personen-Gespräche ausführlich beschrieben. Darin führt er vor, daß Hörersignale z.B. ironisch, etwa im Sinne eines Verschleierungsmittels für Nichtverstehen, eingesetzt werden können, um sich vor einer Blamage zu bewahren. Eine Einzelanalyse einiger ausgewählter Gliederungspartikeln wurde von Willkop (1988) durchgeführt. Sie bestimmt die Funktionen der als Hörersignale verwendeten Gliederungspartikeln wie $u h m h m$, ja usw. nach ihrer Position im Satz und ihren kontextuellen und intonatorischen Gegebenheiten. Aus der Analyse geht hervor, daß Funktionen der Hörersignale trotz ihrer Vielfalt in gewissem Maß „auf einen Nenner gebracht“ werden können.

Zusammenhänge zwischen Suprasegmentalia und Funktionen einiger Interjektionen wie uhmhm, oh, aha usw. wurden von Ehlich $(1979,1986)$ intensiv untersucht. Ehlich vertrat die Meinung, daß sich z.B. verschiedene Realisierungsformen von $u h m h m$ im wesentlichen in vier Grundformen einteilen lassen, die jeweils einer von vier klassifizierten Funktionen

\footnotetext{
${ }^{22}$ C. Schmidt 1986, S. 105-112.
} 
zugeordnet werden können. Diese Funktionen beziehen sich bei Ehlich auf die Konvergenz und die Divergenz des Diskurswissens zwischen dem Sprecher und dem Hörer. Dem Ansatz von Ehlich schließt sich Kucharczik (1989) im großen und ganzen an.

H. Schmidt (1983) untersucht Hörersignale im Zusammenhang sowohl mit segmentalischen als auch suprasegmentalischen Strukturen der Sprecheräußerungen. Dabei hat er vier formal und funktional differenzierbare Typen der Auslösestrukturen (Emphase, Progredienz, Finalität, Pause) herausgefunden, die häufiger als andere Strukturen der Sprecherrede Hörersignale nach sich ziehen. Als Gegenstück dazu werden auch vier Typen der Hörersignale (animierende, registrierende, zustimmende, überraschte) aufgestellt, die nach prosodischen Kriterien unterschieden werden. Durch die Berechnung stellt Schmidt fest, daß alle vier Auslösestrukturen mehr oder minder in regelmäßigen Abständen mit einem der vier Rezipientensignalen reagieren. Dies nennt der Autor „Rezipientenaustausch“, Ausdruck des kooperativen Verhaltens von Sprecher und Hörer. ${ }^{23}$

Wie oben erwähnt, existiert in Japan seit langem unabhängig von der Linguistik im Volksmund ein allgemein verwendetes, alltägliches Wort für gewisse Verhaltensweisen des Hörers: aizuchi. „Aizuchi“ (Gegenhammerschlag des Partners) wurde in der japanischen Hörerverhaltensforschung und auch bei einigen ausländischen Forschern als Fachbegriff für verbale und nonverbale Höreraktivitäten von Japanern übernommen.

In Japan blüht die Hörerverhaltensforschung erst in den 80er Jahren auf, in zahlreichen Untersuchungen über Hörerverhalten werden einige wichtige Regularitäten des Hörerverhaltens von Japanern beschrieben. Vor allem Maynard, die sich intensiv mit Merkmalen (Häufigkeit, Funktionen und Positionen) von „turninternen“ verbalen Hörersignalen der Japaner befaßt, hat in den USA und in Japan einen großen Beitrag bei der Erforschung von japanischen Höreraktivitäten geleistet. Außerdem hat die Arbeit von Sawada (1991) vor allem für meinen Ansatz eine besondere Relevanz. In ihrer Arbeit wurden anhand von mehreren deutschen und japanischen Telefonberatungsgesprächen statistische Analysen über die Frequenz, die prozentuale Verteilung von fünf Typen der Hörersignale (kurze verbale Äußerungen, Wiederholungen, Nachformulierungen, Satzvollendungen und sonstiges) sowie von fünf Typen der Funktionen durchgeführt.

\footnotetext{
${ }^{23}$ H. Schmidt (1983, S. 95)
} 
Eine gute Übersicht über verschiedene Typen von ,,aizuchi“-Äußerungen gibt der Aufsatz von Horiguchi (1987). Sie teilte in Anlehnung an Duncan (1974) „aizuchi“ in vier Kategorien (Partikeln, Wiederholung, Nachfrage, Vorwegnahme) ein. Clancy et al. (1996) verwenden ein ähnliches Klassifikationsraster wie Horiguchi, wobei sie „aizuchi“-Partikeln in eine Gruppe, die als Aufmerksamkeits-, Verstehens- oder Fortsetzungssignale fungieren, und in eine andere, die eine Bewertung ausdrückt, unterteilen. Aus ihrer quantitativen Untersuchung ergibt sich, daß japanische Teilnehmer im Vergleich zu den chinesischen und amerikanischen Beteiligten besonders oft von Hörersignalen, die als Fortsetzungssignal dienen, Gebrauch machen.

Einige interessante Beobachtungen über den Formengebrauch stammen von Mizutani (1988). Aus der von ihr erstellten Liste der ,aizuchi“-Äußerungen, die einzelnen TalkshowTeilnehmern verwendet werden, geht hervor, daß es einige ,aizuchi“-Formen gibt, die generell häufig eingesetzt werden, während die Häufigkeit einiger anderer Hörersignale der individuellen Vorliebe unterliegt.

Auch hinsichtlich der Merkmale der Sprecheräußerungen, die Hörersignale öfters hervorrufen, liegen bereits einige Befunde vor.

Maynard (1986) listete einige der von ,aizuchi“ bevorzugten Umgebungen auf. Demnach wurden ,aizuchi“ häufiger an Satzenden beobachtet, die durch eine gerundive Verbform, (satzfinale) konjunktionale Partikeln, satzfinale Partikeln, Kopfnicken usw. markiert sind. Darüber hinaus können ,aizuchi“ nach Sugifuji (1987) am Satzende mit fallender Intonation häufig auftreten, weil dadurch die Beendigung einer Äußerungseinheit stärker als sonst signalisiert wird. ${ }^{24}$ Koiso et al. (1998) machten eine statistisch verankerte Untersuchung über die Korrelation zwischen syntaktischen und prosodischen Merkmalen des Sprecherturns und der Frequenz der Hörersignale; die Ergebnisse unterstützen die Behauptungen Maynards und Sugifujis.

Clancy et al. (1996) berechnen die Quote der Häufigkeit der „aizuchi“ in Abhängigkeit von intonatorischen und syntaktischen Gegebenheiten der Sprecherrede. Demnach plazieren

\footnotetext{
${ }^{24}$ Sugifuji 1987, S. 119.
} 
japanische Teilnehmer Hörersignale nicht so häufig an intonatorischen und/oder syntaktischen Einheiten, wie es die chinesischen oder die amerikanischen Teilnehmer tun; dafür ist die Anzahl der Hörersignale, die in der Mitte einer solchen Einheit gesendet wurden, häufiger als bei beiden anderen Gruppen.

Über Funktionen von Hörersignalen gibt es ebenfalls einige Arbeiten:

Ausgehend von Aufgaben des Hörers in der Kommunikation stellte Horiguchi (1987) fünf Funktionstypen (Zuhörerschaft, Verstehen, Zustimmung, Ablehnung, emotionaler Ausdruck) der „aizuchi“ auf, die im lokalen Kontext in bezug auf die vorangegangene Sprecheräußerung wirksam werden. Das Funktionsmodell Horiguchis wurde von Matsuda (1988) erweitert. Ôhama et al. (1998) ${ }^{25}$ analysieren die Verteilung und die Funktionen der Hörersignale in Betracht auf verschiedenen Segmente des Gesprächs (Wegauskünfte). Dabei stellte sich heraus, daß „aizuchi“ nicht nur dazu dienen, dem Sprecher die Zuhörerschaft zu indizieren, sondern auch durchaus einen aktiven, also gesprächssteuernden Beitrag leisten. ${ }^{26}$

Untersuchungen über Regularitäten des Kopfnickens liegen bei Maynard (1986) und Sugito (1989) vor. Kopfnicken ist in den japanischen Daten beider Autoren die häufigste bzw. die zweithäufigste Kategorie der „aizuchi“ überhaupt. Die Quote des Zusammentreffens von Kopfnicken mit verbalen Hörersignalen erwies sich als sehr hoch: So wurde über zwei Drittel des Kopfnickens gleichzeitig mit verbalen Hörerreaktionen beobachtet.

\subsection{Forschungen über Hörersignale in intrakulturellen Gesprächen}

Aus der kurzen Skizze der bisherigen Befunde der Hörerverhaltensforschung kristallisieren sich einige Aspekte der Hörersignale heraus, die immer wieder zum Untersuchungsgegenstand wurden:

1. Typen der Hörersignale und deren prozentuale Verteilung

2. Merkmale der Sprecheräußerungen, die Hörersignale häufig hervorrufen

3. Funktionen der Hörersignale

\footnotetext{
${ }^{25}$ Lange o-Laute werden mit „, $\hat{O}^{\text {“ }}$ wiedergegeben.

${ }^{26}$ Meines Erachtens wird in der japanischen Forschungsliteratur oft betont, daß Hörersignale im Japanischen die Aufmerksamkeit oder die Zuhörerschaft anzeigen, während die Betonung in der deutschen Forschungsliteratur eher darin liegt, daß Hörersignale gesprächssteuernd eingesetzt werden.
} 
Im folgenden sollen einzelsprachige Befunde im wesentlichen nach den oben genannten thematischen Gesichtspunkten ausführlich erläutert werden. Anschließend sollen einige Arbeiten vorgestellt werden, die die Ergebnisse der intrakulturellen Untersuchungen miteinander vergleichen. Dann wird auf die Studien eingegangen, die Hörerverhalten in interkulturellen Gesprächen behandelt haben. Das alles soll dazu dienen, einen Überblick über die Hörerverhaltensforschung zu liefern und zugleich den Einstieg in die vorliegende Arbeit zu erleichtern.

\subsubsection{Zu Auffassungen und Klassifikationsmodellen von Hörersignalen und die prozentuale Verteilung der Typen von Hörersignalen}

Hörersignale wurden bislang in der Forschungsliteratur unter verschiedenen Aspekten bestimmt und charakterisiert. Dabei wurden semantisch, pragmatisch oder kommunikativ begründete Kriterien herangezogen. Im folgenden werden einige Definitionen von Hörersignalen angeführt. Da trotz der relativ ähnlichen Auffassungen von Hörersignalen die Anzahl der Typen von Hörersignalen von Forscher zu Forscher variiert, werden dabei nicht nur die Definitionen, sondern auch die Klassifikationsraster der jeweiligen Autoren erwähnt.

\subsubsection{Die Auffassungen und die Klassifikationsraster von Hörersignalen}

Yngve (1970), der als erster den Begriff „back channel“ in die Forschungsliteratur eingeführt hat, definiert Hörersignale in erster Linie relativ zum Status der Gesprächsteilnehmer; mit konkreten Worten stellen die Äußerungen des Turninhabers Turns und die Äußerungen des Nicht-Turninhabers „,back channels“, also Hörersignale dar; ${ }^{27}$ dieser Auffassung Yngves schließt sich Duncan (1974) im wesentlichen an.

Bei Duncan gelten nämlich solche Äußerungen als Hörersignale, die weder einen Turn konstruieren noch einen Turn beanspruchen; somit sind Turnbeanspruchungen des Hörers ausdrücklich von der Kategorie Hörersignal ausgeschlossen. Hörersignale übermitteln dem Sprecher zur Turnprogression nützliche Informationen. ${ }^{28}$ Die so bestimmten Hörersignale werden von Duncan in folgende Typen unterteilt: ${ }^{29}$

\footnotetext{
${ }^{27}$ Yngve 1970, S. 568.

${ }^{28}$ Duncan 1974, S. 166.
} 
1. Kurze verbale Äußerungen wie yeah, uh huh, yes, I see usw.

2. Satzvollendung

3. Bitte um Klärung

4. Kurze Nachformulierung

5. Kopfschütteln, Kopfnicken

Dieses Modell Duncans bildet in der späteren Forschung über Hörerverhalten die Ausgangsbasis bei der Definition und der Kategorisierung der (verbalen) Hörersignale. Das gilt nicht nur in den USA, sondern auch in Deutschland und in Japan.

Ähnlich wie Yngve und Duncan definieren Clancy et al. (1996) Hörersignale (,reactive tokens") als Äußerungen des Hörers, die weder den Turn beanspruchen noch diesen beeinträchtigen: ${ }^{30}$ Ihre Typologie der Hörersignale unterscheidet sich jedoch in manchen Punkten von Duncan:

- Hörersignale („back channel“), die als Verstehens- oder Fortsetzungssignal fungieren oder Interesse bekunden,

- Hörersignale (,reactive expressions“), die eine Bewertung zum Ausdruck bringen,

- Satzvollendungen (,collaborative finishes“),

- Wiederholungen und

- Hörersignale (,resumptive openers“), die an Turnübergangsstellen auftreten, die sich jedoch dem Turn anschließen. ${ }^{31}$

Bei Clancy et al. ist die Affinität zur ethnomethodologischen Konversationsanalyse besonders ersichtlich, wenn sie die Klassen „back channel“ und „reactive expressions“ aufstellen, die sowohl auf Schegloffs Begriff „continuer“ (1982) als auch auf Goodwins Terminus „assessment“ (1986) zurückgeführt werden können.

Zuletzt sei noch ein Modell Reids für das Englische angeführt, bei dem anders als bei der Mehrheit der Autoren nur kurze Höreräußerungen („,minimal responses“) als Hörersignale betrachtet werden. Hörersignale gelten bei Reid als kurze Äußerungen des Hörers, die nur

\footnotetext{
${ }^{29}$ Duncan 1974, S. 166.

${ }^{30}$ Clancy et al. 1996, S. 356.

31 Diese Kategorie untersucht Duncan (1974) nicht, weil er solche nicht als „,back channel“, sondern als dem Turn zugehörig einstuft.
} 
wenig semantischen Gehalt aufweisen und nur Reaktionen auf den Sprecherturn darstellen, ohne dabei den Turn zu übernehmen. Funktional können sie die Anteilnahme am Gespräch und zugleich auch Einstellungen wie Zustimmung signalisieren. ${ }^{32}$ Reid teilt die Hörersignale in drei Typen: einfache Hörersignale, Hörersignale, die einen Turn einleiten, und Fortsetzungssignale (,facilitatives“) ein. ${ }^{33}$

Im deutschsprachigen Raum liegt der Schwerpunkt bei der Definition von Hörersignalen im Vergleich $\mathrm{zu}$ den amerikanischen Forschungen eher auf kommunikativ-pragmatischen Aspekten. Bei der Gruppierung der Hörersignale richtet man sich dennoch meistens nach Duncan (1974).

Henne/Rehbock (1982) gehen wie Yngve ebenfalls zuerst davon aus, daß Hörersignale keinen Turn konstituieren; bei ihnen wird jedoch zusätzlich der funktionale Aspekt bei der Bestimmung in den Vordergrund gestellt: Sie betrachten nämlich Hörersignale als ein Mittel, mit dem der Hörer dem Sprecher seine Aufmerksamkeit versichert. ${ }^{34}$ Bei der Klassifikation der Hörersignale lehnen sie sich weitgehend an Duncan an. Sie fügen jedoch in ihre Typologie eine neue Kategorie „Kommentarschritte“ ein, die sie aus ihrer empirischen Untersuchung gewonnen haben, und die Duncan nicht in seinem Modell berücksichtigt hat.

Eine kommunikativ-pragmatisch orientierte, mehrere Aspekte umfassende Definition findet sich bei Schwitalla: ${ }^{35}$

„Hörersignale sind "solche, mit denen ein aktueller Zuhörer dem aktuellen Sprecher seine Aufmerksamkeit versichert und gegebenenfalls seine Meinung zum Gesagten kurz mitteilt, ohne darauf zu bestehen, die Sprecherrolle zu übernehmen“.

Ebenso präsentiert Rath (1979) eine kommunikativ-funktional verankerte Auffassung von Hörersignalen. Seiner Meinung nach sind Hörersignale „,semantisch leer“ und ,inhaltslos“36; daher können sie nur unter kommunikativ-pragmatischen Gesichtspunkten charakterisiert werden. Rath teilt Hörersignale aufgrund ihrer Funktionen in zwei Gruppen: Die eine Gruppe

\footnotetext{
${ }^{32}$ Reid 1995, S. 494.

${ }^{33}$ Reid 1995, S. 496-497.

${ }^{34} \mathrm{Vgl}$. Henne/Rehbock 1982, S. 177.

${ }^{35}$ Schwitalla 1976, S. 80.

${ }^{36}$ Rath 1979, S. 118.
} 
umfaßt Hörersignale, die als eine bestätigende Antwort des Hörers auf die Vergewisserungsfrage des Sprechers (wie ja, ne, oder) fungieren. Hingegen gibt es andere Hörersignale, die ohne solche Sprechersignale immer wieder an kommunikativ relevanten Stellen eigenmächtig vom Hörer gesendet werden. ${ }^{37}$ Erstere regulieren die Partnerbeziehung, ${ }^{38}$ während letztere einen den Gesprächsverlauf steuernden Beitrag leisten. ${ }^{39}$

Auf Handlungsaspekte der Hörersignale geht Henne (1978) explizit ein. Nach Henne stellen verbale Höreraktivitäten ebenso wie Sprecheräußerungen auch sprachliche Handlungen dar, denn Höreräußerungen erfüllen die Bedingungen einer sprachlichen Handlung: Der Hörer verfolgt nämlich ein Ziel, hat die Absicht, dieses Ziel zu erreichen, und setzt zu diesem Zweck konventionalisierte Mittel ein. Ziele des Hörers können z.B. darin bestehen, den Grad des Verstehens oder der Zustimmung zu übermitteln und somit Einfluß auf das Gespräch zu nehmen. ${ }^{40}$ Henne stellt in diesem Aufsatz auch ein Inventar von konventionalisierten sprachlichen Mitteln auf, das von C. Schmidt (1986) übernommen und für die Analyse verwendet wird. ${ }^{41}$

In bezug auf Hörersignale im Japanischen liegt bei Sugito (1987) eine semantisch und pragmatisch ausgerichtete Festlegung von ,aizuchi“-Äußerungen wie folgt vor:

„Aizuchi enthalten keine sprachlichen Formen, die substantiellen Inhalt aufweisen; sie stellen daher keine Sprechakte wie Aufforderungen, Fragen, Behauptungen usw. dar, mit denen sich der Äußernde dem Adressaten aktiv zuwendet“ ${ }^{42}$

Folgende Äußerungen werden bei Sugito et al. als Hörersignale bzw. „aizuchi“-artig angesehen: ${ }^{43}$

- Äußerungen, die mittels ,aizuchi“-Partikeln wie $a$ :, a: sô desu ka (aha), e: sô desu ne: (ja richtig) ausgedrückt werden,

- Echo-Äußerungen, die die vorangegangenen Sprecheräußerungen wiederholen,

\footnotetext{
${ }^{37}$ Rath 1979, S. 124.

${ }^{38}$ Rath 1979, S. 118.

${ }^{39}$ Rath 1979, S. 124.

${ }^{40}$ Henne 1978, S. 128.

${ }^{41}$ Das Inventar wird im Kapitel 4 vorgestellt.

${ }^{42}$ Sugito 1987, S. 88.

${ }^{43}$ Sugito 1987, S. 88.
} 
- einfache Nachfragen,

- Äußerungen, die mittels Interjektionen wie ee:!, ma:, ho: (Überraschung) übermittelt werden, und

- Lachen.

Horiguchi (1987) führt mehr Typen von Hörersignalen als Sugito (1987) in ihre Typologie ein. Ihre Unterteilung entspricht im großen und ganzen der Duncans (1974):

- „aizuchi“-Partikeln wie hai (ja, uhmhm), e: (ja, uhmhm), sô desu ne (ja ich verstehe),

- Wiederholungen,

- Nachformulierungen (inhaltliche Wiedergabe des Gesagten),

- Vorwegnahmen bzw. Satzvollendungen und

- Vergewisserungsfragen.

\subsubsection{Die prozentuale Verteilung der Typen der Hörersignale}

In bezug auf die prozentuale Verteilung der Typen der Hörersignale liegen Ergebnisse aus einigen empirischen Untersuchungen vor.

Im Englischen untersucht Duncan (1974) die Häufigkeit der Typen der Hörersignale statistisch; aus seiner Tabelle geht hervor, daß unter den verbalen Hörersignalen die kurzen Äußerungen wie $m$-hm die am häufigsten verwendete Klasse bilden: Ihr Anteil macht sogar 82,9\% aller verbalen Hörersignale aus. ${ }^{44}$ Bei White (1986), die das Modell Duncans übernommen hat, stellt sich Ähnliches heraus: Ihrer Auswertung zufolge bestehen 74\% aller verbalen Hörersignale aus kurzen Verbalisierungen wie hmhm, yeah, uh-huh, oh, hmm. ${ }^{45}$ Auch Clancy et al. (1996) erzielen ein vergleichbares Ergebnis: Kurze verbale Hörersignale wie $m h m$, oh, uh huh, yeah, sure, exactly etc. machen $72,6 \%$ aller von ihnen untersuchten verbalen Hörersignale aus. ${ }^{46}$

Die hohe Präferenz des Gebrauchs von kurzen Verbalisierungen wie ja, uhmhm ist auch im Deutschen sehr ähnlich. Leider ist mir bislang nur eine quantitative Untersuchung von

\footnotetext{
${ }^{44}$ Siehe Duncan 1974, S. 168.

${ }^{45}$ White 1986, S. 39.

${ }^{46}$ Clancy et al. 1996, S. 370. Hierbei habe ich ,back channels“ und ,reactive expressions“" zusammengefaßt.
} 
Sawada (1991) zur prozentualen Verteilung bekannt. Aus deren Auswertung ergibt sich, daß 84\% aller verbalen Hörersignale durch kurze verbale Formen wie ja, uhmhm und genau realisiert werden. Bei C. Schmidt (1986) beträgt der Anteil der kurzen verbalen Hörersignale sogar etwa $88 \%{ }^{47}$

Im Japanischen fällt der Anteil der kurzen verbalen Hörersignale bzw. „aizuchi“-Partikeln teilweise noch höher aus: Von allen Hörersignalen gehören bei Clancy et al. 85,3\%, bei Sawada (1991) 95,3 \% und bei Mizutani (1988) 98\% zu der Klasse der ,aizuchi“-Partikeln. Die prozentuale Verteilung anderer Typen wie Wiederholungen, Satzvollendungen, Nachfragen, Kommentare liegt im Vergleich zu kurzen verbalen Äußerungen wie ja, uhmhm in der Regel bei sehr niedrigen Quoten. Das trifft auf alle drei Sprachgruppen zu. ${ }^{48}$

Als Fazit kann folgendes festgehalten werden: Die prozentuale Verteilung der Typen der Hörersignale variiert je nach Studien; diese Schwankungen in den jeweiligen Ergebnissen können einerseits auf kulturelle, soziale oder individuelle Faktoren zurückgeführt werden; aber andererseits können daran unterschiedliche Auffassungen sowie Typologien von Hörersignalen einen großen Anteil haben. Nichtsdestotrotz kann davon ausgegangen werden, daß kurze verbale Formen sowohl im Deutschen als auch im Japanischen die am häufigsten verwendete Gruppe der Hörersignale darstellen. Im empirischen Teil dieser Arbeit wird die prozentuale Verteilung verschiedener Typen der Hörersignale ebenfalls berechnet. Es ist dabei anzunehmen, daß ein ähnliches Ergebnis erzielt wird.

\subsubsection{Zu einzelnen Formen der Hörersignale}

Es ist aus den bisherigen Forschungen bekannt, daß einige Hörersignale existieren, die im Gespräch bevorzugt eingesetzt werden. Im folgenden sollen nur die Untersuchungen über das Deutsche und das Japanische skizziert werden.

\footnotetext{
${ }^{47}$ C. Schmidt (1986) stellt selber keine Berechnungen an; aber ihre Tabellen ermöglichen die Berechnung der Distribution der Typen der Hörersignale.

${ }^{48}$ In den japanischen Daten stellt Sawada fest, daß die restlichen Hörersignale $(4,7 \%)$ aus Wiederholungen $(2,0 \%)$, Satzergänzungen (0,3 \%) und sonstigen bestehen (Sawada 1991, S. 70). Bei Mizutani (1988) ergibt sich, daß nur 2\% aller Hörersignale zu den Resttypen gehören (Mizutani 1988, S. 96). Im Deutschen betragen die restlichen Typen bei C. Schmidt etwa $12 \%$ aller Hörersignale, davon gehören 0,54\% zu Wiederholungen, 4,2\% zu Ergänzungen, 2\% zu Nachformulierungen, 0,27\% zu Nachfragen und 2,8\% zu Kommentaren. Bei Sawada (1991) setzen sich die Reste zusammen aus Wiederholungen $(3,2 \%)$ und sonstigen $(8,6 \%)$.
} 
Im Deutschen kommen ja und uhmhm sehr oft zum Einsatz. Bei Wahmhoff/Wenzel (1979) machen ja und uhmhm zusammen 93,3\% aller verbalen Hörersignale in ihren Gesprächsdaten aus. $^{49}$ In den Daten Willkops (1988) bestehen $80 \%$ aller turninternen Hörersignale (Hörersignale, die nicht unmittelbar in der Nähe des Turnwechsels auftreten) aus ja, uhmhm, genau, klar usw. ${ }^{50}$ Ein ähnliches Ergebnis präsentiert Sawada (1991): Bei ihr betragen ja und ja-Kombinationen 53,8\% und uhmhm 23,7\% aller verbalen Hörersignale; aha bildet mit der Quote von 4,3\% das dritthäufigste Hörersignal. ${ }^{51}$

Hinsichtlich des Japanischen lassen sich vier Gruppen angeben, die mit Abstand häufiger als die anderen zum Gebrauch kommen: die hai-, um-, e:- und sô-Kombinationen. Je nach den Gesprächsbedingungen fallen die Häufigkeit und die Reihenfolge der jeweiligen Formen unterschiedlich aus. ${ }^{52}$

\subsubsection{Zur Gesamtfrequenz der Hörersignale pro Minute und pro Silbe}

Für das Deutsche kann hierzu nur eine Untersuchung Sawadas (1991) herangezogen werden. Sie errechnet die Anzahl der Hörersignale pro Minute und stellt dabei fest, daß deutsche Hörer in ihren Daten im Durchschnitt 7,4 Hörersignale pro Minute senden. ${ }^{53}$

Im Japanischen ergibt sich bei Sawada (1991), daß 13,8 Hörersignale pro Minute gegeben werden. ${ }^{54}$ Nach Maynard (1986) senden japanische Hörer 12,5 Hörersignale pro Minute. ${ }^{55}$ Mizutani (1988) legt eine noch höhere Zahl vor; bei ihr liegt die Anzahl der Hörersignale zwischen 14,2 und 20 Hörersignalen pro Minute. ${ }^{56}$ Es scheinen also gewisse Schwankungen in der Häufigkeit der Hörersignale pro Minute zu existieren, die mit individuellen, sozialen bzw. situationellen Gegebenheiten erklärt werden können.

\footnotetext{
${ }^{49}$ Wahmhoff/Wenzel 1979, S. 274.

${ }^{50}$ Vgl. Willkop 1988, S. 49.

${ }^{51}$ Sawada 1991, S. 70.

52 Z.B. finden sich große Unterschiede zwischen Sawada (1991, S. 70) und Mizutani (1988, S. 96) in der Häufigkeit von hai und $e$ : Bei Sawada liegt die Quote von hai bei $41 \%$ und $e$ : bei 25\%, während hingegen bei Mizutani die Quote von hai nur 12\%, und von $e$ : aber $44 \%$ beträgt.

${ }^{53}$ Sawada 1991, S. 70.

${ }^{54}$ Sawada 1991, S. 70.

${ }^{55}$ Siehe Maynard 1986, S. 1091-1092.

56 Diese Werte erzielte ich, indem ich den Moderator und einen Teilnehmer, der sich extrem anders verhielt, nicht berücksichtigte.
} 
Außer der Minutenzahl der Hörersignale untersucht Mizutani (1988), nach wie viel Silben der Sprecheräußerungen ,aizuchi“ gesendet werden. Demnach kommt ein Hörersignal etwa nach 20 Silben (etwa der Silbenzahl eines Satzes) zum Einsatz. ${ }^{57}$ Dabei ist nach Mizutani die Anzahl der Hörersignale von der Sprechgeschwindigkeit unabhängig. ${ }^{58}$ Das kann eventuell als Indiz dafür genommen werden, daß Hörersignale auf eine gewisse Informationsmenge wie z.B. die eines Satzes reagieren.

In dieser Arbeit werden die Häufigkeit der Hörersignale pro Minute sowie pro Silbenzahl nicht untersucht; das liegt daran, daß solche Kriterien keine adäquate Vergleichsbasis für den deutsch-japanischen Vergleich bieten. Aussagekräftiger ist es meines Erachtens vielmehr, die Häufigkeit der Hörersignale pro Informationseinheit eines Wortes, einer Phrase, eines Satzes usw. zu errechnen.

\subsubsection{Zu Positionen und Positionsmerkmalen mit hoher und niedriger Frequenz von Hörersignalen}

Fragen, wo in der Sprecheräußerung Hörersignale wie häufig plaziert werden, durch welche Merkmale solche Stellen gekennzeichnet sind, werden in vielen Arbeiten (vor allem im Englischen und im Japanischen) über Hörersignale gestellt und beantwortet. Im folgenden werden Befunde aus einigen quantitativen Untersuchungen nach Sprachgruppen getrennt vorgestellt.

\subsubsection{Zu Untersuchungen zur Positionierung der Hörersignale im Englischen}

Dittman und Llewellyn (1968) haben herausgefunden, daß Hörersignale im Englischen fast ausschließlich am Ende einer „rhythmischen Einheit in der Sprecherrede“ vorkommen; diese rhythmische Einheit besteht in der Regel aus fünf Wörtern, die ein Akzent- und Intonationsmuster tragen und mit einer ,juncture“ beendet werden. ${ }^{59}$ Eine ,,juncture“ kann mit einer fallenden, steigenden oder gleichbleibenden Intonation ausgestattet sein. Nach der Berechnung der Frequenz der Hörersignale werden Hörersignale häufiger bei fallender und steigender Intonation als bei gleichbleibender Intonation beobachtet ${ }^{60}$. Dieses Ergebnis deutet darauf hin, daß zwei Merkmale, nämlich intonatorisch definierte Einheiten sowie die

\footnotetext{
${ }^{57}$ Siehe Mizutani 1988, S. 95. Bei der Betrachtung nahm ich einen Teilnehmer mit einem extremen Wert heraus.

${ }^{58}$ Mizutani 1988a, S. 7.

${ }^{59}$ Dittman/Llewellyn 1968, S. 79.

${ }^{60}$ Dittman/Llewellyn 1968, S. 81.
} 
terminale Intonationskontur zusammen für das häufige Auftreten der Hörersignale verantwortlich sind.

Ebenso ermittelt Duncan (1974) die Plazierungstendenzen der Hörersignale in bezug auf die Analyseeinheit, die durch syntaktische, prosodische und nonverbale Kriterien definiert wird. ${ }^{61}$ Dabei unterscheidet Duncan vier Positionen bezüglich des Vollzugspunkts dieser Analyseeinheit: ${ }^{62}$

- kurz vor dem Ende der Analyseeinheit (Frühplazierung),

- an Grenzen zwischen zwei Einheiten,

- nach „sociocentric sequences“ (you know, or something usw.) und

- zu Beginn der nächsten Einheit (Spätplazierung).

Anschließend testet Duncan die Vorkommenshäufigkeit der Hörersignale relativ zu diesen Positionen. Dabei stellt sich heraus, daß Hörersignale zwar am häufigsten an Grenzen der Analyseeinheiten plaziert werden, aber auch häufiger als erwartet in den anderen Positionen auftreten. Turnübernahmen, die Duncan dabei mit untersucht hat, finden sich fast ausschließlich nur an Grenzen der Analyseeinheiten. Daher bezeichnet Duncan jene Grenzen als ,geeignete Orte“ für den Turnwechsel. ${ }^{63}$

Ferner überprüft Duncan die Korrelation zwischen zwei Merkmalen der Sprecheräußerung (das Ende der Analyseeinheit und der Blick des Sprechers zum Hörer) und dem Auftreten der Hörersignale, als Ergebnis dessen er eine sehr hohe Korrelation feststellt. ${ }^{64}$ Insgesamt geben Duncans Analysen Hinweise auf weitere Faktoren, die für das Auftreten der Hörersignale ausschlaggebend sind: Das sind z.B. das Ende einer syntaktischen Einheit, „sociocentric sequences“, der Blick des Sprechers zum Hörer.

Erickson (1979) hat herausgefunden, daß die Umgebungen, in denen Hörersignale häufiger als anderswo auftreten, durch verbale und nonverbale Mittel (den syntaktischen Junktor, die Intonationskontur, die Veränderung des Gesprächstempos, den Richtungswechsel der

\footnotetext{
${ }^{61}$ Duncan 1974, S. 163.

${ }^{62}$ Duncan 1974, S. 170.

${ }^{63}$ Duncan 1974, S. 170.

${ }^{64}$ Duncan 1974, S. 172.
} 
Körperhaltung des Sprechers, den Wechsel der Blickrichtung) markiert sind. ${ }^{65}$ Erickson bezeichnet diese Umgebungen im Sprecherturn als „listening response relevant moment“. In solchen Momenten ist der Hörer verpflichtet, dem Sprecher stärkere Höreraktivitäten als sonst zu zeigen, um die Zuhörerschaft oder das Verstehen des Gesagten zu signalisieren. ${ }^{66}$ Das Ausbleiben einer angemessenen Reaktion des Hörers an diesen hörerreaktionsrelevanten Stellen hat oft negative Konsequenzen zur Folge. Daher kann davon ausgegangen werden, daß verbale Signale wesentlich mehr an diesen Stellen als an anderen Stellen zu erwarten sind.

White (1986) macht in ihrer Dissertation eine umfangreiche Untersuchung zur Positionierung und zu den Funktionen der fünf häufig verwendeten verbalen Hörersignale in ihren Daten (hmhm, yeah, uh-huh, oh!, hmm). Dabei ermittelt sie die Auftretenshäufigkeit dieser Hörersignale in neunzehn linguistisch definierten Umgebungen.

Erstens ist es auffällig, daß in allen Umgebungen mit hoher Frequenz der Hörersignale immer Pausen folgen. ${ }^{67}$ Bei der genaueren Überprüfung stellt sich heraus, daß diese Umgebungen zusätzlich durch folgende Merkmale charakterisiert sind: ${ }^{68}$

- Ende eines abgeschlossenen Satzes oder eines Nebensatzes,

- topikalisierte Nominalphrasen (Topik oder Subjekt),

- Wörter, die einen Kontrastakzent tragen oder eine steigende Intonation haben und

- $\quad$ satzfinales so oder you know.

Das häufige Auftreten der Hörersignale in diesen Umgebungen ist nach White darauf zurückzuführen, daß der Sprecher in diesen Umgebungen Informationen, die er dem Hörer mitteilt, als besonderes wichtig, als gegeben oder bereits bekannt hinstellt oder etwas unausgesprochen läßt. ${ }^{69}$ Damit fordert er vom Hörer ein, zu erkennen zu geben, ob dieser das Gesagte aufgenommen und das Gemeinte verstanden hat.

\footnotetext{
${ }^{65}$ Erickson 1979, S. 107.

${ }^{66}$ Erickson 1979, S. 103-104.

${ }^{67}$ White 1986, S. 108.

${ }^{68}$ White 1986, S. 108.

${ }^{69}$ Vgl. White 1986, S. 112.
} 
Umgebungen mit geringer Frequenz der Hörersignale werden von White folgendermaßen charakterisiert; sie befinden sich:

- innerhalb einer Phrase (nach einem Funktionswort und vor einem Inhaltswort),

- nach gefüllten Pausen,

- nach Fehlstarts,

- nach Verzögerungspausen,

- $\quad$ nach turninternen Konjunktionen. ${ }^{70}$

In diesen Umgebungen ist der Sprecher mit der Redeplanung beschäftigt, so daß er keinen Anlaß dazu sieht, vom Hörer erhöhte Aufmerksamkeit oder ein Extrazeichen zu erhalten. ${ }^{71}$

In der empirischen Analyse zur Positionierung der Hörersignale werde ich mich weitgehend nach White richten.

\subsubsection{Zur Untersuchung über Positionierungen der Hörersignale im Deutschen}

Zur Positionierung der Hörersignale liegt für das Deutsche eine Studie von Wahmhoff/Wenzel (1979) vor. Aus ihrer detaillierten Analyse geht hervor, daß es linguistische Merkmale gibt, die als Auslöser der Hörersignale fungieren können. Nach Wahmhoff/Wenzel lassen sich solche Stimuli auf der syntaktischen, paralinguistischen und inhaltlichen Ebene ansiedeln. ${ }^{72}$ Pausen werden ebenfalls von Wahmhoff/Wenzel als wichtiger Faktor für das Auftreten der Hörersignale im Deutschen betrachtet, weil viele Hörersignale (mehr als $80 \%$ ) in Pausen vorkommen. ${ }^{73}$

Nach genauer Betrachtung stellen die Autorinnen jedoch fest, daß Hörersignale sehr häufig durch Pausen, die zusätzlich mit einem der folgenden Merkmale versehen sind, hervorgerufen werden:

\footnotetext{
${ }^{70}$ White 1986, S. 109.

${ }^{71}$ Vgl. White 1986, S. 110.

${ }^{72}$ Wahmhoff/Wenzel 1979, S. 275.

73 Sawada (1991, S. 72) stellt fest, daß sowohl im Deutschen als auch im Japanischen mehr als $80 \%$ der Hörersignale durch Pausen veranlaßt werden. Hingegen zeigt Barba (1988, S. 58), daß Hörersignale meistens überlappt mit der Sprecheräußerung plaziert werden.
} 
- natürliche Sprechpausen an Wort-, Phrasen-, Nebensatz- und Satzgrenzen sowie an Grenzen von „Sinneinheiten““74 oder

- Pausen, die aufgrund psychologischer Schwierigkeiten (wie Gedächtnislücken, Wortfindungsschwierigkeiten usw.) entstanden sind.

Außerdem finden sich nicht nur Hörersignale, die in die Pause fallen, sondern auch solche, die auf die Pause folgen; letztere beginnen etwa simultan mit dem Beginn einer neuen syntaktischen Einheit der Sprecheräußerung; diese werden von Wahmhoff/Wenzel als „,verspätete Reaktion“ auf die Pause des Sprecherturns angesehen. ${ }^{75}$

Drittens gelten auch Äußerungen mit der „Frageintonation“ (bzw. steigender Intonation) als Auslöser der Hörersignale. ${ }^{76}$

Als vierter Faktor werden „Hörerrollenbestätigungsappelle“ (oder Sprechersignale) wie ne, gell, nicht wahr angegeben. Hörerrollenbestätigungsappelle sind also Mittel, mit denen der Sprecher vom Hörer gewisse Reaktionen evozieren kann. Solche Mittel dienen dem Sprecher dazu, vom Hörer eine Erlaubnis zum Weitersprechen einzuholen. ${ }^{77}$ Bei Existenz des Hörerrollenbestätigungsappells wird der Hörer stärker als sonst in die Pflicht genommen, verbale Hörersignale von sich zu geben; diese Erklärung steht mit der Ansicht Raths (1979) in Einklang, daß zwischen Sprechersignalen und Hörersignalen eine Art Frage- und Antwortbeziehung besteht: Hörersignale sind nämlich (meist bestätigend) Antwort auf Sprechersignale (Vergewisserungsfragen). ${ }^{78}$ Demnach läßt sich eine hohe Frequenz der Hörersignale nach Sprechersignalen erwarten, ${ }^{79}$ denn mit dem Unterlassen der Gegenreaktion an jener Stelle droht dem Hörer die Gefahr, unkooperativ und unhöflich zu wirken. Diese Vermutung wird jedoch überraschenderweise bei Sawada (1991) nicht bestätigt; sie stellt keine Korrelation zwischen Sprechersignalen und Hörersignalen in ihren Daten fest. ${ }^{80}$ Diese beiden widersprüchlichen Positionen veranlaßten mich, die Häufigkeit der Hörersignale in Abhängigkeit von Sprechersignalen zu ermitteln.

\footnotetext{
${ }^{74}$ Was die Autorinnen unter Sinneinheiten verstehen, wird nicht deutlich.

${ }^{75}$ Vgl. Wahmhoff/Wenzel 1979, S. 275. Duncan (1974) berechnet die Vorkommenshäufigkeit der verspäteten Hörersignale.

${ }^{76}$ Wahmhoff/Wenzel 1979, S. 276.

${ }^{77}$ Vgl. Wahmhoff/Wenzel 1991, S. 276.

${ }^{78}$ Rath 1979, S. 119.

79 Auch im Englischen ist die Korrelation zwischen einem „speaker within turn signal“ und einem darauf folgenden Hörersignal sehr hoch (Duncan 1974).
} 


\subsubsection{Zu Untersuchungen zur Positionierung der Hörersignale im Japanischen}

Maynard (1986) führt eine empirische Untersuchung über die jeweiligen Merkmale der Sprecheräußerungen, die ,aizuchi“ begünstigen, durch. Demnach werden Hörersignale auch im Japanischen überdurchschnittlich oft in Pausen zwischen syntaktischen Einheiten beobachtet. ${ }^{81}$ Die Pausen bilden jedoch nicht das alleinige Kriterium für das Vorkommen der Hörersignale, sondern andere Faktoren wirken dabei mit, die zusätzlich durch folgende Merkmale gekennzeichnet sind: ${ }^{82}$

- satzfinale Partikeln (Sprechersignale) wie ne (im Deutschen nicht wahr, gell) usw.,

- die Satzschlußform des Verbs eines selbständigen Satzes,

- satzfinale Konjunktionen, die die Subordination anzeigen, vor allem konditionale Sätze in Ellipsen, ${ }^{83}$

- die gerundive Verbform, die sowohl die Satzgrenze als auch die Fortsetzung anzeigt, und

- die Kopfbewegung des Sprechers, die in der Nähe der letzten Silbe des Satzes auftritt.

Abgesehen von den oben erwähnten Umgebungen, die mit Satzgrenzen eines Satzes oder Nebensatzes assoziiert sind, gibt es im Japanischen weitere Umgebungen, in denen Hörersignale häufig produziert werden: ${ }^{84}$

- turninterne Hörersignale, die lange vor dem Satzende auftreten,

- Hörersignale, die kurz vor einer Satzgrenze plaziert werden, d.h. mit den letzten Silben des betreffenden Satzes überlappt sind.

Clancy et al. (1996) untersuchen die Häufigkeit der Hörersignale sowie der Turnübernahmen in Abhängigkeit von der Beendigung von vier unterschiedlichen syntaktischen und/oder intonatorischen Einheiten im Sprecherturn. Diese Einheiten bestehen aus:

\footnotetext{
${ }^{80}$ Sawada 1991, S. 72.

${ }^{81}$ Maynard 1986, S. 1096.

${ }^{82}$ Maynard 1986, S. 1096-1097.

${ }^{83}$ Maynard 1986, S. 1099.

${ }^{84}$ Maynard 1986, S. 1094-1095.
} 
- der grammatischen und intonatorischen Einheit,

- der grammatischen Einheit,

- der intonatorischen Einheit und

- den nicht-finalen intonatorischen Einheiten.

Die Autoren überprüfen in drei Sprachen (Englisch, Japanisch und Chinesisch), wie oft Hörersignale am Ende einer der vier oben genannten Einheitsgrenzen plaziert werden. In bezug auf das Englische wird festgestellt, daß Hörersignale vor allem am Ende der grammatischen Einheit eingesetzt werden: $78 \%$ aller Hörersignale in den englischen Daten sind dort anzutreffen. Amerikanische Hörer tendieren also dazu, mit der verbalen Reaktion so lange zu warten, bis die betreffende grammatische Einheit komplettiert ist. Hingegen zeigt die Distribution japanischer Hörersignale eine andere Tendenz: Die Auftretenshäufigkeit im Japanischen am Ende einer grammatischen, intonatorischen und grammatisch- und intonatorischen Einheit bleibt wie folgt gleichmäßig: 30,8\%, 36,6\% und 33,3\%; dafür ist die Quote der Hörersignale, die mitten in einer nicht satzletzten, intonatorischen Einheit oder am Ende einer nicht satzletzten intonatorischen Einheit plaziert sind, höher: ${ }^{85} 19,6 \%$ aller Hörersignale werden in den japanischen Daten in der Mitte der nicht satzfinalen intonatorischen Einheit beobachtet. Demnach ist der Anteil der Hörersignale, die mitten in einer Einheit produziert werden, bei den Japanern viel höher als in den beiden anderen Sprachgruppen. ${ }^{86}$

Außerdem wird bei Clancy et al. auch die Anzahl der Hörersignale im Verhältnis zur Gesamtanzahl der oben genannten Grenzen und Einheiten berechnet. Daraus ergibt sich, daß ca. ein Zehntel der oben genannten Einheitsgrenzen mit Hörersignalen ausgestattet sind. Auch wenn man die Anteile der Turnübernahmen sowie der Hörersignale mit in die Berechnung einbezieht, bleibt trotzdem über die Hälfte der Einheitsgrenzen ohne irgendeine verbale Reaktion des Hörers. ${ }^{87}$ Das deutet darauf hin, daß verbale Hörersignale nicht ständig produziert werden müssen, sondern es genügt, wenn sie an strukturell wichtigen Stellen eingesetzt werden.

\footnotetext{
${ }^{85}$ Clancy et al. 1996, Kap. 5.2, 5.3.

${ }^{86}$ Maynard (1986) erwähnt dieses Phänomen ebenfalls.

${ }^{87}$ Clancy et al. 1996, S. 378.
} 
Koiso et al. (1996) errechnen die Korrelation zwischen syntaktischen sowie prosodischen Merkmalen und der Häufigkeit der Hörersignale. Die syntaktischen Merkmale, die der Korrelationsanalyse unterzogen werden, sind folgende:

\begin{tabular}{|l|l|l|}
\hline $\begin{array}{l}\text { Nicht } \\
\text { flektierbar }\end{array}$ & $\begin{array}{l}\text { Flektierbar (Verben, Adjektive, } \\
\text { Hilfsverben) }\end{array}$ & Partikeln \\
\hline \multicolumn{1}{|c|}{ Nomen } & Irreale Form & $(+)$ Kasus-Partikel \\
\hline (-) Adverb & $(+)$ Adverbiale Form & (+) Konjunktionale Partikel \\
\hline Adnomen & „euphonic“ Form $^{89}$ & Satzletzte Partikel \\
\hline (-) Konjunktion & Attributive Form & \\
\hline (-) Interjektion & Konditionale Form & \\
\hline (-) Füller & Imperative Form & \\
\hline
\end{tabular}

Es stellt sich heraus, daß adverbiale Formen, Kasus-Partikeln und konjunktionale Partikeln mit der Produktion der Hörersignale positiv korrelieren. Hingegen wird eine negative Korrelation zwischen Adverbien, Konjunktionen, Interjektionen und Füllern und der Frequenz der Hörersignale festgestellt. ${ }^{90}$ Interjektionale Partikeln, die von Maynard als Auslöser der Hörersignale betrachtet werden, erweisen sich nach der Analyse von Koiso et al. als kein signifikanter Faktor für das Auftreten der Hörersignale. Zu einem ähnlichen Ergebnis kommt auch Sawada (1991). ${ }^{91}$

In bezug auf prosodische Merkmale ergibt sich, daß vor allem die flach-fallende und die steigend-fallende Intonationskontur in der Region der letzten Silbe mit Vorkommen der Hörersignale assoziiert werden. ${ }^{92}$ Dieses Ergebnis unterstützt die Behauptung von Sugifuji (1987), daß die fallende Intonation am Satzende mehr ,aizuchi“ nach sich zieht. ${ }^{93}$

\footnotetext{
${ }^{88}$ Die Autoren erklären diese Kategorie nicht; wahrscheinlich sind die te-Form des Verbs und die ku-Form des Adjektivs gemeint; mit diesen Formen können Verben und Adjektive an das nächste verbale Element angeschlossen werden.

${ }^{89}$ Damit wird wohl die i-Form gemeint sein, die Anschlußform des Verbs an ein Hilfsverb.

${ }^{90}$ Koiso et al. 1998, S. 312.

${ }^{91}$ Sawada 1991, S. 72.

92 Koiso et al.1996, S. 313.

${ }^{93}$ Sugifuji 1987, S. 119.
} 


\subsubsection{Forschungen zu Funktionen und Effekten von Hörersignalen}

Wie man den vorigen Kapiteln entnehmen kann, werden Funktionen von Hörersignalen in der einschlägigen Forschungsliteratur immer wieder thematisiert. Im folgenden werden einige Autoren, die sich mit diesem Thema intensiv beschäftigt haben, je nach Herkunftsländern vorgestellt. Zuerst werden amerikanische Forschungen herangezogen.

\subsubsection{Zu Befunden über Funktionen von Hörersignalen im Englischen}

Duncan (1974) geht davon aus, daß die Funktion der Hörersignale darin besteht, dem Sprecher den Empfang und das Verstehen oder ggf. das Nichtverstehen des Gesagten kenntlich zu machen. ${ }^{94}$ Dabei sind für Duncan die Plazierungspositionen der Hörersignale ausschlaggebend, weil sie nämlich dem Sprecher den unterschiedlichen Verstehensstand des Hörers übermitteln. Duncan differenziert drei Plazierungspositionen: ${ }^{95}$

- die Plazierung an Grenzen zwischen zwei grammatischen Einheiten; diese bedeutet nämlich, daß das Verstehen des Hörers genauso schnell wie die Produktion der Sprecheräußerung verläuft;

- die Frühplazierung, nämlich die Plazierung kurz vor der Beendigung einer syntaktischen Einheit; sie signalisiert, daß der Hörer mit dem Verstehen sogar voraus ist;

- die Spätplazierung, also zu Beginn der neuen Einheit; sie indiziert verspätetes Verstehen der Sprechermitteilung durch den Hörer.

Auch in der vorliegenden Arbeit wird mit Duncan die Ansicht vertreten, daß die Plazierungspositionen der Hörersignale Hinweise auf den Verstehensprozeß des Hörers geben, wobei Duncans Ansatz verfeinert oder modifiziert wird.

Schegloff (1982), einer der Vertreter der ethnomethodologischen Konversationsanalyse, wendet sich gegen die allgemeine Beschreibung der Funktionen von Hörersignalen, die darauf hinausläuft, daß Hörersignale Interesse, Zustimmung und Verstehen des Hörers bekunden. ${ }^{96}$ Stattdessen bestimmt Schegloff Funktionen von Hörersignalen in bezug auf die

\footnotetext{
${ }^{94}$ Duncan 1974, S. 177.

${ }^{95}$ Duncan 1974, S. 179.

${ }^{96}$ Damit meint Schegloff 1982, S. 74, z.B. Yngve (1970).
} 
Zusammenarbeit zwischen Sprecher und Hörer bei der Turnorganisation. ${ }^{97}$ Nach Schegloff fungieren Hörersignale wie yeah, uh huh, mmhmm nicht im wesentlichen als Ausdruck der Aufmerksamkeit, des Verstehens oder der Zustimmung des Hörers, sondern als „,continuer“. Mit „continuers“ zeigt der Hörer an, daß er jetzt die Gelegenheit, den Turn zu übernehmen, nicht ergreift, weil er weiß, daß der Sprecher seinen Turn erweitern will. ${ }^{98}$ Dies begründet Schegloff durch die Plazierungsposition der „continuers“ im Multi-Turn: „Continuers“ werden oft nur an turnübergangsrelevanten Stellen plaziert, an denen der Turnwechsel stattfinden kann, weil der Sprecher dort eine syntaktische Einheit vollendet hat. Der Hörer, der einen „,continuer“ sendet, übernimmt den Turn nicht, sondern macht kurze Äußerungen wie yeah, uh huh.

Außerdem können laut Schegloff einige solcher kurzen Äußerungen ebenfalls indizieren, daß der Hörer die Gelegenheit, eine Reparatur (ein Verstehensproblem, Dissens usw.) vorzunehmen, verpaßt. Hörersignale mit dieser Funktion unterscheiden sich von „continuers“ darin, daß sie nicht an turnübergangsrelevanten Stellen auftreten müssen, sondern prinzipiell nach jedem Satzelement der Sprecheräußerungen stehen können. ${ }^{99}$ Sie können als „claim“ der Zustimmung oder des Verstehens dem Gesagten gegenüber interpretiert werden, weil der Hörer sonst Reparaturhandlungen eingeleitet hätte, um einen Dissens anzuzeigen oder Verstehensprobleme zu beseitigen. ${ }^{100}$

Obwohl Schegloff bei der Betrachtung sowie der Beschreibung der Funktionen von Hörersignalen einen wichtigen Beitrag geleistet hat, stellt sich in der vorliegenden Arbeit klar heraus, daß Funktionen von Hörersignalen nicht lediglich auf die Grundfunktion „continuer“ reduziert werden können, sondern besser in ihrer Vielfalt und ihrer Multifunktionalität charakterisiert werden sollten.

Goodwin (1986) differenziert zwischen „continuers“ und „assessments“; diese Unterscheidung begründet Goodwin durch die Positionierung von „assessments“ und die Reaktion des Sprechers darauf, wodurch sie sich von „,continuers“ merklich unterscheiden:

\footnotetext{
${ }^{97}$ Vgl. Schegloff 1982, S. 74.

${ }^{98}$ Schegloff 1982, S. 81.

${ }^{99}$ Schegloff 1982, S. 88.

${ }^{100}$ Schegloff 1982, S. 88. Die Befunde meiner Arbeit stimmen nicht immer mit den Thesen Schegloffs überein; dies wird im Kapitel 4.5 gezeigt.
} 
- „Continuers“ treten an Satzenden auf und überbrücken dadurch zwei Turneinheiten eines erweiterten Turns; ${ }^{101}$ „assessments“ hingegen werden innerhalb desselben Turns vollzogen. $^{102}$

- Bei „continuers“ setzt der Sprecher seine Rede unbesorgt fort, auch wenn sie mit dem Beginn der nächsten Turneinheit überlappen und noch nicht vollzogen sind; die Überlappung von „,continuers“ scheint also dem Sprecher kein Problem zu bereiten. ${ }^{103} \mathrm{Im}$ Fall von ,assessments“ bemüht er sich, diese bewußt in demselben Turn zu beenden, indem er den betreffenden Turn z.B. durch die Dehnung der Silbe des letzten Satzelementes verlängert; der Sprecher hält also anders als bei „continuers“ das Eindringen von „,assessments“ in den nächsten Turn offenbar für unangemessen. ${ }^{104}$

- Mit „continuers“ demonstriert der Hörer, daß er die vorangegangene Einheit empfangen hat und zugleich die nächste Turneinheit erwartet; ${ }^{105}$ dagegen bezeugen ,,assessments“ die Anteilnahme am Gespräch und die Bewertung des Hörers dem Gesagten gegenüber. Daher ist es nicht angebracht, sie über den betreffenden Turn hinaus in den nächsten Turn eindringen zu lassen, auf den die Bewertung nicht mehr bezogen ist. ${ }^{106}$

Im Kapitel 4.5 dieser Arbeit wird überprüft, ob die These Goodwins auf meine Daten angewendet werden kann. ${ }^{107}$

White (1986) befaßt sich mit Funktionen der Hörersignale auf verschiedenen Ebenen: auf der Satzebene, auf der Ebene der Turnorganisation und auf der Ebene der Konversation.

Ihr Ausgangspunkt ist, daß die Konversation als ein System der zwischenmenschlichen Kommunikation zwei Grunderfordernisse an den Hörer stellt: Das eine ist, daß interpretierbare Mitteilungen empfangen und korrekt verstanden werden müssen; die zweite Forderung besteht darin, daß Mitteilungen angemessen erwidert werden müssen. ${ }^{108}$ Demnach hat der Hörer in der Kommunikation zuerst die Aufgabe zu erfüllen, die Sprechermitteilung zu empfangen, die zugrundeliegende Proposition und die Sprecherintention zu verstehen und

\footnotetext{
${ }^{101}$ Goodwin 1986, S. 207.

102 Goodwin 1986, S. 209.

${ }^{103}$ Vgl. Goodwin 1986, S. 208.

${ }^{104}$ Goodwin 1986, S. 210.

105 Goodwin 1986, S. 208.

${ }^{106}$ Goodwin 1986, S. 215.

${ }^{107}$ Die Beobachtungen Goodwins gelten nicht für meine Daten (siehe Kapitel 4.5).

${ }^{108}$ Vgl. White 1986, S. 116.
} 
außerdem das durch die Sprechermitteilung Implizierte für sich selber zu ergänzen. Darüber hinaus muß er den Sprecher auf eine angemessene Art und Weise über den Stand seines Verständnisses des Gesagten informieren. Dabei dienen Hörersignale bzw. die Auslassung der Hörersignale dazu, die zweite Forderung, nämlich den Empfang und das Verstehen der Proposition und der Sprecherintention anzuzeigen. Eine passende, situationsadäquate Hörerreaktion fördert den reibungslosen Verlauf des Gesprächs, indem sie nämlich den Sprecher dazu aufmuntert, mit der Rede fortzufahren. ${ }^{109}$

Bezüglich der Satzebene formuliert White spezifische Funktionen, die Hörersignale in unterschiedlichen linguistischen Umgebungen ausüben, folgendermaßen: ${ }^{110}$

\begin{tabular}{|l|l|l|}
\hline $\begin{array}{l}\text { Steigende } \\
\text { Intonation }\end{array}$ & $\begin{array}{l}\text { Der Sprecher bezweckt damit, die } \\
\text { Bestätigung oder das Verstehenssignal } \\
\text { vom Hörer zu erhalten, um eine } \\
\text { gemeinsame Basis auszuhandeln. }\end{array}$ & $\begin{array}{l}\text { Hörersignale indizieren die } \\
\text { Gegebenheit einer gemeinsamen Basis } \\
\text { oder bestätigen das Verstehen der als } \\
\text { gegeben hingestellten Information. }\end{array}$ \\
\hline Satzgrenzen & $\begin{array}{l}\text { Sie markieren das Ende einer } \\
\text { Proposition. }\end{array}$ & $\begin{array}{l}\text { Hörersignale geben zu erkennen, daß } \\
\text { die Information aufgenommen und } \\
\text { verstanden wurde, als der betreffende } \\
\text { Satz vollzogen wurde. }\end{array}$ \\
\hline $\begin{array}{l}\text { Thema der } \\
\text { Äußerung }\end{array}$ & $\begin{array}{l}\text { Hebt einen Teil der Information als } \\
\text { gemeinsames Wissen hervor. }\end{array}$ & $\begin{array}{l}\text { Hörersignale bestätigen die gemeinsam } \\
\text { geteilte Information, die im vorherigen } \\
\text { Kontext bereits erwähnt wurde. }\end{array}$ \\
\hline
\end{tabular}

Kraut et al. (1982) führen eine statistisch fundierte Untersuchung durch, um die These zu überprüfen, daß Feedbacks vom Hörer die Sprecherrede in hohem Maße steuern können. Beim Experiment werden die Probanden darum gebeten, sich einen Film anzuschauen und ihn zusammenzufassen. Den Erzählern werden jeweils zwei Hörer zugeordnet: Der eine Hörer hört nur zu, während der andere (verbale) Hörersignale von sich gibt. Dabei stellt sich heraus, daß die Erzählungen der Sprecher, deren Zuhörer Hörersignale senden dürfen, sowohl für die Hörer als auch für Kraut et al. viel verständlicher sind als die Erzählungen mit sehr wenig Hörerrückmeldungen (nur Zuhören). ${ }^{111}$ Daraus wird schlußgefolgert: Feedbacks vom Hörer vermitteln dem Sprecher die Information darüber, was der Hörer bereits weiß und was nicht; sie ermöglichen dem Sprecher, den Redebeitrag so zu gestalten, daß das Gesagte auf den Verstehens- und Wissensstand des Hörers zugeschnitten ist. Mit anderen Worten: Der

\footnotetext{
${ }^{109}$ Vgl. White 1986, S. 114-115.

${ }^{110}$ Vgl. White 1986, S. 111. Hier werden nicht alle Umgebungen und deren Funktionen genannt.

${ }^{111}$ Vgl. Kraut et al. 1982, S. 718, 723.
} 
Sprecher, der viele Hörersignale erhält, kann die Abschnitte, die der Hörer ohne weiteres verstanden hat, schneller abhaken und die Stellen, die dem Hörer Verstehensschwierigkeiten bereiten, hingegen ausführlich erläutern. ${ }^{112}$ So dienen Hörersignale dazu, die Effektivität bei der Wiedergabe des Films und die Verständlichkeit des erzählten Textes zu erhöhen.

\subsubsection{Zu Befunden über Funktionen von Hörersignalen im Deutschen}

Wahmhoff/Wenzel (1979) haben anhand ihres Datenmaterials (Beratungsgespräche) ein Beschreibungsmodell für Funktionen von Hörersignalen erarbeitet. Darin werden drei Ebenen, die kommunikative, die propositionale und die soziale Beziehungsebene unterschieden.

Auf der kommunikativen Ebene sind folgende Funktionen von Hörersignalen angesiedelt, die zur Steuerung der kommunikativen Beziehung beitragen: ${ }^{113}$

- die Bestätigung des aktuellen Sprechers,

- die Legitimierung der Unterbrechung durch den anderen Partner,

- die Aufforderung an den Partner, die Sprecherrolle neu zu übernehmen,

- die Anmeldung des Anspruchs auf die Sprecherrolle.

Außerdem überbringen Hörersignale nach Wahmhoff/Wenzel Informationen über die Art der sozialen Beziehung zwischen den Gesprächsbeteiligten: Die Gesprächsteilnehmer können z.B. „solidarisch“ oder „nicht solidarisch“ zueinander stehen. Unter „Solidarität“ werden Gefühle von Sympathie, Vertrauen und Nähe verstanden; dieses wird in einem freundlichen, bestätigenden, interessierten Verhalten geäußert. Hingegen wird „Nicht-Solidarität“ durch ungeduldiges, desinteressiertes oder ablehnendes Verhalten des Sprechers angezeigt. ${ }^{114}$

Die propositionale Ebene umfaßt die Informationen, die auf die kognitive Einschätzung des Hörers bezogen sind. Die kognitive Einschätzung des Hörers läßt sich nach den Autorinnen in folgende vier Kategorien zusammenfassen:

\footnotetext{
${ }^{112}$ Vgl. Kraut et al. 1982, S. 723, 728.

${ }^{113}$ Wahmhoff/Wenzel 1979, S. 282. Barba (1988, S. 59) gibt ebenfalls ähnliche Funktionen an.

${ }^{114}$ Wahmhoff/Wenzel 1979, S. 284-285.
} 


\section{Konsens}

2. Divergenz (Zweifel, Skepsis usw.)

3. Bekanntgabe des eigenen Informationsstandes (Staunen, Nachfrage usw.)

4. Verzicht auf Stellungnahme ${ }^{115}$

Das Fazit von Wahmhoff/Wenzel ist, daß Hörersignale in hohem Maße gesprächssteuernd sind, indem sie je nach ihrer Art des Einsatzes zur aktiven Konfliktvermeidung oder Konfliktverschärfung dienen können. Konfliktvermeidende Hörersignale sind solche, die den Sprecher zum Weiterreden ermutigen und dadurch den reibungslosen Ablauf des Gesprächs erleichtern; konfliktverschärfende, nicht solidarische Hörersignale hingegen demotivieren den Sprecher beim Weiterreden oder hindern ihn gar daran. ${ }^{116}$

Barba (1988) klassifiziert anhand ihrer empirischen Daten Hörersignale in die nachstehenden drei funktionalen Kategorien:

- Aufmerksamkeitssignale (einfache und verstehende),

- fortführende Signal,

- Einstellungskundgaben (Zustimmung und heterogene Einstellungen). ${ }^{117}$

Mit einfachen Aufmerksamkeitssignalen versichert der Hörer seinem Sprecher, daß er bei der Sache ist und die Aufmerksamkeit auf den Sprecher fokussiert; diese Funktion erfüllen implizit alle Hörersignale. ${ }^{118}$ Verstehende Aufmerksamkeitssignale signalisieren hörerseitiges Verstehen der Sprachhandlung des Sprechers; ${ }^{119}$ diese liegen dann vor, wenn eine Aussage vom Standpunkt des Hörers her abgerundet ist und damit einen Sinn ergibt. ${ }^{120}$

Fortführende Signale fordern den Gesprächspartner dazu auf, seinen Turn weiterzuführen. Da nach Barba diese Funktion mehr oder minder von allen Hörersignalen ausgeübt werden kann, die keinen Anspruch auf die Sprecherrolle erheben, verdienen Hörersignale nur dann diese

\footnotetext{
${ }^{115}$ Wahmhoff/Wenzel 1979, S. 285.

${ }^{116}$ Wahmhoff/Wenzel 1979, S. 288-290.

${ }^{117}$ Barba 1988, S. 42.

${ }^{118}$ Barba 1988, S. 43.

${ }^{119}$ Barba 1988, S. 44.

${ }^{120}$ Barba 1988, S. 47.
} 
Extrabenennung, wenn sie in einem ausgeprägt auffordernden Moment zum Weiterreden gesendet werden. $^{121}$

Unter Einstellungskundgaben versteht Barba solche Signale, die über die eben genannten Funktionen hinaus die Einstellung des Hörers zum Sprecherbeitrag bekunden. Darunter sind vor allem zustimmende Signale, die ohne emotionale Involviertheit das Gesagte des Sprechers bejahen, es für richtig halten oder diesem zustimmen, in den Daten Barbas am häufigsten anzutreffen. $^{122}$

Als heterogene Signale bezeichnet man solche, an denen die emotionale Beteiligung des Hörers (Begeisterung, Staunen, Drohung, Peinlichkeit) erkennbar ist. Sie stellen des öfteren eine Potenzierung der zustimmenden oder verstehenden Signale dar. Heterogene Signale zeichnen sich im Vergleich zu den anderen Signalen dadurch aus, daß sie formal durch unterschiedliche sprachliche Mittel realisiert werden, die vom Nonverbalen bis hin zu kurzen, vollständigen Sätzen reichen; meistens werden sie jedoch als Potenzierung anderer Signale konkretisiert. $^{123}$

Hörersignale können nach Barba verschiedene Effekte auf die Länge des Sprecherbeitrags haben: Aufmerksamkeitssignale bewirken meistens die Fortsetzung des Sprecherbeitrags, weil der Sprecher dadurch zur weiteren Informationsabgabe aufgemuntert wird. Hingegen können verstehende oder zustimmende Signale die Sprecherrede eher verkürzen, denn bei Konsens hinsichtlich des Wissensstands und Ansichten ist die weitere Ausführung zum aktuellen Thema tendenziell überflüssig. Ferner können Hörersignale, die vorzeitig die Turnübernahme des Hörers ankündigen, den Sprecherturn auf das Ende hin steuern. ${ }^{124}$

Insgesamt betrachtet Barba Hörersignale als Steuerungsmittel, die die kommunikative und soziale Beziehung zwischen den Gesprächspartnern regeln. Auf der Ebene der kommunikativen Beziehung koordinieren Hörersignale die Sprecher- und Hörerrolle und sorgen für einen reibungslosen Gesprächsablauf durch die Verhinderung von

\footnotetext{
${ }^{121}$ Zusammengefaßt nach Barba 1988, S. 46-47.

${ }^{122}$ Barba 1988, S. 48.

${ }^{123}$ Zusammengefaßt nach Barba 1988, S. 50-54.

${ }^{124} \mathrm{Vgl}$. Barba 1988, S. 56-57.
} 
Rollenkonflikten $^{125}$; auf der anderen Seite wird je nach der Art der kommunikativen Beziehung entweder ein solidarischer oder nicht-solidarischer Interaktionsmodus zwischen den Gesprächsbeteiligten geschaffen; somit dienen Hörersignale auch als Vehikel zur Herstellung der zwischenmenschlichen Beziehung. ${ }^{126}$

Quasthoff (1981) untersucht die Rolle des Zuhörers in „konversationellen Erzählungen“; eine konversationelle Erzählung ist „eine grundsätzlich mündlich konstituierte Diskurseinheit, die sich spontan in Gesprächen realisiert“. ${ }^{127}$ Außerdem stellt sie nach Quasthoff ein komplexes, interaktives Geschehen dar, ${ }^{128}$ indem hierarchisch strukturierte Inhalte in eine wiederum strukturierte sprachliche Form linearisiert werden; diese Strukturierung des Erzählinhaltes ist bedingt durch die Intentionen des Sprechers sowie die Reaktionen des Zuhörers. ${ }^{129}$

In der Analyse wird herausgestellt, daß Hörersignale jeweils in verschiedenen Erzählsegmenten (Eröffnung, Vollzug, Beendigung) steuernde Funktionen ausüben, indem sie die Erzählaktivität des Sprechers unterstützen oder diese hemmen. Der Sprecher hingegen ändert auch seine Erzählstrategien, je nachdem, ob der Hörer ein erzählfreundliches oder erzählfeindliches Verhalten zeigt: So vermeidet der Sprecher z.B. in einer erzählfeindlichen Situation vor dem Vollzug der narrativen Einheit jegliche Äußerungsformen wie die Erzählankündigung oder Orientierungen, die auf die Erzählung schließen lassen können, weil die Gefahr droht, daß der Hörer die Ratifizierung ihrer Entfaltung verweigern könnte; stattdessen geht der Sprecher in die Vollzugsphase über und schiebt orientierende Elemente, die vor der Vollzugsphase der Erzählung hätten plaziert werden müssen, mitten in der Repräsentation der Vollzugsphase der Erzählung nach. ${ }^{130}$

Außerdem deckt Quasthoff eine strukturierende Leistung der Hörersignale (vor allem in der Vollzugsphase der Erzählung) auf; Hörersignale können nämlich die Diskurseinheit in

\footnotetext{
${ }^{125}$ Vgl. Barba 1988, S. 59; Barba weist an dieser Stelle nicht explizit auf Wahmhoff/Wenzel (1979, S. 258) hin, die Affinität zu letzteren ist jedoch eindeutig zu erkennen.

${ }^{126}$ Barba 1988, S. 59-60. Ihre Beschreibungen sind im großen und ganzen Wahmhoff/Wenzel (1979) sehr ähnlich.

${ }^{127}$ Quasthoff 1981, S. 289; die genauere Definition der konversationellen Erzählung folgt auf derselben Seite.

${ }^{128}$ Das Erzählen von Geschichten wird auch von Sacks (1971) als interaktiver Prozeß aufgefaßt, wie Quasthoff in ihrem Aufsatz erwähnt.

${ }^{129}$ Vgl. Quathoff 1981, S. 290.

${ }^{130}$ Vgl. Quasthoff 1981, S. 307.
} 
einzelne Episoden untergliedern, indem sie den Anfang und/oder das Ende einer solchen Episode markieren. ${ }^{131}$

Ferner können Hörersignale als Verstehenssignale eingesetzt werden, die jedoch nach Quasthoff im allgemeinen vom Sprecher provoziert werden; dabei stehen ihm einige Mittel (kurze Pause, „tag questions“, Unsicherheitsmarkierung usw.) zur Verfügung, die verständnisanzeigende Signale beim Hörer auslösen können. ${ }^{132}$

Insgesamt wird bei Quasthoff deutlich, daß Funktionen von Hörersignalen nicht nur auf der Satzebene (Mikroebene), sondern auch auf einer höheren, satzübergreifenden Ordnungsebene wie z.B. der eines Gesprächsabschnittes bestimmt werden können.

Zuletzt sollen Ehlich (1979) und Rehbein (1977) kurz erwähnt werden, weil sie den Begriff „Konvergenz“ und „Divergenz“ sowie den Verstehensprozeß des Hörers ausführlicher als andere beschreiben.

Ehlich (1979) untersucht verschiedene Realisierungen von $u h m$, die vom Hörer geäußert werden. Dabei stellt er nach den Tönen und den Lautsubstraten (einfache, reduplizierte und kurze $u h m$ ) vier Grundformen von $u h m$ auf; denen jeweils eine der vier Grundfunktionen zugeordnet wird:

\begin{tabular}{|l|l|l|}
\hline Typ I & uhm /uhmhm $\downarrow \uparrow$ & „,einverstanden“, Konvergenz \\
\hline Typ II & uhm /uhmhm $\uparrow$ & ,wieso denn“, Divergenz \\
\hline Typ III & uhm /uhmhm $\rightarrow$ & „,vielleicht, aber“, prä-Divergenz \\
\hline Typ IV & uhm /uhmhm $\downarrow$ & „,das ist ja merkwürdig“, komplexe Divergenz \\
\hline
\end{tabular}

Die Begriffe „Konvergenz“ und „Divergenz“ beziehen sich bei Ehlich auf die Resultate der sprecherseitigen sowie hörerseitigen Prozesse der Verständigungssicherung beim sprachlichen Handeln des Sprechers. Der Sprecher operiert beim Reden mit der Unterstellung, daß zwischen ihm und dem Hörer die zum Verständnis der betreffenden Sprachhandlung nötige Wissensbasis geteilt wird. Da diese Unterstellung nicht immer aufrechterhalten werden

\footnotetext{
${ }^{131}$ Vgl. Quasthoff 1981, S. 295-299.

${ }^{132}$ Vgl. Quasthoff 1981, S. 301; dabei werden auch weitere Auslöser von Verstehenssignalen aufgelistet.
} 
kann, ist dem Sprecher der Einsatz einiger Prozeduren zur Sicherung des Verständnisses erforderlich. ${ }^{133}$

Darüber hinaus bezweckt der Sprecher beim sprachlichen Handeln, daß der Hörer von ihm etwas übernimmt, was er nicht aus eigenem Antrieb übernommen hätte. ${ }^{134}$ Der Hörer hingegen muß die sprachliche Handlung des Sprechers mental verarbeiten, indem er die Ansprüche des Sprechers (das Vorhandensein gemeinsamen Wissens und gemeinsamer Ansichten) auf ihre Kompatibilität mit seinen eigenen Wissens- und Bewertungssystemen hin überprüft und beurteilt. Die Resultate dieses Verarbeitungsprozesses des Hörers werden über Hörersignale wie z.B. $u h m$ an charakteristischen Stellen der Sprecherrede zum Ausdruck gebracht; Hörersignale wie uhm sind also nach Ehlich dem Hörer zur Verfügung stehende sprachliche Prozeduren zur Verständnissicherung, ohne dabei den Turn des anderen anzutasten. $^{135}$

Rehbein (1977) erläutert genauer als Ehlich den kognitiven Verarbeitungsprozeß des Hörers: Nach Rehbein ist der Hörer während des Sprecherturns stets damit beschäftigt, aus dem gehörten Äußerungsprodukt den Sprecherplan zu rekonstruieren. Diese Tätigkeit des Hörers nennt Rehbein „die Bildung des Hörerplans“. ${ }^{136}$ Sie verläuft etwa folgendermaßen: Der Hörer perzipiert das Äußerungsprodukt des Sprechers, um zu erschließen, welches Muster dieser Äußerung zugrunde liegt. Über die Erkennung des Sprechhandlungsmusters erfährt der Hörer das kommunikative Ziel des Sprechers und dessen Motivation; diese Stadien der Perzeption, Planbildungs- und Zielkonstruktion durchläuft der Hörer also in verkürzter Zeit, während der Sprecher die Sprachhandlung ausübt. Das Charakteristische am Hörerplan ist, daß der Hörer oft mit der Planbildung fertig ist, bevor der Sprecher am Handlungspunkt (also am Ende der Äußerung) angelangt ist. Dies läßt sich nach Rehbein daran festmachen, daß der Hörer häufig imstande ist, bei Abbrüchen, Unterbrechungen oder Selbstkorrekturen des Sprechers, seinerseits den Sprecherplan zu ergänzen und zu rekonstruieren. ${ }^{137}$

„Verstehen der sprachlichen Handlung des Sprechers“ heißt bei Rehbein nämlich, den dieser Handlung zugrundeliegenden Sprecherplan zu verarbeiten; diese Verarbeitung wird für den

\footnotetext{
${ }^{133}$ Vgl. Ehlich 1979, S. 512.

${ }^{134}$ Ehlich 1979, S. 512; vermutlich meint Ehlich die Standpunkte des Sprechers.

${ }^{135}$ Vgl. Ehlich 1979, S. 512.

${ }^{136}$ Vgl. Rehbein 1977, S.191.

${ }^{137}$ Rehbein 1977, S.192.
} 
Sprecher durch Hörersignale dokumentiert, was Rehbein als „Exothesen der Hörerplans“ bezeichnet. $^{138}$

Dieses Nach-Außen-Bringen des Hörerplans steuert wiederum den Sprecherplan, indem es den Sprecherturn nach dem bereits konzipierten Plan fortlaufen läßt oder zur Planrevision führt, weil das Nichtverstehen oder der Dissens vom Hörer her angekündigt wird. ${ }^{139}$

\subsubsection{3 $\mathrm{Zu}$ Befunden über Funktionen von Hörersignalen im Japanischen}

Horiguchi (1987) schreibt dem Hörer eine aktive Rolle im Gespräch zu: Der Hörer ist nicht nur Empfänger der Sprechermitteilung, sondern führt Tätigkeiten wie Verstehen, Interpretieren, Nachdenken, Erraten usw. aus, die teils nur mental verlaufen und teils in Form eines ,aizuchi“ nach außen gebracht werden. Verbale und nonverbale Reaktionen des Hörers bilden wiederum für den Sprecher Anhaltspunkte, an denen er sich während seiner Rede orientiert: Bei erwarteter Hörerreaktion kann er die Rede weiter fortsetzen; bei Nachfragen hingegen kann er darauf eine Antwort geben. Mit anderen Worten ist der Sprecher zur Ausführung seines Gesprächsbeitrags stets auf die Signale und die Zuwendung des Hörers angewiesen. $^{140}$

Ausgehend von der oben genannten Vorstellung des aktiven Hörers klassifiziert Horiguchi Hörersignale im Japanischen in fünf Kategorien: ${ }^{141}$

- Zuhörerschaft (ich höre zu): den Fortgang des Gesprächs fördernd,

- Verstehen (die Äußerung soweit verstanden): den Fortgang des Gesprächs erleichternd,

- Zustimmung (soweit verstanden, außerdem stimme ich dir zu): Der Fortgang des Gesprächs wird sehr erleichtert.

- Ablehnung (verstanden, aber ich stimme dir nicht zu): die Modifikation des Redeplans fördernd,

- Ausdruck der Emotionen: Je nachdem kann der Fortgang des Gesprächs erleichtert werden oder auch nicht.

\footnotetext{
${ }^{138}$ Rehbein 1977, S. 190.

${ }^{139}$ Rehbein 1977, S. 193.

${ }^{140}$ Zusammengefaßt nach Horiguchi 1987, S. 14.

${ }^{141}$ Horiguchi 1987, S. 16.
} 
Matsuda (1988) differenziert die Klassifikation Horiguchis noch feiner. Im folgenden wird das erweiterte Modell Matsudas dargelegt:

\section{- Zuhörerschaft}

- Der Hörer hört dem Sprecher zu.

- Der Hörer kommt mit der Sprecherrede mit.

\section{- Verstehen}

- Der Hörer ist mit dem Inhalt der Sprecherrede einverstanden.

- Der Hörer kann die Gefühle oder die Gedanken des Sprechers gut nachvollziehen. ${ }^{142}$

- Der Hörer versteht jetzt langsam, was ihm bis jetzt nicht klar war, der Hörer hat jetzt die gleiche Wissensbasis.

\section{- Zustimmung}

- Der Sprecher hat recht.

- Der Hörer hat Mitleid oder Mitgefühl.

- Der Hörer hat den Gedankengang des Sprechers verstanden. ${ }^{143}$

- Ablehnung

- allgemeine, vage Zustimmung

- Dissens, Zweifel

\section{- Ausdruck der Emotionen}

- Starke emotionale Involviertheit

- Interesse

\section{- Pausenfüller}

Außer den oben genannten Verwendungen von Hörersignalen gibt es nach Matsuda Hörersignale, die das Zuhören nur simulieren oder konfliktäre Einstellungen wie Ärger zum Ausdruck bringen. Ferner kann das Ausbleiben von Hörersignalen eventuell Dissens oder Nichtverstehen indizieren. ${ }^{144}$

Ôhama et al. (1998) untersuchen Funktionen von Hörersignalen anhand von Gesprächen, in denen es um die Wegauskunft geht. Dabei kommen sie zu dem Schluß, daß Hörersignale

\footnotetext{
${ }^{142}$ Maynard spricht von der Empathie des Hörers (1986, S. 1095).

${ }^{143}$ Diese Kategorie kann man meines Erachtens schlecht als Zustimmung gelten lassen, sie paßt besser zur Kategorie Verstehen.

${ }^{144}$ Matsuda 1988, S. 64.
} 
nicht nur die Zuhörerschaft, das Verstehen oder die Zustimmung des Hörers signalisieren, wie oft in der japanischen Forschungsliteratur gezeigt wird, sondern auch den Gesprächsverlauf aktiv steuern können.

In der Analyse teilen Ôhama et al. Wegauskunftsgespräche in fünf Phasen ein, die in der Regel in der unten angegebenen Reihenfolge auftreten; diese Phasen werden durch ihre jeweilige informative Relevanz in bezug auf die Wegauskunft sowie ihre Voraussagbarkeit der Reihenfolge der Informationsteile, die die jeweilige Phase konstituieren, charakterisiert: ${ }^{145}$

\begin{tabular}{|c|c|c|c|}
\hline Phase & $\begin{array}{l}\text { Teile der Informationen } \\
\text { (IT) }\end{array}$ & $\begin{array}{l}\text { Informative } \\
\text { Relevanz }\end{array}$ & $\begin{array}{l}\text { Voraussagbarkeit } \\
\text { der Reihenfolge } \\
\text { der IT }\end{array}$ \\
\hline Eröffnung & $\begin{array}{l}\text { - Vage Richtungsangabe } \\
\text { - Zeitangabe (wie lange man braucht) } \\
\text { - Bewegungsmittel }\end{array}$ & fakultativ & $\begin{array}{l}\text { nicht } \\
\text { voraussagbar }\end{array}$ \\
\hline Beginn der Kernphase & - von wo man startet & wichtig & voraussagbar \\
\hline Kernphase & $\begin{array}{l}\text { - Hinweise für die } \\
\text { Richtungsänderung } \\
\text { - Wo entlang man geht } \\
\text { - Angabe der Anhaltspunkte }\end{array}$ & notwendig & voraussagbar \\
\hline Ende der Kernphase & Zielangabe & wichtig & voraussagbar \\
\hline Beendigung & $\begin{array}{l}\text { - Garantieaussage: „du wirst es } \\
\text { sehen“ } \\
\text { - Aufgabe der Wegauskunft: „frag } \\
\text { dort wieder jemanden“ }\end{array}$ & fakultativ & fakultativ \\
\hline
\end{tabular}

Aus der Berechnung von Ôhama et al. ergibt sich, daß Hörersignale häufiger in der Eröffnungsphase, in der Beendigung der Kernphase und in der Beendigungsphase als anderswo gesendet werden. Dies erklären die Autoren folgendermaßen: In der Gesprächseröffnung ist die Unsicherheit des Hörers groß, ob er die für die Wegfindung relevanten Informationen vom anderen erhalten wird oder nicht; daher versucht er, den Sprecher daraufhin zu lenken, schnell in die Kernphase überzugehen. Am Ende der Kernphase sowie in der Gesprächsbeendigung begibt sich der Hörer verstärkt an die Gesprächssteuerung, weil er die Beendigung des Gesprächs beschleunigen will. In den

\footnotetext{
145 Ôhama et al. 1998, S. 76-77.
} 
anderen Phasen dagegen kann er das Gespräch „dem natürlichen Lauf der Dinge“ überlassen, weil er sich in den anfänglichen und mittleren Kernphasen darin sicher fühlt, gewünschte Informationen vom Sprecher übermittelt zu bekommen. ${ }^{146}$

Außerdem wird bei Ôhama et al. beobachtet, daß „aizuchi“ je nach Phasen unterschiedliche Distributionstendenzen aufzeigen: Einige ,aizuchi“ treten häufiger als andere in bestimmten Phasen auf. Aufgrund der Ähnlichkeit der Verteilung kristallisieren sich insgesamt vier Gruppierungen von ,aizuchi““ heraus: ${ }^{147}$

\section{1. hai-Gruppe}

2. $e$ :-Gruppe

3. substantielle ,aizuchi“: Wiederholungen, Umformulierungen, Nachfragen

4. a:-Gruppe: $a$ : (langsames Verstehen), a: hai (aja), wakarimashita (ich verstehe)

Ôhama et al. ordnen den einzelnen Gruppen von ,aizuchi“ jeweils eine spezifische Funktion $\mathrm{zu}:$

\begin{tabular}{|l|l|l|}
\hline Gruppe & Distribution & Funktion \\
\hline hai-Gruppe & $\begin{array}{l}\text { Beginn der Kernphase, } \\
\text { Kernphase }\end{array}$ & den geplanten Fortgang fördern \\
\hline$e:-$ Gruppe & Kernphase & $\begin{array}{l}\text { den Einstieg in die mittlere Kernphase } \\
\text { fördernd }\end{array}$ \\
\hline substantielle ,aizuchi“ & Eröffnung & $\begin{array}{l}\text { den Einstieg in den Beginn der Kernphase } \\
\text { fördernd }\end{array}$ \\
\hline$a:$-Gruppe & $\begin{array}{l}\text { Ende der Kernphase, } \\
\text { Beendigungsphase }\end{array}$ & die Beendigung des Gesprächs fördern \\
\hline
\end{tabular}

\subsubsection{Ergebnisse aus den empirischen Studien über Funktionen von Hörersignalen}

In einigen Studien wird die Frequenz der Funktionen von Hörersignalen berechnet: Barba (1988) untersucht Experten- und Starinterviews; dabei stellt sich heraus, daß in Starinterviews dreimal so viel Hörersignale wie in Experteninterviews gesendet werden; außerdem werden Einstellungskundgaben viel häufiger in Starinterviews als in Experteninterviews emittiert. Drittens werden Aufmerksamkeitssignale vorzugsweise von Interviewern, fortführende und

\footnotetext{
${ }^{146}$ Ôhama et al. 1998, S. 77.

${ }^{147}$ Ôhama et al. 1998, S. 79.
} 
zustimmende Signale hingegen von den Interviewten eingesetzt. ${ }^{148}$ Solche Differenzen werden auf die unterschiedlichen Rollen (Interviewer, Interviewte), den Interviewtyp (Experten- und Starinterviews) und individuelle Faktoren zurückgeführt. Die in den Daten Barbas am häufigsten vertretenen Funktionen sind Verstehen und Zustimmung. Ähnliches behauptet auch Hartung (1998), ohne eine Statistik zu präsentieren: In seinen Daten (Gespräche unter Freunden) finden sich nämlich am häufigsten Hörersignale, die Verstehen oder Zustimmung signalisieren. ${ }^{149}$

Ein anderes Ergebnis über die Verteilung von Funktionstypen der Hörersignale wird von Sawada (1991) präsentiert: Bei ihr ist der Anteil von Hörersignalen, die die Zuhörerschaft (ich höre zu) indizieren, sowohl in ihren deutschen als auch japanischen Daten am höchsten, darauf folgen Verstehenssignale; Zustimmungssignale hingegen werden nicht so oft beobachtet ${ }^{150}$. Die Rangordnung der Funktionstypen ist in beiden Datengruppen Sawadas im wesentlichen ähnlich, wobei die Zuhörerschaft in den japanischen Daten viel häufiger als im Deutschen signalisiert wird. Für konträre Ergebnisse der Forschungsliteratur sind zum Teil unterschiedliche Kriterien, die die Autoren bei der Zuordnung der Funktionen von Hörersignalen anwendeten, verantwortlich.

\subsection{Forschungen über Hörerverhalten im Kulturvergleich und in interkulturellen Gesprächen}

Das Interesse für Kulturunterschiede im Hörerverhalten wächst nach und nach mit der Etablierung der Hörerverhaltensforschung in der Interaktionsforschung. ${ }^{151}$

Hall (1969), ein Kulturanthropologe, ist einer der ersten, die darüber referierten, ${ }^{152}$ wie sehr Hörerverhalten stereotypisiert, kulturell geprägt und regelgeleitet ist. ${ }^{153}$ Hall thematisiert in seinem Aufsatz hauptsächlich das Blickverhalten von Navaho-Indianern und von Schwarzamerikanern. Navaho-Indianer stoßen in der interethnischen Kommunikation mit weißen US-Amerikanern oftmals auf Probleme, weil sie sich beim Zuhören anders als Weiße

\footnotetext{
${ }^{148}$ Vgl. Barba 1988, S. 55.

${ }^{149}$ Hartung 1998, S. 109.

${ }^{150}$ Sawada 1991, S. 72.

${ }^{151}$ Dabei trug ebenfalls das allgemeine wissenschaftliche Interesse am Kulturvergleich oder der interkulturellen Kommunikation dazu bei. Einen guten Überblick über dieses Arbeitsfeld der Linguistik in der deutschen Sprache liefern z.B. Hinnenkamp 1994, Knapp/Knapp-Kotthoff 1990.

${ }^{152}$ Hall verfaßte auch Arbeiten über Kommunikationsstile von Deutschen (1985) und Japanern (1984).

${ }^{153}$ Vgl. Hall 1969, S. 379.
} 
verhalten: Sie schauen nämlich nicht direkt in die Augen des Partners, weil das Anblicken in ihrer Kultur verboten ist, so daß man beim anderen Ärger provozieren würde, wenn man dies täte. ${ }^{154}$ Bei Schwarzamerikanern stellt Hall ebenfalls fest, daß sie ihre Zuhörerschaft auf eine andere Art und Weise als Weiße signalisieren: Sie brauchen in einer Nahkommunikation weder verbale Zeichen von sich zu geben noch den Sprecher anzuschauen, weil dabei bei Schwarzen automatisch vorausgesetzt wird, daß der Hörer, der sich in greifbarer Nähe des Sprechers befindet, diesem zuhört. Dieses an sich höfliche, respektvolle Hörerverhalten von Schwarzen wird jedoch von Weißen mißverstanden und bereitet ihnen viele Unannehmlichkeiten; ein Grund dafür ist, daß diese Verhaltensweisen der Schwarzen bei Weißen meist negative Bewertungen hervorgerufen haben. ${ }^{155}$

Ähnlich wie Hall macht Erickson (1979) in seinem Aufsatz interethnische Kommunikationsprobleme zwischen Schwarz- und Weißamerikanern zum Untersuchungsgegenstand. Nach dem Vergleich zwischen drei verschiedenen Interviewdaten - weiß-weiß-Interviews, schwarz-schwarz-Interviews und schwarz-weiß-Interviews - wird festgestellt, daß der Gesprächsverlauf in den Interviews zwischen Schwarzen und Weißen in dem Sinne am stärksten verzögert und gestört ist, daß weiße Interviewer häufig ihre Standpunkte wiederholen, mehrfach erläutern oder das Abstraktionsniveau ihrer Äußerungen senken. Dies erklärt Erickson durch kulturelle Differenzen in bezug auf das Sprecher- und Hörerverhalten an hörerreaktionsrelevanten Momenten; kurz vor diesen Momenten gibt der Sprecher zu erkennen, daß er bald aktive Hörerreaktionen vom Hörer erwartet. ${ }^{156}$ Nach der Analyse von Erickson signalisieren Weiße in ihren Daten hörerreaktionsrelevante Momente durch den Vollzug der syntaktischen Einheit (wie z.B. des Satzes) und die darauf folgende, kurze Pause, wobei die Intonationskontur am Ende der Äußerung keine große Rolle spielt. ${ }^{157}$ Hingegen handeln schwarze Interviewte nach einem anderen Signalsystem; demnach sind hörerreaktionsrelevante Stellen mehrfach markiert: Neben dem Ende der syntaktischen Einheit sind sie durch eine stark fallende Intonation und/oder die Wendung you know gekennzeichnet. $^{158}$

\footnotetext{
${ }^{154}$ Hall 1969. S. 379-380.

155 Siehe Hall 1969, S. 380.

156 Vgl. Erickson (1979, S. 115); Thomlison berichtet, daß Schwarze häufiger den Partner während des Sprechens anschauen als während des Zuhörens; Weißen verhalten sich im Gegenteil: Sie richten den Blick viel häufiger nach dem Partner während des Zuhörens als beim Sprechen (1991, S. 114).

${ }^{157}$ Vgl. Erickson 1979, S. 116.

${ }^{157}$ Vgl. Erickson 1979, S. 117.

${ }^{158}$ Vgl. Erickson 1979, S. 116-118.
} 
Eine angemessene Hörerreaktion in hörerreaktionsrelevanten Momenten, in denen der Hörer mehr als sonst verpflichtet ist, aktive Hörerreaktionen zu zeigen, beinhaltet bei Weißen oft den gleichzeitigen Einsatz von einem verbalen Signal und akzentuiertem Kopfnicken, wobei der Blickkontakt immer erforderlich ist. ${ }^{159}$ Anders als bei Weißen ist im System der Schwarzen entweder leichtes Kopfnicken oder ein verbales Signal als aktive Reaktion ausreichend. Dabei stellt der Blickkontakt keine Notwendigkeit dar - man braucht also nur die Augen ein wenig zu erheben und den Sprecher anzuschauen. ${ }^{160}$

Mißverständnisse zwischen weißen und schwarzen Gesprächspartnern entstehen aus zweierlei Gründen: Zum einen werden hörerreaktionsrelevante Stellen, auf die die weißen Interviewer die schwarzen Interviewten hinweisen, von den letzteren nicht als solche wahrgenommen; infolgedessen erhalten die weißen Teilnehmer von ihnen keine erwartete Hörerreaktion. Zweitens werden die Reaktionen der schwarzen Gesprächsteilnehmern an jenen relevanten Stellen von Weißen als nicht aktiv genug eingeschätzt, auch wenn verbale Hörerreaktionen richtig plaziert sind. ${ }^{161}$ Die Folge davon ist ein gestörter Gesprächsverlauf, der durch mehrfache Erläuterungen, Wiederholungen, Vereinfachungen von seiten der weißen Interviewer gekennzeichnet ist. ${ }^{162}$

Außer den Arbeiten, die sich interethnischen Verhaltensunterschieden im Bereich des Hörerverhaltens widmen, finden sich vor allem in den USA eine Reihe von Publikationen, die kulturspezifische Hörerverhaltensstile oder daraus resultierende interkulturelle Mißverständnisse zum Untersuchungsgegenstand machen. Dabei bildet Japan eine beliebte Zielkultur für die kulturvergleichende sowie interkulturell verankerte Hörerverhaltensforschung; aus diesem Grund werden interessante Studien zum Hörerverhaltensstil von Japanern und Amerikanern veröffentlicht.

White (1986, 1989) untersucht die Frequenz, die Positionen und die Funktionen von Hörersignalen in Zweiergesprächen von Amerikanern und Japanern, wobei sowohl intrakulturelle als auch interkulturelle Gesprächsdaten ausgewertet werden.

\footnotetext{
${ }^{159}$ Vgl. Erickson 1979, S. 116-118.

${ }^{160}$ Vgl. Erickson 1979, S. 116-118.

${ }^{161}$ Erickson 1979, S. 117.

${ }^{162}$ Erickson 1979, S. 118.
} 
Aus der Berechnung der intrakulturellen Daten von Amerikanern und Japanern ${ }^{163}$ ergibt sich, daß auffällige Unterschiede zwischen beiden Kulturgruppen vor allem in der Frequenz der Hörersignale bestehen: Japaner senden nämlich insgesamt dreimal so viel Hörersignale wie Amerikaner; ferner fällt die Frequenz der Hörersignale in den japanischen Daten in fast allen Positionen höher aus als in den amerikanischen Daten. ${ }^{164}$ Dieses Ergebnis wird anschließend linguistisch und kulturell erklärt. Die hohe Frequenz der Hörersignale bei den Japanern liegt nach White zum einen an den vielen Pausen in den japanisch-japanischen Gesprächen; Pausen werden in den Gesprächen zwischen den Japanern besonders oft verursacht, weil sich die Gesprächsteilnehmer in der englischen Sprache unterhalten haben, von der sie nur rudimentäre Kenntnisse besitzen. Außerdem betont White, daß das häufigere Auftreten der Hörersignale in allen Positionen in den japanischen Daten mit kulturellen Werten Japans wie Rücksicht, Harmonie oder Empathie im Zusammenhang steht. ${ }^{165}$

Der Hörerverhaltensstil der japanischen Teilnehmer verändert sich kaum zwischen den intraund den interkulturellen Gesprächen, während hingegen die amerikanischen Gesprächsbeteiligten die Frequenz der Hörersignale in den interkulturellen Gesprächssituationen deutlich erhöhen. Diese Veränderung im Hörerverhaltensstil der amerikanischen Hörer wird von White als ein Zeichen für ,accomodation“ aufgefaßt, d.h. die amerikanischen Hörer nähern sich dem japanischen Stil an und senden dadurch häufiger Hörersignale als in den monokulturellen Daten. ${ }^{166}$

Bezüglich der Überprüfung der Bildung von Stereotypen kommt heraus, daß die amerikanischen Gesprächsteilnehmer den japanischen Hörerverhaltensstil als interessiert, aufmerksam und zum Weiterreden ermutigend finden. So hatten bei den amerikanischen Teilnehmern eher positive Stereotype gebildet. Dieses Ergebnis widerspricht der These der „complementary schismogenesis“ Goodwins (1981); im Gegenteil zeigen die Gesprächsbeteiligten bei White eine Annäherungstendenz, statt sich voneinander zu entfernen und zu differenzieren. ${ }^{167}$

\footnotetext{
${ }^{163}$ Die Gespräche zwischen den Japanern wurden alle auf Englisch abgehalten.

164 White 1986, S. 63.

${ }^{165}$ White 1986, S. 67.

${ }^{166}$ White 1989, S. 68.

${ }^{167}$ White 1986, Kap. 4.2.
} 
Maynard (1986, 1989, 1990) vergleicht Hörerverhaltensstile zwischen Japanern und Amerikanern anhand von monokulturellen Gesprächsdaten. Ihr Forschungsschwerpunkt liegt in der Ermittlung der Frequenz und der Plazierung von verbalen Hörersignalen sowie von Kopfnicken. Dabei werden Unterschiede zwischen beiden sowohl in der Frequenz als auch in der Plazierung von Hörersignalen festgestellt: Die japanischen Teilnehmer geben genauso wie bei White (1986) dreimal so viele Hörersignale wie die amerikanischen von sich. ${ }^{168}$ Fast $50 \%$ der verbalen Hörersignale werden in den japanischen Daten von Kopfnicken begleitet, während bei den amerikanischen Gesprächsteilnehmern nur 15\% der Hörersignale mit Kopfnicken zusammentreten. ${ }^{169}$ Hinsichtlich der Plazierung von Hörersignalen ergibt sich, daß Hörersignale in den amerikanischen Daten sehr häufig an hörerreaktionsrelevanten Stellen anzutreffen sind; im japanischen Datenmaterial hingegen finden sich sogar mehrere Positionen, an denen Hörersignale bevorzugt auftreten. ${ }^{170}$ Diese Differenzen im Hörerverhalten zwischen den japanischen und den amerikanischen Daten werden von Maynard z.T. auf kulturelle Normen zurückgeführt: In der Art des Hörerverhaltens spiegeln sich japanische Interaktionsmaxime wie Harmonie, Konfrontationsvermeidung und Empathie wider. $^{171}$

Miller (1991) benutzt als Datenmaterial authentische Gespräche zwischen japanischen und amerikanischen Geschäftsleuten in einer japanischen Firma. Zuerst vergleicht sie die monokulturellen Daten und stellt fest, daß japanische und amerikanische Hörerverhaltensstile teils kritische Differenzen aufweisen: So betrachtet Miller z.B. das Phänomen der Überlappung, das in den japanischen Daten oft auftritt, ${ }^{172}$ als einen erschwerenden Faktor in der amerikanisch-japanischen Kommunikation, denn Überlappungen zwischen verbalen Hörersignalen und Sprecheräußerungen sind zwar bei Japanern nicht verpönt; sie gelten jedoch in den USA als unharmonisch und unrhythmisch. Der zweite kritische Unterschied zwischen den japanischen und den amerikanischen Hörern liegt in der Variation der Hörersignale: Amerikaner variieren häufig die Formen der Hörersignale, weil in den USA die variationsarme Art als ein Ausdruck für Langeweile angesehen wird. ${ }^{173}$ Hingegen erweist sich der Gebrauch von verbalen Höreräußerungen in den japanischen Daten als wenig

\footnotetext{
${ }^{168}$ Maynard 1986, S. 1019-1020.

${ }^{169}$ Maynard 1986, S. 1089.

${ }^{170}$ Maynard 1986, S. 1099. Dieses wird im Kapitel 4.3 ausführlich erläutert.

${ }^{171}$ Maynard 1986, S. 1104.

172 Miller 1991, S. 116.

${ }^{173}$ Miller 1991, S. 119.
} 
abwechslungsreich. Ferner wird von Miller als problematisch eingestuft, daß Hörersignale in den japanischen Daten nicht so oft an turnübergangsrelevanten Stellen plaziert werden, wie dies in den amerikanischen Gesprächen der Fall ist.

Solche kulturspezifischen Hörerverhaltensstile von Japanern und Amerikanern, die in die interkulturelle Kommunikation eingebracht werden, verursachen kommunikative Störungen und Mißverständnisse; dies führt Miller darauf zurück, daß eigenkulturell angemessene, d.h. kooperative und empathische Verhaltensweisen des Hörers vom fremdkulturellen Gesprächspartner nicht als solche erkannt werden und sogar negative Interpretationen hervorrufen. ${ }^{174}$

Clancy et al. (1996) vergleichen die Hörerverhaltensstile zwischen den drei Sprachgemeinschaften: Englisch, Japanisch und Chinesisch.

In bezug auf die Gesamtfrequenz der Hörersignale ergibt sich, daß die japanischen sowie die amerikanischen Teilnehmer dreimal so viel Hörersignale wie die chinesischen von sich geben. Wider Erwarten finden sich keine großen Unterschiede in der Frequenz der Hörersignale zwischen den japanischen und den amerikanischen Daten. ${ }^{175}$

Die prozentuale Verteilung verschiedener Typen der Hörersignale zeigt, daß sich die japanischen Daten im Vergleich zu den beiden anderen Gruppen durch ihre hohe Quote der Fortsetzungssignale auszeichnen: 68,3\% aller Hörersignale in den japanischen Daten bestehen aus Fortsetzungssignalen, während der Anteil dieser Kategorie in den amerikanischen Daten nur $37,9 \%$ ausmacht.

Hinsichtlich der Positionierung der Hörersignale unterscheiden sich die japanischen Daten von den beiden anderen: Während die chinesischen Hörer Hörersignale am häufigsten an Grenzen der grammatischen und intonatorischen Einheiten und die amerikanischen Hörer an Grenzen der grammatischen Einheiten plazieren, tendieren die japanischen Hörer dazu, Hörersignale nicht nur an solchen Stellen, sondern mitten in Sprecherturns einzusetzen. Dies wird von den Autoren als Zeichen emotionaler Unterstützung gedeutet: Der Hörer ermuntert

\footnotetext{
${ }^{174}$ Miller 1991, S. 124.

175 In der einschlägigen Fachliteratur wird häufig empirisch nachgewiesen, daß Japaner dreimal so viele Hörersignale wie Amerikaner von sich geben (Maynard 1986, White 1986 usw.).
} 
den Sprecher dazu, den Turn weiter auszuführen, indem er Hörersignale (Fortsetzungssignale) innerhalb der Sprecherrede verstreut. Ihre Funktion (als „,continuer“) und die Plazierung (mitten im Satz) ist wiederum ein Grund dafür, warum kurze Verbalisierungen wie $e$;, um (ja, uhmhm) von japanischen Teilnehmern bevorzugt verwendet werden. ${ }^{176}$

Nachfolgend sollen zwei Arbeiten über das Deutsche vorgeführt werden.

Sawada (1991) führt statistisch ausgerichtete Analysen über Formen, Positionen und Funktionen von Hörersignalen im Deutschen und im Japanischen durch; dabei werden Telefonberatungsgespräche als Datenmaterial verwendet. Aus ihrer Berechnung ergibt sich, daß Japaner im Durchschnitt mehr Hörersignale als Deutsche von sich geben: In den japanischen Daten werden 13,8 Hörersignale, und in den deutschen Daten 7,4 Hörersignale pro Minute produziert. Die höhere Anzahl der Hörersignale in den japanischen Daten rührt vor allem daher, daß japanische Hörer viel häufiger als deutsche Hörer Aufmerksamkeitssignale senden, die an Stellen auftreten, an denen die betreffende Sprecheräußerung noch nicht vollständig erfaßt werden kann. ${ }^{177} \mathrm{Im}$ Vergleich dazu tendieren deutsche Hörer dazu, mit ihrer Hörerreaktion zu warten, bis sie etwas zu sagen haben oder bis sich die betreffende Sprecheräußerung syntaktisch vollzogen hat. Japanische Hörer haben nach Sawada mehr Bedürfnis, die aktive Gesprächsteilnahme regelmäßig zu bekunden und somit den Sprecher zum Weiterreden zu ermuntern. ${ }^{178}$

Als eine der wenigen deutschen Forscher untersucht Günthner (1993) Hörerverhalten in interkulturellen Gesprächen zwischen Deutschen und Chinesen. Dabei wird herausgefunden, daß chinesische Teilnehmer sehr häufig (Teil)Wiederholungen („Rezipientenechos“) als Hörersignale produzieren. Diese Form der Reaktion verkörpert einerseits nach der Autorin eine aktive Beteiligung der Hörer an der Interaktion, aber andererseits zugleich eine passive Rolle in der Gesprächsführung, weil der Hörer „,nur“ einen Teil der Sprecheräußerung imitiert und dabei keinen Turn übernimmt. ${ }^{179}$

\footnotetext{
${ }^{176}$ Vgl. Clancy et al. 1986, S. 381.

${ }^{177}$ Dieser Befund stimmt mit dem Ergebnis von Clancy et al. überein.

${ }^{178}$ Sawada 1991, S. 73.

${ }^{179}$ Vgl. Günthner 1993, S. 201.
} 
Die Wiederholungen der chinesischen Gesprächsteilnehmer erfüllen nach Günthner folgende Funktionen im Gespräch: ${ }^{180}$

- prosodische und lexikalische Imitation der neuen, zentralen Information des Sprechers

- Bestätigung der Bewertung

- Aufnahme der Kerninformation

- Ausdruck von Höflichkeit

Für deutsche Teilnehmer stellen jedoch Wiederholungen kein präferiertes Verfahren zum Signalisieren von Verstehen oder Kenntnisnahme des Gesagten dar. Dabei werden von ihnen vielmehr kurze verbale Äußerungen wie $j a, u h m$ bevorzugt. Die unterschiedliche Präferenz der Typen der häufig verwendeten Hörersignale führt zu Störungen des Gesprächsverlaufs und Mißverständnissen: Deutsche Gesprächsbeteiligte interpretieren Wiederholungen der chinesischen Gesprächspartner als Kundgabe der Verstehensprobleme oder der Nichtübereinstimmung, woraufhin Pausen, Erklärungen, Korrekturen, Beispiele usw. folgen.

\subsection{Zusammenfassung und Überlegungen für die empirischen Untersuchungen}

Aus den bisherigen Befunden geht hervor, daß sowohl im Deutschen als auch im Japanischen eine Reihe von sprachlichen Mitteln vorhanden ist, die häufig vom Hörer als Reaktionen auf die Sprecheräußerungen eingesetzt werden: Im Deutschen können vor allem ja und uhmhm als prototypische Hörersignale betrachtet werden; im Japanischen hingegen werden hai, e:, um (ja, uhmhm), und sô-Kombinationen (ach so, genau) besonders oft verwendet. In meiner Arbeit wird überprüft, ob und inwieweit diese Befunde aus der gängigen Forschungsliteratur auf meine Daten zutreffen.

Außerdem bestehen Hörersignale aus Äußerungen, die sich in verschiedene Typen einteilen lassen. Typen von Hörersignalen sind sowohl im Deutschen als auch im Japanischen annähernd vergleichbar. Bei der Klassifikation von Hörersignalen dient das Modell Duncans (1974) vielen Forschern als Grundlage. Im empirischen Teil dieser Arbeit werden ebenfalls Hörersignale in verschiedene Kategorien untergliedert, und zugleich wird die prozentuale Verteilung der Typen berechnet.

\footnotetext{
${ }^{180}$ Vgl. Günthner 1993, S. 190-203.
} 
Nach den Untersuchungen einiger deutscher und japanischer Autoren stellen kurzsilbige Hörersignale wie ja, uhmhm im Deutschen und $e:$ um (ja, uhmhm) im Japanischen die am häufigsten eingesetzte Kategorie der Hörersignale dar. Ebenso wird es in meiner Arbeit ermittelt, welche Hörersignale häufig zum Einsatz kommen.

Ferner hat sich herausgestellt, daß sowohl im Deutschen als auch im Japanischen mehrere Stimuli in Sprecheräußerungen vorhanden sind, die häufiger als andere Hörersignale hervorrufen können; solche Auslösestrukturen bestehen aus syntaktischen, lexikalischen, prosodischen und/oder nonverbalen Merkmalen: Im Deutschen können Pausen an Satzgrenzen, Sprechersignale wie ja, nicht, oder usw. sowie die steigende Intonationskontur an Satzenden dazu gezählt werden; dagegen fungieren im Japanischen als Auslöser Pausen an Satzenden, Satzenden mit der gerundiven Verbform, satzfinale Postpositionen, satzfinale konjunktionale Postpositionen, Kopfnicken des Sprechers, die Blickbewegung des Sprechers nach dem Hörer usw. Auch in der vorliegenden Arbeit wird versucht, linguistische Merkmale, die das Auftreten der Hörersignale begünstigen, ausfindig zu machen und die Häufigkeit der Hörersignale in Abhängigkeit von solchen (verbalen und prosodischen) Merkmalen zu berechnen.

Viertens kann man davon ausgehen, daß Hörersignale nicht nur in die Pause fallen, sondern sich auch mit Sprecheräußerungen überlappen, wobei die Überlappung die Folge einer vorzeitigen oder verspäteten Hörerreaktion sein kann. Im Japanischen werden oftmals die letzten Silben einer syntaktischen Einheit von der Überlappung betroffen. Da es direkt zu diesem Thema kaum ausführliche Untersuchungen gibt, bedarf dieses Phänomen einer genaueren Betrachtung.

Als fünfter Punkt sei angemerkt, daß das Senden verbaler Hörersignale keinem starken Zwang unterworfen zu sein scheint; ${ }^{181}$ dies wird bei Clancy et al. durch die relativ niedrige Begleitquote verbaler Hörersignale im Verhältnis zur Gesamtanzahl der Umgebungen, die Hörersignale häufig hervorrufen können, gestützt. Dies deutet darauf hin, daß in vielen Fällen die Aufmerksamkeit des Hörers, die durch nonverbale Höreraktivitäten signalisiert wird, ausreichend ist. Verbale Hörersignale werden eher dann eingesetzt, wenn verstärkte Hörerreaktionen vom Sprecher aus erwartet werden, oder wenn der Hörer sie aus eigenem 
Antrieb von sich geben will. Die Häufigkeit verbaler Hörersignale in Abhängigkeit von einigen Merkmalen der Satzenden wird ebenfalls in meiner Arbeit errechnet.

Sechstens üben Hörersignale Funktionen aus, die verschiedene Aspekte der zwischenmenschlichen Kommunikation betreffen:

1. Hörersignale regeln die kommunikative Beziehung zwischen den Gesprächsbeteiligten:

- Sie können im Fall eines Multi-Turns oder eines simultanen Sprechens den Turnverzicht signalisieren, damit bestätigen sie das bereits bestehende Sprecher- und Hörerrollenverhältnis.

- Sie können vorzeitig die Turnübernahme ankündigen.

2. Hörersignale stellen Mittel dar, innere Einstellungen (Zustimmung, Bestätigung, Empathie) oder Emotionen des Hörers (Begeisterung, Überraschung) in bezug auf die vorangegangene Sprecheräußerung mitzuteilen, ohne dabei den Turn zu übernehmen.

3. Hörersignale können sowohl auf den Verstehensstand als auch auf den Wissensstand des Hörers Bezug nehmen: „,ich habe verstanden, was du sagen willst, jetzt endlich habe ich dich verstanden, die Information ist mir neu“ usw.

4. Hörersignale üben Effekte auf den weiteren Gesprächsverlauf aus, also auf den Redeplan des Sprechers; der Sprecher kann beruhigt seinen Plan fortsetzen oder durch Nachfragen, Dissens oder Nichtverstehen des Hörers zur Planrevision gezwungen werden. Darüber hinaus ist die gesprächssteuernde Kraft der Hörersignale auf einer größeren Gesprächsebene wie die eines Gesprächsabschnittes (Erzählung) oder die eines Gesprächs (Wegauskunft) wirksam. In Erzählungen oder kurzen Wegauskunftsgesprächen, die aus mehreren Phasen bestehen, können Hörersignale den Verlauf des Gesprächs steuern, indem sie z.B. den Einstieg in die nächste Phase fördern bzw. blockieren, die zum aktuellen Zeitpunkt befindliche Phase verlängern oder die Beendigung des Gesprächs bewirken. Je nach dem Zweck werden unterschiedliche Hörersignale eingesetzt.

5. Bei längeren zusammenhängenden Gesprächssequenzen wie in der Vollzugsphase der Erzählung wurde festgestellt, daß Hörersignale die die betreffende Phase konstruierenden

\footnotetext{
181 Barba (1988, S. 58) stimmt ebenfalls Duncan (1973, S. 29) zu, der behauptet, daß Hörersignale nicht „coercive“" sondern ,permissive“ sind.
} 
Äußerungen in kleinere Diskurseinheiten gliedern können, indem sie z.B. am Anfang und am Ende einer solchen Einheit plaziert werden.

6. Hörersignale können die soziale Beziehung zwischen den Gesprächspartnern regeln.

Im empirischen Teil dieser Arbeit werden Hörersignale auf ihre multiplen Funktionen hin analysiert und anhand von prägnanten Beispielen veranschaulicht.

Zum Schluß soll auf Kulturunterschiede im Hörerverhalten hingewiesen werden. Einige Untersuchungen belegen kulturelle Differenzen zwischen Amerikanern und Japanern vor allem in der Frequenz und der Plazierung von Hörersignalen. In bezug auf die deutschen und die japanischen Daten meiner Arbeit kann auch Ähnliches vermutet werden, wenn man die Ergebnisse von Sawada (1991) heranzieht. Hinsichtlich der Funktionen von Hörersignalen liegt die Annahme nahe, daß Aufmerksamkeits- und Fortsetzungssignale häufiger in den japanischen Daten als in den deutschen anzutreffen sind. Den kulturspezifischen Hörerverhaltensmustern liegen womöglich kulturelle Wertvorstellungen wie Rücksicht, Konfliktvermeidung, Harmonie, Empathie usw. zugrunde, wie viele Forscher behaupten. ${ }^{182}$ Daher ist der Hörer im Gespräch möglichst bemüht, die Intention oder die Gefühle des Sprechers zu erraten, ${ }^{183}$ ihn bei seiner Rede emotional zu unterstützen ${ }^{184}$ oder statt der Differenzen den Konsens $\mathrm{zu}$ betonen, ${ }^{185}$ dadurch sorgt er seinerseits für eine gute Gesprächsatmosphäre und die Aufrechterhaltung der guten sozialen Beziehung. ${ }^{186}$

\footnotetext{
182 Diese Prinzipien gelten als japanische Interaktionsmaxime schlechthin. Sie sind bereits Gegenstand vieler Arbeiten gewesen, so z.B. über interkulturelle Kommunikation: Nagatomo 1986, Mae 1985, Okabe 1982, Gudykunst 1994 usw.

${ }^{183}$ Matsuda 1988, S. 64.

${ }^{184}$ Vgl. Clancy et al. 1996, S. 381.

${ }^{185}$ Matsuda 1988, S. 64.

${ }^{186}$ Vgl. LcCastro 1987, S. 110.
} 


\section{Methodische Überlegungen für den empirischen Teil und die Beschreibung des Datenmaterials}

\subsection{Methodische Überlegungen}

\subsubsection{Zur Bestimmung von Analyseaspekten und von Analysekategorien}

In der vorliegenden Arbeit wurden der Untersuchungsgegenstand sowie einige Untersuchungsaspekte unabhängig vom Datenmaterial festgelegt, d.h. die Phänomene, die der Analyse unterzogen werden, sowie die zentralen Fragestellungen wurden nicht aus eigenen Daten heraus entwickelt, wie dies die ethnomethodologische Konversationsanalyse zu tun pflegt; ${ }^{187}$ statt dessen wurden sie der Literatur über Hörerverhalten bzw. Hörersignale entnommen, wobei die Frage nach deren Form und Funktion eine der typischen Untersuchungsperspektiven in der Linguistik darstellt. ${ }^{188}$ Die Entscheidung für dieses o.a. Verfahren ist darin begründet, den Zeitaufwand bei der Entdeckung interessanter Phänomene sowie der Festlegung der geeigneten Methode möglichst zu minimieren.

Ähnliches gilt auch für die Kategoriebildung; es ist angebracht, die vorerst erarbeiteten Kategorien in der Analyse anzuwenden und sie dann bei Bedarf zu modifizieren oder zu erweitern, so daß sie für die vorliegenden Daten besser geeignet sind. ${ }^{189}$ Dadurch läßt sich die Gefahr, daß die Verwendung von vorgeformten Kategorien die Vielseitigkeit des Untersuchungsmaterials einschränkt, verringern. Ein Nachteil einer nachträglichen Anpassung der Kategorien ist, daß man dabei unter Umständen die Analyse mehrmals durchführen muß, was letztendlich sehr zeitaufwendig werden kann.

\subsubsection{Quantitative und qualitative Aspekte dieser Arbeit}

Der empirische Teil dieser Arbeit besteht sowohl aus qualitativen als auch aus quantitativen Aspekten. Auch für die Berechnung der Häufigkeit oder der prozentualen Verteilung sind qualitative Vorüberlegungen unentbehrlich: ${ }^{190}$ Dazu gehören z.B. die Festlegung der Untersuchungskategorien, die Auswertung der quantitativ gewonnenen Ergebnisse, die

\footnotetext{
${ }^{187}$ Hierzu Bergmann 1988, S. 5.

${ }_{188}$ Auch in der Gesprächsanalyse geht es im Kern um diese Fragestellungen (Deppermann 1999, S. 17).

${ }^{189}$ Henne/Rehbock (1982, S. 159) sind ähnlich vorgegangen.

${ }^{190}$ H. Kotthoff plädiert daher für die Integration der qualitativen und quantitativen Methoden (Kotthoff 1989, S. 83).
} 
Interpretation von Ergebnissen und Erklärungen; ${ }^{191}$ und umgekehrt sind quantitative Vorarbeiten bei der qualitativen Beschreibung einiger Kapitel dieser Arbeit eine notwendige Voraussetzung.

Hinsichtlich der quantitativ orientierten Analysen sei im voraus angemerkt, daß dabei keine streng quantitative Methodologie angestrebt wird, die dem Analytiker vorschreibt, unter kontrollierten Bedingungen aufwendige statistische Berechnungen durchzuführen; statt dessen besteht das Ziel des hier angewandten Verfahrens darin, Tendenzen aufzuzeigen, die zuerst nur für eigene Daten gelten können.

\subsubsection{Zur Problematik der Analyse der fremdsprachlichen Daten}

Als Nicht-Muttersprachlerin des Deutschen muß die Verfasserin davon ausgehen, daß die Gefahr der Mißdeutung bei der Interpretation der deutschen Daten (vor allem in Sprecheräußerungen und Hörersignalen) größer ist als bei einer Muttersprachlerin (z.B. Informationen, die durch Prosodie übermittelt werden); vor allem können feine Nuancen der sprachlichen Äußerungen nicht-muttersprachlichen Forschern mit ihrem lückenhaften sprachlichen und pragmatischen-kulturellen Wissen entgehen. Daher ist es ratsam und unumgänglich, bei der Interpretation der deutschen Daten Muttersprachler zu Rate zu ziehen. $^{192}$

\subsubsection{Kontrastives Vorgehen}

In dieser Arbeit werden die Ergebnisse der deutschen und japanischen Daten miteinander verglichen, um Gemeinsamkeiten und Unterschiede herausfinden zu können. Ein Problem bei einer kontrastiven Studie besteht darin, daß die Kategorien, die bei der Analyse verwendet werden, oft nur annähend äquivalent sind oder gar keine Entsprechung darstellen, so daß Ergebnisse in beiden Sprachdaten nicht direkt vergleichbar sind. ${ }^{193}$ Sofern die Kategorien und die Begriffe, mit denen die Untersuchungseinheiten klassifiziert werden, keine Äquivalenz implizieren, werden sie im voraus erklärt.

\footnotetext{
${ }^{191}$ Vgl. C. Schmidt 1986, S. 43.

192 Ebenso bezieht Günther chinesische Informanten bei der Interpretation der chinesischen Daten ein (1989, S. 53-54).

${ }^{193}$ Das gilt vor allem für Kategorien wie Satztypen und Satzpositionen: Das Japanische weist die SOVSatzstruktur auf und ist eine agglutinierende Sprache.
} 


\subsubsection{Die konkrete methodische Vorgehensweise}

In dieser Arbeit wird folgendermaßen vorgegangen: Der Untersuchungsgegenstand, Fragestellungen sowie Untersuchungsaspekte wie Formen, Positionen und Funktionen der Hörersignale werden nicht vom Datenmaterial heraus entwickelt, sondern in Anlehnung an die Forschungsliteratur im vorhinein festgelegt.

Im empirischen Teil dieser Arbeit werden zuerst Hörersignale definiert; bei der Definition werden einerseits bisherige Bestimmungen von Hörersignalen herangezogen, andererseits werden diese so modifiziert und ergänzt, daß sie auf die Daten der vorliegenden Arbeit angewandt werden können.

Zur Untersuchung von Typen von Hörersignalen werden Hörersignale in drei Gruppen eingeteilt und genauer charakterisiert; anschließend wird die prozentuale Verteilung der fünf Gruppen berechnet. Die Gruppenbildung von Hörersignalen basiert zwar z.T. auf einigen vorgefertigten Modellen und Überlegungen, stellt aber dennoch einen innovativen Versuch dar, Hörersignale zu charakterisieren, ohne sie in eine der Kategorien hineinzupressen. Am Ende dieses Kapitels werden die Ergebnisse der deutschen und der japanischen Daten in bezug auf die Formen der Hörersignale miteinander verglichen und diskutiert.

Um die Positionierung der Hörersignale ermitteln zu können, werden zuerst die Positionsbegriffe bestimmt. Dazu fand sich in den bisherigen Forschungen kein geeignetes Konzept; daher wurden die Positionen im Deutschen mittels der Felderstruktur bestimmt. ${ }^{194}$ Für das Japanische wurde ein Positionsmodell entworfen, das der Felderstruktur des Deutschen in etwa entspricht. Danach wurde die Frequenz der Hörersignale je nach ihren Plazierungspositionen berechnet. Hierbei wurden die Ergebnisse der Positionierungen der Hörersignale erklärt und diskutiert, woraus wiederum Anregungen für weitere Analysen entwickelt werden konnten.

Außer den Positionen der Hörersignale soll die Häufigkeit der Hörersignale in Abhängigkeit von einigen wichtigen Faktoren wie Satzenden, Satzkategorien, Intonationskonturen, Sprechersignalen usw. überprüft werden. Auch für diese Analyse ist die Auseinandersetzung

\footnotetext{
${ }^{194}$ Hierzu Drach (1973); ich lehne mich vor allem an das Modell, das bei Maibauer (1999) vorgestellt wird, an.
} 
mit der Literatur notwendig, um den Untersuchungsgegenstand einzugrenzen und die Analysekategorien bestimmen zu können.

Für die funktionale Analyse der Hörersignale wurden ebenso die Kategorien, denen jedes der Hörersignale zugeordnet wird, in Anlehnung an die bisherigen Forschungen entwickelt. Andererseits wurde versucht, Hörersignale dabei nicht nur einer der vorgeformten Kategorien zuzuordnen, sondern auch unabhängig davon Interpretationen oder Eindrücke der jeweiligen Hörersignale aufzuzeichnen; so können feine Nuancen, diverse Einstellungen festgehalten werden, die durch die o.a. Kategorien nicht erfaßt sind (z.B. Interessenbekundung, Nachdrücklichkeit, Emotionalität). Das vorläufige Kategorienbündel wurde im Laufe der Untersuchung ständig verändert, was zur Folge hatte, daß die Untersuchung mehrere Male durchgeführt werden mußte, bis die Systematik der Kategorien endgültig feststand.

\subsection{Zum Datenmaterial}

\subsubsection{Beschreibung des Datenmaterials und der Erhebungssituation}

Als Datenmaterial für diese Arbeit dienen vier deutsch-deutsche und vier japanischjapanische Video- und Tonbandaufnahmen. ${ }^{195}$ Die Dauer der jeweiligen Gespräche beträgt 45 Minuten. Die Aufnahmen fanden bei mir zu Hause im Wohnzimmer statt; die Gesprächsteilnehmer wurden zum Aufnahmezweck eingeladen. Daher handelt es sich um „offene Aufnahmen““196, d.h. die Gesprächsbeteiligten wußten im voraus, daß sie auf Tonband und auf Video aufgenommen werden; sie waren alle mit der Aufnahme einverstanden.

Die Aufnahmesituation war folgende: Die Teilnehmer saßen sich gegenüber; neben ihnen waren zwei große Fenster zu sehen; seitlich vor ihnen war ein Tisch aufgestellt, auf dem ein Mikrophon positioniert war. Die Videokamera stand an der Wohnzimmertür gegenüber dem Fenster und konnte von den Teilnehmern leicht gesehen werden, wenn sie sich in Richtung Wohnzimmertür wendeten.

Nach der Aufnahme wurde ein kurzes Interview mit den Gesprächsbeteiligten durchgeführt, in dem nach dem Namen, dem Alter, den Studienfächern bzw. dem Beruf, dem Herkunftsort

\footnotetext{
195 Ich habe noch mehr Aufnahmen gemacht, die wegen technischer Fehler nicht tauglich für eine Analyse waren.

${ }^{196}$ Vgl. Bringer/Sager (1996, S. 32).
} 
und dem Dauerwohnort, der Empfindung während des Gesprächs (z.B. ob sie die Aufnahmesituation vergessen haben) befragt wurden.

Die Gespräche lassen sich als „,persönliche Unterhaltung“ oder Konversation bezeichnen; ${ }^{197}$ genauer formuliert handelt es sich hierbei um dyadische Gespräche zwischen Unbekannten bzw. flüchtig-Bekannten. Die Entscheidung für die Zweiergespräche lag darin begründet, daß sie im Vergleich zu Mehr-Personen-Gesprächen hinsichtlich der Rollenverteilung überschaubar sind, so daß die Differenzierung zwischen Sprecher- und Höreräußerungen bzw. Hörersignalen und Turns leichter vorzunehmen ist. Außerdem ist es für mich von Vorteil, daß der Bekanntheitsgrad der Teilnehmer untereinander gering ist, weil so gemeinsame Erfahrungen zwischen den Gesprächsbeteiligten, zu denen man als Außenstehende wenig Zugang hat, ausgeschlossen werden können.

Themen wurden vorher nicht festgelegt, daher konnten sich die Teilnehmer frei unterhalten. Da es sich aber meistens um eine Erstbegegnung handelte, finden sich einige Merkmale, die sich in jedem Gespräch abspielten: Die Begrüßung, die Selbstvorstellung, typische Fragen zum Kennenlernen (z.B. nach den Studienfächern, den Berufsaussichten, der Aufenthaltsdauer in Deutschland) sind beim Erstkontakt oft konstitutiv.

Über die Gesprächspaare können folgende Angaben gemacht werden:

\begin{tabular}{|l|l|l|l|l|l|}
\hline Sprache & $\begin{array}{l}\text { Name der } \\
\text { Teilnehmer }\end{array}$ & Geschlecht & Alter & Herkunftsort & Beruf (Studienfächer) \\
\hline Jap. & $\begin{array}{l}\text { Mamoru (MR) } \\
\text { Tsuyoshi (TY) }\end{array}$ & $\begin{array}{l}\text { Mann } \\
\text { Mann }\end{array}$ & $\begin{array}{l}31 \\
29\end{array}$ & $\begin{array}{l}\text { Fukui, Tokyo } \\
\text { bei Tokyo }\end{array}$ & $\begin{array}{l}\text { Politologe } \\
\text { Bankangestellter }\end{array}$ \\
\hline Jap. & Satoru (ST) & Mann & 40 & $\begin{array}{l}\text { Nagano, } \\
\text { bei Tokyo } \\
\text { bei Tokyo }\end{array}$ & Juradozent \\
Student (Biologie)
\end{tabular}

\footnotetext{
${ }^{197}$ Henne/Rehbock 1982.

${ }^{198}$ Alle Personennamen wurden geändert.
} 


\begin{tabular}{|c|c|c|c|c|c|}
\hline Sprache & Teilnehmer & Geschlecht & Alter & Herkunftsort & Beruf (Studienfächer) \\
\hline Dt. & \begin{tabular}{|l} 
Friedrich (FR) \\
Roby (RB) \\
\end{tabular} & $\begin{array}{l}\text { Mann } \\
\text { Mann }\end{array}$ & $\begin{array}{l}26 \\
27 \\
\end{array}$ & $\begin{array}{l}\text { Hamburg } \\
\text { Aschersleben }\end{array}$ & \begin{tabular}{|l|} 
Jurist \\
Volkswirt \\
\end{tabular} \\
\hline Dt. & $\begin{array}{l}\text { Knut (KN) } \\
\text { Heinz (HZ) }\end{array}$ & $\begin{array}{l}\text { Mann } \\
\text { Mann }\end{array}$ & $\begin{array}{l}22 \\
21 \\
\end{array}$ & \begin{tabular}{|l} 
Aurich \\
Göttingen
\end{tabular} & $\begin{array}{l}\text { Student (Politik) } \\
\text { Student (Germanistik) }\end{array}$ \\
\hline Dt. & $\begin{array}{l}\text { Hanna }(\mathrm{HN}) \\
\text { Alex }(\mathrm{AL})\end{array}$ & $\begin{array}{l}\text { Frau } \\
\text { Frau }\end{array}$ & $\begin{array}{l}29 \\
21\end{array}$ & $\begin{array}{l}\text { Bremen } \\
\text { Bremen, Saarbrücken }\end{array}$ & $\begin{array}{l}\text { Studentin (Japanologie) } \\
\text { Studentin } \\
\text { (Ethnologie, Japanologie) }\end{array}$ \\
\hline Dt. & \begin{tabular}{|l} 
Frauke (FK) \\
Klara (KA) \\
\end{tabular} & $\begin{array}{l}\text { Frau } \\
\text { Frau }\end{array}$ & $\begin{array}{l}29 \\
36 \\
\end{array}$ & $\begin{array}{l}\text { Porta Westfalica } \\
\text { bei Göttingen }\end{array}$ & $\begin{array}{l}\text { Kommunikationstrainerin } \\
\text { Sozialwirtin }\end{array}$ \\
\hline
\end{tabular}

Nun soll einiges zu den Einflußfaktoren bemerkt werden, die das Hörerverhalten steuern können. Erstens wurden nur gleichgeschlechtliche Gespräche aufgenommen, um einige Einflußfaktoren, die bei gemischten Paaren auftreten können, auszuschließen. Andererseits ließen sich das Alter, sozialer Status, der Herkunftsort (vor allem bei den Deutschen) der Teilnehmer nicht homogenisieren, wie man aus der Tabelle sehen kann. Ferner ist in einigen Gesprächsgruppen das soziale Verhältnis zwischen den Gesprächspartnern aufgrund der Unterschiede im sozialen Status und im Alter asymmetrisch. Das lag zum einen daran, daß nicht jeder bereit war, sich aufnehmen und analysieren zu lassen; vor allem gab es Schwierigkeiten, japanische Teilnehmer zu finden, weil zum Zeitpunkt der Aufnahme nicht so viele Japaner in Göttingen wohnten.

Im folgenden werden die Gespräche kurz vorgestellt.

Das Gespräch von Mamoru und Tsuyoshi: Die Aufnahmequalität dieses Gesprächs ist relativ gut, so daß es kaum Stellen gab, die akustisch nicht verständlich waren. Die Verteilung der Sprecher- und Hörerrollen war in diesem Gespräch sehr asymmetrisch: Tsuyoshi übernahm die Gesprächsführung, während Mamoru überwiegend die Hörerrolle einnahm. Thematisch gesehen bildeten politische oder wirtschaftliche Sachverhalte den Schwerpunkt des Gesprächs.

Das Gespräch von Satoru und Shigeru: Wegen des größeren Altersunterschiedes sowie des Statusunterschiedes war relativ deutlich $\mathrm{zu}$ erkennen, daß sich Shigeru, der jüngere, zurückhaltender gegenüber Satoru verhielt. Im Laufe des Gesprächs bildete sich eine Art Lehrer-Schüler-Beziehung heraus, indem Shigeru Satoru nach dem japanischen Rechtssystem

${ }^{199}$ Alle Teilnehmer wohnten zu der Zeit der Aufnahme in Göttingen. 
fragte und Satoru wiederum den anderen mit seinem Fachwissen belehrte. Shigeru war aktiv im Gespräch, indem er oft die Initiative ergriff und turneinleitende Fragen an Satoru stellte, der sonst von sich aus nicht so viel geredet hätte. Ähnlich wie bei Tsuyoshi und Mamoru beherrschten eher fachliche Themen das Gespräch. Da Satoru relativ leise sprach, war es an manchen Stellen unklar, ob er Hörersignale sendete oder nicht.

Das Gespräch von Ayumi und Mako: Trotz des Altersunterschiedes wirkte das Verhalten Ayumis, die viel jünger als Mako ist, nicht auffällig zurückhaltend; Ayumis Redezeit war insgesamt länger als Makos. Im Vergleich zu den beiden Männergesprächen wurden weniger fachliche Themen angeschnitten. Vielmehr wurden gemeinsame Bekannte oder andere Personen thematisiert. Dieses Gespräch verlief in einer ruhigen Atmosphäre. Die Aufnahmequalität war für eine Verschriftung des Gesprächs gut genug.

Das Gespräch von Sanako und Haruyo: Am Verhalten Haruyos, vor allem am Anfang, ist zu erkennen, daß sie sich bemühte, höflich zu ihrer älteren Gesprächspartnerin zu sein: Haruyo äußerte sich dazu direkt nach der Aufnahme folgendermaßen: Sie habe darauf aufgepaßt, daß sie mit Sanako nicht im vertraulichen Stil $^{200}$ rede, weil Sanako älter sei als sie. Die beiden hatten aufgrund ihrer Hobbies und ihrer Herkunft aus Tokyo einige gemeinsame Themen. Alles in allem war das Gespräch heiter und reibungsarm.

Das Gespräch von Friedrich und Roby: Für diese Unterhaltung war kennzeichnend, daß sich Roby und Friedrich kaum persönlich annähern konnten. Daher war die Atmosphäre des Gesprächs vor allem in der ersten Hälfte eher kühl und distanziert. Bei ihnen wurden wie bei den japanischen Männergesprächen überwiegend Themen angesprochen, die mit den Studienfächern der beiden Gesprächsteilnehmer im Zusammenhang stehen.

Das Gespräch von Knut und Heinz: Da sie sich flüchtig durch eine gemeinsame Sportaktivität kannten, gab es keine Anlaufschwierigkeiten wie bei Roby und Friedrich; sie wirkten relativ vertraut miteinander. Thematisch wurden die Wahl ihrer Studienfächer, die Berufschancen und die Zukunfspläne usw. bevorzugt abgehandelt. Die Aufnahmequalität war relativ schlecht; an manchen Stellen bereitete es mir Schwierigkeiten, das Gesagte akustisch zu verstehen; das lag z.T. daran, daß beide Gesprächsbeteiligten häufig genuschelt haben.

\footnotetext{
${ }^{200}$ Im Japanischen gibt es drei Höflichkeitsebenen: sehr höflich/höflich, neutral (vertraut) und pejorativ.
} 
Das Gespräch von Hanna und Alex: In diesem Gespräch war eine Asymmetrie in der Rederechtsverteilung zu beobachten, was eventuell auf den Unterschied in der Studiendauer zurückzuführen ist, denn Hanna hatte als Promovendin mehr Studienerfahrungen als Alex, die im zweiten Semester war. Da beide Gesprächsteilnehmerinnen Japanologie studierten, wurden Erfahrungen in Japan oder mit Japanern häufig zum Gesprächsthema. Außerdem hatten beide einen erzählerischen Redestil, so daß sie sich gegenseitig ihre Erlebnisse auf humorvolle Art und Weise schilderten; das trug viel dazu bei, eine lustige, amüsante Stimmung zu erzeugen.

Das Gespräch von Frauke und Klara: Die beiden trafen sich zum zweiten Mal, weil die technische Qualität der ersten Aufnahme ungenügend war. Bei der Unterhaltung zwischen beiden herrschte eine angenehme, lockere, sogar vertraute Atmosphäre. Von Anfang an unterhielten sie sich, ohne sich viel um die Aufnahmesituation zu kümmern. In diesem Gespräch wurden vorherrschend Themen, die mit ihren Arbeitsstellen oder ihren Bewerbungserfahrungen zu tun hatten, besprochen. Die Redeverteilung zwischen den beiden Teilnehmerinnen fiel eher gleichmäßig aus. Beide redeten, wenn sie das Rederecht übernahmen, relativ lang.

Für die Analyse wurden pro Person Abschnitte von 5 Minuten verwendet, in denen die jeweiligen Gesprächsteilnehmer beide die Hörerrolle ausübten; ${ }^{201}$ die Textausschnitte lagen meistens in der ersten Hälfte der jeweiligen Gespräche und wurden beliebig ausgesucht, so daß sie jeweils insgesamt etwa 300 Sekunden betrugen.

\subsubsection{Das Beobachterparadoxon ${ }^{202}$}

Die Gesprächssituation (persönliche Unterhaltung im Wohnzimmer), die für die Aufnahmen dieser Arbeit inszeniert wurde, ist zwar im Alltag durchaus vorstellbar, aber da die Gesprächsbeteiligten sich der Aufnahme bewußt waren, ist zu Recht davon auszugehen, daß die Authentizität und die Natürlichkeit ihres Hörerverhaltens durch die technische Aufnahmesituation mehr oder minder beeinträchtigt ist; an manchen Stellen in meinen Daten kann man sogar beobachten, daß die Teilnehmer sprachlich über die Aufnahmesituation

\footnotetext{
${ }^{201}$ Maynard (1986) verwendet die letzten drei Minuten der jeweiligen Aufnahmen; White (1986) untersucht von jedem Gespräch zehnminütige Abschnitte.
} 
reflektieren ${ }^{203}$ oder deshalb sehr befangen sind. Vor allem ist die Aufregung zu Beginn der Aufnahme relativ deutlich zu spüren. ${ }^{204}$

Auf der anderen Seite ließ sich jedoch an meinen Daten festmachen, daß die Abweichung im Hörerverhalten zwischen anfänglichen und mittleren oder späteren Minuten nicht sehr auffallend war. Ferner behaupteten die Gesprächsbeteiligten bei der Befragung nach der Aufnahme oft, daß sie während des Gesprächs nicht so oft daran dachten, aufgenommen zu werden. $^{205}$ Aus diesen Gründen gehe ich davon aus, daß meine Gesprächsdaten trotz verringerter Natürlichkeit für die Untersuchung verwendet werden können, weil die Gesprächsteilnehmer trotz der besonderen Situation eher routiniert handelten und ihr Verhalten natürlich genug war, um Tendenzaussagen über Hörerverhalten im universitären Alltag machen zu können.

\subsubsection{Die Repräsentativität der Daten und die Generalisierbarkeit der Ergebnisse}

Wie bei Henne/Rehbock (1982) gefordert wurde, ${ }^{206}$ sollte das Datenmaterial der Gesprächsanalyse auch eine „repräsentative Stichprobe“, d.h. ein verkleinertes Abbild der Grundgesamtheit des Untersuchungsgegenstandes, verkörpern, damit die Analyse der Daten eine gültige Generalisierung auf die Grundgesamtheit zuläßt. ${ }^{207}$ Mein Datenmaterial kann kaum den Status der repräsentativen Stichprobe beanspruchen, weil bei der Datengewinnung konstante und variable Merkmale der Grundgesamtheit des Untersuchungsgegenstandes, die repräsentativ sein müssen, nicht hinreichend berücksichtigt werden konnten; ${ }^{208}$ Variablen wie das Alter, der Altersunterschied zwischen den Gesprächspartnern, der Herkunftsort, sozialer Status, die Themenwahl usw., ${ }^{209}$ die das Hörerverhalten der Gesprächsteilnehmer beeinflussen können, konnten bei der Auswahl der Teilnehmer nicht kontrolliert werden.

\footnotetext{
202 Dazu Labov 1972, S. 147.

203 Auch Henne/Rehbock gehen auf diese Problematik ein (1982, S. 50f). In meinen Daten finden sich Äußerungen wie „,ach das darf ich ja gar nicht sagen“, „Sorry, M., daß ich über Japaner lästere“.

${ }^{204}$ Nach A. Deppermann nimmt die Aufmerksamkeit auf die Aufnahmesituation nach einigen Minuten rapide ab (1999, S. 25).

${ }^{205}$ Gesprächsanalytiker berichten im allgemeinen ähnlich: C. Schmidt (1986, S. 45), A. Deppermann (1999, S. 25), usw.

${ }^{206}$ Henne/Rehbock 1982, Kap.22.

${ }^{207}$ Henne/Rehbock 1982, S. 47.

208 Es werden bei Henne/Rehbock einige wichtige Kriterien zur repräsentativen Korpusherstellung genannt (Henne/Rehbock 1982, S. 47-48).

${ }^{209}$ Maynard behauptet auch, daß die Themenwahl Hörerverhalten beeinflußt (1990, S. 401).
} 
Insgesamt läßt sich hinsichtlich der Generalisierbarkeit der Ergebnisse der vorliegenden Arbeit folgendes behaupten: Die Analyseergebnisse gelten nur für meine Daten und können nicht ohne Vorbehalt auf andere Gespräche mit anderen Teilnehmern, erst recht nicht auf die Gesamtheit einer Subkultur oder gar einer Kultur übertragen werden. Es können bestenfalls Tendenzaussagen oder Vermutungen in bezug auf das Hörerverhalten von Studenten in persönlichen Unterhaltungen unter Unbekannten usw. formuliert werden, die Gesprächsforscher wiederum zur Hypothesenbildung sowie zu weiteren Untersuchungen anregen könnten.

\subsubsection{Das Transkriptions- und Notationssystem dieser Arbeit}

Zur Herstellung der Transkripte wurde das Textverarbeitungsprogramm Hiat-Dos 2.2 von Ehlich verwendet, ${ }^{210}$ weil es dem Benutzer eine Partiturschreibweise erlaubt. Für die Analyse dieser Arbeit war es wichtig, daß man auf den ersten Blick erkennen kann, wo in der Sprecherrede Hörersignale plaziert sind.

Bei der Transkription wurden die folgenden Datentypen in die Notation aufgenommen:

- verbale und tonale Äußerungen,

- nichtsprachliche hörbare Äußerungen: Lachen, Husten, Stöhnen etc.,

- Pausen,

- Kommunikative Aktionen der Gesprächsteilnehmer, sofern sie für die Analyse wichtig erscheinen (die Teetasse ergreifen, Tee trinken usw.),

- prosodische Merkmale: Lautstärke, Sprechgeschwindigkeit, Silbendehnungen, Tonhöhenverlauf vor allem am Satzende.

Die oben genannten Datentypen wurden in Anlehnung an das Notationssystem von Henne/Rehbock (1982) mit folgenden Symbolen wiedergegeben:

\footnotetext{
${ }^{210}$ Hierzu im Handbuch zum HIAT-DOS 2.2 Textverarbeitungsprogramm für Transkriptionstexte (Ehlich 1989).
} 


\begin{tabular}{|l|l|}
\hline$:$ & Silbenverlängerung \\
\hline$? ?$ & Unverständlicher Text \\
\hline+ & Kurze Pause unter 0,7 sec. \\
\hline+++ & Kurze Pause unter 1,2 sec. \\
\hline$(2)$ & Pausenlänge bis zu 1,7 sec. \\
\hline LACHEN, HUSTEN, STÖHNEN & Pausenlänge von mehr als 1,7 sec. \\
\hline H & \\
\hline$\uparrow$ & Luft holen \\
\hline$\rightarrow$ & Steigender Tonhöhenverlauf \\
\hline$\downarrow$ & Schwebender Tonhöhenverlauf \\
\hline Pp, p, mp, mf, f, ff & Fallender Tonhöhenverlauf \\
\hline
\end{tabular}

Verbale Zeichen wurden in literarischer Umschrift transkribiert; die japanischen Gespräche wurden in der Hepburn Umschrift ${ }^{211}$ wiedergegeben. In beiden Sprachdaten wurde keine Großschreibung benutzt.

In bezug auf die Notation muß noch einiges angemerkt werden. Erstens wurden bei der Transkription der Sprecheräußerungen prosodische Merkmale weitgehend unberücksichtigt gelassen; das lag z.T. daran, daß die Gespräche vom Anfang bis zum Ende verschriftet werden sollten, was sehr zeitaufwendig war. Daher war es wegen der Effektivität nicht möglich, prosodische Merkmale auf das Genaueste wiederzugeben. Der Verzicht auf Prosodie ist jedoch insofern vertretbar, als der Schwerpunkt dieser Arbeit darin liegt, den Zusammenhang zwischen dem Auftreten der Hörersignale und syntaktischen, inhaltlichinformativen Strukturen der Sprecheräußerungen ausfindig $\mathrm{zu}$ machen. Prosodische Gegebenheiten der Sprecheräußerungen wurden nur dann symbolisch festgehalten, wenn sie für die Feinanalyse nötig waren. Hingegen wurden Hörersignale, die den Untersuchungsgegenstand dieser Arbeit bilden, mit prosodischen Merkmalen versehen; da die

\footnotetext{
${ }^{211}$ Das ist ein modifiziertes Hepburn-System zur lateinischen Umschrift der japanischen Sprache; das HepburnSystem wurde von dem amerikanischen Missionar Hepburn 1866 nach der englischen Aussprache entwickelt. In meiner Arbeit werden lange Vokale durch das folgende Zeichen $\left({ }^{\wedge}\right)$ wiedergegeben.
} 
Prosodie der Hörersignale bei der Interpretation eine große Rolle spielt, war die Notation dieser Phänomene für die funktionale Analyse unentbehrlich. 


\section{Empirischer Teil}

\subsection{Die Bestimmung und die Klassifikation der Hörersignale}

Im folgenden werde ich zuerst den Oberbegriff „Hörerverhalten“ näher erläutern. Anschließend werden verbale und nonverbale Hörersignale nach einem Klassifikationsraster klassifiziert; der Zweck dabei ist, den Untersuchungsgegenstand dieser Arbeit im Gesamtzusammenhang genauer zu lokalisieren. Als letztes werden verbale Hörersignale, die den zentralen Aspekt in dieser Arbeit bilden, unter linguistischen Aspekten definiert.

\subsubsection{Die Bestimmung von Hörerverhalten}

Der Hörer wird in dieser Arbeit aufgefaßt als derjenige, der keinen Turn oder das Rederecht innehat und statt dessen die Aktivitäten ausübt, die als Hörersignale bzw. Turnbeanspruchungen gelten; der Sprecher ist hingegen derjenige, der „substantielle Äußerungen“ produziert; ihm wird also das Rederecht bzw. der „Turn“ zugesprochen.

Als Oberbegriff für verbale und nonverbale Aktivitäten des Hörers dienen im Englischen „listening behavior“, „listening responses“, im Deutschen „Höreraktivitäten“, „Hörerverhalten“ oder „Rückmeldeverhalten“ und im Japanischen „aizuchi““ (Gegenschlag) oder „kikite koudou“ (Hörerverhalten); in dieser Arbeit wird die Bezeichnung Hörerverhalten verwendet.

Hörerverhalten umfaßt alle Aktivitäten des Hörers, die kommunikativ relevant sind; es besteht nach Duncan (1973) aus drei Kategorien: keine Reaktion, sprachliche und nicht sprachliche Höreraktivitäten, die nicht auf die Turnübernahme zielen, sowie Turnbeanspruchungen, die als nicht gelungene Versuche der Turnübernahme betrachtet werden. ${ }^{212}$

Als Hörersignale gelten in dieser Arbeit verbale und nicht verbale Höreraktivitäten, die weder Turns noch Turnbeanspruchungen darstellen, wobei lediglich verbale Hörersignale den Gegenstand der Analyse bilden. Die genauere Bestimmung sowie die Abgrenzung der verbalen Hörersignale wird im Kapitel 4.1.4 vorgenommen.

\footnotetext{
212 Vgl. Duncan 1973, S. 34, Henne/Rehbock 1982, Kap. 4.3.3, Henne 1978, S. 125f., Brinker/Sager 1995, S. $57 \mathrm{f}$
} 


\subsubsection{Die Klassifikation sprachlicher und nichtsprachlicher Hörersignale}

Bisher sind eine Reihe von Arbeiten über Höreraktivitäten veröffentlicht worden. ${ }^{213}$ Verschiedene Bereiche der bisher untersuchten Höreraktivitäten bzw. Hörersignale können folgendermaßen unterschieden werden: ${ }^{214}$

- sprachliche Höreraktivitäten oder Hörersignale: ${ }^{215}$

- verbal (ja, genau)

- segmental: tonal (uhmhm, ach usw.)

- suprasegmental: Prosodie

- nicht sprachliche Höreraktivitäten:

- visuell: Kopfbewegungen (Kopfnicken, Kopfschütteln)

- visuell: Blickrichtung, Blickkontakt

- visuell: Körperhaltung

- visuell: Gestik

- visuell: Mimik

- visuell und hörbar: Lachen, Stöhnen, Atmen

Manche Hörersignale genießen wegen ihres prototypischen Charakters Extrabezeichnungen; dementsprechend hat man ihnen eine besondere Beachtung in der bisherigen Forschung geschenkt: „back channel“ (Yngve 1970, Duncan 1972, Erickson 1979 usw.), „continuer“ (Schegloff 1982), „assessment“ (Goodwin 1986) in den USA, „Hörersignale“ (Schank/Schoenenthal 1976, Rath 1979, Wahmhoff/Wenzel 1979, Bublitz 1980), „Hörerrückmeldungen“ (Henne/Rehbock 1982, C. Schmidt 1986) oder „uptaker“ (Kasper/Færch 1984) in Deutschland und ,aizuchi“ (Horiguchi 1987, Matsuda 1988, Mizutani 1988 usw.) in Japan.

Mit solchen Sondertermini wird oft nur auf einige Typen von verbalen und nonverbalen Höreraktivitäten (kurze verbale Äußerungen und Kopfnicken) referiert. Es variiert je nach Forschern oder Forschungsvorhaben, nach welchen Kriterien man den betreffenden Begriff definiert oder welche Höreraktivitäten man dazu zählt.

\footnotetext{
${ }^{213}$ Das habe ich im Kapitel 2.2.1 ausführlich dargestellt.

${ }^{214}$ Hierbei habe ich mich an Henne/Rehbock (1982, S. 62) angelehnt.

${ }^{215}$ In dieser Arbeit werden sprachliche und tonale Hörersignale unter dem Begriff „verbalen Hörersignalen“ zusammengefaßt.
} 


\subsubsection{Definition verbaler Hörersignale}

Verbale Hörersignale werden in der gängigen Forschungsliteratur in erster Linie über den Turn definiert. Damit ist gemeint, daß Hörersignale keine Turns darstellen, weshalb man also von „out of turns“ spricht. ${ }^{216}$ Welche Äußerungen, die ein Gespräch konstituieren, als Hörersignale gelten, ist je nach Ansätzen unterschiedlich; manche fassen sie enger auf und zählen dazu nur kurze Äußerungen des Hörers wie $j a, u h m h m^{217}$, während andere hingegen längere Höreräußerungen wie das ist ja toll usw. als Hörersignale einstufen. ${ }^{218}$ In der vorliegen Arbeit wird eine weiter gefaßte Definition von Hörersignalen gewählt, weil dies angesichts des Gesprächstyps des Zweiergesprächs günstig erscheint. Für ein klares Verständnis sollen die Hörersignale im folgenden ausführlicher charakterisiert werden. Dabei werden in Anlehnung an bisherige Forschungen semantisch-thematische sowie kommunikativ-pragmatische Aspekte der Hörersignale in Betracht gezogen: ${ }^{219}$

- Hörersignale stellen keinen Turn dar, d.h. es findet bei der Äußerung von Hörersignalen kein Turnwechsel statt.

- In der Regel wird mit ihnen keine aktive Turnübernahme beabsichtigt, was man daran festmachen kann, daß der Turnwechsel faktisch nicht erfolgt. Aber in manchen Fällen können sie unmittelbar vor der Turnübernahme geäußert sein und somit den bevorstehenden Turnbeginn einleiten; sie gehören jedoch nicht zum eigenen Turn.

- In semantisch-thematischer Sicht weisen sie „wenig“ inhaltlichen Gehalt auf ${ }^{220}$ und liefern auch „wenig“ neue Informationen, die zur thematischen Entwicklung beitragen. Ferner wird kein neues Thema mit Hörersignalen eingeleitet.

- Pragmatisch gesehen dienen Hörersignale als Mittel, um Einstellungen des Hörers dem Gesagten gegenüber zu erkennen zu geben und damit einen Einfluß auf das Gespräch zu nehmen. ${ }^{221}$ Dabei sind illokutionäre Kräfte der Hörersignale eher darauf beschränkt, Verstehen, Zustimmung, Überraschung usw. zu signalisieren.

\footnotetext{
216 Yngve 1970, S. 568.

217 Jefferson (1984), Maynard (1986), Wahmhoff/Wenzel (1979) usw.

${ }^{218}$ Henne/Rehbock (1982, S.177f.), C. Schmidt (1986), Hartung (1998), Sutigo (1987), Matsuda (1988), Horiguchi (1989) usw.

${ }^{219}$ Insbesondere werden Rath (1979), Wahmhoff/Wenzel (1986), Sugito (1987) herangezogen.

${ }^{220}$ Ob sie als „semantisch leer“ zu gelten haben, wie Rath (1979, S. 116) behauptet, ist zu bezweifeln. Denn die Partikel $j a$ hat einen Verweischarakter auf das Ganze der vorangegangenen Äußerung des Sprechers. Außerdem können einige Hörersignale wie ach so, richtig, genau, wao usw. speziell auf gewisse Gegenstände Bezug nehmen.

${ }^{221}$ Vgl. Henne 1978, S. 128-129.
} 
- Auf der interpersonalen Ebene regulieren sie soziale Beziehungen zwischen den Gesprächspartnern: Sie können z.B. auf eine kooperative und harmoniestiftende Art eingesetzt werden, um gute Stimmungen zwischen den Gesprächsbeteiligten zu erzeugen; hingegen führt die Anhäufung der konkurrierenden, weniger kooperativen Anwendung der Hörersignale auf Dauer eher zur Mißstimmung zwischen den Beteiligten.

Zuletzt soll noch auf längere Äußerungen (länger als ein Satz), die in dieser Arbeit als Hörersignale betrachtet werden, eingegangen werden. Das wichtigste Kriterium bei der Abgrenzung der satzförmigen Verbalisierungen von Turns ist, daß kein aktiver Versuch des Hörers zur Turnübernahme erkennbar ist und faktisch nicht erfolgt ist; außerdem ist dabei folgendes zu beachten.

- solche Äußerungen kommen entweder zwischen zwei Redebeiträgen desselben Sprechers vor oder vor der eigenen Turnübernahme,

- sie bringen informativ nichts Neues (floskelhaft, starker inhaltlicher Bezug zur Sprecherrede, Wiederholungen dessen, was schon vorher gesagt wurde, Begründung der Nicht-Stellungnahme usw.) und

- sie können intonatorisch (durch schnelles, beiläufiges, leises Sprechen) markiert sein oder durch Pausen von den nachstehenden Äußerungseinheiten eindeutig getrennt sein.

Im weiteren gelten in meiner Arbeit ja, genau, richtig usw., die als Antworten auf Fragen des Sprechers fungieren, nicht als Hörersignale. Ferner werden lexikalische Einheiten wie ja, nee usw., die den eigenen Turn einleiten, d.h. die Elemente, die zusammen mit einem darauf folgenden Turn eine intonatorische Einheit bilden, nicht als Hörersignale eingestuft, auch wenn sie nach dem Ende des Redebeitrags des Sprechers plaziert sind. Hingegen gelten kurze Äußerungen, die im Moment des Sprecherwechsels auftreten, als Hörersignale, wenn sie durch eine Pause und die Intonation von dem beginnenden, eigenen Turn eindeutig abgetrennt sind. Ferner werden in dieser Arbeit Hörersignale, mit denen der Sprecher während seines Turns auf Höreräußerungen reagiert, ${ }^{222}$ nicht als Hörersignale des Hörers angesehen und somit aus der Analyse ausgeschlossen.

\footnotetext{
${ }^{222}$ Yngve 1970, S. 575, Duncan 1974, S. 169. Yngve bezeichnet diese Reaktion des Sprechers während seines Turns als „,back back channel“.
} 


\subsection{Formen der verbalen Hörersignale}

\subsubsection{Die Beschreibung der Typen der Hörersignale und die prozentuale Verteilung der Typen im Deutschen}

In diesem Kapitel werden verschiedene Typen der Hörersignale differenziert und jeweils genauer charakterisiert. Dabei wird Wert darauf gelegt, daß die einzelnen Schritte, die bei der Bestimmung der Typen der Hörersignale vollzogen werden, klar nachvollziehbar sind. Außerdem ist die Charakterisierung darum bemüht, die einzelnen Typen der Hörersignale ausführlicher und anschaulicher darzustellen. Wenn nötig, werden Diagramme zur Veranschaulichung vorgeführt. Zum Einstieg werden zwei Modelle zur Klassifikation der deutschen Hörersignale aus der bisherigen Forschung vorgestellt.

\subsubsection{Die Klassifikationsmodelle von Henne/Rehbock und C. Schmidt}

Verbale Hörersignale lassen sich in verschiedene Typen untergliedern; bis jetzt wurden in der Forschungsliteratur einige Klassifikationsraster vorgeschlagen.

Zuerst werde ich auf die Klassifikation von Henne/Rehbock (1982) eingehen, die sich im wesentlichen an Duncan (1974) anlehnen. Folgende Typen von Hörersignalen werden bei Henne/Rehbock aufgestellt: ${ }^{223}$

1. Rückmeldungspartikeln sowie deren Kombinationen wie ja, hm, mm, jawohl usw.

2. Satzvollendung

3. Bitte um Klärung (Zwischenfrage)

4. Kurze Nachformulierung

5. Spontane Kommentarschritte (Einstellungskundgaben): das ist ja reizend, das finde ich so gut usw.

An Henne/Rehbock ist zu kritisieren, daß sie die Typen der Hörersignale anscheinend nach gemischten Kriterien (syntaktisch, lexikalisch, funktional) aufgeteilt haben, ohne dabei ihre Vorgehensweisen oder ihre Kriterien explizit ausgeführt zu haben.

${ }^{223}$ Henne/Rehbock 1982, S. 179ff. 
Zweitens gibt es einige Hörersignale, die sich schlecht einem der von Henne/Rehbock benannten Typen zuordnen lassen: Phrasen- und satzförmige Äußerungen wie auf jeden Fall, so denke ich auch, in der Tat nicht usw., die oftmals als Hörersignale eingesetzt werden und ähnlich wie ja, genau usw. fungieren, können im Modell von Henne/Rehbock schlecht erfaßt werden; man kann solche eventuell zu den „Kommentarschritten“ rechnen, aber dann müßte der Typ „Kommentarschritte“ weiter als bei den beiden Autoren gefaßt werden.

Ein etwas differenzierteres Klassifikationsraster wird von C. Schmidt (1986), die sich weitgehend an Henne (1978) orientiert, präsentiert. Ihr Modell besteht aus sieben sprachlichen Realisierungstypen: ${ }^{224}$

- Rückmeldungspartikeln: ja, mh, genau usw., die „die Funktion der Aufmerksamkeitsbezeugung“ haben;

- idiomatische Zeichenkombinationen: ach so, ach das, ja ja stimmt; solche signalisieren nicht nur Aufmerksamkeitsbezeugung, sondern besonderes Interesse des Hörers am Gesagten und ermuntern den Sprecher zur Fortführung der Rede; ${ }^{225}$

- Ergänzungen:

- Gleiches zur gleichen Zeit sagen (Wiederholung) ${ }^{226}$

- geforderte Worthilfe

- nicht-geforderte Worthilfe

- vorgezogene Wortergänzung (Satzvollendung)

- modifizierende Ergänzung (damit wird der Sprecherbeitrag modifiziert;)

- gedanklich weiterführende Ergänzung

- Nachformulierungen,

- kurze Bitte um Klärung,

- Satzzeichen: wertende Kommentarschritte. Sie übermitteln die Einstellung des Hörers zum Gesagten wie z.B. das stimmt, das ist gut, das finde ich gut usw.;

- Satzzeichen: metakommunikative Äußerungen. Die Funktion ist nur einzeln im Kontext zu bestimmen.

\footnotetext{
${ }^{224}$ C. Schmidt 1986, S. 58-71.

${ }^{225}$ C. Schmidt 1986, S. 64.

${ }^{226}$ Die Ergänzungen in Klammern stammen von der Verfasserin.
} 
C. Schmidt differenziert Hörersignale anscheinend nach der syntaktischen Größe in Sätze und andere Wortverbindungen. Zu den Hörersignalen aus Sätzen (,Satzzeichen“) gehören „wertende Kommentarschritte“ und „metakommunikative Äußerungen“. ${ }^{2} 27$

Bei diesem Modell bleiben aber einige Fragen offen: Es ist unklar, ob alle Sätze einen der beiden Typen verkörpern. Ebensowenig weiß man, ob Hörersignale, die keine Sätze darstellen, einer der anderen Kategorien zugeordnet werden müssen. Außerdem treten ähnlich wie bei Henne/Rehbock Probleme auf: Es finden sich immer einige Hörersignale in den eigenen Daten, die sich nicht eindeutig einer der aufgestellten Kategorien zuordnen lassen; so sind z.B. in meinem Datenmaterial ein paar Sätze vertreten, die man sowohl als Kommentare als auch als Wiederholungen einstufen könnte. Zum zweiten sind bei mir viele satzförmige Höreräußerungen vorhanden, die das Gesagte kommentieren oder gedanklich und inhaltlich ergänzen; viele solcher Äußerungen sprengen den Umfang dessen, was bei C. Schmidt oder Henne/Rehbock unter den Kommentaren verstanden wurde. Ferner bleibt es unklar, welche Äußerungen als metakommunikative Äußerungen aufzufassen sind, weil C. Schmidt ihre Kriterien zur Bestimmung dieser Kategorie nicht angegeben hat.

Aufgrund der oben genannten Kritiken und Mängel scheint es mir sinnvoll, Hörersignale nicht in die Typen, die bei Henne/Rehbock (1982) oder C. Schmidt (1986) usw. aufgelistet sind, einzuordnen, sondern ein z.T. eigenes Klassfikationsmodell zu entwickeln; nichtsdestotrotz werde ich ggf. die Konzepte von Henne/Rehbock und C. Schmidt bei der Beschreibung der Typen der Hörersignale berücksichtigen. Im nächsten Kapitel werden das eigene Klassifikationsmodell und die dabei verwendeten Kriterien der Verfasserin dargelegt.

\subsubsection{Drei syntaktische Typen der Hörersignale und deren prozentuale Verteilung}

Als erster Schritt werden Hörersignale nach syntaktischen Merkmalen wie Satz, Phrase und Wort klassifiziert, um sie anschließend nach syntaktischen, lexikalischen und funktionalen Gesichtspunkten charakterisieren oder ggf. in Unterklassen differenzieren zu können.

Die Kategorien, denen Hörersignale im Deutschen zuerst zugeordnet werden sollen, sind wie folgt:

${ }^{227}$ C. Schmidt hat dies aber nicht explizit formuliert. 
- satzförmige Höreräußerungen: Sätze, Nebensätze oder elliptische Sätze,

- Phrasen: in Deutschland, zu teuer usw. und

- einzelne Wörter bzw. Wortkombinationen: ja, ja klar, Karteileichen usw.

$\mathrm{Zu}$ Illustrationszwecken möchte ich die Ergebnisse der prozentualen Verteilung von drei syntaktischen Typen vorführen. Untersucht wurden jeweils etwa siebenminütige Abschnitte:

Abbildung 1

\section{Prozentualer Anteil der Hörersignale je nach syntaktischen Größen}

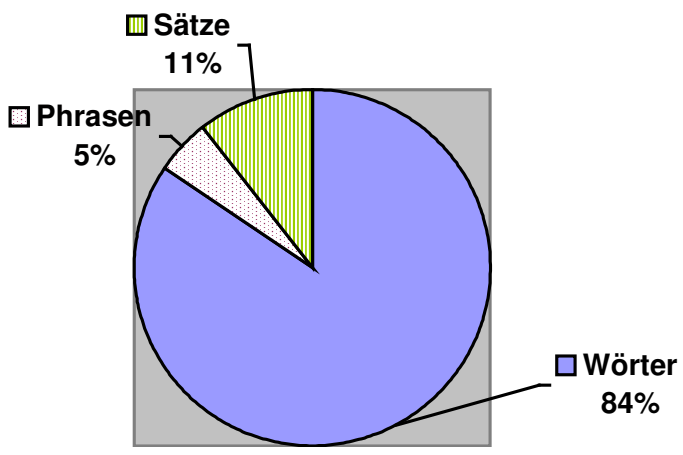

Es war zu erwarten, daß die meisten Hörersignale durch einzelne Wörter (ein Wort oder eine Wortkombination) realisiert werden, denn Hörersignale sollen weder turnübernehmend noch raumeinnehmend sein. Daß der Anteil der satzförmigen Äußerungen relativ groß ist, hängt zum Teil damit zusammen, daß teils längere Äußerungen als Hörersignale eingestuft wurden. ${ }^{228}$

Im folgenden Kapitel werden drei syntaktische Typen der Hörersignale genauer charakterisiert.

${ }^{228}$ Einige Argumente, die dafür sprechen, werden im Kap. 4.1 erwähnt. 
4.2.1.3 Genauere Charakterisierung der Typen der Hörersignale aus einem Wort oder einer Wortkombination

Hörersignale, die aus einem Wort oder einer Wortkombination bestehen, können nach der Kontextgebundenheit und der Verwendungshäufigkeit in meinen Daten und auch im Alltagsgespräch in zwei Gruppen unterteilt werden:

1) Hörersignale aus einem Wort (meistens einer Partikel oder einer Interjektion) oder zweifachen bzw. mehrfachen Wortkombination wie ja, mhm, ja genau, ja stimmt usw. und

2) Hörersignale, die formal und funktional stärker an den Gebrauchskontext gebunden sind.

Hörersignale, die zur ersten Gruppe gezählt werden, zeichnen sich dadurch aus, daß sie im Alltag immer wieder auftreten und in meinem Datenmaterial oft verwendet werden. Diese Gruppe wird in meiner Arbeit „Kurzformen“ genannt und in zwei Klassen - „Kurzformen aus einem Wort“ und „Kombinationen der Kurzformen“ - unterteilt.

Die zweite Gruppe bezieht sich auf Ein-Wort-Äußerungen, die nicht prototypischerweise als Hörerrückmeldungen eingesetzt werden, sondern in ihrer Verwendung gewissermaßen einmalig sind, weil sie stark an den aktuellen Verwendungskontext gebunden sind.

Nun werde ich im folgenden Höreräußerungen aus einem Wort oder einer Wortkombination genauer erläutern

\section{$\underline{\text { Kurzformen (KF) }}$}

Kurzformen, die in meinen deutschen Daten anzutreffen sind, bestehen aus folgenden Wortklassen:

- Interjektionen (uhmhm, ach, wao),

- Partikeln (ja, nee) oder

- andere Wortarten wie genau, stimmt, richtig, toll, schade, interessant.

In der deutschen Forschungsliteratur werden manche Kurzformen wie ja, uhmhm, genau usw. aufgrund ihres häufigen Vorkommens als Hörersignale extra als „Rückmeldungspartikel“ 
bezeichnet. ${ }^{229}$ Auch in meinem Datenmaterial werden vor allem ja und uhm sehr häufig verwendet (54,6\% aller Hörersignale). ${ }^{230}$ Sie stellen also „,prototypische Hörersignale“ im Deutschen dar. $^{231}$

Aus semantischer Sicht beinhalten Kurzformen (vor allem ja, uhmhm) „,kein Denotat“232 oder besser „keine substanziellen Informationen“ ${ }^{233}$ so daß sie wenig zur inhaltlich-thematischen Progression beitragen. Andererseits weisen sie jedoch meines Erachtens, wenn auch vage, gewissen Verweischarakter auf, insofern als sie auf die vorangegangene Äußerung des Sprechers gänzlich bzw. teilweise Bezug nehmen, um diverse Einstellungen des Hörers anzuzeigen, wobei ihr Bezug nur durch ihre Plazierung festgemacht werden kann.

Außerdem finden sich viele Kurzformen, die spezifischere Bedeutungen innehaben oder bei denen bestimmte funktionale Aspekte stärker zum Vorschein kommen. Im folgenden werden Kurzformen, die in meinem Datenmaterial beobachtet werden, je nach vordergründigen Funktionen, solange diese erkennbar sind, in Gruppen aufgeteilt und aufgelistet:

1. Hörersignale, die den Verstehensstand des Hörers zu erkennen geben: $m h m, j a$

2. Hörersignale, die den Wissensstand des Hörers (vorher nicht vorhandenes Wissen oder mit der Sprechermitteilung nicht übereinstimmendes Wissen) in bezug auf das Gesagte übermitteln: achso, aha, aja,

3. bestätigende und zustimmende Signale: ja, genau, das stimmt, klar, richtig,

4. Zweifel oder Überraschung ausdrückende Hörersignale: echt?, ja?, nee?

5. Hörersignale, die emotional aufgeladene, bewertende Einstellungen des Hörers mitteilen: boa, pfu:, wao, schade

6. Hörersignale, die einen Dissens andeuten und den Willen der Turnübernahme signalisieren.

\footnotetext{
${ }^{229}$ Siehe Henne (1978, S. 45), C. Schmidt (1986, S. 62) usw.

${ }^{230} \mathrm{Da} \beta$ ja und uhmhm die zwei häufigsten Kurzformen bilden, wird auch bei der Untersuchung von Wahmhoff/Wenzel (1979, S. 274) bestätigt, wobei die beiden Kurzformen in den Gesprächsdaten der Autorinnen (Beratungsgespräche) 93,3 \% aller Hörersignale ausmachen.

${ }^{231}$ Coulmas (1981) zählt einige Hörersignale wie ja, uhm zu „Routineformeln“. Solche Routineformeln sind nach Coulmas „Muster für die Konstituierung von Handlungen, [...] die sich in der alltäglichen kommunikativen Praxis jeder Sprachgemeinschaft wiederholen. [...] Sie sind in jeder Sprache verfestige organisierte Reaktionen auf soziale Situationen; ihr Gebrauch gewährt dem einzelnen Gruppenmitglied ein hohes Maß an Verhaltenssicherheit [...]“" (1981, S. 13f.).

${ }^{232}$ Rath 1979, S. 118, White 1986, S. 40.
} 
Die prozentuale Verteilung der Kurzformen im deutschen Datenmaterial ist relativ hoch: In meinen Daten beträgt die Verwendungsquote der Kurzformen 65,8\%, also zwei Drittel aller Hörersignale. Das spricht wiederum dafür, daß Hörerrückmeldungen in vielen Fällen standardisierte Reaktionen darstellen, die in kürzester Zeit ausgeführt werden können und müssen; dem Hörer steht nämlich während der Rede des Sprechers nur wenig Zeit zum Reagieren zur Verfügung: Er muß die Mitteilung des Sprechers empfangen, entschlüsseln und ihm ein angemessenes Feedback geben. Die Auswahl aus dem Reservoir konventionalisierter Mittel ermöglicht dem Hörer eine schnelle Übermittlung der für den Sprecher notwendigen Information.

\section{$\underline{\mathrm{Zu} \text { Kombinationen von Kurzformen (KKF) }}$}

Zumindest zwei Arten von Kombinationen sind zu unterscheiden:

- Reduplizierte oder verdreifachte Formen wie ja ja, ja ja ja und

- Kombinationen von zwei oder mehr verschiedenen Kurzformen: ja eben, ja nee klar, mhm mhm ja ja usw.

Kombinationen von Kurzformen weisen als Einheit unterschiedliche Festigkeit auf: naja, achso oder aja werden in dieser Kombination so oft verwendet, daß man sie fast als ein Wort empfindet, ${ }^{234}$ während na klar, ja genau, ja stimmt usw. trotz häufiger Anwendung als die Anreihung von zwei Zeichen angesehen werden. mhm ja, naja ja, das stimmt ja naja werden in dieser Zusammensetzung noch seltener gebraucht, so daß sie mehr oder minder als ,ad hoc"-Bildung betrachtet werden könnte. Hierbei ist es interessant, zu beobachten, daß die jeweiligen Funktionen der kombinierten Kurzformen - seien sie fester oder lockerer zusammengesetzt - nicht verschmolzen sind, sondern beide gleichermaßen bewahrt bleiben. So heißt z.B. aja, daß etwas Neues aufgenommen und als richtig erkannt wird. Ebenso ist die Funktion von achso die Addition von ach (etwas unerwartetes) und so (das Gesagte als wahr erkannt).

Hörersignale, die in meinen Daten häufiger mit anderen Hörersignalen kombiniert werden, sind ja, achso, mhm, nee usw. Vor allem finden sich eine Reihe von Kombinationen zwischen

\footnotetext{
${ }^{233}$ Sugito 1987, S. 88; das Zitat ist von mir übersetzt.

${ }^{234}$ Willkop (1988, S. 215, S. 225) ist auch der Meinung, daß a mit ja und ach mit so häufig kombiniert werden.
} 
der Partikel ja und einem anderen zustimmenden Hörersignal: ja genau, ja stimmt, ja klar usw. ${ }^{235}$ Von den kombinierten Kurzformen gehören 69,7\% zu ja-Kombinationen; die achsoKombinationen bilden mit der Quote von 9,2\%, die zweithöchste Gruppe.

In bezug auf den funktionalen Aspekt der kombinierten Kurzformen läßt sich Folgendes beobachten: Kombinationen der Kurzformen können zugleich verschiedene Funktionen explizit zum Ausdruck bringen, die meistens die Summe der Funktionen der einzelnen, zusammengebündelten Kurzformen darstellen. Das Verhältnis zwischen den Funktionen der separaten kombinierten Kurzformen kann verstärkend, verdeutlichend, vervielfachend sein. Hierzu sind einige Beispiele je nach ihren Funktionen aufgelistet:

- Verstärkung: die Funktion, die durch die erste Kurzform der KKF ausgeübt wird, wird durch die zweite Kurzform wiederholt: genau genau, ja: + (Pause) ja: (etwas gedehnt, eine kleine Pause zwischen den beiden ja).

- Verdeutlichung: ja genau (ja ist eine allgemeine Zustimmung zum Gesagten; genau zeigt den Umfang der Übereinstimmung an), ja stimmt (stimmt besagt, daß der Hörer die Richtigkeit des Gesagten nachvollzogen hat).

- Ausdruck des Willens der Turnübernahme oder der Ungeduld mit der aktuellen Information: jaja, jaja gut (schnell, kurz hintereinander gesprochen); mit ihnen kann der Hörer klarer signalisieren, daß er die Sprecherintention sehr gut verstanden hat, daß der Sachverhalt bereits bekannt ist und er in Kürze den Turn übernehmen will. ${ }^{236}$

- Ausdruck des Gedankengangs des Hörers beim Verstehen: aja genau (Aufnahme einer neuen Information und Ratifizierung der Richtigkeit); das stimmt ja naja (Bestätigung der logischen Stimmigkeit, allgemeine Bestätigung, Abstufung der Relevanz mit dem Willen der Turnübernahme).

Der prozentuale Anteil der KKF beträgt 17,3\% und liegt viel niedriger als die $\mathrm{KF}(65,8 \%)$. Wenn man die KKF und die KF zusammenzählt, machen sie beide zusammen 83,7\% aller Hörersignale in meinen Daten aus. ${ }^{237}$ Der Hörer schöpft also bei der Formenauswahl in den meisten Fällen aus dem Reservoir der standardisierten Mittel.

\footnotetext{
${ }^{235}$ Auch Willkop (1988, S. 278) beobachtet Ähnliches.

${ }^{236}$ Vgl. Willkop (1988, S. 93).

${ }^{237}$ C. Schmidt (1986, S. 106-107) und Sawada (1991, S. 70) erzielten ein ähnliches Ergebnis: Bei C. Schmidt sind etwa $88 \%$, und bei Sawada mindestens $84 \%$ aller Hörersignale Kurzformen und deren Kombinationen.
} 


\section{$\underline{\text { Zu den Ein-Wort- } \ddot{u} \text { ßerungen (EWÄ) }}$}

Ein-Wort-Äußerungen, die nicht als ,,prototypische Hörersignale“ gelten, bilden eine absolute Minderheit in meinen Daten. Sie betragen insgesamt $1,4 \%$ aller Hörersignale. Nichtsdestotrotz sind sie in funktionaler Hinsicht sehr vielfältig. Im folgenden werden ihre formalen und funktionalen Merkmale dargelegt.

Formal gesehen stellen Ein-Wort-Äußerungen oft die Wiederaufnahmen von Satzelementen der vorangegangenen Sprecheräußerung dar. Solche Höreräußerungen werden in der Literatur als „Wiederholungen“ bezeichnet. Äußerungen, die das Gesagte nicht wörtlich, aber inhaltlich sinngemäß wiedergeben, werden von Wiederholungen abgegrenzt und extra „Nachformulierungen“ genannt. Äußerungen, die Wiederholungen oder Nachformulierungen darstellen, können nicht nur in Aussagesätzen, sondern auch in Fragesätzen (Vergewisserungsfragen) auftreten.

Außer den Ein-Wort-Äußerungen, die zu einem dieser Typen gezählt werden können, gibt es aber auch solche, die weder formal noch inhaltlich das Gesagte wiedergeben, sondern die betreffende Sprecheräußerung eher weiterführen, indem sie einen ergänzenden, kommentierenden Beitrag dazu leisten; so gehören z.B. „Satzvollendungen“ dazu; außerdem können vor allem in den japanischen Daten „Worthilfe“, Satzvollendungen oder Vorwegnahmen dazu gezählt werden.

Ein-Wort-Äußerungen können alle Funktionen, die ich bei Kurzformen auflistet habe, erfüllen. Ein großer Unterschied zwischen beiden besteht darin, daß bei Ein-WortÄußerungen der Gegenstand des Verstehens, der Verwunderung, der Vergewisserung, der Bewertung, der Zustimmung usw. direkt genannt werden kann. Hierzu werden zur Veranschaulichung ein paar Beispiele angeführt: 
Gesprächskontext 1

Hanna und Alex thematisieren die Differenz zwischen der Studentenanzahl auf dem Papier und der Anzahl der real studierenden Studenten:

$1 \quad \mathrm{HN}$

$\mathrm{AL} \quad$ ich glaube es sollen acht hundert leute + in

$2 \mathrm{HN}$ so viel

$\mathrm{AL}$ ethnologie eingeschrieben sein und ich hab ja und

$3 \mathrm{HN}$

$\mathrm{AL} \quad$ ich hab noch nie mehr als hundert gesehen also

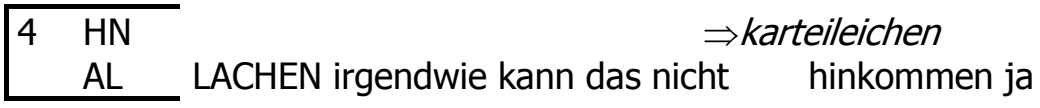

In diesem Beispiel ist Karteileichen eine inhaltliche Wiedergabe der Studenten, die eingeschrieben sind, aber nicht in den Vorlesungen erscheinen, also eine Nachformulierung. ${ }^{238}$ Diese Ein-Wort-Äußerung wird von Hanna ergänzend zum Sprecherbeitrag von Alex geäußert. Mit dieser Hinzufügung bestätigt Hanna wohl nicht die Richtigkeit des Gesagten (der angegebenen Studentenzahl); sie weiß jedoch im allgemeinen, daß es öfters solche Studenten gibt. Dies läßt sich an dem Turn von Hanna belegen, den sie nachfolgend übernimmt; so fängt Hanna anschließend an zu erzählen, daß es viele Karteileichen in ihrem Fach gibt.

Ein-Wort-Äußerungen sind gelegentlich mit einer oder mehreren Kurzformen versehen: fünf hundert oh Gott!, Zimmermann aha: usw. In solchen Beispielen können nicht nur der Gegenstand der Verwunderung oder der Kenntnisnahme explizit erwähnt, sondern auch mittels Kurzformen die Haltung des Hörers gegenüber der vorangegangenen Sprecheräußerung deutlich angezeigt werden:

\footnotetext{
${ }^{238}$ Horiguchi 1987, S. 20.
} 
Gesprächskontext 2

Frauke erzählt Klara über ihre Bewerbungserfahrungen; dabei gab es fünfhundert Bewerber für eine Stelle:

$1 \mathrm{KA}$

FK da habe ich öfters zurückgekriegt $\mathrm{H}$ und dann einfach

mit dem zusatz tut uns leid, daß wir sie unter den

fünf hundert bewerbern leider nicht $\mathrm{H}$ auswählen

$2 \quad \mathrm{KA} \quad \Rightarrow$ fünf hundert!? oh gott

FK konnten und kein problem habe ich

Mit der Äußerung fünf hundert, oh Gott! wiederholt Klara einen Satzteil der Sprecherrede; dabei kommt zusätzlich die große Überraschung von Klara durch das Hörersignal oh Gott! zum Ausdruck.

\section{$\underline{\mathrm{Zu} \text { den phrasenförmigen Höreräußerungen }}$}

Die phrasenförmigen Höreräußerungen sind nur geringfügig in meinen Daten vertreten (5\% aller Hörersignale). Insofern können an dieser Stelle nur ein paar Hinweise auf diesen betreffenden Typ vermittelt werden.

Ähnlich wie bei der Klasse einzelner Wörter können phrasenförmige Höreräußerungen ebenso in zwei Gruppen: Generell häufig eingesetzte Hörersignale und Hörersignale, die aus dem aktuellen Kontext entstanden sind, differenziert werden, obwohl die Grenzübergänge oft fließend sind. Vieles, was über Ein-Wort-Äußerungen erläutert wurde, trifft ebenfalls auf phrasenförmige Hörersignale zu, die nicht als typisch gelten. Hierzu werden ein paar Beispiele für diese Gruppe angeführt.

Gesprächskontext 3

Hanna und Alex unterhalten sich über die Anzahl der Studierenden, die für die Ethnologie eingeschrieben sind.

$1 \quad \mathrm{HN}$

$\mathrm{AL} \quad$ ich glaube es sollen acht hundert leute + in

$2 \mathrm{HN} \quad \Rightarrow$ so viel?!

$\mathrm{AL}$ ethnologie eingeschrieben sein und ich hab ja und 
Hier geht es darum, daß auf dem Papier viel mehr Studenten eingeschrieben sind, als tatsächlich studieren. Die Äußerung so viel von Hanna, die einen Kommentar zum Sprecherbeitrag darstellt, ist zugleich ein Überraschungsausdruck, was durch die Bedeutung der beiden Lexeme und die prosodischen Merkmale eindeutig als solcher erkennbar ist.

Im nächsten Beispiel äußert Frauke eine positive Meinung zur Einführung einer Checkliste für die Qualitätssicherung im Bildungssektor.

Gesprächskontext 4

Frauke äußert sich positiv über ein Handbuch mit Checklisten, das zur Überprüfung der Qualitätssicherung dienen soll. Diese Checkliste soll im Bildungssektor, wo Frauke arbeitet, eingeführt werden.

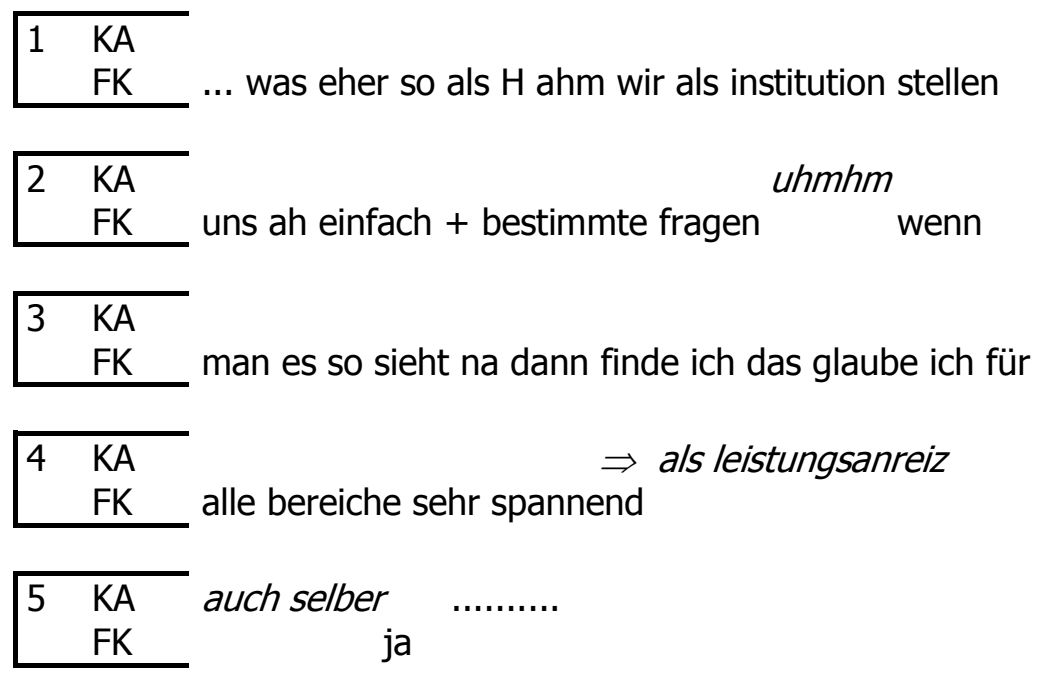

In diesem Beispiel unterstützt Klara zum einen die Meinung von Frauke; zum anderen leistet diese Äußerung eine Ergänzung zum Sprecherbeitrag, indem Klara einen anderen guten Aspekt zusätzlich erwähnt, den Frauke nicht geäußert hat.

Ferner können einige Ein-Wort-Äußerungen als Ausdruck der Informationsaufnahme und des Denkanstoßes des Hörers fungieren, der ausführlicher erläutert oder erklärt werden soll oder über den der Hörer etwas aussagen möchte: 
Gesprächskontext 5

Klara erzählt etwas über eine Stelle, für die sich Klara beworben hat; dabei gab es 70 Bewerber. Frauke findet die Anzahl der Bewerber gar nicht so hoch, denn.....

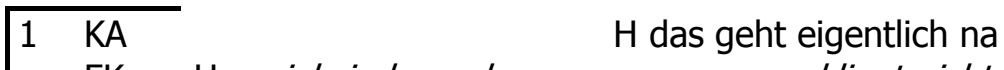

FK $\mathrm{H} \Rightarrow$ siebzig bewerbungen klingt nicht schlecht ja

2 KA geht eigentlich noch na

FK hört sich sehr ??? an meins ??? über

$3 \mathrm{KA}$

FK hundert oder so ++ wo ich mich dann beworben hab ....

Nachdem Klara über ihre Erfahrungen mit der Bewerbung berichtet hat, reagiert Frauke mit einer phrasenförmigen Äußerung siebzig Bewerbungen. Frauke wiederholt denjenigen Teil der Information der Sprecheräußerung, um den ihre Gedanken kreisen. Dies wird durch die Äußerungen deutlich, die sich dieser Phrase anschließen.

Zur anderen Gruppe gehören Phrasen, die im Alltagsgespräch des öfteren verwendet werden und mehr oder minder floskelhaft wirken: auf jeden Fall, in der Tat nicht usw. Idiomatische Wendungen wie um Gottes willen, wie so Schluck usw. können manchmal solche Phrasen darstellen. Viele solcher immer wiederkehrend eingesetzten Ausdrücke haben in meinen Daten die Funktion, emotionale Regungen oder Zustimmung des Hörers zu signalisieren.

\section{$\underline{\mathrm{Zu} \text { den satzförmigen Höreräußerungen }}$}

Ebenso wie bei Phrasen lassen sich satzförmige Äußerungen in zwei Gruppen einteilen: Höreräußerungen, die häufig als Hörersignale eingesetzt werden, und solche, die stärker an den aktuellen Kontext gebunden sind. $\mathrm{Zu}$ den „typischen Sätzen“ zählen solche Formulierungen, die in der gängigen Literatur als „spontane bzw. wertende Kommentarschritte“ oder „,idiomatische Zeichenkombinationen“239 genannt bzw. zusammengefaßt werden. ${ }^{240}$

\footnotetext{
${ }^{239}$ Henne 1978, S. 125. Er listet die Wendungen wie z.B. ich verstehe, das denke ich mir, kaum zu glauben usw. auf.

${ }^{240}$ Das heißt aber nicht, daß sie nur als Hörersignale verwendet werden können. Willkop (1988) zeigt, daß Wörter, die als Hörersignale häufig vorkommen, auch in der Sprecherrede häufig zu beobachten sind; deshalb hat sie alle solche Wörter als „Gliederungspartikeln“ zusammengefaßt.
} 


\section{$\underline{\mathrm{Zu} \text { den für Hörersignale typischen Sätzen }}$}

Es ist charakteristisch für die Sätze, die in meinen Daten häufig als Hörersignale verwendet werden, daß sie durch eine der unten aufgelisteten Konstruktionen gebildet werden:

- das ist (ja) Adjektiv: interessant, gut, toll, blöd, fies usw.,

- das/es klingt (ja) Adjektiv : gut, nicht schlecht, interessant usw.,

- das/es hört sich Adjektiv an: nicht schlecht usw.,

- das finde ich (echt) Adjektiv: gut usw.

Äußerungen mit einer der o.a. Konstruktionen dienen dazu, Bewertungen des Hörers dem Gesagten gegenüber auszudrücken. In manchen Fällen klingen sie floskelhaft und wenig authentisch; sie erwecken den Eindruck, daß sie eher aus Höflichkeit geäußert wurden.

Außer Bewertungen finden sich bei mir auch zustimmende Höreräußerungen, die ebenso im Alltag häufig gebraucht werden: (ja) das ist echt so, (ja) denke ich auch (ja), (ja) dass natürlich usw. Ferner kommt zur Vergewisserung die Konstruktion meinst du/meinste des öfteren zur Anwendung.

Die prozentuale Frequenz der typischen satzförmigen Äußerungen ist im Vergleich zu Kurzformen und deren Kombinationen sehr gering; der Anteil liegt bei 4,6\%.

\section{$\underline{\mathrm{Zu} \text { den nicht typischen Sätzen }}$}

Neben diesen oben genannten Typen finden sich auch andere Höreräußerungen, die stärker an den Verwendungskontext gebunden sind, indem sie aus Satzteilen bestehen, die formal und/oder inhaltlich direkt auf die vorangegangene Sprecheräußerung bezogen sind. Solche Äußerungen verkörpern oft Ergänzungen oder Kommentare. Sie wirken des öfteren stereotyp, obwohl sie nicht oft als Hörersignale zum Einsatz kommen; sie werden jedoch in bestimmten, immer wiederkehrenden Gesprächskontexten in einigen Variationen häufig verwendet. Hierzu ein paar Beispiele: 
Gesprächskontext 6

Hanna erzählt, daß sie kurz vor der Japanreise krank geworden ist und deswegen dort nicht als Dolmetscherin arbeiten konnte. Sie macht sich jetzt Sorgen, ob sie den Job eventuell verliert.

$1 \mathrm{HN}$ und das sind ja immer so: die sachen wo ich denke naja da ist noch ein risiko dabei es kann doch noch sein, daß er sich jemand anderen einstellt na

$\mathrm{AL}$ $\Rightarrow j a+$ aber da kannst du ja echt

$2 \mathrm{HN}$ nee

$\mathrm{AL}$ nichts dafür, wenn du krank bist

Hier kommentiert Alex verständnisvoll die Äußerung von Hanna; sie zeigt also in ihrer längeren Äußerung Verständnis für die Sorge der Sprecherin und tröstet sie darüber hinaus. Die Formulierung da kannst du nichts dafür wird häufig gebraucht, wenn man z.B. den Betreffenden vom Schuldgefühl entlasten will.

Gesprächskontext 7

Knut und Heinz studieren Japanologie; Heinz hat jedoch nicht vor, das Fach „so richtig" zu studieren.

\begin{tabular}{|c|c|c|}
\hline$\overline{1}$ & $\mathrm{HZ}$ & $\begin{array}{l}\mathrm{H} \text { und tja un:: also ich denke auf dauer } \mathrm{H} \text { kann ich japanisch nicht so } \\
\text { nebenbei machen nur so aber ich } \\
\text { machs halt einfach um }\end{array}$ \\
\hline & $\mathrm{KN}$ & $\Rightarrow$ ja solange es geht halt kann mans ja \\
\hline 2 & $\begin{array}{l}\mathrm{HZ} \\
\mathrm{KN}\end{array}$ & \\
\hline
\end{tabular}

Knuts Kommentar unterstützt das Vorhaben von Heinz; die Zustimmung wird verstärkt durch $j a$, das sich dem Kommentar anschließt. Diese Formulierung ist in vergleichbaren Situationen im Alltag häufig zu hören.

Der Anteil nicht typischer satzförmiger Äußerungen beträgt 5,9\% aller Hörersignale. Interessant ist, daß keine Satzvollendungen in meinen deutschen Daten zu beobachten sind, ${ }^{241}$ die sich in den japanischen Daten oftmals finden lassen.

\footnotetext{
${ }^{241}$ Satzvollendungen kommen jedoch bei Sawada (1991) oder C. Schmidt (1986) nicht selten vor.
} 
Als letztes wird die prozentuale Verteilung der jeweiligen Typen in Form eines Diagramms vorgeführt:

Abbildung 2

Prozentualer Anteil der

Typen der Hörersignale

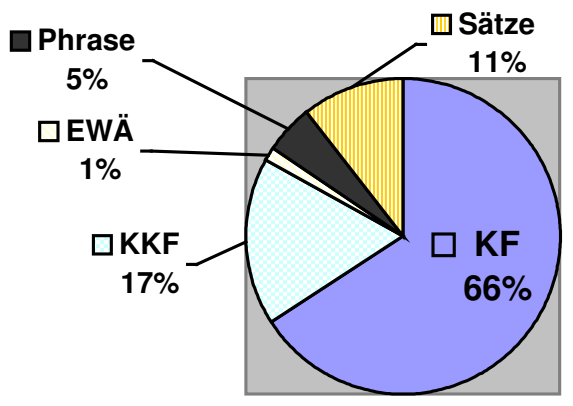

\subsubsection{Die Beschreibung der Typen der Hörersignale und die prozentuale Verteilung der Typen in den japanischen Daten}

\subsubsection{Drei syntaktische Typen der Hörersignale und deren prozentuale Verteilung}

Im japanischen Teil werden wie im deutschen Teil Hörersignale zuerst in drei syntaktisch definierte Gruppen aufgeteilt: Wörter, Phrasen und Sätze. Zu satzförmigen Höreräußerungen werden in den japanischen Daten Äußerungen gezählt, die aus mindestens zwei Phrasen, nämlich einer Verbphrase und einer anderen Phrase, bestehen. Äußerungen mit einer Verbphrase wie wakaranai (nicht wissen), arimasu (es gibt) usw. werden als Phrasen betrachtet, obwohl es sich bei ihnen um Ellipsen handelt, bei denen ausgelassene Informationen vom Kontext her ohne weiteres ergänzt werden können. Außerdem gehören Äußerungen wie Nomina u.ä. und Postpositionen: watashi mo (ich auch) zu der Klasse Phrasen. Einzelne Wörter sind solche wie hai (ja), honto (wirklich?), gogakukôza (Sprachkurs) usw.

Die Verteilung dieser drei syntaktischen Typen sieht in den japanischen Daten folgendermaßen aus: 
Abbildung 3

\section{Prozentualer Anteil der Hörersignale je nach der syntaktischen Größe}

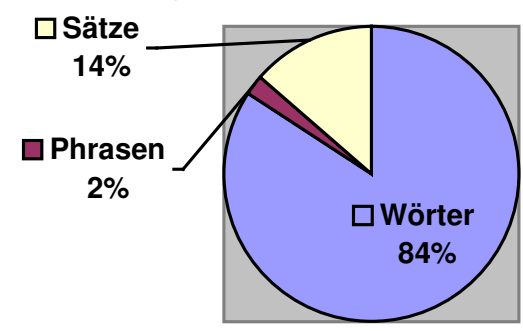

Ähnlich wie in den deutschen Daten werden ebenso in den japanischen Daten einzelne Wörter am häufigsten als Hörersignale verwendet. Der Anteil der satzförmigen Äußerungen in den japanischen Daten ist relativ hoch, weil viele Satzäußerungen mit dem Nomen sô (so) wie z.B. a sô desu $k a$ (ach, so ist das) in meinen Daten vertreten sind, die in der Forschungsliteratur als ,aizuchi“ bezeichnet werden.

\subsubsection{Die genauere Charakterisierung der Untertypen der Hörersignale}

In den japanischen Daten lassen sich Hörersignale in einige Typen unterteilen: Kurzformen bzw. „aizuchi““ aus einem Wort, Kombinationen von „aizuchi“, phrasenförmige ,aizuchi“, satzförmige ,aizuchi“, phrasenförmige Äußerungen und satzförmige Äußerungen. Unter „aizuchi“ verstehen sich Hörersignale, die als Hörersignale prototypisch sind und in der Forschungsliteratur immer als solche angeführt werden. ${ }^{242} \mathrm{Im}$ folgenden wird auf diese Klassen näher eingegangen.

\section{$\underline{\text { Kurzformen }(\mathrm{KF})}$}

Kurzformen in meinen japanischen Daten werden durch folgende Wortklassen realisiert:

- Interjektionen: hai und $e$ : (ja, mhm), um (ja, mhm), he: (positive Überraschung) usw.,

- Satzletzte Partikeln: ne: (nicht wahr),

- andere Wortarten: honto $\uparrow$ (wirklich?), naruhodo (einverstanden, so kann man es auch sehen), sô (ja so ist das, achso) usw.

\footnotetext{
${ }^{242}$ Hierbei habe ich mich vor allem an Mizutani (1988) und Matsuda (1988) angelehnt.
} 
Solche Kurzformen werden in der Literatur in der Regel als ,aizuchi“-Partikeln zusammengefaßt.

„Aizuchi“-Partikeln weisen ähnlich wie Kurzformen in den deutschen Daten wenig substantiellen Inhalt auf, ${ }^{243}$ statt dessen bringt der Hörer dadurch bestimmte Einstellungen dem Gesagten gegenüber zum Ausdruck, die den Sprecher bei der Weiterführung des Turns unterstützen. Japanische ,aizuchi““-Partikeln üben im großen und ganzen ähnliche Funktionen wie Kurzformen in den deutschen Daten aus:

- Hörersignale, die den Verstehensstand sowie die Kenntnisnahme des Hörers zu erkennen geben: hai, ha, e:, um, naruhodo (ja, mhm), sô (achso);

- Hörersignale, die den Wissensstand des Hörers in bezug auf das Gesagte übermitteln: $a:$ : (jetzt weiß ich es!);

- Zweifel oder Überraschung ausdrückende Hörersignale: $e e: \uparrow$, honto $\uparrow$ (wirklich?),

- Bestätigende und zustimmende Hörersignale: honto $\downarrow$ (ja so ist das), mehrmals akzentuierte, länger gedehnte $e$ : und um wie e:e:e:, umumum, (du hast wirklich recht, ganz deiner Meinung),

- Hörersignale, die die emotionale, bewertende Einstellung des Hörers mitteilen: he: (positive Überraschung), ho: (das ist ja toll);

- bestätigungserheischendes Hörersignal ne:

Hinzuzufügen ist, daß länger gedehnte, in hoher Stimmlage artikulierte he: (positive Überraschung) und $n e$ : (nicht wahr) in meiner Untersuchung nur von den Frauen benutzt wurden. $^{244}$

Kurzformen wie naruhodo (einverstanden), sô (so) sind des öfteren mit einer satzletzten Partikel ne ausgestattet. Mit ne kann der Hörer eventuell vom Sprecher eine Reaktion auf seine Hörerrückmeldung evozieren. Aber die Verwendung von ne bei sô ne oder naruhodo ne

\footnotetext{
243 Sugito 1987, S. 88.

${ }^{244}$ Dieses Phänomen kann man im Rahmen der Männer- und Frauensprache behandeln; nach Kato et al. lassen sich geschlechtsspezifische Unterschiede zwischen Männern und Frauen in einigen Hinsichten der Sprachverwendung heute noch erkennen: Dazu gehört z.B. der Gebrauch von satzletzten Partikeln, Interjektionen, Anredeformen oder Sprachstil usw. (Kato et al. 1990, S. 208-209).
} 
ist eher auf sich selbst gerichtet als auf den Sprecher: Mittels ne wird angezeigt, daß der Hörer seine neu gewonnene Kenntnis oder Erkenntnis für sich bestätigt.

Hinsichtlich der Distribution liegt der Anteil der „aizuchi“ aus einem Wort bei 77,8\% aller Hörersignale in meinen Daten. ${ }^{245}$ Von ihnen werden $u m$ (wie uhm, ja) mit 49,9\% und $e$ : (ja, uhm) mit einer Quote von 16,7\% besonders oft verwendet. Die dritthäufigste Form ist $a$ :, die anfängliches Verstehen, langsames Erkennen ausdrückt (4,7\%). Die Verwendung von um,e: und hai, die Zuhörerschaft und/oder Verstehen signalisieren können, variiert vor allem je nach dem sozialen Verhältnis wie Statusunterschied, Altersunterschied usw., weil $e$ : und hai höflicher und formeller als um klingen.

\section{Zu Kombinationen von Kurzformen (KKF)}

Kombinationen von Kurzformen in meinen Daten setzen sich aus folgenden Gruppen zusammen:

- die verdoppelten oder vervielfachten Formen: hai hai hai hai (ja ich verstehe, ich verstehe), sô sô sô (genau genau),

- Kombinationen von zwei oder mehreren verschiedenen Kurzformen: $a$ : hai (ach so ja), $a$ : he: (aha: interessant) usw.

Wie ja, mhm, ach usw. in den deutschen Daten existieren auch in den japanischen Daten Formen, die oftmals in Kombination mit anderen Hörersignalen verwendet werden:

- sô-Kombinationen (so): a sô desu ka (achso) usw.,

- naruhodo-Kombinationen (einverstanden): a: naruhodo (ach ja stimmt),

- hai-Kombinationen (ja): a: hai (ach ja jetzt kapiert) usw.

Die stärkste Gruppe bilden die sô-Kombinationen (so) mit der Quote von 8,6\% aller Hörersignale in meinen Daten. Darauf folgen die hai-Kombinationen $(1,7 \%)$ und dann die naruhodo-Kombinationen (einverstanden) mit 1,1\%.

\footnotetext{
${ }^{245}$ Auch Sawada (1991, S. 70) stellt fest, daß 87\% aller Hörersignale im Japanischen aus ,aizuchi“-Äußerungen bestehen. Bei Mizutani (1988, S. 96) liegt der Anteil bei 98\%.
} 
Kombinierte Kurzformen unterscheiden sich funktional gesehen kaum von einzelnen Kurzformen; sie verdeutlichen jedoch die Einstellungen des Hörers dem Gesagten gegenüber und transportieren stärkeren emotionalen Beigeschmack. Wie in den deutschen Daten können kombinierte Kurzformen dazu dienen, unterschiedliche Funktionen auf einmal zum Ausdruck zu bringen; so signalisiert z.B. die Einheit wie a: naruhodo he: folgendes: langsames Verstehen $(a:)$, Kenntnisnahme einer unerwarteten oder neuen Information (naruhodo), positive Überraschung (he:).

Der prozentuale Anteil der kombinierten ,aizuchi“ beträgt 4,7\% und ist damit viel niedriger als das Ergebnis in den deutschen Daten (17,3\%).

$\underline{\text { Zu phrasenförmigen ,aizuchi“ }}$

In den Abschnitten, die der Analyse unterzogen worden sind, wird nur ein einziges Beispiel für phrasenförmige ,aizuchi“ gefunden: die Wortverbindung zwischen einem Nomen und einer Postposition, nämlich honto ni (wirklich). In der Forschungsliteratur werden kaum ,aizuchi“-Äußerungen in Phrasen angeführt.

\section{$\underline{\text { Zu satzförmigen ,aizuchi““ }}$}

Satzförmige ,aizuchi“-Äußerungen in meinen Daten setzen sich syntaktisch gesehen aus sôVarianten (so) zusammen:

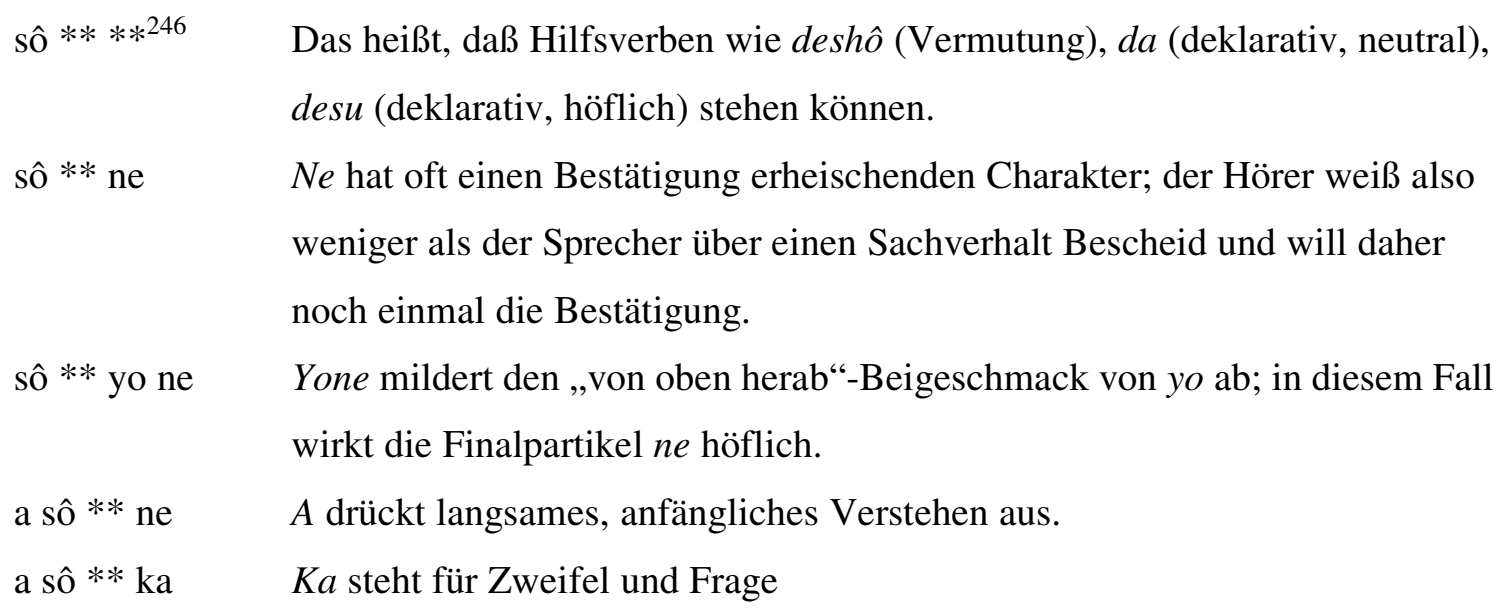

\footnotetext{
246 ** heißt, daß ein oder mehrere Hilfsverb(en) zwischen sô und ne/yone stehen kann/können: so wie z.B. sô desune.
} 
Solche Konstruktionen können vor allem Verstehen, Kenntnisnahme und Zustimmung signalisieren, wobei satzletzte Partikeln wie ne, yo und yone eine feine Nuancierung zwischen Zustimmung und Dissens oder zwischen dem Grad der Erwartungs- und Wissensdivergenz möglich machen.

Einige ,aizuchi“-Satzkonstruktionen, die ich in meinen Daten gefunden habe, werden exemplarisch vorgeführt:

\begin{tabular}{|c|c|c|c|c|c|c|}
\hline & & sô * & sô ** ne & sô * * yo ne & a sô $* *$ ne & a sô $* * \mathbf{k a}$ \\
\hline \multirow[t]{3}{*}{ Unsicherer } & $\begin{array}{l}\text { deshô } \\
\text { (Vermutung, } \\
\text { höflich) }\end{array}$ & $\begin{array}{l}\text { sô deshô } \\
\text { (es wird so sein) }\end{array}$ & $\begin{array}{l}\text { sô deshô ne } \\
\text { (du wirst wohl } \\
\text { recht haben) }\end{array}$ & |---------- & $\mid----$ & |---- \\
\hline & $\begin{array}{l}\text { desu } \\
\text { (deklarativ, } \\
\text { höflich) }\end{array}$ & $\begin{array}{l}\text { sô desu } \\
\text { (ich bestätige, } \\
\text { daß du recht } \\
\text { hast) }\end{array}$ & $\begin{array}{l}\text { sô desu ne } \\
\text { (wahrscheinlich } \\
\text { hast du recht) }\end{array}$ & $\begin{array}{l}\text { sô desu } \\
\text { yone } \\
\\
\text { (meinst du auch } \\
\text { so?, ne, ich } \\
\text { auch) }\end{array}$ & $\begin{array}{l}\text { a sô desu ne } \\
\text { (wo du das } \\
\text { sagst, denke ich, } \\
\text { daß du recht } \\
\text { hast) }\end{array}$ & $\begin{array}{l}\text { a sô desu ka } \\
\text { (ach so, ahan, } \\
\text { aja) }\end{array}$ \\
\hline & $\begin{array}{l}\text { nan desu } \\
\text { (deklarativ, } \\
\text { betont, höflich) }\end{array}$ & \begin{tabular}{|l} 
sô nan desu \\
(ja so ist das, du \\
hast richtig \\
erkannt)
\end{tabular} & $\begin{array}{l}\text { sô nan desu } \\
\text { ne } \\
\text { (ja ehrlich } \\
\text { gesagt ist das so } \\
\text { ja) }\end{array}$ & \begin{tabular}{|l} 
sô nan desu \\
yone \\
(ja ehrlich \\
gesagt ist das so \\
ja, meinst du \\
auch, oder?)
\end{tabular} & ---------- & $\begin{array}{l}\text { a sô nan } \\
\text { desu ka } \\
\text { (ach ja, ist das } \\
\text { so, wußte ich } \\
\text { nicht) }\end{array}$ \\
\hline
\end{tabular}

Die Frequenz dieser Gruppe (8,4\%) ist im Vergleich zu ,aizuchi“ aus einem Wort eindeutig niedriger, aber höher als Kombinationen $(4,7 \%)$ und phrasenförmige ,aizuchi“-Äußerungen $(0,5 \%)$. Von den „aizuchi“-Sätzen wird die Formulierung a sô desu ka (aha, achso) am häufigsten verwendet.

\section{$\underline{\mathrm{Zu} \text { den Ein-Wort-Äußerungen }}$}

Hierbei meine ich Ein-Wort-Äußerungen, die nicht als ,,aizuchi“ angesehen werden können. Die Quote dieses Typs liegt bei 1,8\% und ist also fast genauso niedrig wie in den deutschen Daten.

Viele solcher Ein-Wort-Äußerungen sind formal gesehen vollständige oder (Teil)Wiederaufnahmen von Satzelementen der Sprecheräußerung. Sie werden verwendet, um verschiedene Einstellungen des Hörers dem Sprecher gegenüber zu signalisieren: 
Überraschung, Zustimmung, Vergewisserung usw. Außerdem dienen Wiederholungen dazu, den Denkinhalt, über den der Hörer gerade nachdenkt, zu explizieren.

Außer den oben genannten Beispielen gibt es auch einige Ein-Wort-Äußerungen, die sich als Satzvollendungen oder Worthilfen einstufen lassen. Unter Worthilfen seien mit C. Schmidt (1986) solche Äußerungen verstanden, die der Hörer macht, wenn der Sprecher mit der Wortfindung Probleme hat. ${ }^{247}$

Im folgenden wird ein Beispiel für eine Ein-Wort-Äußerung angeführt, in dem die Hörerin Mako der Sprecherin Ayumi geholfen hat, einen geeigneten Begriff zu finden.

Gesprächskontext 8

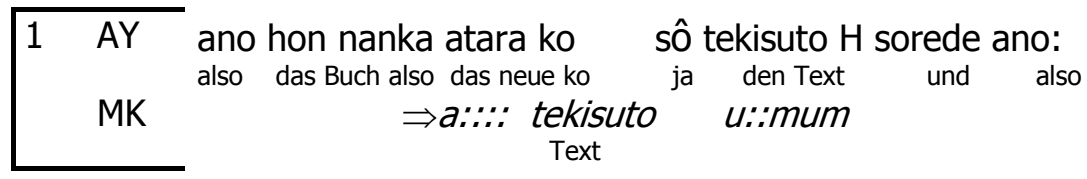

Ayumi, die eigentlich sagen wollte, daß sie „Lektüre“ kopieren wollte, fand den Begriff „Lektüre“ nicht. Mako fiel nach kurzem Nachdenken ein passendes Wort dafür ein und sprach es aus: a:: tekisuto (Zeile 1); so konnte Mako Ayumi helfen, die Schwierigkeiten hatte, dieses Wort zu finden, wodurch der Turn Ayumis wieder fortgeführt werden konnte.

\section{$\underline{\text { Zu den nicht-, ,aizuchi“"-Sätzen }}$}

Nicht-,,aizuchi“-Äußerungen - seien sie aus einem Wort oder einem Satz - weisen viel niedrigere Werte auf $(8,8 \%)$ als ,aizuchi“-Äußerungen. Satzförmige Höreräußerungen, die nicht zu den ,aizuchi“ gezählt werden, verkörpern häufig Kommentare zur Sprecheräußerung, die diverse Einstellungen des Hörers zum Ausdruck bringen: Zustimmung, Überraschung, Lob, Zweifel, Mitleid usw. Zum Teil enthalten solche Sätze Elemente, die von der vorangegangenen Sprecheräußerung wiederaufgenommen werden, wobei es selten vorkommt, daß satzförmige Höreräußerungen ausschließlich aus Wiederholungen bestehen; stattdessen werden Teilwiederholungen präferiert: Bei der Äußerung têsetsu desu keredomo ne (ja das ist

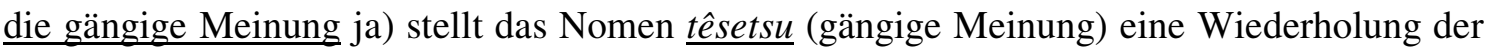
vorangegangenen Sprecheräußerung dar - die anderen Satzeile jedoch nicht. Solche Sätze mit

\footnotetext{
${ }^{247}$ Siehe C. Schmidt (1986, S. 66).
} 
wiederholten Elementen signalisieren des öfteren eine stärkere Zustimmung oder fungieren als Verständnissicherung.

Im Vergleich zu den deutschen Daten sind in den japanischen Daten auffällig viele Satzvollendungen anzutreffen, ${ }^{248}$ wobei nicht alle japanischen Teilnehmer diese Kategorie besonders präferieren.

Gesprächskontext 9

Sanako geht jetzt in einen kostenlosen Deutschkurs; von diesem Kurs erfuhr sie bei einem anderen gebührenfreien Deutschunterricht. Sanako will Haruyo erzählen, wie sie zum jetzigen Kurs gekommen ist; als sie die erste Hälfte der Information liefert, setzt die Hörerin Haruyo vorweg den Satz fort, den Sanako vollendet hätte.

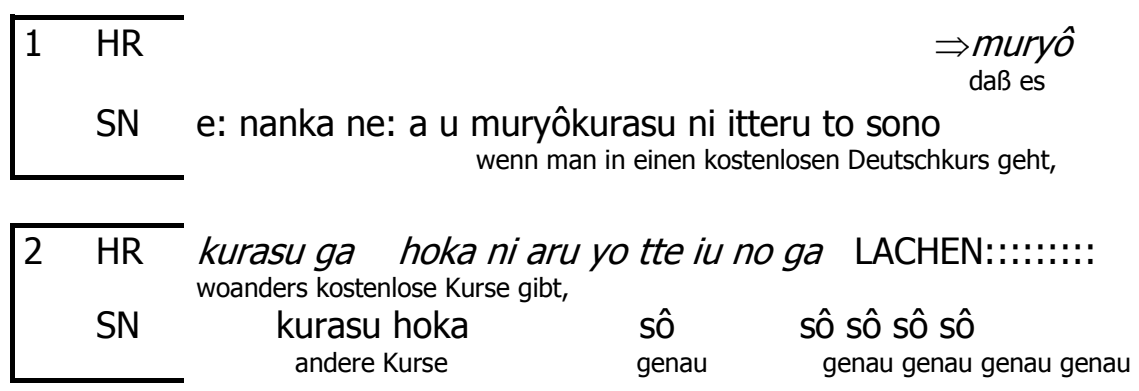

In Zeile 1 ist ein Beispiel für die Satzvollendung $\mathrm{zu}$ sehen. Nachdem Sanako den Konditionalsatz „wenn man in den kostenlosen Kurs geht“ geäußert hat, setzt Haruyo den Hauptsatz fort und vollendet so das Satzgefüge. Sanako bestätigt mit großer Begeisterung der Hörerin, daß sie mit ihrer Vorwegnahme richtig liegt.

Zum Schluß zeigt uns ein Diagramm die prozentuale Verteilung der jeweiligen Typen der „aizuchi“.

\footnotetext{
${ }^{248}$ Dies gilt als Beleg für die gegenseitige Kooperation und Abhängigkeit zwischen Sprecher und Hörer in Gesprächen unter Japanern (Mizutani 1988, S. 97). Bei Sawada (1991) oder Clancy et al. (1996) waren die Quoten der Satzvollendungen bei deutschen oder amerikanischen Teilnehmern höher.
} 
Abbildung 4

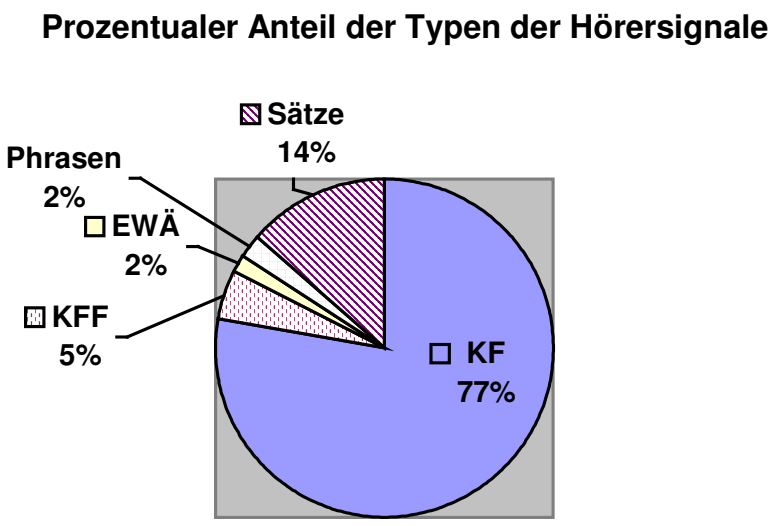

\subsubsection{Zusammenfassung}

Es gibt sowohl in den deutschen als auch in den japanischen Daten Wörter, Wortkombinationen, Phrasen und Sätze, die häufig oder prototypischerweise als Hörersignale verwendet werden: In den deutschen Daten stammen 88,6\% aller Hörersignale aus diesem Reservoir von Mitteln, die stark standardisiert sind, die Quote der japanischen Daten ist ein wenig höher und liegt bei 91,3\%.

Hörersignale lassen sich in beiden Datengruppen nach ihrer syntaktischen Größe sowie ihrem Grad der Konventionalisiertheit in einige Kategorien aufteilen: Kurzformen, Kombinationen von Kurzformen, Ein-Wort-Äußerungen, phrasenförmige und satzförmige Äußerungen.

Kurzformen umfassen einzelne Wörter wie ja, uhmhm, um, e: (ja), die im Alltag und auch in meinen Daten häufig als Hörersignale verwendet werden. Trotz ihres relativ bedeutungsarmen semantischen Gehalts üben sie im Gespräch verschiedene Funktionen aus: Verstehen, Zustimmung, Kenntnisnahme einer neuen bzw. unerwarteten Information, negative oder positive Bewertung, Überraschung usw.

Prozentual gesehen nehmen sowohl im deutschen als auch im japanischen Datenmaterial die Kurzformen mit großem Abstand den ersten Platz ein. Japanische Teilnehmer verwenden im Vergleich zu deutschen Teilnehmern etwas häufiger Kurzformen: Die Quoten liegen in den japanischen Daten bei 78,4\%, und in den deutschen Daten bei $65,8 \%$. 
Formen, die in den deutschen Daten besonders häufig zur Anwendung kommen, sind Kurzformen ja und $u h m h m$, in den japanischen Daten um und $e$.. Für beide Datengruppen gilt, daß über die Hälfte der verbalen Hörerreaktionen durch diese Kurzformen bzw. „aizuchi““ realisiert werden: Die Quote beträgt 54,6\% in den deutschen und 66,6 \% in den japanischen Daten. Bei letzteren ist also die Konzentration auf die beiden Formen (um und $e$ :) noch höher als bei den ersteren.

Ein geschlechterspezifischer Unterschied im Gebrauch der Kurzformen kann im japanischen Datenmaterial vermutet werden: Länger gedehnte, langsam steigend intonierte getönte he: (positive Überraschung) und $n e$ : (nicht wahr) werden in meinen Daten nur von den Frauen benutzt.

Kombinationen von Kurzformen wie ja ja ja, aja klar (im Dt.), hai hai, a: hai (im Jap.) usw. finden sich ebenfalls sowohl in den japanischen und den deutschen Daten, wobei die Quote dieses Typs in den deutschen Daten höher ist als in den japanischen (17,3\% vs. 4,8\%). KKF dienen im wesentlichen dazu, die Funktion der ersten Kurzform der KKF zu verstärken ( $j a$ ja), zu verdeutlichen (ja genau), oder verschiedene Funktionen gleichzeitig zum Ausdruck zu bringen (stimmt ja naja), außerdem können sie ggf. dafür verwendet werden, den Willen der Turnübernahme im voraus anzukündigen.

Ein-Wort-Äußerungen sind sowohl in den deutschen als auch in den japanischen Daten nur wenig zu registrieren; die Quote ist insgesamt sehr niedrig (1,4\% für die deutschen Daten und $1,8 \%$ für die japanischen Daten). Dennoch bilden sie formal und funktional einen interessanten Untersuchungsgegenstand: Formal stellen sie häufig (vollständige) Wiederholungen von Satzelementen der Sprecherrede dar. Ihre Funktionen sind dabei sehr vielfältig: Sie können ähnlich wie KF oder KKF alle o.a. Funktionen ausüben; dabei dienen sie vor allem der Vergewisserung des Gesagten, also der Verständnissicherung. Ein großer Unterschied zwischen Ein-Wort-Äußerungen und KF bzw. KKF besteht darin, daß erstere den Gegenstand des Verstehens, der Zustimmung, der Verwunderung usw. explizit benennen können.

Phrasenförmige Höreräußerungen sind sowohl in den deutschen als auch in den japanischen Daten sehr wenig vertreten (5\% für erstere und $2 \%$ für letztere). Sie können Formen darstellen, die oftmals als Hörersignale eingesetzt werden oder auch stärker aus dem aktuellen 
Kontext heraus entwickelt worden sind. Letzere enthalten daher mehrere formale oder inhaltliche Bezüge (deiktische Ausdrücke, Wiederholungen usw.) auf die Sprecheräußerungen.

„Prototypische phrasenförmige Hörersignale“ verhalten sich wie Kurzformen oder Kombinationen von Kurzformen, während hingegen vieles, was bei Ein-Wort-Äußerungen erläutert wurde, auf Phrasen zutrifft, die klare Kontextbezüge aufweisen.

Satzförmige Hörersignale lassen sich ebenso wie bei Phrasen in zwei Typen einteilen. Satzäußerungen, die in den deutschen Daten häufig als Hörersignale zum Einsatz kommen, sind solche wie das ist ja toll, die hauptsächlich Bewertungen zum Ausdruck bringen. In den japanischen Daten dagegen bestehen Satzäußerungen, die als ,aizuchi“ gelten, aus sôVarianten wie a sô desu ka (achso). Sie dienen dazu, Verstehen, langsames Verstehen oder Zustimmungen zu realisieren, wobei die Variationen je nach ihren Formulierungen feinere Nuancierungen in bezug auf die Überzeugtheit des Hörers gegenüber dem Gesagten und die vom Hörer eingeschätzte Wissensdivergenz zwischen Sprecher und Hörer übermitteln können: Beispielsweise unterscheiden sich a sô nan desu ka (aha, das wußte ich nicht) und $a$ sô desu ka (achso, ich verstehe) darin, daß erstere deutlicher die Wissenslücke des Hörers hinsichtlich des aktuellen Sachverhaltes andeutet als letztere.

Für satzförmige Höreräußerungen, die nicht als für Hörersignale prototypisch oder als „aizuchi“ angesehen werden, ist es charakteristisch, daß sie formal und/oder inhaltlich mehrere Bezüge auf die Sprecheräußerungen aufweisen, auf die sie bezogen sind; viele solcher Äußerungen sind teilweise oder gänzliche Wiederaufnahmen von Elementen der Sprecheräußerungen ((Teil)wiederholungen); außerdem können in den deutschen Daten Sätze oft deiktische Ausdrücke enthalten; während in den japanischen Daten Informationsteile (z.B. Thema, Objekt, Verb des Satzes), die vom Kontext her ergänzt werden können, getilgt werden.

Hingegen besitzen Höreräußerungen, die formal keine Wiederholungen darstellen, inhaltlichthematische Bezüge auf die Sprecheräußerungen, auf die sie zielen; dazu gehören z.B. inhaltliche Wiedergaben (Nachformulierungen), Weiterführungen des Sprecherbeitrags, inhaltliche Ergänzungen oder Kommentare zum Redebeitrag usw. Ferner können nicht „prototypische Hörersignale“ als Satzvollendungen oder Worthilfen fungieren und so den 
Turn des Sprechers vorantreiben; vor allem in den japanischen Daten sind Satzvollendungen oder Vorwegnahmen relativ oft vertreten.

Ferner können nicht „prototypische Satzäußerungen“ wie „prototypische Hörersignale“ diverse Einstellungen des Hörers zum Gesagten zum Ausdruck bringen, wie bereits gezeigt wurde; abgesehen davon können sie explizit den Gegenstand des Verstehens, der Bewertung, der Zustimmung oder der emotionalen Regung oder Einstellungen des Hörers gegenüber dem Gesagten benennen und ausführlich darlegen (Kommentare).

Einige der nicht „prototypischen Satzäußerungen“ klingen in manchen Kontexttypen stereotypisch oder floskelhaft wie z.B. kann man nur hoffen, du kannst ja nichts dafür usw.

Aus den o.a. Ergebnissen können folgende Thesen aufgestellt werden:

- Die Hörerrückmeldung stellt ein routiniertes und mustergesteuertes Verhalten dar, das in regelmäßigen Abständen immer wieder fast ohne Nachdenken ausgeführt wird; dabei bedient sich der Hörer zum großen Teil des Reservoirs konventionalisierter Formen.

- Der Hörer bevorzugt beim Feedback kurze verbale Hörersignale, die standardisiert sind, viel eher als längere kontextbezogene Höreräußerungen, die raumeinnehmender sind; dies hängt womöglich mit der kurzen Reaktionszeit zusammen, die der Hörer zur Verfügung hat; der Hörer muß während des Turns des Sprechers verschiedene Tätigkeiten (hören, verstehen, erwidern) blitzschnell erledigen, um den Gesprächsverlauf nicht unnötig zu verlangsamen.

- Der Formengebrauch der Hörersignale ist zwar in beiden Sprachgruppen hochgradig standardisiert; die Ergebnisse deuten jedoch darauf hin, daß der Grad der Normiertheit in den japanischen Daten tendenziell stärker ausgeprägt ist als in den deutschen Daten. 


\subsection{Positionen der Hörersignale}

Die Frage, wo und wie häufig im Verlauf von Sprecheräußerungen Hörersignale plaziert werden, ist in einigen Studien (vor allem über das Englische und das Japanische) aufgegriffen und quantitativ untersucht worden. Dabei wurden einige Regularitäten in der Plazierung von Hörersignalen festgestellt. In diesem Kapitel wird ebenfalls dieser Frage nachgegangen, wobei hauptsächlich syntaktische Einheiten, die einem Satz entsprechen, untersucht werden.

Der zweite Untersuchungsschwerpunkt dieses Kapitels besteht darin, Hörersignale nach der Art ihrer Plazierung (die überlappte Plazierung oder Pausenplazierung) zu analysieren. Hörersignale werden nämlich nicht nur an Wort-, Phrasen- und Satzgrenzen plaziert, sondern überschneiden sich oft mit Sprecheräußerungen. Die genauere Betrachtung dieses Phänomens ist von großer Bedeutung, weil die Plazierungsart der jeweiligen Hörersignale unterschiedliche Hinweise für den Verstehensstand des Hörers übermittelt. Die Leitfragen sind dabei, ob Hörersignale überlappt oder in der Pause gesetzt werden, und wie verschiedene Plazierungsfälle in den jeweiligen Positionen im Satz zu erklären und zu interpretieren sind.

Im folgenden wird als erstes auf die Positionen sowie die Plazierungstypen der Hörersignale in den deutschen Daten eingegangen. Es wird ein Unterkapitel vorausgeschickt, in dem die Positionsbegriffe vorgestellt und erklärt werden. Nach der Darstellung und der Interpretation der Ergebnisse der deutschen Daten werden die japanischen Daten behandelt. Anschließend werden in einem Fazit die Ergebnisse beider Sprachgruppen miteinander verglichen und zusammengefaßt.

\subsubsection{Die Positionen der Hörersignale in den deutschen Daten}

Da es bezüglich der Positionen der Hörersignale kaum Untersuchungen über das Deutsche gibt, soll zuerst festgestellt und aufgezeigt werden, wo in der Sprecherrede Hörersignale wie oft auftreten. Der Schwerpunkt der Untersuchung bilden in diesem Kapitel Sätze, nach deren Felderstruktur die Positionen der Hörersignale ermittelt werden. Das soll dazu dienen, sich einen groben Überblick über die Positionierung der Hörersignale zu verschaffen.

Ferner werden die Hörersignale nach ihrer Plazierungsart (überlappt und in der Pause plaziert) charakterisiert. Dabei stellt sich die Frage, wie viele Hörersignale in Pausen oder in Überlappung mit der Sprecheräußerung auftreten und warum dies geschieht. 
Nachfolgend werden die Positionsbegriffe sowie die Plazierungstypen erläutert.

\subsubsection{Die Bestimmung der Analysekategorien}

$\underline{\text { Die Positionsbegriffe nach der Felderstruktur }}$

Die Felder eines Satzes werden wie folgt kategorisiert: ${ }^{249}$

- Vorvorfeld (VVF) (linker Außenrand): Dazu gehören Konjunktionen, Konjunktionaladverbien, Formulierungen am Satzanfang wie gut, klar, O.K., Antwortpartikeln wie ja, nein, doch usw.

- Vorfeld (VF): die Position vor dem finiten Verb; dazu gehören Subjekte und topikalisierte Elemente.

- Linke Satzklammer (LK): die Position des finiten Verbs bei der Verbzweitstellung.

- Mittelfeld (MF) und (slW): Das letzte Inhaltswort des MF (slW) wird von den anderen getrennt, weil Hörersignale häufig in der Position des slW und in der folgenden Pause auftreten.

- Rechte Satzklammer (RK/slV): die Position, die durch den abhängigen Teil des Verbalkomplexes besetzt ist. Das letzte Verb der RK (slV) wird von den anderen Verben abgegrenzt; die Differenzierung rechtfertigt sich durch die relativ hohe Konzentration der Hörersignale in der Position des slV und der Pause nach dem slV.

- Nachfeld (NF): Es setzt sich zusammen aus „Etceteraformeln“ (ETC) wie oder so, und so und „Sprechersignalen“250 wie ja, oder, ne (SS) ${ }^{251}$ usw. und/oder einer oder mehreren ausgeklammerten Phrasen (AK).

Da das Ziel dieses Kapitels darin besteht, die Positionierungen der Hörersignale in bezug auf die Stellungsfelder des Satzes aufzuzeigen, werden satzwertige Äußerungen, die sich nicht in die Felderstruktur einordnen lassen, aus der Untersuchung ausgeschlossen. Dazu gehören vor allem nominale Ellipsen, denen das Prädikat fehlt. Ebenfalls werden Satzabbrüche, die sich nicht mehr zu einem vollständigen Satz rekonstruieren lassen, oder Hörersignale des Sprechers auf Hörersignale des Hörers wie ja, uhmhm, richtig usw. hier nicht berücksichtigt.

\footnotetext{
${ }^{249}$ Siehe Maibauer (1999, S. 135).

${ }^{250}$ Zur Bezeichnung Schwitalla (1997, S. 50).
} 
Als Sätze gelten in dieser Arbeit folgende syntaktische Einheiten, die sich meines Erachtens in die Felderstruktur eingliedern lassen können: ${ }^{252}$

- Sätze: SVO(V)- und SOV(V)-Satztypen

- Infinitivphrase mit oder ohne $z u$

In der linearen Ordnung sieht z.B. die Felderstruktur des SVO-Typs folgendermaßen aus:

\begin{tabular}{|l|l|l|l|l|}
\hline VVF & VF & MF & SlW d. MF & NF \\
\hline $\begin{array}{l}\text { Konjunktionen, } \\
\text { Antwortpartikeln }\end{array}$ & $\begin{array}{l}\text { Subjekte, } \\
\text { topikalisierte } \\
\text { Satzglieder }\end{array}$ & Elemente zw. VF u. slW & $\begin{array}{l}\text { MF-letztes } \\
\text { Element }\end{array}$ & $\begin{array}{l}\text { Etceteraformeln, } \\
\text { Sprechersignale } \\
\text { Ausklammerungen }\end{array}$ \\
\hline
\end{tabular}

Hingegen haben Sätze mit dem SVOV-Typ die folgenden Stellungsfelder:

\begin{tabular}{|l|l|l|l|l|l|}
\hline VVF & VF & MF & RK & SlV d.RK & NF \\
\hline $\begin{array}{l}\text { Konjunktionen, } \\
\text { Antwortpartikeln }\end{array}$ & $\begin{array}{l}\text { Subjekte, } \\
\text { topikalisierte } \\
\text { Satzglieder }\end{array}$ & $\begin{array}{l}\text { Elemente zw. } \\
\text { VF u. slW }\end{array}$ & $\begin{array}{l}\text { Verben vor dem } \\
\text { letzten Verb }\end{array}$ & $\begin{array}{l}\text { das letzte } \\
\text { Verb }\end{array}$ & $\begin{array}{l}\text { Etceteraformeln, } \\
\text { Sprechersignale, } \\
\text { Ausklammerungen }\end{array}$ \\
\hline
\end{tabular}

Satzelemente des SOV(V)-Satztyps werden in meiner Arbeit in die folgenden Felder eingeteilt:

\begin{tabular}{|l|l|l|l|l|l|}
\hline VVF & VF & MF & RK & SlV d.RK & NF \\
\hline $\begin{array}{l}\text { Konjunktionen, } \\
\text { Antwortpartikeln }\end{array}$ & $\begin{array}{l}\text { das erste Satzglied } \\
\text { nach dem VVF }\end{array}$ & $\begin{array}{l}\text { Elemente zw. VF } \\
\text { u. slW }\end{array}$ & $\begin{array}{l}\text { Verben } \\
\text { vor dem letzten } \\
\text { Verb }\end{array}$ & $\begin{array}{l}\text { das letzte } \\
\text { Verb }\end{array}$ & $\begin{array}{l}\text { Etceteraformeln, } \\
\text { Sprechersignale, } \\
\text { Ausklammerungen }\end{array}$ \\
\hline
\end{tabular}

Zuletzt wird die Feldereinteilung der Infinitivkonstruktion vorgestellt:

\begin{tabular}{|l|l|l|l|l|}
\hline VVF & MF & RK & S1V d.RK & NF \\
\hline $\begin{array}{l}\text { Konjunktionen, } \\
\text { Antwortpartikeln }\end{array}$ & $\begin{array}{l}\text { Elemente zw. } \\
\text { VF u. slW }\end{array}$ & $\begin{array}{l}\text { infinite Verben } \\
\text { vor dem letzten } \\
\text { Verb }\end{array}$ & $\begin{array}{l}\text { das letzte } \\
\text { infinite Verb }\end{array}$ & $\begin{array}{l}\text { Etceteraformeln, } \\
\text { Sprechersignale, } \\
\text { Ausklammerungen }\end{array}$ \\
\hline
\end{tabular}

${ }^{251}$ Solche Ausdrücke werden „Gliederungssignale“ genannt: Schwitalla (1997, S. 54-55), Weinrich (1993, S. 829) usw.

${ }^{252}$ Es gibt viele Satzdefinitionen von syntaktischen, semantischen, pragmatischen Standpunkten aus (siehe Bünting/Bergenholz 1989). 


\section{$\underline{\text { Die Bestimmung der Typen der Plazierung der Hörersignale }}$}

Es sind grundsätzlich zwei Typen der Plazierung der Hörersignale zu unterscheiden: ${ }^{253}$

- die überlappte Plazierung und

- die Pausenplazierung.

Zwei häufig beobachtete Arten der Plazierung, die die Überlappung zur Folge haben, sind:

- die Überlappung mit versetztem Beginn zu einem Satzelement der Sprecheräußerung und

- die Überlappung mit gleichzeitigem Beginn mit einem Satzelement der Sprecheräußerung.

Ebenso läßt sich die Pausenplazierung weiter unterteilen in:

- die Pausenplazierung direkt nach einem Satzelement ${ }^{254}$ oder kurz nach dem Beginn der Pause $^{255}$ und

- die Pausenplazierung nach längerer Verzögerung als „kurz nach dem Beginn der Pause“.

In beiden Fällen ist die Spätüberlappung möglich, d.h. Hörersignale werden zwar in der Pause plaziert, überlappen sich jedoch später mit dem nächsten Wort, weil sie über die Pause hinaus gedehnt werden.

4.3.1.2 Die Gesamtübersicht der Distribution der Hörersignale in den verschiedenen Feldern des Satzes

Die prozentuale Verteilung der Hörersignale in den deutschen Daten sieht folgendermaßen aus:

\footnotetext{
${ }^{253}$ Die Plazierungstypen weisen eine gewisse Affinität zu den Typen des Turnwechsels, die Sacks et al. (1974) aufgestellt haben, auf.

${ }^{254}$ Diese Art der Plazierung stellt eine Äquivalent zu den Begriffen von Sacks et al.: „no gap“ und „,no overlap“ (1974, S. 700) dar.

${ }^{255}$ Ebenso kann man sagen, daß dieser Plazierungstyp dem Turnwechsel mit „slight gap“ bei Sacks et al. entspricht (1974, S. 700). In meinen Daten werden Hörersignale, die an Satzgrenzen plaziert werden, zum großen Teil kurz nach dem Beginn der Pause eingesetzt.
} 
Abbildung 5

\section{Die prozentuale Verteilung der Hörersignale}

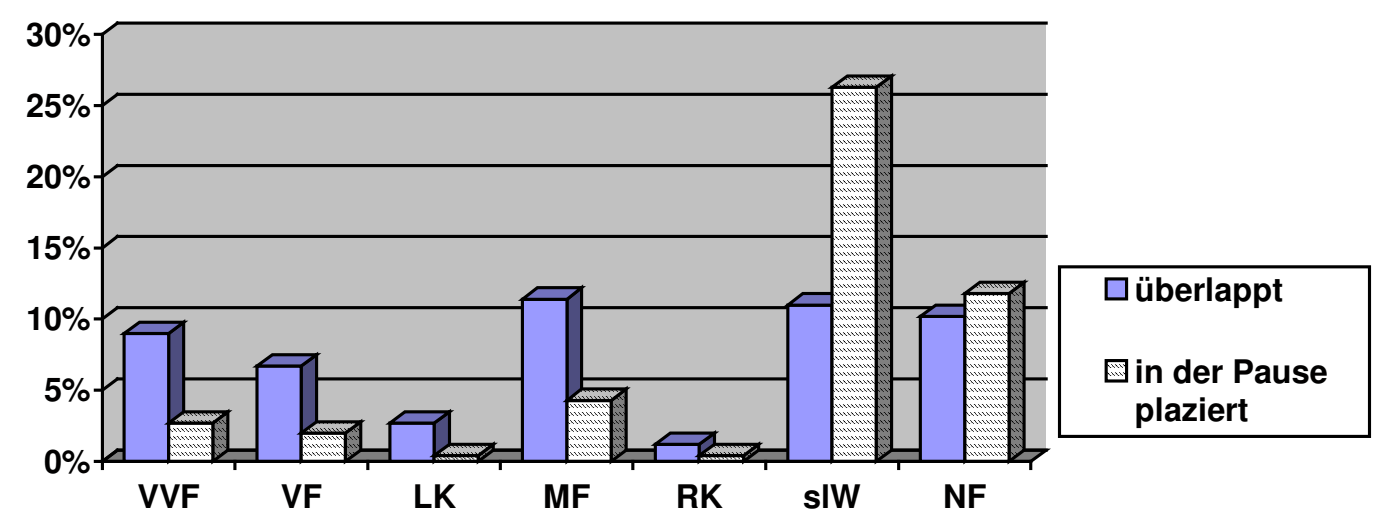

Es ist ersichtlich, daß Hörersignale in der Pause nach dem satzletzten Wort (slW) bzw. dem satzletzten Verb (slV) am häufigsten auftreten. Außerdem lassen sich Hörersignale relativ oft im MF, VVF, NF sowie in der Position des letzten Inhaltswortes oder Verbs und in der folgenden Pause beobachten.

Drittens ist die Anzahl der überlappten Hörersignale in fast allen Feldern höher als die Anzahl der nicht überlappten; die einzige Ausnahme bildet die Pause direkt nach dem satzletzten Inhaltswort (slW) bzw. Verb (slV). Dort fällt der prozentuale Anteil der nicht überlappten Hörersignale merklich höher aus als der der überlappten. Insgesamt übertrifft jedoch die Gesamtüberlappungsquote die Quote der Pausenplazierung: Aus der Berechnung ergibt sich, daß die überlappten Hörersignale 52,2\% aller hier berücksichtigten Hörersignale ausmachen. Die Überlappungsquote ist in meinen Daten überraschenderweise viel höher als bei einigen anderen Studien; diese berichten, daß sich die überwiegende Mehrheit der Hörersignale in Pausen befindet. ${ }^{256}$

Im folgenden werden zuerst die in der Pause plazierten Hörersignale in den jeweiligen syntaktischen Satzfeldern erläutert. Im Mittelpunkt der Beschreibung stehen dabei die Kurzformen sowie die kombinierten Kurzformen, weil beide die zwei am häufigsten verwendeten Klassen der Hörersignale darstellen.

\footnotetext{
${ }^{256}$ Die Quoten der nicht überlappten Hörersignale sind bei mir viel niedriger als bei Sawada (1991, S. 72). Bei ihr sind 80\% der Hörersignale Erwiderung auf Pausen. Das könnte eventuell daran liegen, daß Hörersignale in meiner Untersuchung nicht darauf untersucht wurden, ob sie von Pausen losgelöst auftreten können oder nicht.
} 


\subsubsection{Die Hörersignale im VVF und in der Pause nach dem VVF}

\section{$\underline{\text { Hörersignale, die sich im VVF befinden }}$}

Die Quote der Hörersignale, die sich im VVF befinden, liegt bei 9\%. Viele von ihnen sind jedoch mit dem ersten Element des VVF, wie Konjunktionen, Konjunktionaladverbien wie also, und, aber oder topikalisierte Elemente, überlappt. Die betreffenden Hörersignale sind direkt nach dem Vollzug des letzten Satzes plaziert und zielen dabei auf den vorangegangenen Satz. Die Überlappung entsteht in solchen Fällen dadurch, daß der Sprecher das VVF direkt an das slW bzw. sIV oder das NF anschließt, ohne dabei eine Pause einzulegen, so daß der Hörer keine Möglichkeit hat, Hörersignale in die Pause hineinzuschieben. Dies wird an einem folgenden Beispiel dargelegt:

Gesprächskontext 10

Frauke erzählt von der Qualitätssicherung in der Organisation, in der sie angestellt ist.

$1 \quad \mathrm{KA}$

FK das ist jetzt son handbuch mit so stichworten das als modell

$2 \quad \mathrm{KA} \Rightarrow$ uhmhm

FK dient und das kommt jetzt irgendwie in den nächsten zwei

\begin{tabular}{|ll}
\hline 3 & KA \\
& FK
\end{tabular} uhmhm

In Zeile 2 setzte Frauke, nachdem ein komplexer Satz vollzogen war, ihre Rede sofort mit und fort, ohne dort eine Pause einzulegen; das führte dazu, daß das uhmhm von Klara auf das nächste Wort fallen mußte, obwohl sie das Signal sofort nach dem Vollzug des slV (dient) eingesetzt hatte. Das Hörersignal uhmhm in Zeile 3 ist ein Beispiel für die Pausenplazierung nach dem slV. In beiden Fällen löste die grammatische Vollendung des Satzes die Hörersignale von Klara aus.

Neben den rechtzeitig gesendeten Hörersignalen gibt es sporadisch auch solche, die im VVF plaziert werden, obwohl vor dem VVF Pausen an Satzgrenzen vorhanden sind. Solche Fälle können als verspätete Reaktionen des Hörers auf den vorigen Satz betrachtet werden. 


\section{Die Hörersignale in der Pause in/nach dem VVF}

In der Pause in/nach dem VVF befinden sich insgesamt 2,7\% der Hörersignale. Sie sind oft in der Pause nach dem ersten Wort des VVF plaziert und sind auf die vorangegangene Satzinformation bezogen. Die Plazierung der Hörersignale erst in der Pause in/nach dem VVF kommt ähnlich wie bei den überlappten Fällen dadurch zustande, daß der Sprecher nicht direkt nach dem slW bzw. slV, sondern erst nach dem ersten Wort des VVF Pausen macht; so bilden der vorangegangene Satz und das erste Wort des nächsten Satzes eine intonatorische Einheit. Der Hörer wartet dabei mit der Rückmeldung, bis eine günstige Gelegenheit sprecherseits geboten wird. Dies kann meines Erachtens als Ausdruck der Anpassung und der Kooperationsbereitschaft des Hörers angesehen werden.

Ferner gibt es in der Pause des VVF oder nach dem VVF Hörersignale, die mit merklicher Verspätung geäußert werden, wobei diese zahlenmäßig viel weniger vertreten sind.

\subsubsection{Die Hörersignale im VF und in der Pause in/nach dem VF}

Im VF sind Hörersignale generell weniger oft plaziert: Die Hörersignale, die dort anzutreffen sind, betragen insgesamt 6,7\% aller hier behandelten Hörersignale. Wie im VVF überlappen sich hierbei auch viele der im VF eingesetzten Hörersignale nur mit dem ersten Wort des VF, vor allem wenn dieses das erste Wort des nächsten Satzes darstellt. Solche Hörersignale werden in der Regel direkt nach dem Satzende geäußert, um das Verstehen des vorangegangenen Satzes zu bestätigen. Der Hauptgrund für die Überschneidung liegt ebenfalls darin, daß der Sprecher an Satzgrenzen entgegen der Erwarten des Hörers keine Pause einlegt, sondern im direkten Anschluß an den letzten Satz seine Rede fortsetzt.

Außerdem gibt es (selten) Hörersignale, die sich auf eine Phrase im VF oder den aktuell laufenden Satz beziehen. Für eine verbale Hörerreaktion ist jedoch die Informationsmenge im VF in der Regel nicht ausreichend.

Die Quote der Hörersignale in der Pause in oder nach dem VF ist ziemlich niedrig (2\%). Das erklärt sich ebenfalls dadurch, daß Informationsträger im VF zur Evozierung eines verbalen Hörersignals noch keine genügende Menge an Informationen beinhalten. ${ }^{257}$ Außerdem

\footnotetext{
${ }^{257}$ White erzielt jedoch andere Ergebnisse: Sie stellt in ihren englischen Daten fest, daß vorangestellte „Topic“Phrasen, die mit Pausen usw. auffällig hervorgehoben werden, häufig Hörersignale nach sich ziehen:
} 
existieren kaum natürliche Sprechpausen nach dem VF in den deutschen Daten. Da die Anzahl der Hörersignale in dieser Position so gering ist (insgesamt nur 5 Hörersignale), läßt sich kaum etwas über Tendenzen aussagen.

\subsubsection{Die Hörersignale in der LK und in der Pause nach der LK}

Hörersignale sind in der LK relativ wenig distribuiert: 2,7\% der Hörersignale werden überlappt mit der LK eingesetzt. Die Überlappung der Hörersignale mit der LK läßt sich ebenfalls auf fehlende Pausen in den vorangegangenen Positionen oder auf Verstehensschwierigkeiten seitens des Hörers zurückführen; es gibt jedoch auch Fälle, in denen man annehmen kann, daß Hörersignale das vorzeitige Verstehen des betreffenden Satzes signalisieren.

Zwischen der LK und dem MF wird lediglich ein Hörersignal plaziert. Als Erklärung gilt hierbei das Gleiche wie in bezug auf die Pause nach dem VF.

\subsubsection{Die Hörersignale im MF und in der Pause im MF}

11,4\% der Hörersignale sind mit Elementen (außer dem letzten Wort) des MF überlappt. ${ }^{258}$ Die Quote der Hörersignale im MF fällt zum Teil deswegen höher aus, weil im MF am meisten Satzelemente enthalten sind; einige von ihnen liefern dem Hörer relevante Informationen für den Verstehensprozeß.

Die Überlappung kann hierbei prinzipiell gleichzeitig oder versetzt mit einem Wort beginnen.

Die meisten Hörersignale im MF lassen sich als vorzeitige Reaktion des Hörers auf den aktuell laufenden Satz einstufen; damit übermittelt der Hörer also dem Sprecher, daß er den betreffenden Satz für bereits erfaßt hält, bevor der Satz grammatikalisch komplett geäußert worden ist. Die (vermeintlich) frühzeitige Erschließung der Bedeutung des Satzes ist in vielen Fällen darauf zurückzuführen, daß oft der unmittelbar vorangegangene Informationsträger die Kerninformation oder einen Teil der für den Verstehensprozeß des Hörers relevanten Informationen des Satzes liefert, wodurch die Sprecherintention sowie die Satzbedeutung nach dem Vollzug der betreffenden Informationseinheit transparenter wird. Der Hörer, der

Hörersignale treten in etwa 30\% der Gesamtzahl solcher Umgebungen auf. Hingegen sinkt die Quote bei als Subjekt fungierenden Phrasen auf 17\% (1986, S. 75, 77).

${ }^{258} \mathrm{Im}$ MF ist das letzte Wort im MF nicht enthalten; das letzte Wort wird gesondert behandelt. 
sich des Verstehens der betreffenden Satzinformation sicher ist, sendet Hörersignale und markiert so das Verstehen des vorangegangenen Informationsträgers und gleichzeitig den Endpunkt der frühzeitigen Verarbeitung des noch nicht abgeschlossenen Satzes. Die Frühplazierung der Hörersignale dieser Art läßt sich meines Erachtens als ein Beweis dafür ansehen, daß der Hörer versucht, den Sprecherplan seinerseits zu rekonstruieren; ${ }^{259}$ in manchen Fällen gelingt es dem Hörer, das Gesagte sowie das Gemeinte des Sprechers (weit) im voraus zu erschließen, bevor der betreffende Satz gänzlich zu Ende geführt wird. Ferner ist es für diese Art Hörersignale charakteristisch, daß sie normalerweise vom Hörer eigenmächtig, also ohne Aufforderung von seiten des Sprechers geäußert werden. ${ }^{260}$

Nachfolgend wird zur Veranschaulichung ein Beispiel vorgeführt, in dem das hörerseitige Erschließen der Satzbedeutung des aktuell laufenden Satzes angedeutet wird:

Gesprächskontext 11

Friedrich, der selber Jurist ist, behauptet, daß man im Fach Jura in zwei Jahren eine Doktorarbeit abschließen kann; für Roby, der VWL studiert hat, war dies unvorstellbar:

$\begin{array}{lll}1 & \text { FR } & \text { also man kann es in zwei jahren eigentlich schaffen }\end{array}$ $\mathrm{RB}$

2 FR muß ich sagen ja kann man wenn man sich da RB in zwei jahren doch ja so schnell

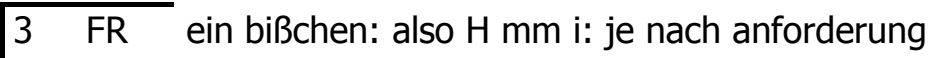
RB $\quad \Rightarrow$ uhmhm

In Zeile 3 setzte Roby das Hörersignal uhmhm, um zu zeigen, daß er sich die Reste des Satzes vorstellen kann; so machte er die weitere Ausführung überflüssig. Dementsprechend brach Friedrich den Satz ab und ging zum nächsten Aspekt über. ${ }^{261}$

Ferner finden sich manche Hörersignale, die sich nicht eindeutig interpretieren lassen, weil in ihrer unmittelbaren Nähe keine Informationsträger vorhanden sind, die Hörersignale hervorrufen könnten; solche Hörersignale sind meines Erachtens nur als Fortsetzungssignal interpretierbar.

\footnotetext{
${ }^{259}$ Vgl. Rehbein 1977, S. 190.

${ }^{260}$ Nach Rath (1979, S. 124) gibt es Hörersignale im Deutschen, die unabhängig vom Sprecher an für den Hörer strategisch wichtigen Stellen gesetzt werden.
} 
Seltener sind Fälle, in denen Hörersignale mit großer Verspätung auf die vorangegangene Satzinformation gerichtet sind. Des weiteren finden sich ebenso wenig Hörersignale, die direkt nur auf die vorangegangene kleinere Informationseinheit wie die eines Wortes oder einer Phrase ausgerichtet sind.

In der Pause innerhalb des MF treten 4,3\% der Hörersignale auf. Sie sind entweder auf den aktuell laufenden Satz oder auf den unmittelbar vorangegangenen Informationsträger, der häufiger das Stichwort des betreffenden Satzes darstellt, bezogen.

\subsubsection{Die Hörersignale im slW bzw. slV und in der Pause nach dem slW bzw. slV}

Hörersignale, die sich mit dem slW bzw. slV überlappen

Hörersignale, die sich mit dem slW bzw. slV überlappen, lassen sich im deutschen Datenmaterial relativ häufig beobachten: 11,3\% aller hier berücksichtigten Hörersignale überlappen sich mit dem slW bzw. slV.

Die Überlappung kann hierbei sowohl den gleichzeitigen als auch den versetzten Beginn mit dem slW bzw. slV beinhalten, wobei oft nur die letze(n) Silbe(n) des betreffenden Wortes oder des (finiten)Verbs von der Überlappung betroffen ist/sind. Im letzteren Fall handelt es sich um die frühzeitige Plazierung, für die jedoch keine so schnelle Auffassungsgabe des Hörers erforderlich ist wie für Hörersignale im MF, weil zu dem Zeitpunkt der Überlappung (wie z.B. mit der letzten Silbe des slV) bereits fast alle wichtigen Informationen des Satzes gegeben sind.

Bezüglich der Frage, was den Hörer motiviert, Hörersignale (bewußt) frühzeitig zu senden, obwohl er dadurch die Überlappung verursacht und überlappte Satzelemente nur mit verringerter Aufmerksamkeit wahrnehmen kann, können an dieser Stelle nur einige Vermutungen angestellt werden: Erstens können frühzeitig gesendete Hörersignale dem Sprecher anzeigen, daß er ohne weiteres mit der Rede fortfahren kann, weil der Hörer so gut folgt, daß er die betreffende Satzinformation sogar frühzeitig mental verarbeitet hat. ${ }^{262}$ Demnach können die Hörersignale der Frühreaktion den Effekt erzielen, die Sprecherrede

\footnotetext{
${ }^{261}$ Funktionen der Frühplazierung der Hörersignale werden beim slW und bei der RK ausführlicher behandelt.

${ }^{262}$ Duncan (1974, S. 179 ) deutet auch die Frühplazierung ähnlich.
} 
zügig voranzutreiben, ${ }^{263}$ indem sie weitere Ausführungen zum aktuellen Thema verhindern. Außerdem ist die kurze Überlappung mit Elementen des VF oder des VVF für den Sprecher nicht weiter störend. ${ }^{264}$

Darüber hinaus kann die verfrühte, überlappte Plazierung in manchen Fällen über frühzeitiges Verstehen hinaus noch die hörerseitige Übersättigung mit dem aktuellen Thema zum Ausdruck bringen, so daß einige der so plazierten Hörersignale etwas ungeduldig wirken: Der Hörer will das aktuelle Thema nicht mehr weiter ausgeführt bekommen, weil er alles schon gut verstanden hat. Dafür sei hier ein Beispiel angeführt:

Gesprächskontext 12

Es geht um die Griechischkenntnisse von Hanna. Hanna hat einmal für eine griechische Delegation gedolmetscht, aber nicht Griechisch-Deutsch, sondern Englisch-Deutsch. Sie kennt aber ein paar Begrüßungsformeln auf Griechisch.

$1 \quad \mathrm{HN}$ ich hab dann natürlich englisch deutsch übersetzt na

$\mathrm{AL} \quad \Rightarrow j a$

$2 \mathrm{HN}$ so gut kann ich es auch nicht aber halt kleine

$\mathrm{AL} j a \quad \Rightarrow j a: \cdots::$

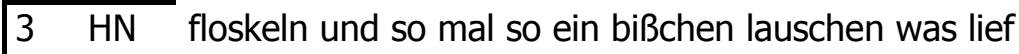

$\mathrm{AL} \quad \Rightarrow$ ja::::::::.ja::

$4 \quad \mathrm{HN}$ konnte ich

$\mathrm{AL} \quad \Rightarrow$ uhmhm

Die gänzliche Überlappung mit dem slW befindet sich in Zeile 4; außerdem ist die Teilüberlappung mit dem slW in Zeile $2 \mathrm{zu}$ sehen. $J a$ in Zeile 1 ist ein Beispiel für die Pausenplazierung nach dem NF (dem Sprechersignal $n a$ ). In diesem Beispiel wird deutlich, daß die Hörersignale deswegen überlappt mit der Sprecherrede gesendet wurden, weil Hanna an dieser Stelle wiederholt aussagte, wie wenig Griechisch sie kann (ich kann es nicht, kleine Floskeln, ein bißchen lauschen). Alex hat schon alles verstanden und wurde wohl langsam ungeduldig, was allein an der erhöhten Anzahl der Hörersignale und an der

\footnotetext{
${ }^{263}$ Duncan (1974, S. 179) ist auch der Meinung, daß die Frühplazierung die Funktion ausübt, den Fortgang des Sprecherbeitrags zu beschleunigen.

${ }^{264}$ Für das Englische argumentiert Goodwin (1986, S. 208), daß „,continuers“, die sich mit dem Beginn der nächsten Einheit überlappen, den Sprecher am Fortgang der Rede nicht weiter hindern.
} 
Plazierungsposition zu erkennen ist. Die überlappten Hörersignale in dieser Position lassen sich nicht unbedingt mit dem Willen zur Turnübernahme in Verbindung bringen, denn in den deutschen Daten findet sich nur ein einziger Fall, in dem ein Hörersignal, das sich mit dem satzletzten Element überlappt, den Turnwechsel eingeleitet hat.

Hörersignale in den Pausen nach dem slW bzw. slV

Es ergibt sich aus der Berechnung, daß Hörersignale am häufigsten in der Pause nach dem letzten Inhaltswort wie Nomen, Adjektiv, Verb usw. auftreten. Dies läßt sich meines Erachtens auf folgende Faktoren zurückführen: In der Position des slW bzw. slV wird in der Regel eine größere syntaktische Einheit wie ein Satz sowohl syntaktisch und informativ fast zu Ende geführt, es sei denn, daß ausgeklammerte Phrasen im NF stehen. Diese Menge von Informationen, die etwa einen Satz bzw. Nebensatz umfaßt, bildet eine Informationseinheit, die der Hörer ohne große Anstrengung auf einmal verarbeiten kann. ${ }^{265}$ Die große Relevanz der Satzgrenze für den Verstehensprozeß des Hörers offenbart sich im nachstehenden Zitat: ${ }^{266}$

"Psycholinguistic research on sentence processing strategies [...] suggests that sentences are generally perceived one clause at a time. After each clause is processed, its surface structure is erased from short-term memory and the underlying meaning is stored in working memory. Underlying meaning is generally defined as a proposition [...]. Listeners hold the propositions in working memory as units and erase them from memory soon after they have passed sentence boundary".

So markiert der Hörer womöglich mittels Hörersignalen für sich den Endpunkt einer Informationsmenge, die bereits den Verstehensprozeß durchlaufen hat, ${ }^{267}$ um dann den Kopf für weitere Informationen ,freiräumen“ zu können. Gleichzeitig bestätigt er für den Sprecher den Empfang und das Verstehen.

Ein weiterer Grund besteht darin, daß der Sprecher häufig nach dem slW bzw. slV Sprechpausen einlegt, wenn der betreffende Satz damit abgeschlossen werden soll. Die Pausen helfen dem Hörer dabei, das Ende einer syntaktischen Einheit wie die eines Satzes zu

\footnotetext{
${ }^{265}$ Siehe White 1986, S. 98; sie zieht einige psycholinguistische Forschungen heran, die sich mit dem ,sentence processing“ befassen. Nach Mizutani kann man die Informationsmenge eines Satzes oder Nebensatzes problemlos aufnehmen (1988a, S. 7).

${ }^{266}$ White 1986, S. 98
} 
erkennen. Daß Pausen einen effektiven Stimulus der Hörersignale darstellen, wurde bereits in einigen Forschungen erwiesen. ${ }^{268}$

Satzenden sind ebenfalls für den Sprecher in bezug auf den weiteren Verlauf seines Redebeitrags von Gewicht, weil er in jenen Positionen den Verstehensstand des Hörers überprüft, um zu wissen, wie er weiter mit seiner Rede fortfahren kann; je nach dem Verstehensstand des Hörers muß die Rede modifiziert werden. Pausen dienen dem Sprecher in zweierlei Hinsicht: Einmal kann er damit versuchen, verbale Hörerrückmeldungen zu evozieren; zum anderen gewinnt er Zeit zur Planung der weiteren Rede. ${ }^{269}$ Abgesehen von Pausen können auch prosodische und nonverbale Mittel wie die Intonationskontur oder der Blickkontakt an Satzenden einen Einfluß auf das Hörerverhalten geben. ${ }^{270}$

Was die Art der Plazierung der Hörersignale in Pausen nach dem sIW bzw. sIV angeht, finden sich in meinen Daten zwei Typen, die bereits aufgelistet wurden. Hörersignale werden im deutschen Datenmaterial zumeist kurz nach dem Beginn der Pause eingesetzt und fallen so in die Pause hinein oder folgen ihr nach. Hingegen ist die Pausenplazierung nach längerer Verzögerung relativ selten.

Hörersignale, die kurz nach dem Beginn der Pause gesendet werden, werden, abgesehen von der syntaktischen sowie informativen Abgeschlossenheit, womöglich auch durch die Pausen des Sprechers motiviert. Dabei ist es für den Hörer außer einer schnellen Auffassungsgabe erforderlich, daß er bereits erahnt, wann in der Sprecherrede Pausen entstehen können, um in kürzester Zeit darauf reagieren zu können.

\footnotetext{
${ }^{267}$ Rehbein nennt Hörersignale „Extozen des Hörerplans“, die die vermeintlich erfolgreiche Nachbildung des Sprecherplans zwischendurch dokumentiert (1977, S. 190, 193).

${ }^{268}$ White fand heraus, daß nur 2\% der Hörersignale an Satzenden plaziert werden, die nicht mit Pausen versehen sind; hingegen liegt die Quote der Hörersignale, die an Satzenden mit Pausen auftreten, bei 34\% (1986, S. 99). Maynard ist der Ansicht, daß die Mehrheit der Hörersignale in der Pause auftritt (1986, S. 1096). Wahmhoff/Wenzel behaupten, daß Pausen auf jeden Fall Auslöser der Hörersignale sind (1979, S. 275).

269 Nach Rehbein (1977, S. 189) nimmt der Sprecher bezüglich Erfolg und Korrektheit seines Sprechhandlungsplans eine permanente Überprüfung vor, indem er die Reaktionen des Hörers ständig kontrolliert.

${ }^{270}$ Nach Duncan bildet die Blickbewegung des Sprechers zum Hörer an Satzenden einen zweiten Faktor für das Auftreten der Hörersignale (1974, S. 172). Nach H. Schmidt (1983, S. 45 und 59) ruft die klar absinkende Intonation mit zugleich zurückgehender Intensität, die die Finalität andeutet, sehr oft Hörersignale hervor. Hingegen geht die Frequenz der Hörersignale bei ansteigender Intonation, die die Fortsetzung signalisiert, merklich zurück.
} 
Diese Art der Pausenplazierung kann als eine perfekte Koordination der Sprecher- und Hörerhandlungen und zugleich als Kooperation zwischen dem Sprecher und dem Hörer betrachtet werden, vor allem, wenn die Hörersignale gänzlich in die Pause hineinpassen; hier ist die exakte Plazierung in der Pause fast eine Sache der Geschicklichkeit. In diesem Fall paßt sogar die japanische Metaphorik des Gegenhammers, also ,aizuchi“, zu einigen deutschen Hörersignalen. Die rechtzeitig und gänzlich in die Pause hineingeschobenen Hörersignale füllen wie der Gegenschlag des Hammers die Pause des Hauptschlags, also die Lücken der Sprecherrede und treiben so die Rede weiter voran. Dabei verhalten sich Sprecher und Hörer gegenseitig kooperativ und rücksichtsvoll, denn der Hörer geht auf den Wunsch des Sprechers ein, ihm den Verstehensstand zu übermitteln; der Sprecher wartet hingegen mit der Fortsetzung seiner Rede, bis die Höreräußerung vollzogen ist. Dies wird im nachfolgenden Beispiel veranschaulicht.

Gesprächskontext 13

Friedrich will wissen, ob Roby sich in Japan gut auskennt:

$1 \quad$ FD hast du was mit japan irgendwie zu tun? hast du:::: ???? RB äh

nee

2 FD

RB eigentlich überhaupt nicht ja $\mathrm{H}$ ahn ein bißchen dadurch daß

$\begin{array}{ll}3 & \mathrm{FD}\end{array} \Rightarrow j a$ :

RB ich mariko kenne sie erzählt halt einiges .....

In Zeile 3 ist das Hörersignal $j a$ von Friedrich direkt nach kenne, also der RK des Objektsatzes plaziert. Roby setzte nach diesem Signal die Rede unmittelbar fort.

Fälle, in denen Hörersignale nach auffälliger Verzögerung gesendet werden, sind in meinen Daten selten anzutreffen. In solchen Fällen kommt es leichter zur Spätüberlappung mit dem nächsten Satzelement, wobei die Spätplazierung in der Regel vom Sprecher ignoriert wird, so daß er seine Rede ohne Zögern weiter fortführt. ${ }^{271}$ Wenn die verzögerten Hörersignale trotzdem gänzlich in die Pause hineinpassen, liegt dies an der Anpassung des Sprechers, d.h. er hat gewartet, bis das betreffende Hörersignal fertig ausgesprochen worden ist. Da es in

\footnotetext{
271 Goodwin (1986, S.208) bringt dieses Verhalten des Sprechers mit der „contninuer“-Funktion in Zusammenhang.
} 
meinen Daten nicht so viele Beispiele für diese Art der Pausenplazierung gibt, kann über Verzögerungsgründe nur spekuliert werden: Womöglich sind sie zum Teil darauf zurückzuführen, daß sich der Hörer beim Abschluß der vorangegangenen Informationseinheit noch im Verstehensprozeß befindet. Eine andere Erklärung wäre, daß der Hörer durch die Pause des Sprechers erst dazu veranlaßt wird, ein Hörersignal zu senden, obwohl er dies ursprünglich nicht geplant hat.

\subsubsection{Die Hörersignale im NF und in/nach der Pause des NF}

Die überlappten Hörersignale im NF

Die Überlappungsquote im NF ist relativ hoch und liegt bei 10,2\% der hier analysierten Hörersignale. Hörersignale, die sich mit einem Element des NF wie z.B. „Etceteraformeln“ wie oder so, ne, nicht, oder überschneiden, sind in der Regel auf die Informationen der vorangegangenen Teile des Satzes bezogen. Viele dieser Hörersignale werden zwar rechtzeitig, also direkt nach dem slW bzw. slV gesendet, es kommt jedoch zur Überlappung mit einem NF-Element, weil zwischen dem slW bzw. slV und dem ersten Wort des NF keine Pause vorhanden ist. Dabei ist davon auszugehen, daß der Verstehensprozeß fast gleichzeitig mit dem Vollzug der Äußerung des Satzes abgeschlossen wird. Die Überlappung in dieser Position beeinträchtigt das Verständnis des Hörers kaum, weil Elemente wie „Etceteraformeln“, die typischerweise zum NF gehören, in der Regel keine für den Verstehensproze $ß$ wesentlichen Informationen darstellen.

Verspätete Reaktionen des Hörers, die oftmals daran festgemacht werden können, daß Hörersignale nicht eingesetzt werden, obwohl genügend Pausen nach dem slW bzw. slV eingebaut sind, lassen sich nicht so oft in meinen Daten beobachten. Dafür gibt es allerdings mehrere denkbare Erklärungen: Zum einen können der Verspätung Verstehensschwierigkeiten oder die Nachdenklichkeit des Hörers zugrunde liegen. Sie kann aber ebenso von dem Ungeschick oder dem Nachlassen der Aufmerksamkeit herrühren, so daß dem Hörer eine exakte Plazierung der Hörersignale nicht gelungen ist. Außerdem wäre es möglich, daß die Hörersignale erst durch die Pause veranlaßt werden, obwohl Hörersignale hörerseits nicht vorgesehen sind.

Außer den Hörersignalen, die sich mit einem Gliederungssignal überlappen, gibt es solche, die sich auf Phrasen beziehen, die aus dem MF auf den NF nachgeschoben sind. Dabei sind 
vielerorts nur die letzten Silben einer solchen ausgeklammerten Phrase von der Überlappung betroffen. In diesem Fall können Hörersignale sowohl auf den vorangegangenen Satz als auch auf die betreffende ausgeklammerte Phrase gerichtet sein.

\section{Hörersignale in der Pause im NF und nach dem NF}

In meinen Daten finden sich relativ viele Hörersignale, die in die Pause im und nach dem NF fallen (12\% der Hörersignale).

In dieser Position sind Sätze, auf die Hörersignale bezogen sind, bereits komplett beendet. Außerdem sind Sätze häufig mit einem der Sprechersignale wie ja, nicht, oder, ne oder na versehen. Solche Sprechersignale fungieren zusätzlich zur syntaktischen Abgeschlossenheit des Satzes als Stimuli für Hörersignale in der Pause im NF. ${ }^{272}$ In meinen Daten weisen insgesamt 65 Sätze ein Sprechersignal auf; etwa 30\% dieser Sätze werden von einem Hörersignal begleitet. Demnach liegt es nahe, zu vermuten, daß Sprechersignale als einer der Auslöser der Hörersignale fungieren. Hörersignale, die nach einem solchen Sprechersignal gesendet werden, können als solche angesehen werden, die vom Sprecher veranlaßt worden sind; Hörersignale dienen dann als eine Art Antwort auf den Rückversicherungsversuch des Sprechers. ${ }^{273}$ Hörersignale in dieser Position werden überwiegend rechtzeitig, d.h. direkt nach dem NF geäußert; manche treten hingegen mit etwas Verspätung auf.

\subsubsection{Die Positionen der Hörersignale in den japanischen Daten}

In diesem Kapitel werden wie in den deutschen Daten auch in den japanischen Daten die Positionen der Hörersignale auf der Satzebene bestimmt. Nach der Erläuterung der Analysekategorien werden die Ergebnisse in bezug auf die Distribution der Hörersignale in den einzelnen Positionen dargelegt und interpretiert. Dabei wird außerdem die Art der Plazierung in den jeweiligen Positionen genauer betrachtet.

\footnotetext{
${ }^{272}$ Wahmhoff/Wenzel (1979, S. 276) vertreten die Meinung, daß Sprechersignale den Hörer verpflichten, ein Signal zu erteilen; wenn der Hörer dies unterläßt, wirkt das Verhalten nicht kooperativ und unhöflich. Meines Erachtens begünstigen zwar Sprechersignale das Auftreten der Hörersignale; die Hörerreaktion ist jedoch nicht zwingend, vor allem wenn Hörersignale bereits vorher gesendet werden. Außerdem haben Sprechersignale unterschiedliche Wirkungen auf den Hörer: So scheint z.B. oder stärker als ne dem Hörer zur verbalen Reaktion verpflichtend zu sein.

${ }^{273}$ Rath (1979, S. 128) betrachtet solche Hörersignale als komplementären Teil einer größeren kommunikativen Einheit, die er „Kontaktformel“ nennt; diese Einheit besteht aus einem Hörer- und einem Sprechersignal.
} 


\subsubsection{Die Bestimmung der Analysekategorien}

\section{Die Klärung der Positionsbegriffe}

Bevor die Positionsbegriffe dargelegt werden, soll an dieser Stelle der Begriff „Satz“ im Japanischen definiert werden. Ein japanischer Satz besteht notwendigerweise aus einem Prädikat $^{274}$ und, wenn nötig, aus einem oder mehreren prädikatsbezogenen Satzgliedern. ${ }^{275}$ Für die Wortstellung gilt als Regel, daß prädikatsbezogene Funktionselemente vor dem Prädikat stehen, d.h. daß das Prädikat stets am Satzende positioniert ist.

Da im Japanischen die Verbposition auf das Satzende festgelegt ist, lassen sich japanische Sätze generell in drei Bereiche einteilen:

- der präverbale Bereich,

- der Bereich des Prädikats ${ }^{276}$ und

- der postverbale Bereich.

Der präverbale Bereich kann aus folgenden Satzelementen bestehen:

- einleitende Elemente (EL): Konjunktionen wie de, sorede (und dann) tte iu ka (oder, andersherum gesagt), ja: (das heißt, also),

- Verbergänzungen (VE): wa-Phrase (Thema), ni-Phrase (Ziel), o-Phrase (Objekt), Adverbien usw.,

- Sonstige (SNS): Interjektionen und Wörter zur Zeitgewinnung wie e:to (äh:), sono: (äh:), ma: (irgendwie, also), nanka (irgendwie, also); sie tragen also keine für die Proposition des Satzes wichtigen Informationen.

Die Reihenfolge von Elementen des präverbalen Bereichs ist nicht streng vorgegeben; es besteht jedoch die Tendenz, daß einleitende oder "sonstige“ Elemente eher vor obligatorischen bzw. fakultativen Verbergänzungen stehen. Dabei sind einleitende Elemente

\footnotetext{
${ }^{274}$ Im Japanischen können außer Verben auch Adjektive als Prädikat des Satzes fungieren (Kato et al. 1990, S. 132, Lewin et al. 1984, S. 330 usw.); außerdem gibt es wie im Deutschen auch im Japanischen Kopula-Sätze.

275 Die Mehrheit der Sätze enthält prädikatsbezogene Satzglieder und andere Elemente wie Konjunktionen, Interjektionen verschiedener Art usw. (Minami 1985, S. 40).

${ }^{276}$ Der Begriff Prädikat umfaßt hier das Vollverb und Hilfsverben bzw. Verbalsuffixe wie z.B. des Passivs, des Kausativs, der Negation, des Potentialis, der Vergangenheit, der Höflichkeit; solche Hilfsverben bzw. Verbalsuffixe werden an das Verb angehängt und bilden eine verbale Phrase.
} 
nicht immer im Satz vorhanden, d.h. der Satz kann direkt mit einer Verbergänzung wie z.B. einer Thema-Phrase beginnen. „Sonstige“ Elemente treten relativ frei zwischen Verbergänzungen auf.

Der Bereich des Prädikats (VP) kann ebenfalls feiner unterteilt werden in:

- Vollverb(en) (V) und Hilfsverben des Passivs, des Kausativs, der Vergangenheit, der Verneinung usw. und

- Hilfsverben (HV): desu, masu (Hilfsverben der Höflichkeit). ${ }^{277}$

Die Wortstellung innerhalb der verbalen Phrase ist einer strengen Restriktion unterworfen: An erster Stelle steht das Vollverb, darauf folgen die Hilfsverben bzw. Vervalsuffixe, die zum betreffenden Prädikatsverbund gehören, in einer festen Reihenfolge, wie das folgende Beispiel zeigt. Das Prädikat eines deutschen Satzes: Er hätte doch nicht dazu gezwungen werden können, (die Karotten) zu essen kann im Japanischen folgendermaßen wiedergegeben werden:

\begin{tabular}{|c|c|c|c|c|c|c|c|}
\hline $\begin{array}{l}\text { verbale } \\
\text { Phrase }\end{array}$ & tabe & sase & rare & naka & $t t a$ & darô & ne \\
\hline Kategorie & $\begin{array}{l}\text { Vollverb } \\
\text {,essen“" }\end{array}$ & $\begin{array}{l}\text { Kausativ } \\
\text {,lassen“ }\end{array}$ & Passiv & Verneinung & $\begin{array}{l}\text { Vergangen- } \\
\text { heit }\end{array}$ & Vermutung & \begin{tabular}{|l}
$\begin{array}{l}\text { satzfinale PP, } \\
\text { „doch“ }\end{array}$ \\
\end{tabular} \\
\hline
\end{tabular}

Der postverbale Bereich läßt sich untergliedern in: ${ }^{278}$

- Konjunktionale Postpositionen (kjPP): keredomo (adversativ), noni, temo (konzessiv), kara, node (kausal), to, nara, reba (konditional),

- Satzfinale Postpositionen (slPP): ne (nicht wahr, ich bin mir nicht so sicher), yo (von oben herab, ich weiß besser), $k a$ (Zweifel), na (es wäre nett, wenn),

- Ausgeklammerte Phrasen (AK): Ausgeklammerte Elemente kommen nach der verbalen Phrase: kare-wa tabe-ta keredomo ne ninjin-o (er hat doch gegessen, ich meine die

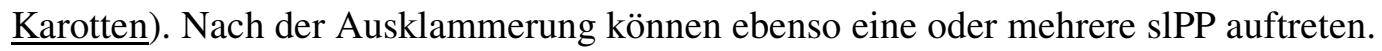

\footnotetext{
277 Hilfsverben der Höflichkeit werden von den anderen Hilfsverben abgegrenzt, weil sie eine pragmatische Funktionen ausüben: Damit wendet sich der Sprecher dem Hörer zu und zeigt seinen Respekt dem Hörer gegenüber.

${ }^{278}$ Zur Klassenbildung der konjunktionalen PP und der satzfinalen PP wurde das Wörterbuch Basic JapaneseEnglish-Dictionary 1993 herangezogen.
} 
Zum Zweck der Analyse werden die folgenden Positionsbegriffe verwendet:

- die präverbalen Positionen der einleitenden Elemente (EL)

- die präverbalen Positionen der sonstigen Elemente (SNS)

- die präverbalen Positionen der Verbergänzungen (VE)

- die verbalen Positionen des Verbs und einiger Hilfsverben (V)

- die verbalen Positionen der Hilfsverben der Höflichkeit u.ä. (HV)

- die postverbale Position der Ausklammerung (AK)

- die postverbale Position der konjunktionalen PP sowie der PP des Zitierens (kjPP)

- die postverbale Position der satzletzten PP (slPP)

Im folgenden sollen zum besseren Verständnis der japanischen Satzstruktur einige Satztypen vorgeführt werden.

Die Satzstruktur eines einfachen bzw. erweiterten Satzes kann folgendermaßen veranschaulicht werden:

$$
\text { EL VE VP SIPP ..... }
$$

Sätze dieser Kategorie enden mit der Verbphrase (VP), die die Schlußform Verbstamm $+u / r u$ aufweist, wobei nur das letzte verbale Element der VP die Schlußform trägt. Auf die verbale Phrase können noch eine oder zwei satzfinale Postpositionen (slPP) wie ne, yo folgen:

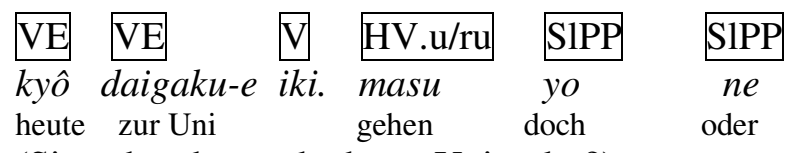

(Sie gehen heute doch zur Uni, oder?)

In meinen Daten finden sich häufig Sätze mit der sogenannten Vte-Form (bzw. Gerundivien); sie indizieren die Fortsetzung verschiedener Art (Vorzeitigkeit, Modalität, Zweck, Grund usw.). Ihre Satzstruktur sieht folgendermaßen aus:

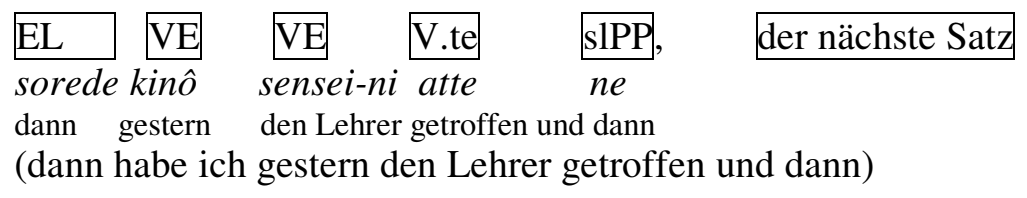


Adversative sowie adverbiale Sätze werden meistens durch eine kjPP gekennzeichnet:

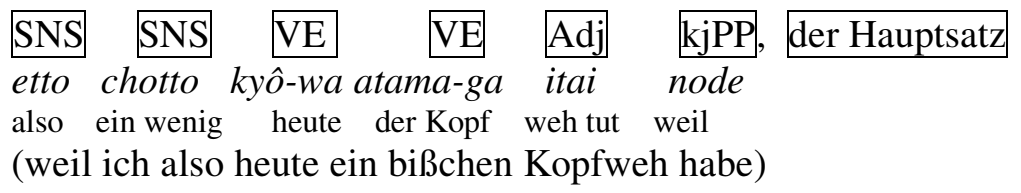

Ein Objektsatz wird im Japanischen durch eine PP des Zitates wie to, tte mit dem Hauptsatz verbunden:

\begin{tabular}{|c|c|c|c|}
\hline $\mathrm{VE}$ & VE & $\mathrm{PP}$ & V + HV des Hauptsatzes \\
\hline itsuka & furansu-ni ikô & & omoi. masu \\
\hline
\end{tabular}

Zum Schluß wird die Satzstruktur eines attributiven Satzes vorgeführt:

$\mathrm{VE} \quad \mathrm{VE} \quad \mathrm{V} \quad$ BezugsN
shûshoku-no tame-ni naru hon -
Bewerbung für nätzlich Buch
(Bücher, die für die Bewerbung nützlich sind,)

Der Hauptsatz steht im Japanischen - anders als im Deutschen -, in der Regel erst nach dem Attributsatz.

Folgende Äußerungen werden in diesem Kapitel nicht der Analyse unterzogen, weil sie nicht syntaktisch vollständige Sätze darstellen:

- Hörersignale des Sprechers auf die Hörersignale des Hörers, ${ }^{279}$

- $\quad$ satzwertige Äußerungen wie Antworten und

- Satzabbrüche.

Die Aussonderung aus der Untersuchung läßt sich vor allem dadurch rechtfertigen, daß solche Äußerungen kaum Hörersignale hervorrufen.

${ }^{279}$ Duncan kommentiert ebenfalls dazu (1974, S. 169). 
Ellipsen, bei denen kontextuell erschließbare Satzelemente ausgespart sind, werden zur Analyse herangezogen, solange sie das Prädikat des Satzes aufweisen und ohne weiteres zu syntaktisch vollständigen Sätzen rekonstruiert werden können. Bei elliptischen Äußerungen werden häufig verbergänzende Phrasen getilgt. ${ }^{280}$ Beispielsweise werden im folgenden Dialog die Themen des Fragesatzes (heute, du, also Masa-kun) sowie das propositionale Objekt (zur Uni) im Antwortsatz ausgelassen:

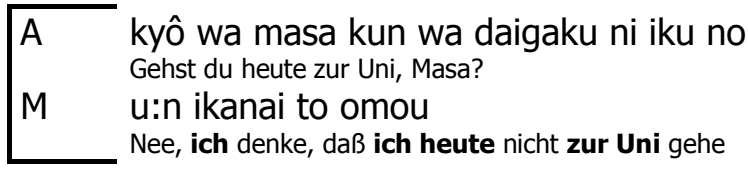

Die Bestimmung der Typen der Plazierung der Hörersignale

Wie in den deutschen Daten werden auch in den japanischen zwei häufig anzutreffende Arten der Überlappung, die sich in allen Bereichen des Satzes befinden können, unterschieden:

- die Überlappung mit versetztem Beginn mit einem Satzelement der Sprecheräußerung; hierbei geht es um die Hörersignale, die mitten in das Wort hinein plaziert werden,

- die Überlappung mit gleichzeitigem Beginn mit einem Satzelement der Sprecheräußerung.

Im Vergleich zu den Ergebnissen bei den deutschen Hörern können die überlappten Hörersignale der japanischen Teilnehmer länger mit der Sprecheräußerung überlappt sein, so daß sie sich nicht nur auf ein Wort, sondern auf eine Phrase oder sogar auf ein oder zwei Sätze erstrecken. ${ }^{281}$

4.3.2.2 Die Gesamtübersicht der Distribution der Hörersignale in den verschiedenen Positionen des Satzes

Im folgenden werden die Positionierungen der Hörersignale in Form eines Diagramms dargestellt:

\footnotetext{
${ }^{280}$ Siehe Japanese-English-Dictionary (1993, S. 926)

${ }^{281}$ Hayashi (1988, S. 280) behauptet Ähnliches.
} 
Abbildung 6

\section{Die prozentuale Verteilung der Hörersignale}

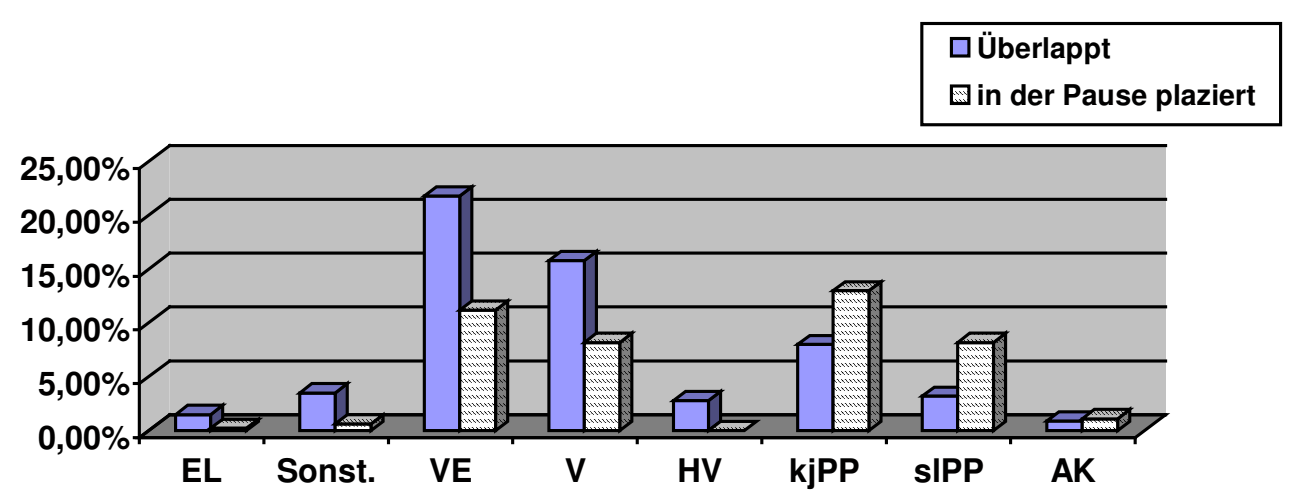

Es stellt sich heraus, daß Hörersignale in den japanischen Daten in der Position der VE am häufigsten anzutreffen sind. Darauf folgen die Positionen nach dem Verb und der kjPP. Außerdem begünstigen die Pausen direkt in und nach der VE, nach dem Verb und nach der kjPP ebenfalls das Auftreten der Hörersignale.

Ferner fallen die Überlappungsanteile insgesamt höher aus, was auf die hohe Frequenz der überlappten Hörersignale im präverbalen Bereich zurückzuführen ist. Nach der Berechnung treten ca. der zwei Drittel der Hörersignale (57,3\%) überlappt mit Sprecheräußerungen auf. ${ }^{282}$

Dagegen lassen sich in den postverbalen Positionen mehr Hörersignale finden, die in der Pause plaziert sind, als überlappte Hörersignale.

Im folgenden werden Hörersignale hinsichtlich ihrer Positionen und Plazierungsart beschrieben und erklärt.

4.3.2.3 Die Hörersignale in der Position des präverbalen Bereichs und in der Pause des präverbalen Bereichs

$\underline{\text { Die Hörersignale in der Position der EL und der Sonstigen (SNS) }}$

Es finden sich in der EL und der SNS insgesamt nicht sehr viele Hörersignale, die sich mit Satzelementen der Sprecheräußerungen überlappen. Viele von ihnen überlappen sich mit dem

\footnotetext{
${ }^{282}$ Nach Hinds (1978, S. 86) soll simultanes Sprechen zwischen den Gesprächspartnern in der gesprochenen japanischen Sprache sehr häufig beobachtet werden.
} 
ersten Wort des nächsten Satzes; dabei sind oft folgende Elemente von der Überlappung betroffen: Konjunktionen wie de (und dann), sô suru to (dann), dakara (daher), die in der satzersten Position stehen, oder Ausdrücke wie e:to (also, u::m), ma: (also, naja), nanka (irgendwie, was weiß ich).

Ein Grund für die Überlappung mit „,dem ersten Wort des nächsten Satzes“ besteht meines Erachtens darin, daß der Sprecher nach dem Vollzug des letzten Satzes seinen Turn fortsetzt, ohne an Satzgrenzen genügend Pausen eingebaut zu haben. Außerdem kommt es in den japanischen Daten oft vor, daß der Hörer Hörersignale nicht direkt nach dem Vollzug des letzten Satzes, sondern erst nach kurzer Verzögerung plaziert. Dabei gibt es zwei Typen der Überlappung: gleichzeitigen Beginn oder versetzten Beginn mit dem überlappten (ersten) Wort. In beiden Fällen ist die vorangegangene Satzinformation als Auslöser der Hörersignale anzusehen. Nachfolgend wird anhand eines Beispiel die überlappte Plazierung mit dem „,ersten Wort“"veranschaulicht:

Gesprächskontext 14

Ayumi und Mako reden über ihre gemeinsame Bekannte, Shun. Beide finden Shun sehr nett. Es gibt noch eine andere Frau, die von Shun als sehr nett bezeichnet wird. Mako, die diese Frau kennt, ist der gleichen Meinung. Ayumi ist sehr überrascht darüber:

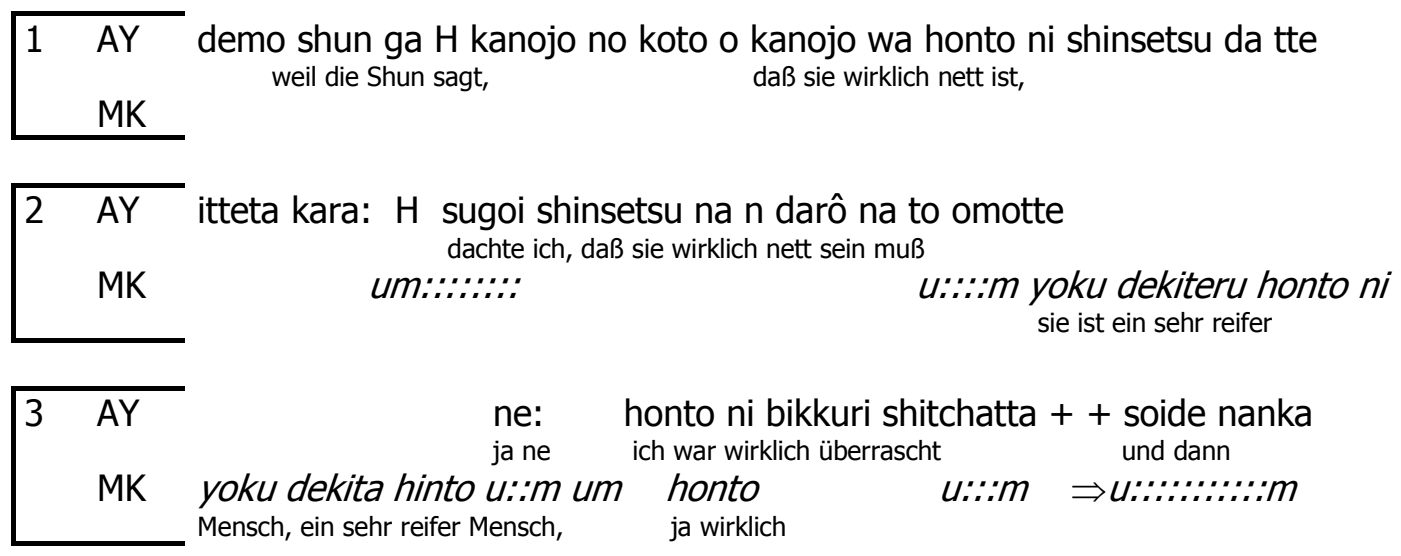

In Zeile 3 plaziert Mako nach längerer Verzögerung das Hörersignal $u::: m$; das ist die zweite Reaktion von Mako auf den vorangegangenen Satz von Ayumi. Mako wartet kurz mit dem Signal, weil sie bereits ein Verstehenssignal gesendet hat. Als sie merkt, daß Ayumi nicht sofort mit dem neuen Satz anfängt, setzt Mako ein zweites Hörersignal ein, um noch einmal das Verstehen zu bestätigen und zugleich Ayumi zum Weiterreden zu ermutigen. Diese 
langsame Art des Reagierens, die Mako hier zeigt, kommt in japanisch-japanischen Gesprächen relativ häufig vor, so daß man diese nicht als markiert ansehen muß.

In der VE befinden sich anders als in der EL und SNS (Sonstige) zahlreiche Hörersignale, die sich mit Elementen, die diesen Bereich konstituieren, überschneiden: Solche Hörersignale machen insgesamt 21,8\% aller hier behandelten Hörersignale aus.

Ein Teil der Hörersignale, die sich der in der VE befinden, überlappt sich mit Elementen der VE, die am Satzbeginn positioniert sind, weil der betreffende Satz weder EL noch SNS enthält. Vor allem bei attributiven Sätzen werden Hörersignale häufig während des Vollzugs des Bezugsnomens geäußert. Das kann auf die Satzstruktur eines attributiven Satzes zurückgeführt werden; ein attributiver Satz ist folgendermaßen strukturiert:

$\mathrm{VE} \mathrm{V}$ BN+PP Pause $\ldots . .$.

Nach dem Vollzug eines attributiven Satzes - ein attributiver Satz endet in der Regel mit dem Verb - entsteht normalerweise keine Pause; die Pause wird bei attributiven Sätzen erst nach der Phrase des Bezugsnomens eingelegt. Daher stellt die Position des Bezugsnomens eine bevorzugte Umgebung für Hörersignale dar, die sich auf den Attributsatz beziehen, ohne die Phrase des Bezugsnomens einzuschließen.

Im weiteren gibt es viele andere Hörersignale, die mit Verbergänzungen zur Überschneidung kommen, welche nicht in die satzerste Position gerückt sind. Das erklärt sich meines Erachtens dadurch, daß im Satz mehrere Verbergänzungen stehen können, die zum Teil für den Verstehensprozeß des Hörers relevante Teilinformationen liefern. ${ }^{283}$ Dies führt dazu, daß Hörersignale in den präverbalen Positionen in den japanischen Daten mehr als in den deutschen Daten anzutreffen sind; japanische Hörer bestätigen tatsächlich häufiger als deutsche Hörer den Empfang und das Verständnis von kleineren Informationsträgern wie Phrasen mit verbalen Hörersignalen, weil sich die präverbale Phase eventuell (viel) länger als in den deutschen Daten hinziehen kann. Außerdem sendet der Sprecher selber nonverbale

\footnotetext{
${ }^{283}$ Nach der Berechnung von Clancy et al. werden Hörersignale häufig in der Satzmitte eingesetzt; sie erklären dieses Phänomen damit, daß der Hörer den Sprecher beim Weiterreden unterstützen will. Meines Erachtens hat der Hörer außerdem einen weiteren Grund, hin und wieder Hörersignale von sich zu geben: Erstens kann sich die
} 
Signale, um die Aufmerksamkeit des Hörers auf die sich gerade vollziehende Informationseinheit zu lenken und die Reaktion des Hörers zu erheischen: Die letzte Silbe des prädikatsbezogenen Funktionselements (oftmals einer Kasus- oder modifizierenden PP) wird häufig gedehnt und betont. ${ }^{284}$

Solche Hörersignale haben hauptsächlich zwei mögliche Bezugsbereiche:

- kleinere Informationseinheiten und

- die aktuell laufende Satzbedeutung.

Bezüglich der Hörersignale, die sich auf kleinere Informationseinheiten wie eine Phrase beziehen, gibt es wiederum verschiedene Plazierungsmöglichkeiten: Eine Plazierungsart besteht in der Überlappung mit dem Informationsträger, auf den sie zielen; der Hörer reagiert also bereits im voraus, ohne $\mathrm{zu}$ warten, bis der betreffende Informationsträger vollends geäußert ist. Die Frühreaktion setzt die vermeintliche, frühzeitige Erschließung der Bedeutung der betreffenden Phrase u.ä. voraus. Das nachfolgende Beispiel zeigt, daß der Hörer ein Hörersignal in dem Moment setzt, in dem er die gewünschte Information erhalten und sich seine Frage geklärt hat.

Gesprächskontext 15

Shigeru weiß nicht, was das deutsche Wort „Betreuer" auf Japanisch heißt. Daraufhin übersetzt Satoru dieses Wort ins Japanische:

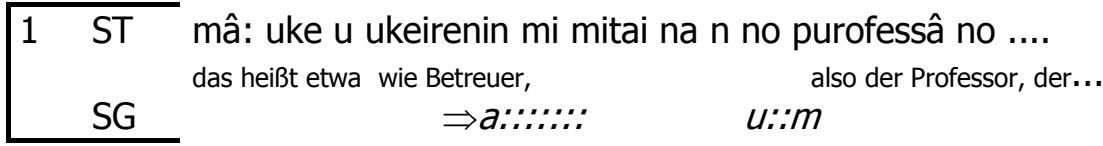

Shigeru setzte zuerst das Hörersignal des langsamen Verstehens: $a:$ mitten ins Wort ukeirenin (Betreuer) ein. Dies konnte er sich deswegen erlauben, weil er die Restinformation nin (Mensch) für sich erschließen konnte, nachdem er den Teil ukeire (Aufnahme) gehört hat. Mit dem zweiten Hörersignal $u:: m$ zeigte Shigeru an, daß seine Wissenslücke jetzt komplett

präverbale Phase im Japanischen lange hinziehen; zweitens sind in diesem Bereich kleinere, für das Verstehen es Satzes wichtige Teilinformationen enthalten.

${ }^{284}$ Nach der Untersuchung von Koiso et al. besteht zwischen dem Auftreten der Kasus-PP und den Hörersignalen eine positive Korrelation (1998, S. 312). 
gefüllt ist und daher kein Verstehensproblem mehr vorhanden ist. Danach setzte sich der Turn von Satoru eine Weile fort.

Außerdem finden sich Überlappungsfälle, die sich mit Satzelementen überschneiden, die direkt nach dem für das Verstehen relevanten Informationsträger stehen; dabei werden häufig Kasus- oder wortmodifizierende PP überlappt. ${ }^{285}$

Drittens können Hörersignale erst nach der betreffenden Phrase, also nach der Kasus-PP plaziert sein; dabei können sie sich ebenfalls mit der nächsten syntaktischen Einheit überlappen, weil der Sprecher keine Pause nach dieser Phrase und der nächsten eingelegt hat oder weil der Hörer mit dem Reagieren etwas langsamer ist. Das nächste Beispiel steht für den zuerst genannten Fall:

Gesprächskontext 16

Shigeru erzählt, daß er Deutsch beim Goetheinstitut gelernt hat. Daraufhin wollte Satoru genauer wissen, wo Shigeru war.

\begin{tabular}{|c|c|c|}
\hline 1 SM & $\begin{array}{l}\text { doko no gête insutichûto desu ka } \\
\text { wo war dieses Goethe Institut? }\end{array}$ & $\Rightarrow \mathrm{u}::: m$ \\
\hline SB & $\begin{array}{l}\text { sono to } \\
\text { damals }\end{array}$ & 'RA \\
\hline
\end{tabular}

\begin{tabular}{|lll}
\hline 2 & SM & um \\
& SB & insutichûto datta n desu keredomo \\
& & $\substack{\text { aber }\\
}$
\end{tabular}

In Zeile 1 setzte Satoru ein Hörersignal nach dem Vollzug einer attributiven Phrase ein: rôtenburuku no (von Rothenburg); dieses Hörersignal überlappte sich jedoch mit dem darauf folgenden Wort der nächsten Phrase gête insutichûto (Goetheinstitut).

Das nächste Hörersignal $u m$ in Zeile 2 ist sehr wahrscheinlich auf die für Satoru bereits bekannte Information, nämlich gête insutichûto bezogen. Die beiden Hörersignale sind meines Erachtens nicht nur durch die jeweiligen vorangegangenen Informationseinheiten

\footnotetext{
${ }^{285}$ Hierzu siehe Lewin 1984, S. 328; in japanischen Grammatiken nennt man modifizierende PP „fukujoshi“ (PP des Zusatzes); siehe z.B. Kato et al. 1990, S.126.
} 
motiviert, sondern durch die „Synchronizität mit dem Sprecherbeitrag““286. Mit anderen Worten bilden sie zusammen eine Einheit und begleiten so die Sprecheräußerung wie ein Baßinstrument, indem sie den Rhythmus schlagen. Ihre Plazierung, ihre Betonung sowie ihre Länge sind der Mora-Struktur (eine Silbe ein Takt) der überlappten Satzelemente der Sprecheräußerung angepaßt und befinden sich mit ihnen im Einklang. ${ }^{287}$ Zum Beispiel besteht

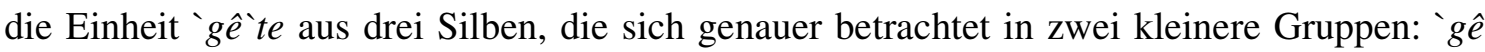
und `te + kleine Pause unterteilen lassen. In der Verbindung von zwei Silben trägt die erste Silbe eine stärkere Betonung als die zweite. Man sieht und hört, daß das Hörersignal in Zeile 1 genau auf dem betonten Konsonanten $g$ der Silbeneinheit 'gê plaziert wird und ebenso wie die Silbeneinheiten `gête intoniert wird. Das gleiche gilt auch für das zweite Hörersignal, das mit `chûto synchronisiert. Diese Art des musikalischen Zusammenspiels läßt sich relativ oft in meinen japanischen Daten beobachten. In manchen Fällen kann sich die Synchronie über einen Satz oder noch länger hinziehen.

Neben den auf kleinere Informationen bezogenen Hörersignalen gibt es auch solche, die sich auf den aktuell laufenden Satz beziehen und vermeintliches frühzeitiges Verstehen des Hörers bekunden; dabei tragen die Phrasen, die Hörersignale mitten im Satz hervorrufen, des öfteren die Kerninformation des Satzes, so daß sich die Satzaussage nach dem Vollzug dieser Informationseinheit im wesentlichen enthüllt.

\section{Die Hörersignale in der Pause der EL, SNS und VE}

Hörersignale in der Pause des präverbalen Bereichs (EL, SNS, VE) sind etwas weniger vertreten als die überlappten $(12,1 \%) .{ }^{288}$ Vor allem in der Pause der EL und SNS treten nur sehr wenige Hörersignale auf. Das kommt daher, daß Elemente der EL sowie SNS kaum Informationen liefern, deren Empfang extra verbal bestätigt werden müßte. ${ }^{289}$

\footnotetext{
${ }^{286}$ Nach Hayashi (1988, S. 280f) wird simultanes Sprechen oft von Kopf- und Körperbewegung begleitet. Die gleichzeitig ausgeführten verbalen und nonverbalen Aktivitäten der Gesprächsbeteiligten werden zu einer rhythmischen Einheit.

${ }^{287}$ Bei gête insutichût (Goetheinstitut) sieht die Mora-Struktur folgendermaßen aus;

'ge e I 'te \# (Pause)| 'i n I’su ti I ‘chu:I to \# . Der Trennstich zeigt eine Gruppe von zwei Silben mit zwei Takten, bei denen jedoch die erste stärker betont wird. Zur Mora-Sturktur ist bei Minami (1985, S. 37) und Kato et al. (1990, S. 44) nachzuschlagen.

${ }^{288}$ Nach Mizutani (1988, S. 98) reden japanische Sprecher öfter mit Verzögerungen, weil sie stets bei ihren Hörern nach der Reaktion suchen und ihre Bereitschaft zum Zuhören prüfen. Diese häufige Überprüfung des Sprechers kann dazu führen, daß Hörersignale auch im Satzinneren gesendet werden.
} 
Hingegen steigt die Frequenz der Hörersignale in der Pause in der VE deutlich an. Dabei können Hörersignale entweder in der Pause direkt nach dem Inhaltswort oder nach der darauf folgenden Postposition plaziert sein. Die Funktion der Hörersignale besteht hierbei ebenso darin, die Kenntnisnahme der betreffenden kleineren Informationseinheit zu bestätigen und somit den Sprecherturn voranzutreiben.

In der Pause plazierte Hörersignale können sich ähnlich wie die überlappten auf den letzten und den aktuell laufenden Satz sowie auf die unmittelbar vorangegangene Phrase beziehen. Im folgenden wird ein Beispiel für ein auf den nächsten Satz zielendes Hörersignal dargelegt:

Gesprächskontext 17

Ayami erzählt Mako, daß sie Indologie studiert und Mako vermutet, daß man dabei eventuell etwas über Buddhismus lernt.

\begin{tabular}{|c|c|c|}
\hline 1 & AY & $\begin{array}{l}\qquad \begin{array}{c}\text { sô desu demo mada: mô honto ni } \\
\text { ja, so ist das, aber }\end{array} \\
\text { e:ja ano: bukkyô kankei toka } \\
\text { Lernst du dann etwas über den Buddhismus? }\end{array}$ \\
\hline 2 & $\begin{array}{l}\text { AY } \\
\text { MK }\end{array}$ & $\begin{array}{l}\text { ima wa H kotoba dake de sansukuritto no: re renshû tte iu ka } \\
\text { die Übungen von Sanskrit } \\
\begin{array}{c}\Rightarrow \text { um die Sprache, } \\
\Rightarrow \text { oder so }\end{array}\end{array}$ \\
\hline
\end{tabular}

In diesem Beispiel ist das Hörersignal um:: direkt nach der PP des Stichwortes des Satzes gesendet; nachdem dieses Wort produziert worden ist, ist die Satzäußerung von Ayumi leicht zu erschließen: Ayumi lernt jetzt Sanskrit. So markiert das Hörersignal den Punkt, an dem der Verstehensprozeß hörerseits beendet ist. Das hat zur Folge, daß Ayumi nichts weiteres mehr hinzufügen muß, sondern mit dem nächsten thematischen Aspekt ihrer geplanten Rede fortfahren kann.

\subsubsection{Die Hörersignale in der Verbposition und in der Pause nach dem Verb}

\section{Die Hörersignale in der Position des Verbs}

Der Anteil der Hörersignale in der Verbposition ist relativ hoch und liegt bei 15,8\%. Das ist die zweithäufigste Position der Hörersignale in meinen japanischen Daten.

\footnotetext{
${ }^{289}$ Nach Sugifuji kommen Hörersignale nicht oft an Stellen vor, an denen keine genügenden Pausen vorhanden sind oder keine wichtigen Informationen geliefert werden (1987, S. 116).
} 
Die Erklärung liegt darin, daß das Verb einer der letzten wichtigen Informationsträger des Satzes darstellt; darauf folgen eine kjPP, PP des Zitates und/oder eine oder zwei slPP. Der Hörer, der während der Sprecherrede stets damit beschäftigt ist, den Sprecherplan seinerseits nachzuvollziehen und $\mathrm{zu}$ rekonstruieren, ${ }^{290}$ ist in der Verbposition bereits genügend informiert, um seinen Verstehensprozeß langsam abschließen zu können; dabei kann er sich seines Verständnisses der betreffenden Satzbedeutung jedoch nicht hundertprozentig sicher sein, weil der Satz je nach Satzkategorien beim Verb noch nicht komplettiert ist. Wenn er dennoch im Verb Hörersignale von sich gibt, ist dies immer mit dem Risiko verbunden, daß er sein Verstehen zu voreilig angemeldet hat, ohne die Satzbedeutung richtig erfaßt zu haben. Dies gilt vor allem für kjPP- und Objektsätze, bei denen nach dem Verb noch eine kjPP oder PP des Zitates positioniert wird. Dennoch finden sich in meinen Daten nicht wenige Hörersignale, die sich mit dem Verb der Objekt- oder der kjPP-Sätze usw. überlappen. Nachfolgend wird ein Beispiel für die Überlappung mit dem gleichzeitigen Beginn mit dem Verb eines Objektsatzes angeführt:

Gesprächskontext 18

Satoru fragt Shigeru, was Shigeru studiert. Daraufhin antwortet Shigeru folgendermaßen:

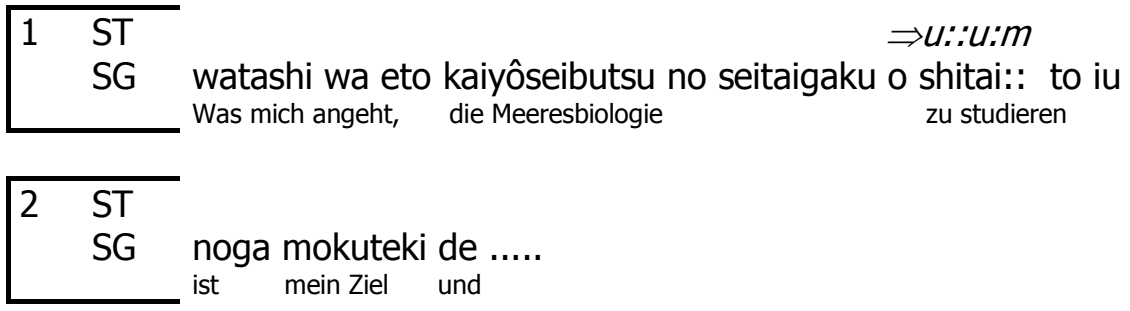

Das Hörersignal $u:: u: m$ in Zeile 1 wird gleichzeitig mit dem Verb eingesetzt, weil zwischen der Kasus-Postposition $o$ (Objekt) und der verbalen Phrase shitai (tun wollen) keine Pause existiert. Diese Hörerrückmeldung kann hier nur auf das Stichwort kaiyôseibutsu no seitaigaku (Meeresbiologie) gerichtet sein, denn dieses Wort liefert die vom Hörer gewünschte Information, die die Antwortsequenz von Shigeru initiiert hat. Nach dem Vollzug dieses Wortes ist die Wissenslücke von Satoru schon gefüllt, so daß der Rest für ihn im Grunde überflüssig ist. Daher schadet ihm die Überlappung mit dem Verb kaum. Auch hier ist

\footnotetext{
${ }^{290}$ Hierzu Rehbein 1977.
} 
nicht zu übersehen, daß das Hörersignal vom Rhythmus und der Betonung her auf das Verb abgestimmt ist.

Das nächste Beispiel zeigt eine Überlappung mit versetztem Beginn mit dem Verb eines kjPP-Satzes:

Gesprächskontext 19

Satoru fragt Shigeru, wie er den Aufenthalt in Deutschland finanziert:

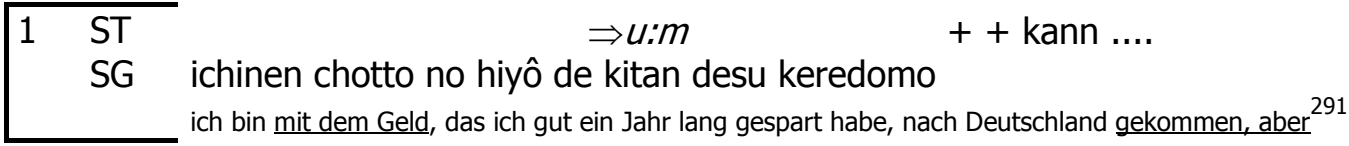

Die Information, die das Verb kita (gekommen) liefert, ist für Satoru im Grunde nicht relevant, weil er schon weiß, daß Shigeru in Deutschland lebt. Daher kann Satoru das Hörersignal in das Verb hinein plazieren, ohne sein Verstehen zu gefährden, denn die wichtigeren Informationen, die Satoru haben wollte, sind bereits vor dem Verb genannt. Aber dennoch wartete Satoru mit der Frühplazierung, bis die erste Silbe des Verbs $k i$, die den Verbstamm darstellt und die Verbbedeutung trägt, ausgesprochen war; mit anderen Worten verzichtete Satoru nur auf den letzten Teil des Verbs, der informativ am wenigsten wert ist: $t a$ $+n$ (Vergangenheit + sozusagen). Das ist ein Beleg dafür, daß zum Verstehen weniger bedeutende Informationsträger leichter überlappt werden. Die Funktion der Frühüberlappung besteht hier darin, dem Sprecher mitzuteilen, daß der Hörer die gewünschte Information erhalten hat und dazu keine weitere Ausführung mehr benötigt. Der Hörer beschleunigt so den Abschluß des Themas und damit den Turnwechsel. Das ist ein Beispiel dafür, daß die Überlappung strategisch eingesetzt wurde, um sich dadurch den Weg zum bevorstehenden eigenen Turn zu bahnen. ${ }^{292}$

\footnotetext{
${ }^{291}$ Nicht unterstrichene Satzelemente sind für das bessere Verständnis der Leser von mir ergänzt; nur die unterstrichenen Wörter wurden im Original geäußert.

${ }^{292}$ Bei Sugifuji wird angedeutet, daß die Überlappung dieser Art öfter zum Turnwechsel führt (1987, S. 131).
} 
Die Begleitquote der Hörersignale erweist sich bei Vte-Sätzen, bei denen das Verb das letzte Inhaltswort des Satzes darstellt, als besonders hoch; ${ }^{293}$ fast die Hälfte der Hörersignale tritt bei diesen Sätzen in der Verbposition auf:

$$
\text { VE Vte }
$$

Im Fall eines Vte-Satzes erreicht der Verstehensprozeß des Hörers in der Verbposition den Höhepunkt; dort wird die Satzäußerung des Sprechers vervollständigt wird. Zu diesem Zeitpunkt ist der Hörer in der Regel fast sicher darin, worauf der Sprecher mit seiner Äußerung hinaus will; daher kann er beruhigt etwas frühzeitig ein Verstehenssignal senden, ohne dabei eine Fehlinterpretation $\mathrm{zu}$ befürchten, wie dies bei der Rückmeldung im präverbalen Bereich der Fall sein könnte. Außerdem wird das Verbalsuffix -te oftmals gedehnt und betont, was wie am Ende einer Phrase mehr als sonst die Aufmerksamkeit des Hörers auf sich lenkt und dadurch den Effekt erzielt, Hörersignale hervorzurufen.

Hörersignale werden ebenfalls entweder gleichzeitig oder versetzt mit dem Verb plaziert. Unabhängig von der Plazierungsart läßt sich annehmen, daß sich Hörersignale auf den aktuell laufenden Satz beziehen und dabei indizieren, daß der Hörer die betreffende Satzaussage im voraus erfaßt hat, wobei die Gefahr des Falschverstehens bei der versetzten Überlappung geringer ist, wie schon im vorigen Abschnitt gezeigt wurde.

Anders als Vte-Sätze, enthalten Vru-Sätze in der Verbposition eine geringere Anzahl von Hörersignalen als Vte-Sätze, obwohl das Verb bei Vru-Sätzen das letzte Inhaltswort des Satzes ist: Die Werte liegen bei 8,6\%. Ein Grund für die beachtlich niedrige Frequenz mag hierin liegen: Das Verb stellt zwar bei diesem Satztyp auch das letzte inhaltlich relevante Wort des Satzes dar; darauf können jedoch noch ggf. einige Elemente wie Hilfsverben oder slPP folgen. Der Hörer ahnt spätestens zum Zeitpunkt des Vollzugs des Verbs, daß der betreffende Satz ein Vru-Satz ist, dessen Verb in der Schlußform steht, welche eine syntaktische Abgeschlossenheit signalisiert; bei der Beendigung solcher Sätze kann der Hörer mehr als sonst sicher sein, daß ihm die Gelegenheit geboten wird, Hörersignale zu senden, um

\footnotetext{
${ }^{293}$ Bei Vte-Sätzen wird das Verbalsuffix -te untrennbar an die Anschlußform des Verbs - Verbstamm $+i$ angehängt -, so daß Hörersignale, die sich mit der Anschlußform des Verbs oder dem Verbalsuffix -te überlappen, zusammengezählt wurden.
} 
sein Verstehen kenntlich zu machen. Dieses Vorwissen führt womöglich dazu, daß der Hörer mit Hörersignalen wartet, bis der betreffende Satz komplett abgeschlossen ist.

\section{Die Hörersignale in der Pause nach dem Verb}

In der Pause nach dem Verb liegt die Quote der Hörersignale bei 8,2\%. Ähnlich wie im letzten Kapitel ausgeführt, weisen Vte-Sätze in der Pause nach dem Verb einen hohen Anteil an den Hörersignalen $(38,7 \%)$ auf. Die sehr hohe Frequenz der Hörersignale ist hierbei ebenso auf ihre Satzstruktur zurückzuführen:

\section{VE Vte Pause d. nächste Satz}

Wie man sieht, endet der Vte-Satz in vielen Fällen mit dem Verb, es sei denn, eine slPP wird an die Verbphrase angehängt. Nach dem Vollzug des Verbs folgen häufig Pausen, die wiederum oft durch die Dehnung der letzten Silbe der verbalen Phrase, nämlich te, im voraus angedeutet werden.

Die Funktion der Hörersignale in der Pause nach dem Vte-Satz besteht darin, zum einen das Verstehen des Hörers zu signalisieren und zum anderen den Sprecher dazu zu ermutigen, seinen Turn fortzusetzen. In der Forschungsliteratur wird diese aufmunternde, unterstützende Leistung der Hörersignale oft in den Vordergrund gestellt. ${ }^{294}$

Bei Sätzen anderer Satzkategorien existieren Pausen nicht direkt nach dem Verb; so ist die Pausenplazierung in der Position direkt nach dem Verb häufig schlecht möglich.

\subsubsection{Die Hörersignale im HV und in/nach der Pause des HV}

Die Gesamtquote der Hörersignale im HV (Hilfsverben der Höflichkeit) erweist sich als ziemlich niedrig $(2,8 \%)$. Hörersignale im HV sind ausschließlich auf die vorangegangenen Informationen bezogen, die von den Verbergänzungen sowie dem Verb des betreffenden Satzes übermittelt worden sind.

\footnotetext{
294 Z.B. Mizutani (1988b, S. 4, 9), LcCastro (1987, S. 110), White (1989, S. 68), Clancy et al. (1996, S. 381) usw.
} 
In der Pause nach dem HV treten in meinen Daten keine Hörersignale auf. Da Hilfsverben der Höflichkeit keine substantiellen Informationen liefern, können sie an sich nicht als Stimuli für Hörersignale dienen; daher existieren nach der Position des HV keine längeren Pausen, in die Hörersignale hineinpassen könnten, es sei denn, die Position des HV stellt das allerletzte Element des Satzes dar. Ansonsten werden ein oder mehrere HV direkt an das darauf folgende Wort wie eine kjPP und/oder eine oder zwei slPP angeschlossen.

4.3.2.6 Die Hörersignale in der Position der kjPP und PP des Zitates und in der Pause nach der kjPP und PP des Zitates

$\underline{\text { Die Hörersignale in der Position der kjPP und PP des Zitates }}$

Unter der Bezeichnung kjPP werden zwei Arten der Postpositionen - konjunktionale PP und PP des Zitates - zusammengefaßt. Zuerst werden kjPP-Sätze thematisiert.

Die Position der kjPP kommt nur bei den kjPP-Sätzen (adversativen und adverbialen Sätzen) vor; dort gibt es 19,2\% der Hörersignale, die Sätze (mit der kjPP) begleiten; diese Quote ist die dritthöchste bei diesem Satztyp. Die Satzstruktur eines kjPP-Satzes ist wie folgt zu vereinfachen:

\section{VE V kjPP nächster Satz}

Wie man sieht, steht die kjPP nach dem Verb, d.h. die Satzinformation ist zwar erst nach dem Vollzug der kjPP komplett, aber in der Position der kjPP ist bereits ein großer Teil der Satzinformation geliefert worden, so daß die Bedeutung des Satzes sowie die Sprecherintention mit hoher Sicherheit erschlossen werden können.

Eine Mehrheit der Hörersignale wird in der Position der kjPP zu Beginn der kjPP plaziert; diese wird meist direkt nach dem Vollzug des Verbs bzw. HV gesendet; es kommt jedoch zu einer Überschneidung mit der kjPP, weil keine Pause nach dem Verb bzw. HV existiert. Das deutet darauf hin, daß der Hörer die Satzbedeutung für erschlossen oder verstanden hält, nachdem er das Prädikat des Satzes empfangen hat; weitere nachfolgende Informationen werden von ihm offenbar nicht mehr als zum Verständnis des betreffenden Satzes relevant betrachtet. Abgesehen davon gibt es auch Plazierungsfälle mit versetztem Beginn, bei denen 
oft nur die letzte Hälfte der kjPP von der Überlappung betroffen wird. Bei dieser Art der überlappten Plazierung ist die Sicherheit des richtigen Verständnisses des Satzes noch höher.

Mittels Hörersignalen, die sich mit der kjPP überlappen, kann der Hörer dem Sprecher übermitteln, daß er den betreffenden Satz bereits verarbeitet hat, bevor der Satz gänzlich zu Ende ist, und daß der Sprecher einen Redebeitrag weiter fortführen, im Klartext in den Hauptsatz übergehen kann.

Gesprächskontext 20

Sanako erzählt Haruyo von ihren Erlebnissen im Deutschkurs; ihrer Meinung nach kann man dort keine guten Freunde finden, weil man sich wegen mangelhafter Sprachkenntnisse nur oberflächlich kennenlernen kann.

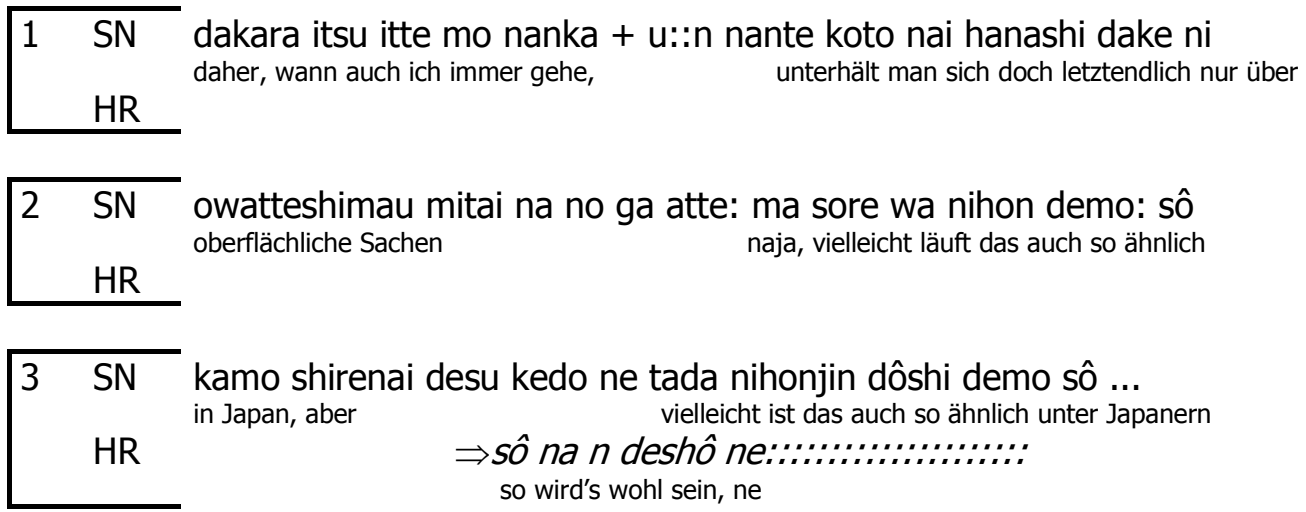

Die satzförmige Höreräußerung sô nan deshô ne (so ist das wohl, ne) in Zeile 3 wurde mitten in die kjPP plaziert; dabei ist die letzte Silbe von der Überlappung betroffen. Zum Zeitpunkt der Artikulation der kjPP erhellt sich die Äußerungsbedeutung des Satzes bereits weitgehend; daher bereitet die Überlappung kein Problem beim Verstehen des Satzes. So markiert Haruyo den Moment ihrer erfolgreichen Verarbeitung der Satzinformation. Sanako läßt sich von der längeren Überlappung nicht stören und redet weiter.

Ähnliches gilt für Objektsätze, wobei bei diesen Sätzen der Anteil der Hörersignale noch höher ausfällt: Er liegt bei 34\% und stellt bei diesem Satztyp die Position dar, die am häufigsten von Hörersignalen begleitet wird. Das ist womöglich darauf zurückzuführen, daß der Hörer nach dieser PP nicht immer mit Pausen rechnen kann, wie dies bei kjPP-Sätzen der Fall ist. Objektsätze werden in meinen Daten des öfteren ohne Pause an den Hauptsatz angeschlossen. Dementsprechend sinkt die Quote der Pausenplazierung im Vergleich zur 
Quote der überlappten Plazierung: 24\% der Hörersignale sind in der Pause nach der PP des Zitates anzutreffen.

Die Hörersignale in der Pause nach der kjPP und der PP des Zitates

Die Pause nach der kjPP erzielt die dritthöchste Begleitquote der Hörersignale überhaupt und die höchste Quote unter allen Pausen, obwohl nicht alle Sätze eine kjPP enthalten - etwa $12,7 \%$ der Sätze sind mit dieser PP versehen. Nachfolgend ist die grobe Struktur dieses Satztyps noch einmal illustriert:

$$
\text { VE VV kjPP Pause nächster Satz }
$$

Die Pause nach der kjPP ist die Position, in der der betreffende Satz bereits grammatisch komplett abgeschlossen ist, und der nächste Satz, also der übergeordnete Satz, noch nicht begonnen hat. Die bevorzugte Plazierung der Hörersignale in dieser Position ist dadurch erklärbar, daß nach der kjPP oft längere Sprechpausen eingelegt werden, in die Hörersignale hineinpassen können, wenn anschließend keine slPP plaziert wird. ${ }^{295}$ Außerdem ist diese Umgebung oftmals durch die Dehnung der letzten Silbe der kjPP markiert. ${ }^{296}$ Mit solchen Mitteln versucht der Sprecher zur Planung seiner weiteren Rede, die Zuhörerschaft und den Verstehensstand des Hörers zu überprüfen, wodurch der Hörer stärker als sonst dazu veranlaßt wird, verbale Reaktionen zu zeigen.

Die Positionierung der Hörersignale in dieser Umgebung ist ebenfalls ein Beispiel für ein Zusammenspiel zwischen Sprecher und Hörer in der Koordination von Sprecher- und Hörerhandlungen (KjPP - Pause - Hörersignal), vor allem wenn Hörersignale ohne Verzögerung direkt in der Pause oder kurz nach der Pause eingesetzt werden. ${ }^{297}$

\footnotetext{
${ }^{295}$ Nur in wenigen Fällen wird/werden die slPP an die kjPP angehängt.

${ }^{296}$ Hierzu Maynard (1986, S. 1096f).

${ }^{297}$ Sugifuji stellt fest, daß Hörersignale häufig nicht direkt nach der Pause, sondern kurz nach deren Beginn $(0,1$ bis 0,3 sek danach) gesendet werden (1987, S. 116). Dieses Ergebnis ist jedoch nicht direkt auf kjPP-Sätze bezogen.
} 


\subsubsection{Die Hörersignale in der Position der slPP und in der Pause nach der slPP}

\section{$\underline{\text { Die Hörersignale in der Position der slPP }}$}

Von der Gesamtquote der Hörersignale her betrachtet, bildet die Position der slPP eine Umgebung, die das Auftreten der Hörersignale nicht sonderlich begünstigt.

Ein Grund für die geringere Frequenz der Hörersignale ist, daß nicht an jedem Satzende eine slPP steht; vor allem attributive Sätze weisen selten slPP auf. Zweitens wird die überwiegende Mehrheit der Hörersignale bei Vte- und kjPP-Sätzen bereits im Vorfeld (bei dem Verb oder der kjPP) eingesetzt, so daß kein weiteres Zeichen vom Hörer für den vorangegangenen Satz nötig ist. Bei Objektsätzen treten Hörersignale erst in der Position der PP des Zitates, die nach der slPP direkt folgt, häufiger auf; der Hörer wartet hierbei solange mit einer verbalen Reaktion, bis ein Objektsatz beendet ist und der Hauptsatz beginnt.

Hingegen ist der Anteil der Hörersignale bei den Vru-Sätzen relativ hoch (12,1\%), was ebenso mit dem Strukturwissen des Hörers erklärt werden kann. Alle Hörersignale werden in

dieser Position direkt nach dem HV gesendet; so kann der Hörer sehr sicher sein, alles wichtige vom Satz mitbekommen und nichts verpaßt zu haben.

$\underline{\text { Die Hörersignale in der Pause nach der slPP }}$

Die Verteilung der Hörersignale in der Pause nach der slPP ist insgesamt nicht sehr hoch. Die Häufigkeit der Hörersignale ist wiederum sehr stark von der Satzkategorie abhängig: Der Anteil der Hörersignale ist nur bei Sätzen in der Schlußform (Vu/ru) besonders hoch. 41,4\% der Hörersignale, die Vru-Sätze begleiten, treten in dieser Umgebung auf. Die Satzstruktur von Vru-Sätzen wird zur Veranschaulichung wie folgt vereinfacht dargestellt:

$$
\text { VE Vru HVi: }
$$

Die Positionen nach der slPP zu Ende; an solchen Satzenden sind häufig längere Pausen vorhanden. Außerdem weisen Satzenden für den Sprecher für die Weiterführung seines Turns eine große Relevanz auf, wie in den letzen Kapiteln öfter festgestellt wurde. Außer Pausen können die 
slPP wie ne (nicht wahr), yo (das ist so, daß) selbst als Auslöser für Hörersignale fungieren: Sie können ein Verstehens- oder Zustimmungssignal des Hörers erheischen.

In dieser Position werden die meisten Hörersignale rechtzeitig, d.h. kurz nach dem Beginn der Pause gesendet oder fallen direkt in die Pause. Daran erkennt man, wie sehr Sprecher und Hörer an Satzenden bemüht sind, ihre Handlungen aufeinander abzustimmen. Im folgenden wird ein prototypisches Beispiel für die rechtzeitige Pausenplazierung in der Pause nach der slPP dargestellt:

Gesprächskontext 21

Satoru erzählt, daß seine Frau in Deutschland Heimweh hat und gerne nach Japan zurückfahren will. Sie hat vor, dort wieder zu arbeiten.

1 ST nihon ni kaette mata mata hatarakitai tte iu yô na koto sie sagt zwar, daß sie nach Japan zurückkehren und dort wieder arbeiten will, SG

2 ST ittemasu kedo ne: SG $\Rightarrow u:: m u: m$

Das Hörersignal in Zeile 2 ist in der Pause nach der kjPP kedo (aber) und der slPP ne (das ich weiß), also am Satzende plaziert. Ähnlich wie in den deutschen Daten ist die Art der Plazierung ein Ausdruck der Koordination von Sprecher- und Höreraktionen und der Kooperation zwischen beiden. Mit den rechtzeitig plazierten Hörersignalen erwidert der Gegenschlag des Hörers den Hauptschlag des Sprechers und füllt so die Lücken der Sprecherrede.

Bei den anderen Satzkategorien kann hingegen keine hohe Distribution in der betreffenden Position festgestellt werden. Als Begründung dafür gilt ähnliches wie für die Position in bezug auf die slPP aufgeführt wurde.

\subsubsection{Die Hörersignale in der Position der AK und in/nach Pause der AK}

Die Anzahl der Hörersignale, die in der AK auftreten, ist in meinen Daten ziemlich gering. Hörersignale in der AK sind entweder auf den vorangegangenen Satz und/oder die ausgeklammerte Phrase gerichtet. 
Die in/nach der Pause der AK plazierten Hörersignale treten fast alle unverzögert nach dem Vollzug der Phrase der AK auf und zielen auf die ganze vorhergehende Satzinformation. Da der Sprecher bei Sätzen mit der AK dazu tendiert, die Phrase der AK unmittelbar im Anschluß an den vorangegangenen Satz zu äußern, wird der Hörer dabei eher dazu verleitet, Hörersignale nicht nach dem vorläufigen Ende des Satzes, sondern erst nach dem Vollzug der AK zu setzen.

\subsubsection{Zusammenfassung}

Als Resümee der Positionsanalyse können folgende Ergebnisse und Beobachtungen festgehalten werden:

In den deutschen Daten bleiben die Plazierungstendenzen der Hörersignale unabhängig von den Satztypen (SVO-, SOV(V)-Typen) eher gleichmäßig: Hörersignale werden mit Abstand häufiger an Satzgrenzen, d.h. in der Pause nach dem slW bzw. slV als anderswo beobachtet.

Hingegen hängt die Positionierung der Hörersignale in den japanischen Daten oft von den Satzkategorien ab, wobei dennoch die Tendenz erkennbar ist, Hörersignale entweder in der Position des letzten substantiellen Informationsträgers des Satzes (Verb, kjPP, PP des Zitates) oder in der direkt folgenden Pause einzusetzen. Die Ausnahme bilden Vru-Sätze, bei denen Hörersignale in der Pause nach der slPP, also an Satzgrenzen, am häufigsten auftreten. Demnach liegt die Annahme nahe, daß japanische Hörer im voraus (spätestens beim Verb) erahnen, um welche Satzkategorie es sich bei der aktuellen Äußerung handelt und wo Sprechpausen entstehen können. Dabei hilft der Sprecher dem Hörer, indem er z.B. die letzte Silbe des slW oder slV dehnt oder dies unterläßt (bei Vru-Sätzen).

Die höhere Anzahl der Hörersignale im Satzendbereich - der Satzendbereich umfaßt die Positionen, die zwischen dem Verb und der slPP und zwischen dem slW bzw. slV und dem NF liegen - kann sowohl in den deutschen als auch in den japanischen Daten auf die folgenden Faktoren zurückgeführt werden: 
- auf die grammatische Abgeschlossenheit einer größeren Informationseinheit,

- $\quad$ auf diese folgende Sprechpausen und

- $\quad$ auf Sprechersignale wie oder, ne, na, ne, yo, yone usw.

Sowohl in den deutschen als auch in den japanischen Daten gibt es nicht wenige Hörersignale (etwa ein Viertel der Hörersignale), die sich nicht im Satzendbereich befinden. Viele der Hörersignale, die sich im VVF, VF (in den deutschen Daten) und in der EL und SNS (in den japanischen Daten) befinden, werden direkt nach oder kurz nach dem Vollzug der letzten Satzäußerung eingesetzt und signalisieren das Verstehen des betreffenden Satzes.

Hingegen fungieren Hörersignale im $\mathrm{MF}$ in den deutschen Daten als bloße Fortsetzungssignale oder bekunden hörerseitiges frühzeitiges Erschließen der Bedeutung des aktuell laufenden Satzes. Relativ selten anzutreffen sind Hörersignale im MF, die sich auf unmittelbar davor stehende, kleinere Informationseinheiten wie Phrasen oder Wörter beziehen. Dagegen sind solche Hörersignale in den japanischen Daten im präverbalen Bereich viel häufiger als in den deutschen Daten festzustellen.

Stellen in der Sprecherrede, die mit Verzögerungen oder Formulierungsschwierigkeiten beladen sind, ${ }^{298}$ rufen in meinen Daten besonders wenig Hörersignale hervor; solche Passagen bestehen z.B. aus Phrasen- oder Satzabbrüchen, Selbstkorrekturen, gefüllten Pausen wie äh, ähm, e:to, u:m, Floskeln wie z.B. was war das, a: nan datta kke na: (wie heißt das, äh:) usw. Außerdem ziehen satzwertige Äußerungen wie Antworten aus Antwortpartikeln oder Einschübe wie ich meine, was weiß ich selten Hörersignale nach sich. Die Umgebungen mit niedriger Frequenz der Hörersignale zeichnen sich insgesamt dadurch aus, daß sie im Vergleich zu Umgebungen mit hoher Frequenz der Hörersignale wenig Informationswerte besitzen.

Befunde in bezug auf die überlappte Plazierung und die Pausenplazierung der Hörersignale können folgendermaßen zusammengefaßt werden:

\footnotetext{
298 Wahmhoff/Wenzel stellen in ihren Daten bei Formulierungsschwierigkeiten eine höhere Häufigkeit der Hörersignale fest; das kann an ihrem Datentyp - Gesprächstherapie - liegen. Hingegen berichten White (1986, S.109) und Sugifuji (1987, S. 116), daß die Umgebungen mit weniger Informationswerten wenig Hörersignale hervorrufen.
} 
Die Überlappungsquote ist sowohl in den deutschen als auch in den japanischen Daten häufiger als die Quote der Pausenplazierung.

Der hohe Anteil der Überlappungsfälle kommt in den deutschen Daten oftmals dadurch zustande, daß die Pausenplazierung schwierig ist, wenn sprecherseits im Satz nicht genügende Pausen zur verbalen Rückmeldung geboten werden, in die Hörersignale eingeschoben werden können. Solche Pausen werden zwar in der Regel an Satzgrenzen eingebaut; der Hörer kann jedoch nicht immer im voraus ahnen, wo genau der Sprecher Pausen einlegt: Sie können in den deutschen Daten nach dem slW bzw. sIV oder in/nach dem NF oder dem VVF entstehen. Dies führt häufig dazu, daß Hörersignale mit dem NF- oder VVF-Element überschnitten plaziert werden. Dagegen sind Überlappungsfälle im MF eher darauf zurückzuführen, daß der Hörer aus eigenem Antrieb sein vermeintliches vorzeitiges Verstehen des betreffenden Satzes zu erkennen gibt oder auf den vorangegangenen, zum Verständnis relevanten Informationsträger wie ein Wort oder eine Phrase reagiert.

In den japanischen Daten stellte sich heraus, daß häufig der präverbale Bereich, die Verbposition, die Position der kjPP bzw. PP des Zitates von der Überlappung betroffen sind. Abgesehen vom präverbalen Bereich gibt es jedoch je nach den Satzkategorien Unterschiede darin, welche Positionen höhere Überlappungsquoten aufweisen: Bei den attributiven Sätzen und den Vte-Sätzen sind überlappte Hörersignale am häufigsten in der Verbposition zu finden, während bei den kjPP-Sätzen die Position der kjPP und bei den Objektsätzen die Position der PP des Zitates eine hohe Überlappungsquote aufweisen.

Die Überlappung entsteht nicht immer, jedoch in vielen Fällen, durch die Zuversicht des Hörers, daß er die Verarbeitung der Informationseinheit, sei es ein Satz, ein Wort, oder eine Phrase, bereits im voraus für abgeschlossen hält, bevor der Sprecher die betreffende Informationseinheit $\mathrm{zu}$ Ende ausgesprochen hat. Somit markiert er den Endpunkt seines Verstehensprozesses. Ferner kommt es in den japanischen Daten des öfteren vor, daß der Hörer sich mit der Rückmeldung etwas Zeit läßt, so daß Hörersignale gleichzeitig mit der nächsten Einheit des Sprecherturns eingesetzt werden; das ist jedoch meines Erachtens kein Indiz für Verstehensschwierigkeiten des Hörers.

Dabei zeichnen sich in vielen Fällen überlappte Satzelemente dadurch aus, daß sie keinen hohen Informationswert enthalten, sondern vielmehr folgende Elemente wie etwa 
konjunktionale Ausdrücke, Kasus-PP, letzte Silben der Vollverben bzw. des letzten Inhaltswortes und Interjektionen wie ne, nicht, oder, ne (nicht wahr), yo (das ist so, daß) nach dem letzten Inhaltswort beinhalten. Daraus kann die These abgeleitet werden, daß die überlappten Hörersignale eine informationsgliedernde Funktion besitzen. Sie unterteilen die Sprecheräußerung nach für den Hörer verständnisrelevanten und weniger relevanten Einheiten. Die ersteren müssen also aufmerksam verfolgt werden, die letzeren hingegen gerade nicht, so daß sie von der Überlappung getroffen werden können.

Die überlappten Hörersignale, die eine Frühreaktion darstellen, erfüllen bei beiden Sprachgruppen folgende Funktionen: Eine Funktion besteht darin, die Sprecherrede voranzutreiben, indem angezeigt wird, daß der Hörer anscheinend so gut versteht, daß er das Gesagte sogar im voraus zu erfassen vermag. In manchen Fällen kann ein Überdruß in bezug auf das aktuelle Thema zum Ausdruck kommen. Außerdem kann die bevorstehende Turnübernahme zwar die Überlappung dieser Art verursachen, aber zwischen ihnen besteht kein starker Zusammenhang.

Hörersignale (KF, KKF) werden bei den deutschen Hörern im Vergleich zu den japanischen Hörern eher punktuell eingesetzt und erstrecken sich in der Regel auf zwei oder drei Wörter der Sprecheräußerung. Hingegen begleiten japanische Hörer Sprecheräußerungen gerne länger; in extremen Fällen werden Hörersignale sogar über zwei Sätze hingezogen: Das kann wiederum ein Indiz dafür sein, daß die länger hingezogene Überlappung bei den deutschen Hörern weniger präferiert ist als bei den japanischen Hörern, die die längere Überlappung zu genießen scheinen.

Häufige Überlappungen scheinen den japanischen Gesprächsteilnehmern kein großes Problem zu bereiten, sondern sie werden im Gegenteil vielmehr benötigt, ${ }^{299}$ um bestimmte Effekte zu erzielen. ${ }^{300}$ Zum einen können überlappte Hörersignale die Sprecherrede schneller vorantreiben, weil dadurch angekündigt wird, daß der Hörer das Gesagte schon im voraus verstanden hat. Zweitens schafft die Überlappung ein solidarisches und harmoniestiftendes Moment zwischen Sprecher und Hörer, indem die überlappten Hörersignale (Kurzformen wie

\footnotetext{
${ }^{299}$ Nach Sugito et al. kommen mehr Überlappungen im Gespräch vor, wenn die Gesprächsbeteiligten in guter Stimmung sind oder sich gut kennen (1987, S. 121).

${ }^{300}$ Hayashi (1988, S. 286) vertritt die ähnliche Meinung, daß simultanes Sprechen dazu dient, in amüsanter, harmonischer Atmosphäre die Sprecherrede des Sprechers zu unterstützen.
} 
um, $a:, e$ :) so intoniert werden, daß sie sich den prosodischen Gegebenheiten der überlappten Satzelemente anpassen und so in musikalischem Einklang mit diesen stehen.

Die Pausenplazierung gibt ebenso Aufschlüsse über den Verstehensstand des Hörers sowie die Beziehung zwischen Sprecher und Hörer. Die rechtzeitige, gänzliche Pausenplazierung erfordert eine gute Koordination und Kooperation zwischen Sprecher und Hörer und ist ebenfalls ein harmonieschaffendes Moment im Gespräch. Die Voraussetzung dafür ist zum einen das Verstehensvermögen des Hörers, der fast genauso schnell das Gesagte verarbeitet wie der Sprecher es ausspricht; zum anderen muß der Hörer im voraus wissen, wo Pausen entstehen, um gleichzeitig Hörersignale dann exakt in die Pause hineinplazieren können. Auf der anderen Seite kann der Sprecher auch seinen Teil dazu beitragen, indem er die Pausen ausdehnt oder gar extra für den Hörer einlegt. 


\subsection{Die Frequenz der Hörersignale in Abhängigkeit von Merkmalen von Satzenden}

\subsubsection{Die Frequenz der Hörersignale in Abhängigkeit von Merkmalen von Satzenden in den deutschen Daten}

Nach der Deutung der Positionen der Hörersignale soll in diesem Kapitel die Frequenz der Hörersignale in Abhängigkeit von den folgenden Kategorien untersucht werden:

- Sätze,

- Satzkategorie,

- Satzstellungen der Sätze bei Satzgefügen sowie

- Intonationskonturen der Satzenden.

4.4.1.1 Die Frequenz der Hörersignale in Abhängigkeit von Sätzen und von Satzkategorien mit Berücksichtigung der Satzstellung

In diesem Kapitel soll überprüft werden, ob und inwieweit die Verteilung der Hörersignale je nach Sätzen sowie Satzkategorien unterschiedlich ausfällt. Zuerst werde ich die Satzkategorien erläutern, die in diesem Kapitel verwendet werden.

\section{Die Bestimmung der Satzkategorien}

Für die Analyse werden folgende Satzkategorien verwendet ${ }^{301}$ :

- Allein stehende Sätze: einfache Sätze, erweiterte Sätze sowie Sätze, die mit gleichordnenden Konjunktionen und, aber, denn oder Konjunktionaladverbien eingeleitet werden, ${ }^{302}$

- Hauptsätze in Satzgefügen und

- Nebensätze in Satzgefügen:

Adverbialsätze: u.a. kausale, konditionale, temporale, modale, finale, konzessive Sätze,

- Relativsätze, ${ }^{303}$

\footnotetext{
${ }^{301}$ Die Kategorien, die ich hierfür heranziehe, sind aus den Ergebnissen der Voruntersuchung entstanden.

${ }^{302}$ Das liegt daran, daß die Plazierung der Hörersignale an Satzenden meines Erachtens kaum davon beeinflußt wird, ob es sich um einen einfachen oder erweiterten Satz oder ein Satzgefüge handelt.

303 Nach der Voruntersuchung werden Relativsätze nicht so oft wie andere Nebensätze von Hörersignalen begleitet.
} 
- Subjekt- und Objektsätze: Sätze, die mit $d a \beta$ eingeleitet werden sowie Sätze mit der SVO(V)-Verbstellung,

- Infinitivkonstruktionen.

Ferner werden Sätze, die zusammen ein Satzgefüge konstruieren, zusätzlich unterschieden in:

- Sätze, die nicht am Ende eines Satzgefüges stehen und

- Sätze, die am Ende eines Satzgefüges positioniert sind.

\section{Die Darstellung und die Interpretation der Ergebnisse}

Es ergibt sich aus der Berechnung, daß im Schnitt 40,3\% aller hier analysierten Sätze von Hörersignalen begleitet werden, ${ }^{304}$ wobei sich nicht alle Hörersignale im Satzendbereich befinden. Hörersignale, die an oder nah an Satzgrenzen auftreten, machen etwa $71 \%$ aller Hörersignale aus, ${ }^{305}$ d.h. knapp 30 \% der Sätze erhalten Hörersignale im Satzendbereich.

Demnach kann davon ausgegangen werden, daß es zwar vom Sprecher aus erwünscht und veranlaßt wird, daß der Hörer verbale Hörersignale in regelmäßigen Abständen sendet, aber der Hörer ist nicht dazu verpflichtet oder gar gezwungen, an jeder der für die Hörerreaktion relevanten Stellen (Satzenden) verbal zu reagieren; er hat gewissen Spielraum für die Entscheidung, wann und wie oft er den Akt der Hörerrückmeldung tatsächlich durchführt. ${ }^{306}$

Außerdem gibt es andere Mittel, die zusätzlich zu verbalen Hörersignalen eingesetzt werden, um die Aufmerksamkeit und die aktive Anteilnahme am Gespräch in ausreichendem Maße zu signalisieren. Dabei spielen nonverbale Höreraktivitäten wie Kopfnicken oder die

\footnotetext{
304 Nach Clancy et al.(1996, S. 378) liegt die Quote verbaler Hörersignale und der Turnübernahme an Satzgrenzen in ihren amerikanischen Daten bei $39,1 \%$, d.h. $61 \%$ der Satzenden erhalten keine verbalen Reaktionen des Hörers: ihr Ergebnis ist meinen Befunden ähnlich. Bei White (1989, S. 66) ist die Quote der Hörersignale noch niedriger: 8 bis $24 \%$ aller Satzenden sind in ihren amerikanischen Daten mit Hörersignalen ausgestattet.

305 Dabei habe ich Hörersignale zwischen der Position des slW bzw. slV und der Pause nach dem VVF zusammengezählt.

306 Die Auslassung von verbalen Hörersignalen muß in einem akzeptablen Rahmen sein, oder es müssen annehmbare Gründe (Trinken, Verstehensprobleme) vorliegen; sonst kann dies als Zeichen für Desinteresse usw. ausgelegt werden.
} 
Blickrichtung eine ergänzende, womöglich sogar noch wichtigere Rolle als verbale Hörersignale. $^{307}$

Im kommenden werden die Sätze in verschiedene Kategorien eingeteilt und analysiert. Die Ergebnisse sehen folgendermaßen aus:

Abbildung 7

\section{Prozentualer Anteil der Hörersignale in Abhängigkeit von den Satzkategorien}

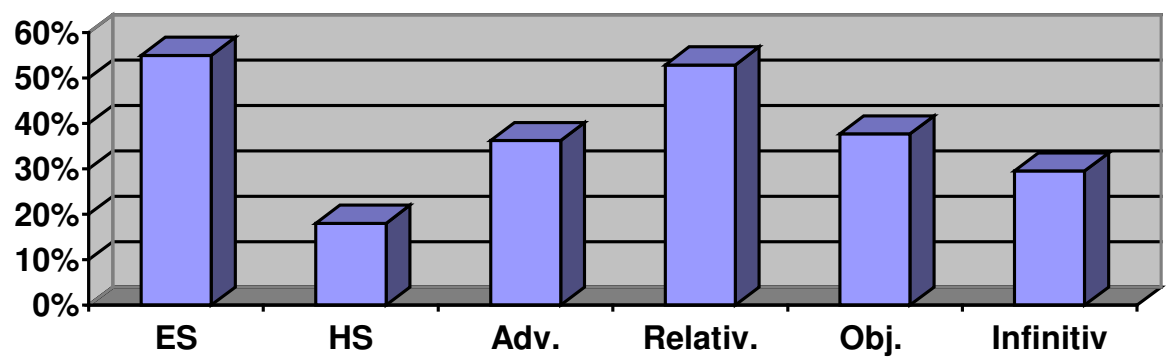

Aus dem Diagramm ist es ersichtlich, daß die Frequenz der Hörersignale je nach Satzkategorien etwas variiert: ES (einfache, erweiterte sowie gleichkoordinierte Sätze) werden am häufigsten von Hörersignalen begleitet, während HS (Hauptsätze) eine sehr niedrige Quote aufweisen. Die hohe Distribution der Hörersignale auf allein stehende Sätze (ES) kann dadurch erklärt werden, daß Sätze dieser Kategorie von deutschen Hörern als eine abgeschlossene Einheit betrachtet werden, die eine gewisse Menge an Information besitzt, die wiederum auf einmal verarbeitet werden kann. ${ }^{308}$

Dagegen kann der niedrige Anteil der Hauptsätze aus Folgendem resultieren: Sie stellen des öfteren Sätze dar, die ankündigen, daß sich der informativ wichtige Teil wie der Denkinhalt, das Zitat usw. anschließt. Solche sind z.B. Äußerungen wie ich denke, ich habe das Gefühl, sie sagte, ich habe gehört, das ist so, daß usw.; solche Sätze mit Verweischarakter enthalten weniger inhaltlich-thematisch relevante Informationen. Zweitens sind Hauptsätze in der Regel den abhängigen Sätzen vorangestellt. Es stellt sich nach der Berechnung heraus, daß 88,7\%

\footnotetext{
${ }^{307}$ Aufgrund einer flüchtigen Beobachtung des Videomaterials kann davon ausgegangen werden, daß die Anzahl des Kopfnickens bei den deutschen Hörern höher ist als die Anzahl verbaler Hörersignale.

${ }^{308}$ Siehe White 1986, S. 98ff.
} 
aller Hauptsätze in den deutschen Daten vorangestellt sind, also nicht am Ende des Satzgefüges stehen.

Abhängige Sätze und Infinitivkonstruktionen sind hingegen häufiger mit Hörersignalen ausgestattet als Hauptsätze; erstere verkörpern von der Menge der Information her eine ähnliche Größe wie ES. Die Frequenz der Hörersignale in abhängigen Sätzen sowie Infinitivkonstruktionen ist dennoch niedriger als in ES; dies kann zum Teil darauf zurückgeführt werden, daß sie oftmals $(62,7 \%)$ vorangestellt sind und deswegen ihr Vollzug keinen Abschluß der betreffenden Satzgefüge markiert, d.h. nach ihrer Beendigung sind die betreffenden Satzgefüge nur teilweise fertig und müssen noch weitergeführt werden, um syntaktisch und inhaltlich komplettiert $\mathrm{zu}$ werden. Nachfolgend wird die prozentuale Verteilung der Hörersignale in Abhängigkeit von der Satzstellung vorgeführt:

Abbildung 8

\section{Prozentualer Anteil der Hörersignale in Abhängigkeit von den Satzkategorien und von der Satzstellung}

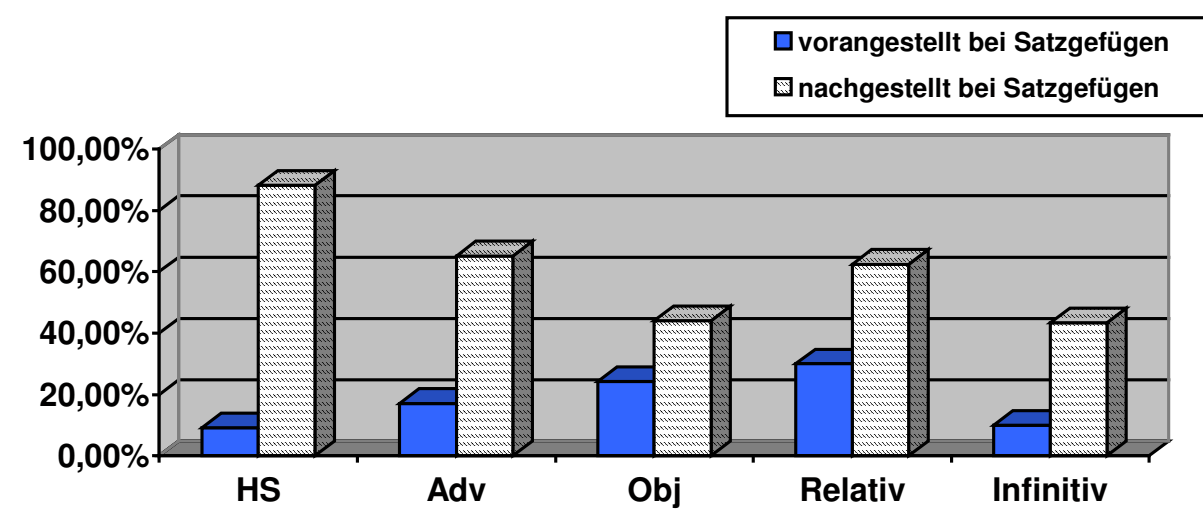

Am Diagramm kann man erkennen, daß unabhängig von den Satztypen eine gewisse Tendenz dahingehend besteht, daß sich Hörersignale häufiger am potentiellen oder faktischen Abschluß von Satzgefügen als von vorangestellten Sätzen befinden. ${ }^{309}$ Das deutet darauf hin, daß Hörersignale nicht nur einfach auf die Informationsmenge eines allein stehenden Satzes, sondern auf die Abgeschlossenheit eines Satzgefüges gerichtet sind, das aus einem Satz oder mehreren Sätzen bestehen kann. 
Hauptsätze und Infinitivkonstruktionen, die vorangestellt sind, d.h. nicht den letzten Satz eines Satzgefüges darstellen, erhalten verhältnismäßig weniger Hörersignale; das hängt meines Erachtens mit ihrem relativ geringen Informationswert zusammen: Sie kündigen oft nur an, daß auf sie abhängige Sätze folgen.

Geringfügig erhöhte Werte bei vorangestellten Adverbial-, Objekt- und Relativsätzen sind in meinen Daten vielerorts darauf zurückzuführen, daß der Hörer ab und an Hörersignale frühzeitig sendet, nämlich bevor das betreffende Satzgefüge vollzogen ist. Dafür soll ein Beispiel gezeigt werden:

Gesprächskontext 22

Roby kommt aus Aschersleben; Friedrich kannte diese Stadt bereits vom Namen her, weil der Vater seines Bekannten dort ein Geschäft aufgemacht hatte. Friedrich wollte jetzt erklären, woher er den Namen der Stadt kennt. Danach resümierte er seinen Redebeitrag mittels eines Satzgefüges:

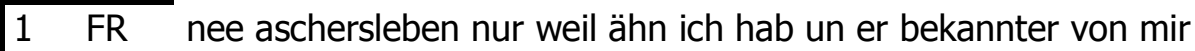
RO

2 FR dessen eltern hatten da mal irgendwie mal was mit nem RO

$\begin{array}{ll}3 & \mathrm{FR} \\ & \text { sanitärbetrieb über oder elektroinstallation gemacht }[\ldots . . . .]^{310}\end{array}$ RO

$4 \quad$ FR der name der sonst wahrscheinlich gar nichts sagen würde RO $\quad \Rightarrow$ uhmhm

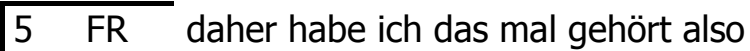
$\mathrm{RO} j a j a$

Nach der Erklärung von Friedrich ist Roby sehr gut darüber informiert worden (Zeile 4), woher Friedrich den Stadtnamen kennt. Das Hörersignal uhmhm in Zeile 4 kann deswegen so früh gesendet werden, weil es jetzt nur um eine Abrundung der vorangegangenen Begründung geht. Angesichts der großen Transparenz der Sprecherintention wartete Roby nicht mehr auf die Beendigung des Satzgefüges.

\footnotetext{
${ }^{309}$ White (1986, S. 87) stellt fest, daß 24\% der selbständigen Sätze, der Satzreihen sowie der Satzgefüge von Hörersignalen begleitet werden.
} 


\subsubsection{Die Frequenz der Hörersignale in Abhängigkeit vom finalen Tonverlauf am Satzende}

In diesem Kapitel soll geklärt werden,

- welches Tonmuster wie oft bei welchen Satzkategorien auftaucht,

- und welches Tonmuster bei welchen Satzkategorien wie oft Hörersignale hervorruft.

Es werden in meiner Arbeit drei Typen der Tonbewegung unterschieden: ${ }^{311}$ fallend, steigend und gleichbleibend. Darüber hinaus werden sie weiter danach differenziert, ob sie mit einer Pause ausgestattet sind. Insgesamt werden also sechs Typen für die Analyse dieses Kapitels aufgestellt:

- fallend mit oder ohne Pause: $\downarrow / \downarrow$,

- $\quad$ steigend mit oder ohne Pause: $\uparrow / \uparrow P$ und

- gleichbleibend mit oder ohne Pause: $\rightarrow / \rightarrow \mathrm{P}$.

Da es hierbei darum geht, Tendenzen aufzuzeigen, wird eine technisch verankerte präzise Untersuchung über den Zusammenhang zwischen Intonationskonturen und dem Auftreten der Hörersignale nicht angestrebt; aus diesem Grund wird das Tonmuster am Satzende nicht feiner differenziert. ${ }^{312}$ Hingegen wird das Pausenverhalten des Sprechers als wichtiger Auslöser der Hörersignale angesehen; ferner kommt noch hinzu, daß sich die Existenz und die Nicht-Existenz der Pause leichter als der Tonhöhenverlauf feststellen läßt.

Nachfolgend werden die Ergebnisse dargelegt und diskutiert. Dabei werden nur Hörersignale berücksichtigt, die an Satzgrenzen oder kurz danach auftreten. Hörersignale, die sich mit Elementen überlappen, die unmittelbar auf den letzten Satz folgen, werden ebenfalls berücksichtigt. Solche Elemente können je nachdem dem NF, dem VVF oder dem VF zugehörig sein. Als erstes wird die prozentuale Verteilung der jeweiligen Intonationstypen in den Sätzen vorgeführt.

\footnotetext{
${ }^{310}$ Einige Sätze wurden ausgelassen, weil sie für die Interpretation dieses Beispiels keinen Einfluß haben.

311 Es werden im allgemeinen fünf Tonmuster angenommen (Willkop 1988, S. 77); da ich hierbei keine technisch versierte Analyse angestrebt habe, sondern nur Tendenzen aufzeigen wollte, habe ich auf eine feinere Unterscheidung von Tonhöhenbewegungen verzichtet; es wurde nur darauf geachtet, ob die letzte Silbe des Satzes im Vergleich zur vorletzten Silbe steigend, fallend oder gleichbleibend ist.
} 
Abbildung 9

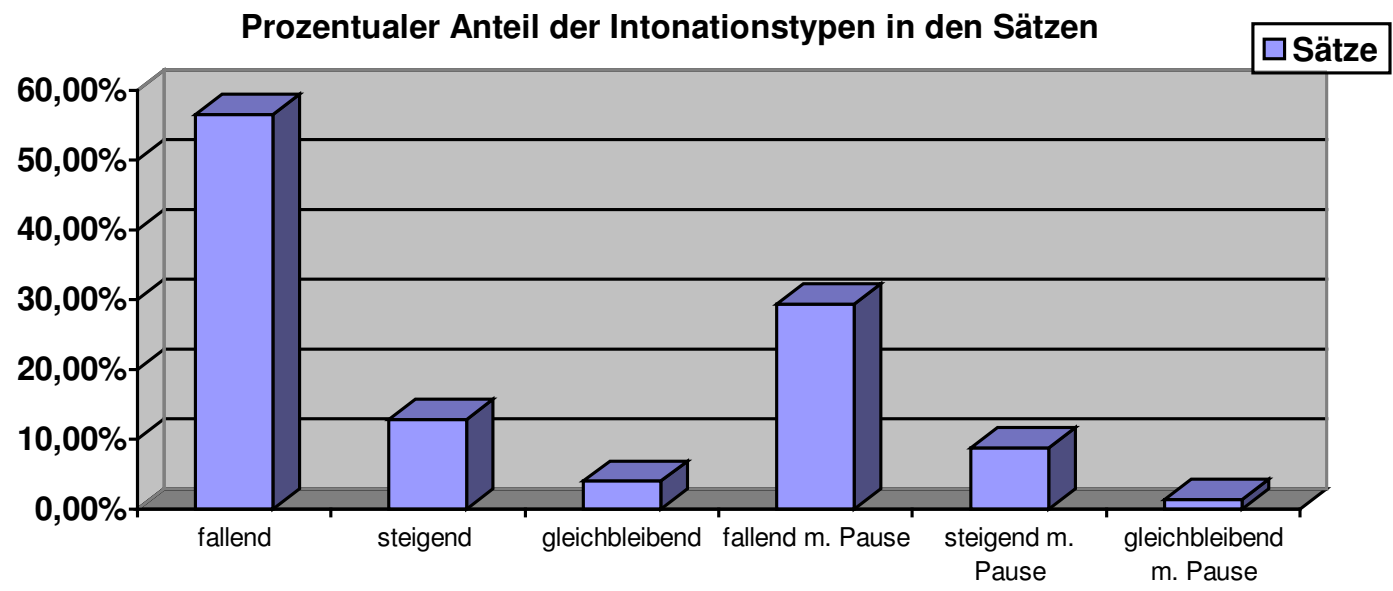

Bei der Berechnung stellte sich heraus, daß fallende Intonation ohne Pause in den deutschen Daten am häufigsten verwendet wird. Dieser Intonationstyp ohne Pause markiert im allgemeinen den Abschluß einer Satzäußerung wie eines allein stehenden, vorangestellten Satzes sowie eines Satzgefüges. Dabei interessiert den Sprecher der Verstehensstand des Hörers oder gar das Einverständnis zur Weiterrede nur zweitrangig, weil er pausenlos in den nächsten Satz übergeht, d.h. der Vollzug von Sätzen mit dieser Intonationsvariante besitzt für den Sprecher für seinen Redeplan keinen großen Stellenwert.

Den zweithäufigsten Intonationstyp bildet fallende Intonationskontur mit Pause; dieser indiziert vor allem die Finalität und zugleich die Erwartung einer Hörerreaktion: Der Sprecher signalisiert dadurch, daß sein Redebeitrag oder zumindest ein wichtiger Abschnitt seines Turns beendet ist oder einen strategisch wichtigen Punkt erreicht hat und er sich daher eine Rückmeldung des Hörers auf das bereits Gesagte wünscht. ${ }^{313}$ Aus meinen Daten geht hervor, daß nachgestellte Sätze der Satzgefüge sowie allein stehende Sätze häufiger mit fallender Intonation mit Pause versehen sind als vorangestellte Sätze der Satzgefüge. Dieses unterstützt die o.a. Interpretation dieses Intonationstyps: Es ist eher selten der Fall, daß der Sprecher nach dem Vollzug vorangestellter Sätze der Satzgefüge vom Hörer Hörerrückmeldungen erwartet, weil er bei Satzgefügen in der Regel dazu neigt, seinen Plan zu vollenden, um das betreffende Satzgefüge zu komplettieren.

\footnotetext{
${ }^{312}$ Sugito et al. (1998) haben technisch fundierte Untersuchungen durchgeführt.
} 
Steigender Tonhöhenverlauf ohne Pause wird in meinen Daten gelegentlich produziert. Die Hebung der Stimme am Satzende zeigt „eine wie auch immer geartete Unabgeschlossenheit“ an. $^{314}$ Da darauf keine Pause folgt, deutet dies darauf hin, daß es dem Sprecher nicht erforderlich erscheint, nach dem Abschluß von Sätzen mit diesem Intonationstyp verbale Hörersignale zu erhalten, weil er vorerst lieber seinen Redeplan, der oft aus einem Bündel von mehreren Sätzen besteht, fortführen will. Der Befund, daß viele der vorangestellten Sätze bei Satzgefügen durch diesen Intonationstyp realisiert werden, spricht für die o.a. Funktion dieser Intonationsvariante.

Pausen, die auf ein steigendes Tonmuster folgen, übermitteln dem Hörer: Der Sprecher hat zwar seinen Redeplan noch nicht komplett durchgeführt, aber er will sich trotzdem jetzt das Verstehen des bereits Gesagten vom Hörer bestätigen lassen, um in seiner Rede fortfahren zu können. ${ }^{315}$ So gibt steigende Intonation, die mit einer Pause ausgestattet ist, dem Hörer einen Anlaß, mittels Hörersignalen darauf zu reagieren, um dem Sprecher das Verstehen zu bekunden und ihn dadurch zur Weiterrede zu ermutigen.

Gleichbleibende Intonation mit oder ohne Pause wurde sehr wenig an Satzenden produziert. Sie zeigt vordergründig Progredienz an; bei gleichbleibender Intonation mit Pause kommt außerdem ein weiterer Aspekt zum Ausdruck, daß nämlich der Sprecher gerade überlegt, wie er den Turn weiterführen soll. In diesem Fall dient die Pause nicht in erster Linie dazu, verbale Hörersignale zu veranlassen, sondern eher dazu, Zeit zur Redeplanung zu gewinnen. Überwiegend sind Satzenden der vorangegangenen Sätze der Satzgefüge sowie der allein stehenden Sätze mit einer eher gleichbleibenden Intonation ausgestattet als Satzenden der letzten Sätze der Satzgefüge.

Im folgenden wird ein Diagramm in bezug auf die Distribution der Hörersignale auf die jeweiligen Intonationstypen vorgeführt:

\footnotetext{
${ }^{313}$ Vgl. H. Schmidt 1983, S. 76; nach Willkop (1988, S.78) wird der Senkung der Stimme im allgemeinen die Funktion zugeschrieben, die Abgeschlossenheit einer Äußerung anzuzeigen.

314 Willkop 1988, S. 78. Ähnlich charakterisiert H. Schmidt die suprasegmentale Struktur der Sprecheräußerungen, die ansteigende und hochbleibende Tonhöhe, verstärkte Intensität und gedehnte Ultima aufweisen; er nennt diese Auflösestruktur Progredienz (H. Schmidt 1983, S. 42-44).

${ }^{315}$ Vgl. H. Schmidt 1983, S. 72.
} 
Abbildung 10

\section{Prozentualer Anteil der Hörersignale in Abhängigkeit vom Tonmuster}

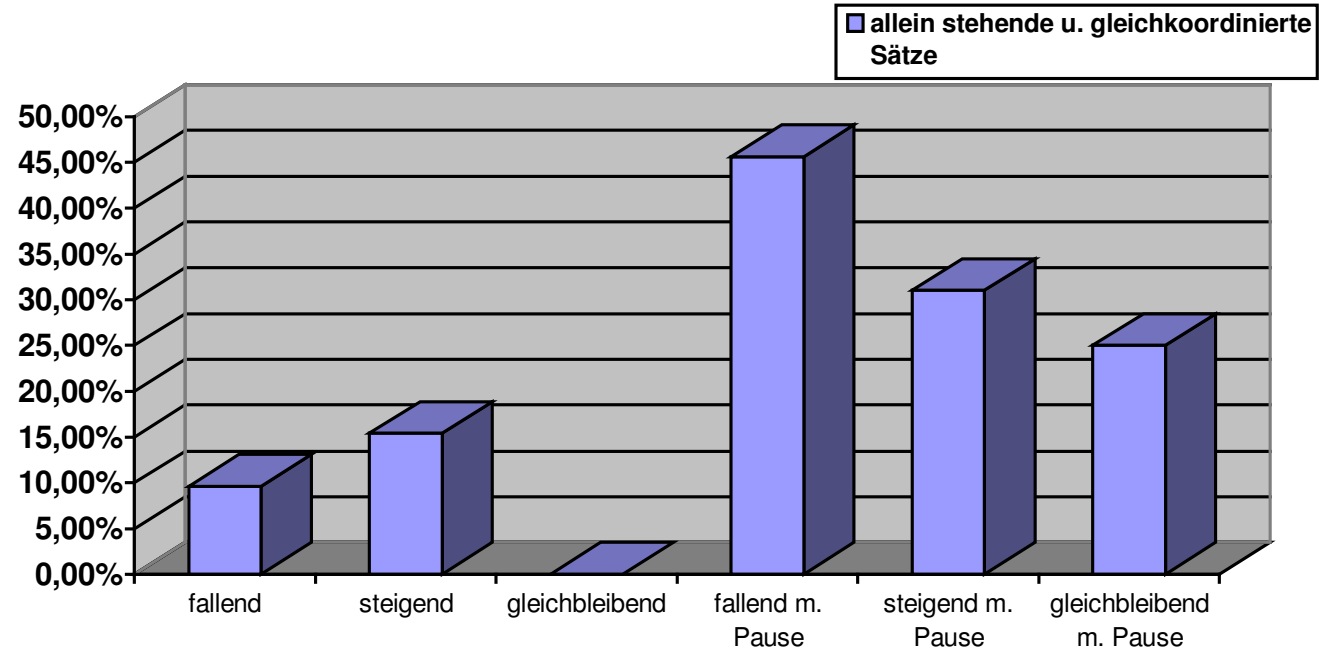

Die fallende Intonationskontur mit Pause erhält die höchste Quote der Hörersignale. Hörersignale treten also bevorzugt auf, wenn der Abschluß einer Satzäußerung (eines Satzes oder eines Satzgefüges) intonatorisch indiziert wird, und wenn der Sprecher mittels Pause vom Hörer verbale Reaktionen verlangt. Es ist ebenso nicht verwunderlich, daß der Typ steigender Intonation mit Pause relativ häufig Hörersignale hervorruft, weil eine steigende Intonation durch die darauf folgende Pause unterstrichen ist.

Die niedrigeren Quoten beim fallenden und steigenden Typ ohne Pause können darauf zurückgeführt werden, daß dem Hörer eine angemessene Plazierung der Hörersignale durch das Fehlen der Pause an Satzgrenzen erschwert wird. An jenen Stellen erwartet der Sprecher keine verbale Hörerreaktion, sondern zieht es vor, den Turn ohne Pause in einem Zug fortzusetzen. So kann er eventuell der Gefahr entkommen, das Rederecht (den Turn) während der Pause zu verlieren.

Bei gleichbleibender Intonation ohne Pause ist die Quote relativ niedrig. Sätze mit diesem Intonationstyp besitzen in meinen Daten oftmals keinen hohen Informationswert - oft sind sie Äußerungen folgender Art wie: das ist so, mal gucken usw. -, folglich ist es nicht überraschend, daß am Ende solcher Satzäußerungen generell weniger Hörersignale eingesetzt werden. Dabei trägt auch die Nicht-Existenz der Pause ebenso dazu bei, daß an Satzenden mit dieser Intonationskontur nur wenige Hörersignale auftreten. Gleichbleibende Intonation mit Pause wird fast genauso selten wie ihre pausenlose Version von Hörersignalen begleitet. Eine 
Erklärung für diesen Befund könnte sein, daß der Sprecher wegen seiner Schwierigkeiten mit dem Redeplan Pausen einlegt, um Zeit zur Neuerstellung des Redeplans zu gewinnen. In der Tat sind Sätze mit dieser Intonationsvariante zum Teil durch Verzögerungen wie Satzabbrüchen, gefüllten Pausen, merklich längeren Pausen in der Sprecherrede usw. gekennzeichnet. An solchen Stellen tendiert der Hörer dazu, Hörersignale zurückzuhalten, weil er den Sprecher bei der Problembeseitigung nicht stören will ${ }^{316}$.

Ferner ist die Frequenz der Hörersignale vom Satzstatus abhängig: Letzte Sätze der Satzgefüge und allein stehende Sätze, die zu diesem Intonationstyp gehören, werden wesentlich häufiger als vorangestellte Sätze der Satzgefüge von Hörersignalen begleitet. Das heißt, daß der Hörer vorsichtig ist, Hörersignale nach dem Vollzug vorangestellter Sätze zu senden, weil er weiß, daß die betreffenden Satzgefüge, denen die vorangestellten Sätze untergeordnet sind, noch nicht komplettiert sind.

Zuletzt wird zur Veranschaulichung noch ein Diagramm präsentiert:

Abbildung 11

Prozentualer Anteil der Hörersignale in Abhängigkeit vom Satzstatus und von den Intonationstypen

$\square$ vorangestellt

⿴nachgestellt

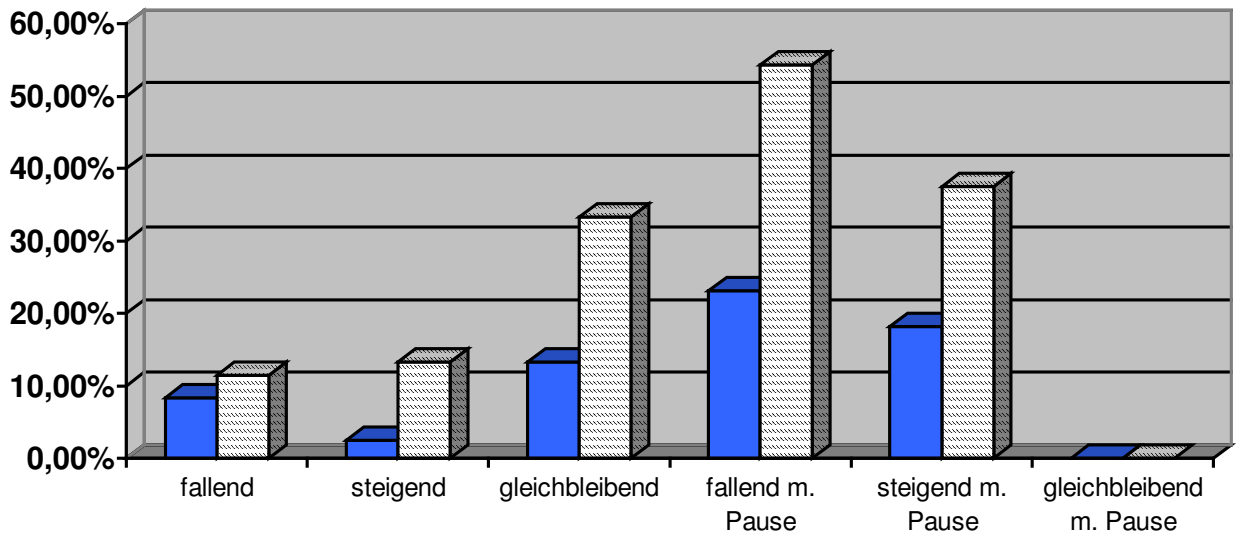

Die Quoten der vorangestellten sowie der nachgestellten Sätze bei Satzgefügen sind bei fallender und steigender Intonation mit Pause höher als ohne Pause. Das bedeutet, daß Pausen

\footnotetext{
${ }^{316}$ Nach White (1986, S. 109) treten Hörersignale in ihren amerikanischen Daten bei Formulierungsschwierigkeiten weniger oft auf.
} 
in jenem Fall als Auslöser der Hörersignale fungieren. Außerdem ist es klar erkennbar, daß das Zusammenkommen von beiden Faktoren (Pause und der Vollzug eines Satzgefüges) mehr Hörersignale hervorruft als Pause und die Beendigung eines vorangestellten Satzes. So kann der Effekt der Pause durch das Zusammentreffen mit bestimmten zusätzlichen Faktoren geschwächt oder gestärkt werden.

Nachfolgend werden die Quoten der Hörersignale bei nachgestellten Sätzen der Satzgefüge sowie bei allein stehenden Sätzen miteinander verglichen.

Abbildung 12

\section{Prozentualer Anteil der Hörersignale in Abhängigkeit vom Satzstatus und vom Intonationsmuster}

$\square$ allein stehende, gleichkoordinierte Sätze

⿴囗十achgestellte Sätze der Satzgefüge

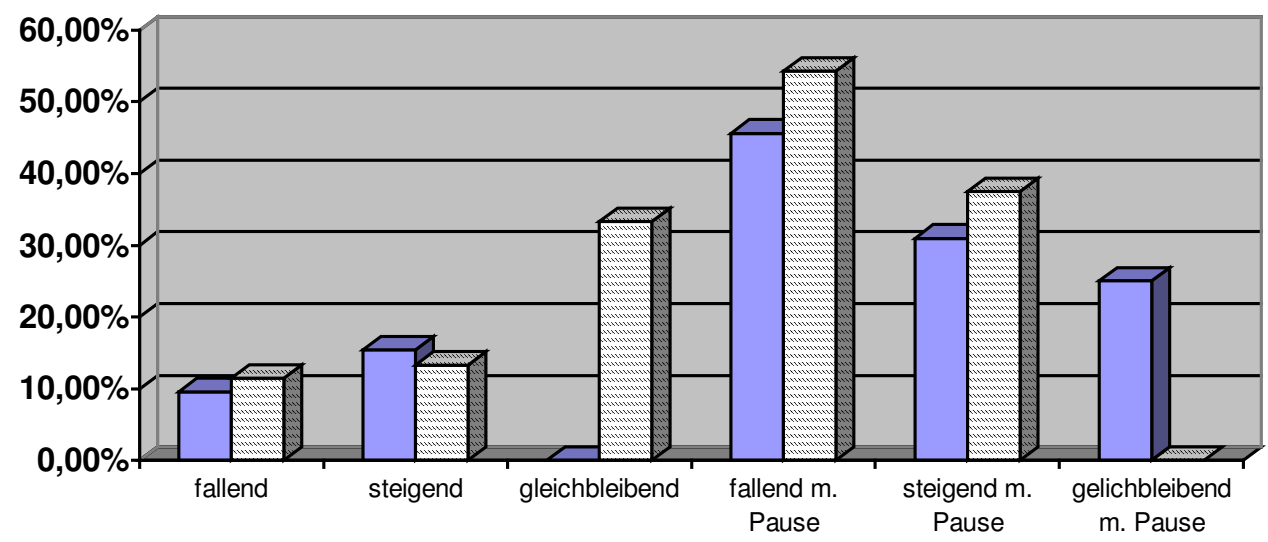

Die Quote der nachgestellten Sätze der Satzgefüge ist ebenfalls höher als jene bei allein stehenden und gleichkoordinierten Sätzen. Dabei zeigen die Werte der Hörersignale bei den jeweiligen Intonationstypen keine einheitliche Tendenz:

Aus dem Diagramm geht hervor, daß die Quoten der Hörersignale bei steigendem und fallendem Intonationstyp mit oder ohne Pause je nach Satzstatus (allein stehende und nachgestellte Sätze bei Satzgefügen) keine großen Unterschiede aufweisen. Sätze, deren Satzenden durch fallende oder steigende Intonation mit Pause realisiert werden, erhalten mit Abstand höhere Werte als jene mit den beiden Intonationstypen ohne Pause. Wegen der geringfügigen Differenzen in den Quoten bei allein stehenden und nachgestellten Sätzen läßt sich nicht eindeutig festlegen, welcher Satzstatus das Auftreten der Hörersignale stärker 
begünstigt. Man kann dennoch aufgrund der Befunde im Kapitel 4.3.1.1 davon ausgehen, daß der Vollzug eines Satzgefüges mit Pause zusammen mehr Hörersignale stärker nach sich zieht als der Abschluß eines allein stehenden Satzes und Pause. Ein Grund dafür liegt darin, daß in Satzgefügen eine größere Menge von Informationen als in allein stehenden und gleichkoordinierten Sätzen enthalten ist. Außerdem beinhaltet der Vollzug eines Satzgefüges häufiger den Abschluß einer Sinneinheit als dies bei letzteren der Fall wäre. Dieses Ergebnis führt wiederum zur Annahme, daß der Informationsmenge, die eine Sinneinheit präsentiert, als Auslöser der Hörersignale eine größere Bedeutung zukommt.

\subsubsection{Die Frequenz der Hörersignale in Abhängigkeit von Sprechersignalen am Satzende} Unter „Sprechersignalen“ verstehe ich direktive Gliederungspartikeln wie ja, nicht, ne, na, die am Ende eines Satzgefüges, eines Satzes oder einer Phrase vorkommen, um zum einen die vorangegangene(n) Äußerung(en) abzurunden und damit den Abschluß zu markieren (,Endmarkierung“ $)^{317}$ und zum anderen sich der Aufmerksamkeit, des Verständnisses oder der Zustimmung des Hörers zu vergewissern. ${ }^{318}$

Im kommenden wird überprüft,

- wie oft Sprechersignale am Satzende auftauchen und

- wie oft sie von Hörersignalen begleitet werden.

Insgesamt sind 12,9\% aller Sätze (Satzenden) mit Sprechersignalen versehen; Sprechersignale werden dabei mit Abstand häufiger am Ende der Satzgefüge oder der allein stehenden Sätze geäußert als vorangestellte Sätze bei Satzgefügen. Dies deutet darauf hin, daß Sprechersignale nicht nach jedem Abschluß eines Satzes, sondern eher nach dem Ende einer Satzäußerung auftreten, die für den Sprecher strategisch, d.h. für die weitere Planung seines Redebeitrags wichtig ist. An jenen Stellen veranlaßt der Sprecher den Hörer zur kurzen Rückmeldung, um sich des Verstehens des Gesagten durch den Hörer zu vergewissern und zugleich von diesem ein Einverständnis zur Fortsetzung zu erhalten.

\footnotetext{
${ }^{317}$ Siehe Schwitalla 1997, S. 53.

${ }^{318}$ Vgl. Rath 1979, S. 128.
} 
Die Quote der Hörersignale ist bei Sätzen mit Sprechersignalen höher als bei Sätzen ohne Sprechersignale. 24,4\% aller Sätze mit Sprechersignalen sind mit Hörersignalen versehen, während die Quote der Hörersignale bei Sätzen ohne Sprechersignale 17,5\% beträgt. Dieses Ergebnis, daß Sprechersignale stärker als Sätze mit verschiedenen Intonationskonturen Hörersignale begünstigen, ist nicht überraschend, denn Sprechersignale werden vom Sprecher bewußt eingesetzt, um die Zustimmung oder die Verstehensbestätigung des Hörers zu erlangen. Die Begleitquote der Hörersignale ist jedoch in meinen Daten zu gering, um daraus schlußfolgern $\mathrm{zu}$ können, daß zwischen Sprechersignalen und Hörersignalen ein komplementäres Verhältnis besteht, wie Rath (1979) es behauptet. ${ }^{319}$ Das Ergebnis meiner Untersuchung spricht eher für Sawada (1991), die keine statistische Signifikanz zwischen beiden festgestellt hat. ${ }^{320}$

In bezug auf Intonationstypen der Sprechersignale stellte sich heraus, daß Sprechersignale überwiegend mit steigender Intonation ohne Pause oder mit Pause realisiert werden: Beide zusammen machen fast $94 \%$ aller Sprechersignale aus. Es werden jedoch wenige Sprechersignale registriert, die zum fallenden Typ mit Pause gehören.

Von diesen drei Typen der Sprechersignale erreicht die steigende Intonationskontur mit Pause die höchste Quote der Hörersignale: 27,1\% aller Sprechersignale mit dieser Intonation mit Pause sind mit Hörersignalen versehen. Ein ähnliches Ergebnis erzielt die steigende Intonation ohne Pause: Die Quote beträgt bei diesem Typ 24,1\%. Hingegen gibt es keine Hörersignale, die sich auf Sprechersignale fallenden Typs mit Pause beziehen. Aus diesen Ergebnissen kann vermutet werden, daß Sprechersignale mit steigender Intonation einen der einflußreichen Faktoren für das Auftreten der Hörersignale darstellen. Ob Sprechersignale mit fallender Intonation als Auslöser der Hörersignale betrachtet werden können, kann aufgrund der geringeren Anzahl an dieser Stelle nicht beantwortet werden.

\subsubsection{Die Frequenz der Hörersignale in Abhängigkeit von Merkmalen von Sätzen in den japanischen Daten}

In diesem Kapitel soll wie in den deutschen Daten ermittelt werden, wie häufig Hörersignale in Abhängigkeit von Merkmalen von Sätzen auftreten; dabei wird die Anzahl der

\footnotetext{
${ }^{319}$ Siehe Rath 1979, S.128.

${ }^{320}$ Sawada 1991, S. 72.
} 
Hörersignale zur Gesamtzahl der jeweiligen Merkmale (Satzkategorien, Satzstellung und Intonationskonturen des Satzendes) ins Verhältnis gesetzt.

\subsubsection{Die Satzkategorien für die Analyse der japanischen Daten}

Zuerst sollen hierbei Satzkategorien vorgestellt werden, die in diesem Kapitel verwendet werden: ${ }^{321}$

- allein stehende Sätze: einfache, erweiterte oder gleichkoordinierte Sätze: ${ }^{322}$

- Vru-Sätze: Sie werden grammatisch komplett abgeschlossen.

- Vte-Sätze: Sie kündigen die Fortsetzung an.

- Sätze mit shi: Sie kündigen die Fortsetzung an.

- Adversative Sätze: Sie indizieren einen Gegensatz.

- Abhängige Sätze:

- Adverbiale Sätze (konditionale, kausale, temporale, konzessive, finale Sätze)

- Objektsätze

- To iu-Sätze

- Attributive Sätze

Vru-Sätze enden mit dem Verb der Schlußform: Verbstamm $+u / r u$ und zeigen an, daß der betreffende Satz grammatisch und inhaltlich komplett abgeschlossen ist. An das Verb der Schlußform können ein Hilfsverb der Höflichkeit masu und/oder eine oder zwei satzfinale Postpositionen (slPP) wie ne, yo usw. angehängt werden:

\begin{tabular}{|c|c|c|c|c|}
\hline Jap. Satz & kyô daigaku-e & ik.i.masu & yo & ne \\
\hline Positionen & $\mathrm{VE}$ & $\begin{array}{lll}\mathrm{V} & \mathrm{HV}\end{array}$ & SIPP & SIPP \\
\hline Wortbedeutng & (heute) (zur Uni) & (gehen) & (doch) & (oder) \\
\hline Satzbedeutung & \multicolumn{4}{|l|}{ Sie gehen doch $\mathrm{h}$} \\
\hline
\end{tabular}

Vru-Sätze können allein stehen oder einem oder mehreren abhängigen Sätzen übergeordnet sein, also als Hauptsätze fungieren. Hauptsätze sind im Japanischen in der Regel dem/den Nebensätzen nachgestellt. In diesem Fall markiert ihr Vollzug den Abschluß der jeweiligen untergeordneten Satzverbindungen.

\footnotetext{
${ }^{321}$ Hier werden nicht alle Satzkategorien im Japanischen behandelt, sondern nur solche, die für meine Analyse relevant sind.
} 
Vte-Sätze zeichnen sich dadurch aus, daß sie die Verbform: Verbstamm $+(i)+t e$ aufweisen und indizieren, daß sie durch andere Sätze fortgesetzt werden. Die semantische Beziehung zwischen dem Vte-Satz und dem darauf folgenden Satz kann verschiedener Art (Vorzeitigkeit, Modalität, Zweck, Grund usw.) sein:

\begin{tabular}{|c|c|c|c|c|}
\hline Jap. Satz & kyô hachiji-ni & oki.te & ha-o & migaita \\
\hline Position & $\mathrm{VE}$ & Vte & $\mathrm{VE}$ & Vru \\
\hline Wortbedeutung & (heute) (um 8:00) & (aufgestanden) & (Zähne) & (geputzt) \\
\hline Satzbedeutung & Heute bin ich um & aufgestanden ur & abe die $Z_{i}$ & e geputzt. \\
\hline
\end{tabular}

Vte-Sätze können z.B. durch Vru-Sätze, Vte-Sätze, adversative Sätze. Sätze gleichkoordiniert werden. Sie sind oftmals inhaltlich in sich abgeschlossen und selbständig wie Vru-Sätze, wobei erstere weniger direkt wirken als letztere. Außerdem können Vte-Sätze ebenso Hauptsätze darstellen und einen oder mehrere abhängige Sätze bei sich haben; dabei runden sie oft eine satzübergreifende Sinneinheit inhaltlich ab, obwohl sie von der Verbform her eine Fortsetzung andeuten.

Shi-Sätze enden mit der kjPP shi, die sich an das Verb anschließt; dabei indizieren sie eine additive Abfolge.

\begin{tabular}{|c|c|c|c|}
\hline Jap. Satz & kyô-wa tenki-mo & shi & attakai \\
\hline Position & \begin{tabular}{ll|}
$\mathrm{VE}$ & $\mathrm{VE}$ \\
\end{tabular} & $\mathrm{kjPP}$ & $\mathrm{V}$ \\
\hline Wortbedeutung & (heute) (das Wetter) & (ist gut) (und außerdem) & (warm) \\
\hline Satzbedeutung & Heute ist das Wetter & on und außerdem warm. & \\
\hline
\end{tabular}

Hierbei gilt Ähnliches wie bei Vte-Sätzen.

Adversativsätze werden durch kjPPen wie ga und keredomo realisiert; sie werden ebenso an das Verb angehängt:

\begin{tabular}{|c|c|c|c|}
\hline Jap. Satz & $k y \hat{-}-w a$ tenki-wa & keredomo & samui \\
\hline Position & $\mathrm{VE}$ & $\mathrm{kjPP}$ & $\mathrm{V}$ \\
\hline Wortbedeutung & (heute) (das Wetter) & (ist gut) (aber) & (kalt) \\
\hline Satzbedeutung & Heute ist das Wetter & ön, aber kalt. & \\
\hline
\end{tabular}

\footnotetext{
${ }^{322}$ Siehe Kato et al. 1990, S. 174-177.
} 
In einigen Fällen stellen adversative Sätze eine Äquivalenz zu den entsprechenden VruSätzen dar, weil sie trotz der kjPP des Gegensatzes eine inhaltliche Abgegrenztheit und Selbständigkeit wie Vru-Sätze indizieren; ${ }^{323}$ im Vergleich zu einfachen Sätzen wirken „selbständige“ kjPP-Sätze milder und sanft. Adversative Sätze, die als Hauptsatz fungieren, schließen ebenso wie Vte- oder shi-Sätze des öfteren eine größere Informationseinheit inhaltlich ab.

Adverbiale Sätze wie z.B. kausale, konzessive, finale oder auch konditionale Sätze werden im Japanischen meistens durch satzletzte konjunktionale Postpositionen wie noni (obwohl), node (weil) usw. zum Ausdruck gebracht. Adverbiale Sätze können in der Regel nicht allein stehen wie Vru-Sätze oder sanftere Äquivalenzformen für Vru-Sätze darstellen, sondern benötigen die Hauptsätze, um inhaltlich komplett zu sein; sie stellen also Gliedsätze von untergeordneten Satzverbindungen dar und liefern vom Ganzen eine Teilinformation, die zusammen mit ihren jeweiligen Hauptsätzen eine Sinneinheit bildet. Die Satzstellung einer subordinierten Satzverbindung erfolgt normalerweise dadurch, daß der übergeordnete Satz dem abhängigen Satz nachgestellt wird:

\begin{tabular}{|c|c|c|c|}
\hline Satzkategorie & Adverbialsatz & & Hauptsatz \\
\hline Jap. Satz & kare-wa ninjin-o & node & $m e-g a$ \\
\hline Satzstruktur & n-sbj.pp n-obj.pp & $\mathrm{KjPP}$ & n-Sbjpp \\
\hline Bedeutung & (Karotten) (essen) & (weil) & (Augen) \\
\hline Satzbedeutung & weil er Karotten ißt, & & sind seine Augen gut \\
\hline
\end{tabular}

Nichtsdestotrotz kommt es vor, daß bei adverbialen Sätzen deren Hauptsätze weggelassen sind, was gelegentlich bei adverbialen Sätzen der Fall ist, die einen anderen abhängigen Satz aufweisen.

Objektsätze werden im Japanischen durch eine der Postpositionen wie to, tte, toka (daß) an die jeweiligen Hauptsätze angeschlossen. Ein komplexer Satz aus einem vorangestellten Objektsatz und einem darauf folgenden übergeordneten Satz ist folgendermaßen strukturiert:

${ }^{323}$ Ôishi (1984, S. 48) nennt diese Verwendung der kjPP „,die Umfunktionierung der kjPP in die satzletzte PP“. 


\begin{tabular}{|c|c|c|c|}
\hline Satzkategorie & Objektsatz & & Hauptsatz \\
\hline Jap. Satz & kare-ga ninjin-o & to & kanojo-wa iu \\
\hline Satzstruktur & N-Sbj.PP N-Obj.PP V & PP des Zitates & $\mathrm{N}-\mathrm{SbjPP}$ \\
\hline Wortbedeutung & (Karotten) (essen) & $(\mathrm{da})$ & $\overline{(\text { sie } \text { sagt })}$ \\
\hline Satzbedeutung & Sie sagt, daß er Karotten ißt. & & \\
\hline
\end{tabular}

Objektsätze sind normalerweise als Gliedsätze von ihren jeweiligen Hauptsätzen abhängig, aber können in Ausnahmefällen ohne übergeordnete Sätze stehen; dabei handelt es sich um eine Auslassung der Hauptsätze aufgrund der kontextuellen Transparenz. Solche allein stehenden Objektsätze indizieren die Fortsetzung des Turns:

\begin{tabular}{llll}
\hline Satzkategorie & \multicolumn{2}{l}{ Objektsatz } & nächster Satz \\
\hline Jap. Satz & yuki san ashita kuru tte & demo kanojo: \\
Satzstruktur & N-Sbj.PP Zeit V V PP des Zitates & & Konj N-Sbj.PP \\
Wortbedeutung & (Yuki) (morgen) (kommen) (daß) & & (aber)(sie ...) \\
Satzbedeutung & (Yuki, sagte,) daß sie morgen kommt, & aber sie ist .... \\
\hline
\end{tabular}

To iu-Sätze fungieren in vielen Fällen wie Relativsätze im Deutschen; in diesem Fall werden sie durch die Kombination von einer der Postpositionen wie to, tte, toka (daß) und dem Verb iu (heißen) mit dem Bezugsnomen verbunden: ${ }^{324}$

\begin{tabular}{lllll}
\hline Satzkategorie & To iu-Satz & & Hauptsatz \\
\hline Jap. Satz & kare-ga & ninjin-o taberu & to iu no-wa & uso da \\
Satzstruktur & N-Sbj.PP & N-Obj.PP $\quad$ V & PP+V & \\
Wortbedeutung & (er) $\quad$ (Karotten) $\quad($ essen) & (daß man sagt) & (Lüge) \\
Satzbedeutung & Daß er angeblich Karotten ißt, ist eine Lüge. & \\
\hline
\end{tabular}

Ferner können to iu-Sätze als Mittel zur Nachformulierung verwendet werden:

\begin{tabular}{lllll}
\hline Satzkategorie & To $i u$-Satz & & Hauptsatz \\
\hline Jap. Satz & kare-wa & konai & to iu $\mathrm{ka}$ & korarenai $n$ desu \\
Satzstruktur & N-sbj.pp & V+neg & PP+v+pp & \\
Wortbedeut. & (er) & (nicht kommen ) & (oder besser gesagt) & (kann nicht kommen) \\
Satzbedeutung & Er kommt nicht, oder besser gesagt: er kann nicht kommen. \\
\hline
\end{tabular}

\footnotetext{
${ }^{324}$ To iu bedeutet „etwas, was folgendermaßen heißt“; z.B. nihon to iu kuni (Land, das Japan heißt).
} 
Ebenso können manche to iu-Sätze ohne ihre Hauptsätze stehen. So kann im obigen Beispiel ggf. der Hauptsatz weggelassen werden, wodurch die eventuell verletzende Behauptung, daß „er nicht kommt“, etwas indirekter wirkt.

Als Attributsätze gelten in dieser Arbeit Sätze, die an eines der folgenden Satzelemente angehängt werden:

- an ein Bezugsnomen,

- an ein „Formalnomen“, 325

- an ein Nominalisierungselement wie no,

- an eine modifizierende Postposition wie gurai (ungefähr so viel), bakari (nur so viel) usw.

Ein Attributsatz, der sich sich einem Formalnomen anschließt, weist die folgende Struktur auf:

\begin{tabular}{|c|c|c|}
\hline Satzkategorie & Attributsatz & Hauptsatz \\
\hline Jap. Satz & kare-ga & mita \\
\hline Satzstruktur & N-Sbj.PP N-Obj.PP V & $\mathrm{V}$ \\
\hline Wortbedeutung & (er) $\quad$ (Karotten) $($ essen $) \quad(\mathrm{da} ß)$ & (gesehen) \\
\hline Satzbedeutung & $\mathrm{Da} ß$ er Karotten ißt, habe ich gesehen & \\
\hline
\end{tabular}

\subsubsection{Die Frequenz der Hörersignale in Abhängigkeit von Sätzen sowie Sätzen verschiedener Satzkategorien mit Berücksichtigung der Satzstellung}

Als erstes wird wie in den deutschen Daten die Häufigkeit der Hörersignale in Abhängigkeit von Sätzen errechnet: Die Quote der Hörersignale liegt im japanischen Datenmaterial höher als in den deutschen Daten: 57,9\% aller Sätze sind mit Hörersignalen ausgestattet. Dieses Ergebnis entspricht der Alltagserfahrung und den Ergebnissen einiger Studien. ${ }^{326}$

Ein Grund für die höhere Quote der Hörersignale ist, daß ein Drittel der Hörersignale in den japanischen Daten auf eine kleinere Informationseinheit wie die eines Wortes oder einer

\footnotetext{
325 Unter „Formalnomina“ versteht man Nomina, die ihre ursprünglichen Bedeutungen weitgehend verloren haben und eher grammatische Funktionen aufweisen; zu dieser Klasse gehören Nomina wie koto (Sache, Nominalisierung von Verben), toki (Zeit), tokoro (Ort), wake (Grund), yô (Art und Weise) usw. Hierzu Lewin 1984, S. 319, Basic Japanese-English-Dictionary 1993, S. 930 usw.

${ }^{326}$ Es wird oft sowohl von Japanern in Deutschland als auch von Deutschen berichtet, daß Japaner, auch wenn sie Deutsch reden, häufiger Hörersignale von sich geben als Deutsche. Außerdem behauptet v. Helmolt (1993, S.61), daß Japaner intensivere Hörerrückmeldungen von ihren Hörern erwarten als Deutsche.
} 
Phrase ausgerichtet sind, so daß sie ,mitten im Satz“ auftreten. Wenn man nur die Hörersignale berücksichtigt, die in Erwiderung auf eine Satzinformation geäußert werden, dann ergibt sich, daß 40,8\% aller Sätze von Hörersignalen begleitetet werden. Demnach sind die Quoten der Hörersignale in Abhängigkeit von Sätzen in den deutschen und in den japanischen Daten annähernd gleich. Es gibt einige Gründe Warum japanische Hörer mehr Hörersignale mitten im Satz einsetzen, um das Verstehen der kleineren Informationsträger zu bestätigen, dafür: Zum einen gibt der Sprecher in den japanischen Daten dem Hörer durch die Pause und die Dehnung der letzten Silbe einer syntaktischen Einheit des öfteren die Gelegenheit, Hörersignale zwischendurch zu senden. Außerdem kann die Haltung des japanischen Hörers eine Rolle dabei spielen, so daß er den Sprecher beim Weiterreden unterstützen will oder sich aktiver am Geschehen beteiligen und das Gespräch mit dem Sprecher gemeinsam gestalten will, ohne dabei den Turn des anderen zu übernehmen. ${ }^{327}$

Im folgenden betrachten wir den prozentualen Anteil der Hörersignale bei Sätzen verschiedener Satzkategorien:

Abbildung 13

\section{Prozentualer Anteil der Hörersignale in Abhängigkeit von Satzkategorien}

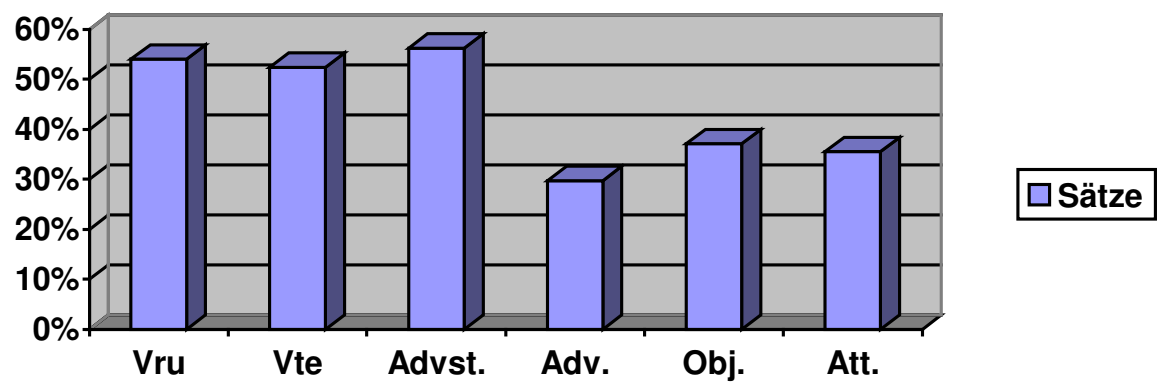

Aus dem Diagramm geht hervor, daß Vru-, Vte- und adversative Sätze mit Abstand mehr Hörersignale als abhängige Sätze hervorrufen. Zur Erklärung können folgende Faktoren herangezogen werden: Bei Vru-Sätzen, die etwa einfachen oder erweiterten Sätzen im Deutschen entsprechen, scheint ihre grammatische Abgeschlossenheit (Schlußform des Verbs) als Auslöser der Hörersignale zu fungieren. Vte-Sätze indizieren, daß ein

\footnotetext{
${ }^{327}$ Hierzu Mizutani (1988, S. 10). Sie ist der Meinung, daß der Hörer, der häufig „aizuchi“ sendet, als positiv angesehen wird.
} 
fortführender Satz folgt. Dies fördert das Auftreten der Hörersignale in erhöhtem Maße. Ähnliches gilt für adversative Sätze, die auf einen Gegensatz hindeuten, ohne ihn zu explizieren. Diese Sätze sind inhaltlich relativ selbständig und häufig mit Vru-Sätzen austauschbar; dabei implizieren sie etwas und mildern dadurch die Aussagekraft des Satzes $a b .{ }^{328}$ Gerade dieses offene Ende der adversativen Sätze zieht viele Hörersignale nach sich: Der Hörer fühlt sich dabei dazu motiviert, das Unausgesprochene selber zu ergänzen und dem Sprecher die erfolgreiche Erschließung des Unausgesagten anzuzeigen.

Drittens ist anzunehmen, daß der Sprecher am Ende von Vru-, Vte und adversativen Sätzen mehr als sonst versucht, durch verschiedene Mittel Hörerreaktionen zu evozieren. Der Abschluß solcher Sätze stellt oftmals eine Schnittstelle zwischen einer vollbrachten und einer neu beginnenden syntaktischen Einheit dar, an der der Sprecher den Verstehensstand des Hörers überprüfen will, um einen weiteren Redeplan auf den Hörer zugeschnitten gestalten zu können.

Abhängige Sätze wie adverbiale, attributive, to $i u$ - und Objektsätze erhalten insgesamt weniger Hörersignale als Vru-, Vte- und adversative Sätze. Das läßt sich darauf zurückführen, daß erstere in der Regel ihren übergeordneten Sätzen vorangestellt werden, d.h. sie sind normalerweise nicht am Ende eines Satzgefüges plaziert, was im Deutschen jedoch öfters der Fall ist. Es besteht in den japanischen Daten ebenso die Tendenz, daß der Hörer Hörersignale zurückhält, wenn die betreffenden Satzgefüge noch nicht vollbracht sind. Nichtsdestotrotz werden abhängige Sätze gelegentlich von Hörersignalen begleitet; das deutet wiederum darauf hin, daß eine größere Informationseinheit wie die eines Satzes an sich als Stimulus der Hörersignale fungieren kann, auch wenn sie sich mitten in Übermittlung einer komplexen Einheit befindet.

\footnotetext{
328 Mizutani (1988, S. 97) schreibt, daß Sätze mit der kjPP, die wie selbständige Sätze fungieren, als rücksichtsvoll und zurückhaltend empfunden werden.
} 
4.4.2.3 Die Frequenz der Hörersignale in Abhängigkeit von Sätzen verschiedener Satzkategorien mit Berücksichtigung der Satzstellung

Im folgenden wird die Häufigkeit der Hörersignale daraufhin überprüft, ob sie an einem Vollzugspunkt eines Satzgefüges auftauchen oder nicht. ${ }^{329}$ Als erstes sollen die Analysekategorien erläutert werden. Zunächst werden zwei Kategorien unterschieden:

- Sätze, denen keine abhängigen Sätze (adverbiale, attributive, Objektsätze usw.) untergeordnet sind; dazu gehören Sätze aller Satzkategorien, die nicht als Hauptsatz fungieren.

- Hauptsätze, denen ein oder mehrere abhängige Sätze untergeordnet sind; dazu werden ebenfalls Sätze aller Satzkategorien, die abhängige Sätze besitzen, gezählt.

Beide Kategorien werden jeweils weiter in zwei Gruppen unterteilt:

- Vru-, Vte-, shi- und adversative Sätze und

- adverbiale, attributive, to iu- und Objektsätze.

In dieser Arbeit wird der Abschluß einer komplexen Einheit folgendermaßen festgelegt: Hauptsätze, die aus Vru-Sätzen sowie aus gleichkoordinierten Sätzen bestehen, beenden (vorläufig) die jeweiligen subordinierten Satzverbindungen. Vte-, shi- und adversative Sätze verkörpern gewissermaßen inhaltliche Abgeschlossenheit und Selbständigkeit ${ }^{330}$ und stellen in vielen Fällen eine „,sanftere“ Alternative zum Vru-Satz dar, ${ }^{331}$ wie bereits häufig behauptet wurde. Daher haben sie mehr mit Vru-Sätzen gemein als mit Sätzen der anderen Satzkategorien wie Objekt-, attributiven und adverbialen Sätzen usw., die stärker mit ihren übergeordneten Sätzen verbunden sind.

\footnotetext{
${ }^{329}$ Die Bestimmung der Analysekategorien dieses Kapitels war mit einigen Problemen behaftet, weil im Japanischen das Ende eines Satzgefüges anders als in den deutschen Daten nicht immer an syntaktischen Merkmalen festgemacht werden kann. Sätze können durch gleich- oder subordinierte Sätze aneinander gereiht werden; dabei lassen sich Sinneinheiten oftmals nur inhaltlich-thematisch erkennen. Das liegt daran, daß sich Vru-Sätze, die einen syntaktischen Abschluß anzeigen, wenig in meinen Daten fanden: 14,4\% aller Sätze gehörten zu diesem Typ; davon waren ungefähr die Hälfte allein stehend.

330 Die Ergebnisse meiner Untersuchung zeigen sehr deutlich, daß satzabschließende Vru-Sätze und gleichgeordnete Sätze mehr gemein haben als Sätze anderer Kategorien.

${ }^{331}$ Ein selbständiger Satz, der mit keredomo abgeschlossen wird, wirkt im Vergleich zum Vru-Satz abgemildert und andeutungsvoll. Hierzu im Basis Japanese-Englisch-Dictionary 1993, S. 340, im Japanisch-JapanischWörterbuch Shinchôs 1979, S. 619.
} 
Im folgenden wird ein Beispiel für zwei verschiedene Arten des Hauptsatzes angeführt:

\begin{tabular}{|c|c|c|c|}
\hline & Konditionalsatz & $\begin{array}{l}\text { Objektsatz, Hauptsatz d. } \\
\text { Konditionalsatzes }\end{array}$ & $\begin{array}{l}\text { Hauptsatz d. } \\
\text { Objektsatzes }\end{array}$ \\
\hline \multirow{4}{*}{$\begin{array}{l}\text { Jap. Satz } \\
\text { Position } \\
\text { Wortbedeutung } \\
\text { Satzbedeutung }\end{array}$} & masa-wa yumi ga & kuru & itta \\
\hline & $\mathrm{V}+$ Kond. & PP des Zitates & \\
\hline & (Yumi) (kommen würde & (kommen) (daß) & (sagen) \\
\hline & \multicolumn{3}{|c|}{ Masa sagte, daß er kommt, wenn Yumi kommt. } \\
\hline
\end{tabular}

In diesem Beispiel ist ein Konditionalsatz einem Objektsatz untergeordnet, der wiederum an seinen Hauptsatz (Vru-Satz) angeschlossen ist.

Nachfolgend werden die Ergebnisse der Untersuchung dargelegt; dabei wurden nur Hörersignale berücksichtigt, die auf die Satzinformation bezogen sind. ${ }^{332}$ Zuerst wird der prozentuale Anteil der Hörersignale bei Vru-, Vte- und adversativen Sätzen vorgeführt: ${ }^{333}$

Abbildung 14

\section{Prozentualer Anteil der Hörersignale bei Vru, Vte und adversativen Sätzen}
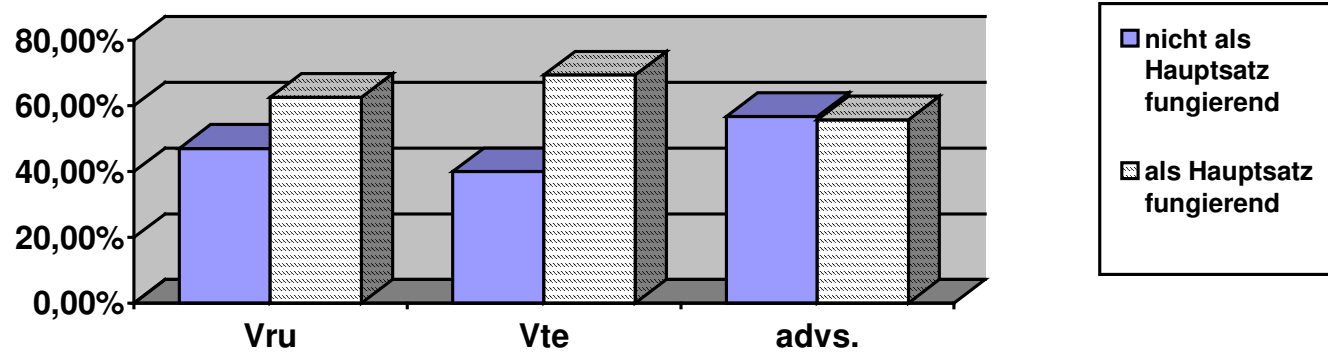

Die Quoten der Hörersignale sind bei allen drei Satzkategorien relativ hoch, d.h. bei Vru-, Vte- und adversativen Sätzen scheint allein der Vollzug des Satzes als wirksamer Auslöser der Hörersignale zu fungieren. Bei Vru-Sätzen ist deren syntaktische und inhaltliche Abgegrenztheit als Anlaß zur verbalen Hörerrückmeldung ausschlaggebend, während hingegen Vte-Sätze und adversative Sätze bei den Hörern einen stärkeren Reaktionsbedarf aufgrund ihrer andeutungsvollen Art des Äußerungsvollzugs erwecken.

\footnotetext{
${ }^{332}$ Hörersignale, die auf den betreffenden Satz gerichtet sind, betragen 73,9\% aller Hörersignale.

${ }^{333}$ Shi-Sätze sind nur wenig vertreten; daher werden sie mit Vte-Sätzen zusammengezählt.
} 
Zweitens ist es ersichtlich, daß als Hauptsatz fungierende Vru- und Vte-Sätze mehr Hörersignale hervorriefen als allein stehende Sätze. Dies läßt sich als Indiz dafür ansehen, daß eine größere Informationseinheit aus Satzverbindungen, die syntaktisch in einem Abhängigkeitsverhältnis stehen, in erhöhtem Maße das Auftreten der Hörersignale begünstigt als allein stehende Vru- oder Vte-Sätze.

Anders als bei Vru- und Vte-Sätzen liegen die Quoten bei adversativen Sätzen sowohl bei allein stehenden als auch bei als Hauptsatz fungierenden Sätzen gleichmäßig. Dies kann an dieser Stelle nicht zufriedenstellend erklärt werden; möglicherweise handelt es sich um eine kontextbedingte, abweichende Verteilung, die korrigiert werden kann, wenn noch längere Abschnitte untersucht werden würden.

Adverbiale, attributive und Objektsätze zeigen eine einheitlichere Tendenz, die den deutschen Daten ähnlich ist: $:^{334}$

Abbildung 15

Prozentualer Anteil der Hörersignale bei abhängigen Sätzen

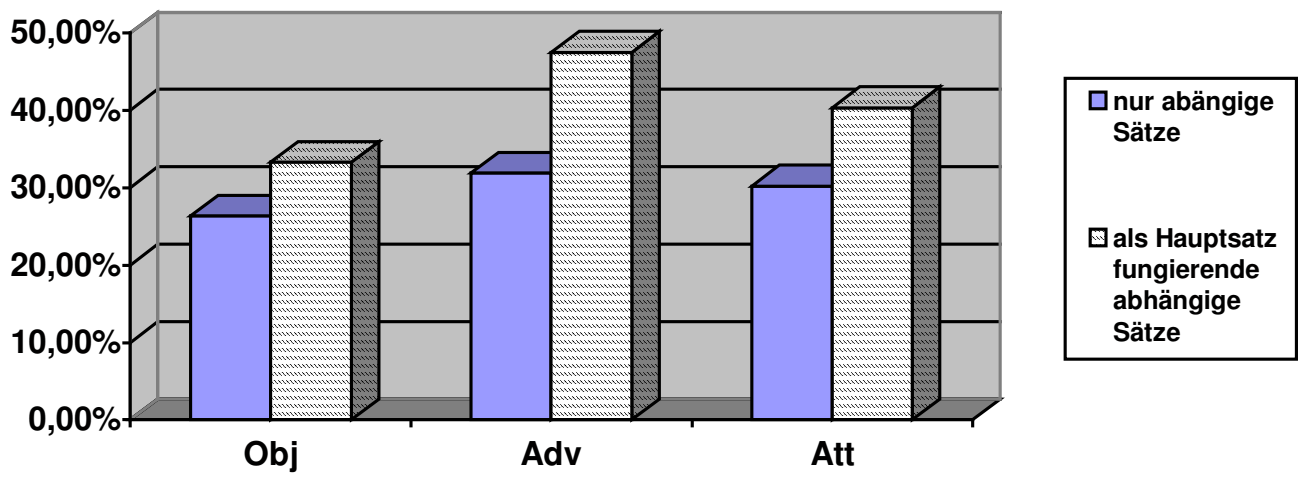

Objekt-, adverbiale- und attributive Sätze erhaten ebenfalls mehr Hörersignale, wenn sie als Hauptsatz fungieren, als wenn sie keinen Hauptsatz darstellten. Das unterstützt die These, daß eine größere Informationsmenge mehr Hörersignale initiieren kann. Andererseits ist der Anstieg der prozentualen Verteilung der Hörersignale bei den o.a. Sätzen geringer als bei Vru- oder Vte-Sätzen. Das heißt, daß japanische Hörer ebenso beim Abschluß eines 
abhängigen Satzes mit verbalen Signalen vorsichtig sind, weil sie wissen, daß der Sprecher noch den Hauptsatz äußern wird. Daß dennoch einige Hörersignale nach dem Vollzug eines abhängigen Satzes plaziert werden, hängt mit Folgendem zusammen: Abhängige Sätze tragen wichtige Teilinformationen, oftmals die Kerninformationen der betreffenden Satzgefüge; daher kann sich ggf. die Bedeutung der betreffenden komplexen Sätze bereits nach dem Vollzug der abhängigen Sätze so weit erhellen, daß der Hörer sie mit hoher Wahrscheinlichkeit erschließen kann.

Zur Veranschaulichung wird ein Beispiel angeführt:

Gesprächskontext 23

Ayami und Mako redeten über die Anforderungen der Japanologie; für Japanologen ist klassisches Japanisch ein Pflichtfach.

\begin{tabular}{|ll}
1 & AY \\
& de sono nihongaku o yatteiru node: + soide kobun o torana \\
MK & da ich jetzt klassisches Japanisch mache; und ich mache es jetzt,
\end{tabular}

2 AY kya ikenai tte iu kara ma totte +

weil man mir sagte, daß ich klassisches Japanisch nehmen muß und

MK u::m

Die Satzverbindung: soide kobun o torana kya ikenai tte iu kara (und weil man mir sagte, daß ich klassisches Japanisch nehmen muß) setzt sich zusammen aus einem Objektsatz und einem Kausalsatz; hierbei ist der Objektsatz dem Hauptsatz: tte iu (man sagt) übergeordnet, der sich der KjPP kara (weil) anschließt und so einen Kausalsatz bildet. Dieser Kausalsatz ist wiederum mit einem Vte-Satz ma totte (mache ich es jetzt und) verbunden.

Bezogen auf das obige Beispiel sendete Mako kein Hörersignal nach der Beendigung des ersten Nebensatzes: soide kobun o torana kya ikenai tte (daß ich klassisches Japanisch nehmen muß), sondern erst nach dem Vollzug des Kausalsatzes: soide iu kara (und da man mir sagte...), der als Hauptsatz für den o.a. Objektsatz agiert. Dabei ist der komplexe Satz noch nicht vollständig zu Ende gebracht, sondern erhält noch den Vte-Satz: ma totte (mache ich es jetzt und), von dem der Kausalsatz abhängt. Mako setzte hier ein Hörersignal u:m, weil sie zum einen das Verstehen der beiden vorangegangenen Sätze übermitteln will und zum

\footnotetext{
${ }^{334}$ To iu-Sätze und attributive Sätze werden als attributive Sätze zusammengefaßt.
} 
anderen die Bedeutung des Vte-Satzes, mit dem das betreffende Satzgefüge abschließt, erschlossen hat.

\subsubsection{Die Frequenz der Hörersignale in Abhängigkeit vom finalen Tonverlauf am Satzende}

Ähnlich wie in den deutschen Daten wird hierbei untersucht, welche Tonmuster am Satzende wie oft Hörersignale hervorrufen. Für die Analyse werden ebenfalls die finale Tonhöhenbewegung der jeweiligen Sätze einem der sechs Typen zugeordnet: ${ }^{335}$

- fallend mit oder ohne Pause: $\downarrow / \downarrow P$,

- $\quad$ steigend mit oder ohne Pause: $\uparrow / \uparrow \mathrm{P}^{336}$ und

- gleichbleibend mit oder ohne Pause: $\rightarrow / \rightarrow \mathrm{P}$.

Die Begründung für diese Vorgehensweise wurde bereits im vorigen Kapitel (4.3.2.3) erläutert. Hörersignale, die an dieser Stelle herangezogen werden, sind solche, die an Satzgrenzen oder unmittelbar danach gesendet werden; sie können sich je nachdem mit einer slPP desselben Satzes oder mit dem Element der EL (z.B. Konjunktionen), der SNS (Füllwörter zur Zeitgewinnung) und der VE (Verbergänzungen) überlappen.

Zuerst wird ein Diagramm gezeigt, das die prozentuale Verteilung dieser Intonationstypen in den Sätzen ermittelt:

\footnotetext{
${ }^{335}$ Koiso et al. unterscheiden ebenso drei Tonhöhenverläufe der finalen Mora-Region (der letzten Silbe) einer Intonationseinheit, wobei sie dazu noch zwei weitere Typen, das steigend-fallende sowie flach-fallende Muster, zur Analyse heranziehen.

${ }^{336}$ Vor allem nach steigender Intonation mit oder ohne Pause kann die letzte Silbe gedehnt werden.
} 
Prozentualer Anteil der Intonationstypen in den Sätzen

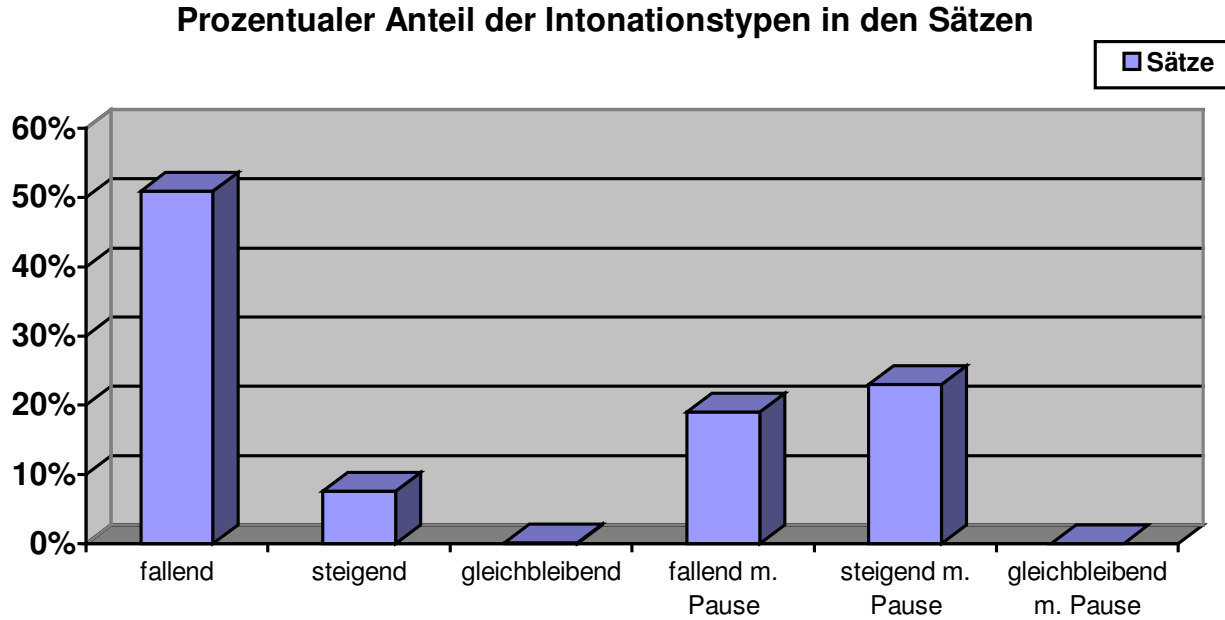

Es geht aus dem Diagramm hervor, daß fallende Intonation ohne Pause in den japanischen Daten am häufigsten verwendet wird. Ferner werden auch steigende und fallende Intonation mit Pause präferiert. Hingegen kommen steigende Intonation ohne Pause sowie gleichbleibender Tonhöhenverlauf mit oder ohne Pause weniger oft oder kaum vor. Die Ergebnisse sind denen der deutschen Daten relativ ähnlich.

Der fallende Intonationstyp indiziert ähnlich wie in den deutschen Daten einen allgemeinen Abschluß einer Satzäußerung, ${ }^{337}$ die jedoch für den Sprecher keine strategische Relevanz hat, sondern fortgesetzt wird, ohne ein explizites Einverständnis vom Hörers zu verlangen. Überwiegend werden Satzenden der Vru-Sätze oder der abhängigen Sätze fallend intoniert.

Fallender Tonhöhenverlauf mit Pause indiziert hingegen, daß der Abschluß der vorangegangenen Informationseinheit für den Sprecherplan besonders wichtig ist; daher erwartet der Sprecher an jenen Stellen eine verbale Hörerreaktion, die das Verstehen des Hörers übermittelt. Der Turnwechsel ist nach Satzenden mit diesem Intonationstyp mit Pause häufiger als nach Satzenden mit fallender Intonationskontur ohne Pause, wobei er nicht zwingend ist. Aus diesem Grund gehe ich davon aus, daß fallender Tonhöhenverlauf mit Pause nicht mit der Turnaufgabe gleichzusetzen ist. ${ }^{338}$

\footnotetext{
${ }^{337}$ Nach Koiso et al. (1998, S. 308) signalisieren flach-fallende und steigend-fallende Tonhöhenbewegungen in der finalen Mora-Region (der letzten Silbe des Satzes) „,hold“, d.h. der Sprecher will den Turn noch beibehalten und seine Rede weiterführen.

${ }^{338}$ Koiso et al. (1998, S. 312) sind der Meinung, daß stark steigende Intonation am Satzende „change“ bekundet und daher häufiger den Turnwechsel herbeiführt. Meine Daten widersprechen ihrer Ansicht.
} 
Steigende Intonationskontur ohne Pause ist in meinen Daten viel weniger vertreten. Dieser Typ wird häufig am Ende der Vte-Sätze, Konditionalsätze und attributiven Sätze registriert. Es ist eindeutig, daß steigende Intonation am Ende dieser Sätze dazu dient, ihren konsekutiven Charakter zu verstärken: Vte-Sätze zeigen aufgrund ihrer Verbform die Fortsetzung des Turns, während Konditionalsätze stets durch ihre übergeordneten Sätze ergänzt werden müssen. Bei attributiven Sätzen wird die letzte Silbe der Sätze oftmals gehoben, wodurch angedeutet wird, daß darauf das Bezugsnomen folgt. Der Wille des Sprechers zur Fortführung des Turns wird auch durch die Dehnung der letzten Silbe erkennbar; oft wird die finale Mora (Silbe) des Satzes bei steigender Intonation gedehnt. Bei diesem Intonationstyp ohne Pause wird jedoch vom Hörer gefordert, auf das Gesagte verbal zu reagieren.

Hingegen signalisiert steigende Intonation mit Pause über die Fortsetzung des Turns hinaus noch den Wunsch des Sprechers nach einer verbalen Reaktion, wobei der Sprecher bei steigender Intonation mit Pause mit der Übergabe des Rederechts rechnen muß, denn der Turnwechsel fand in meinen Daten oftmals nach Satzenden mit diesem Intonationstyp mit Pause statt.

Die Verteilung der Hörersignale in den verschiedenen Intonationstypen sieht folgendermaßen aus: 


\section{Prozentualer Anteil der Hörersignale in Abhängigkeit von Intonationstypen}

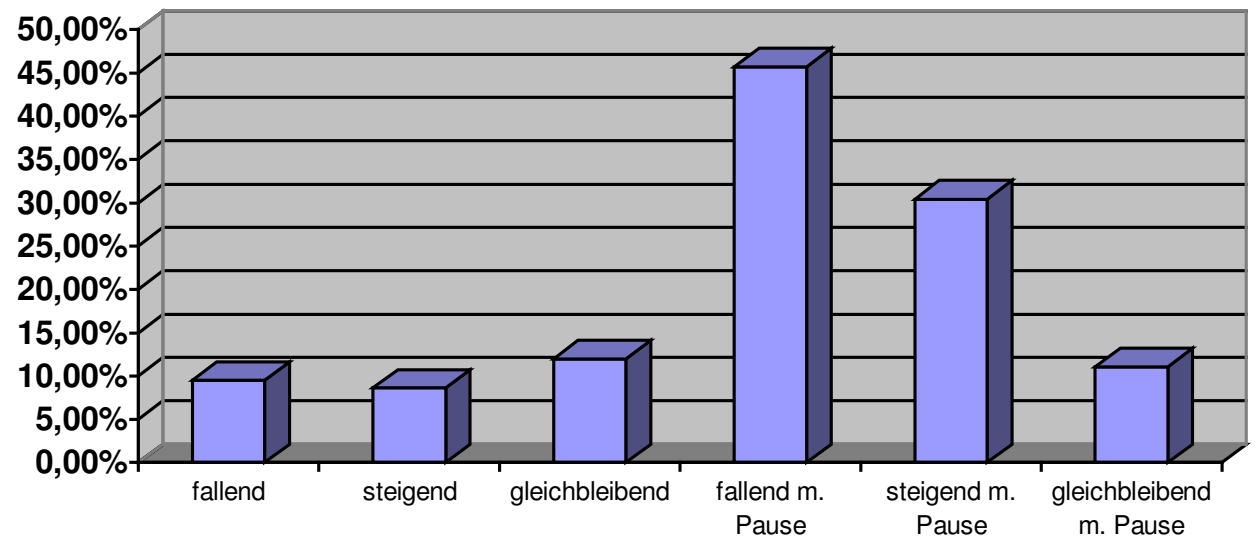

Aus dem Diagramm geht hervor, daß Hörersignale wie erwartet häufiger nach Satzenden mit den Intonationstypen mit Pause gesendet werden als ohne Pause; die Pause erweist sich ebenso in den japanischen Daten als einflußreicherer Auslöser der Hörersignale als das Intonationsmuster. Außerdem ist die Quote der Hörersignale bei Satzenden mit fallendem Intonationstyp mit Pause höher als bei Satzenden mit steigender Intonation mit Pause. $\mathrm{Ob}$ man daraus schlußfolgern kann, daß erstere als effektiverer Stimulus der Hörersignale fungiert als letzterer, bedarf einer genaueren Untersuchung, denn diese Befunde widersprechen sowohl den der bisherigen Studien ${ }^{339}$ als auch der Intuition .

${ }^{339}$ Vgl. Wahmhoff/Wenzel 1979, S. 276. 
Abbildung 18

\section{Prozentualer Anteil der Hörersignale in bezug auf den Satzstatus und Intonationskonturen}

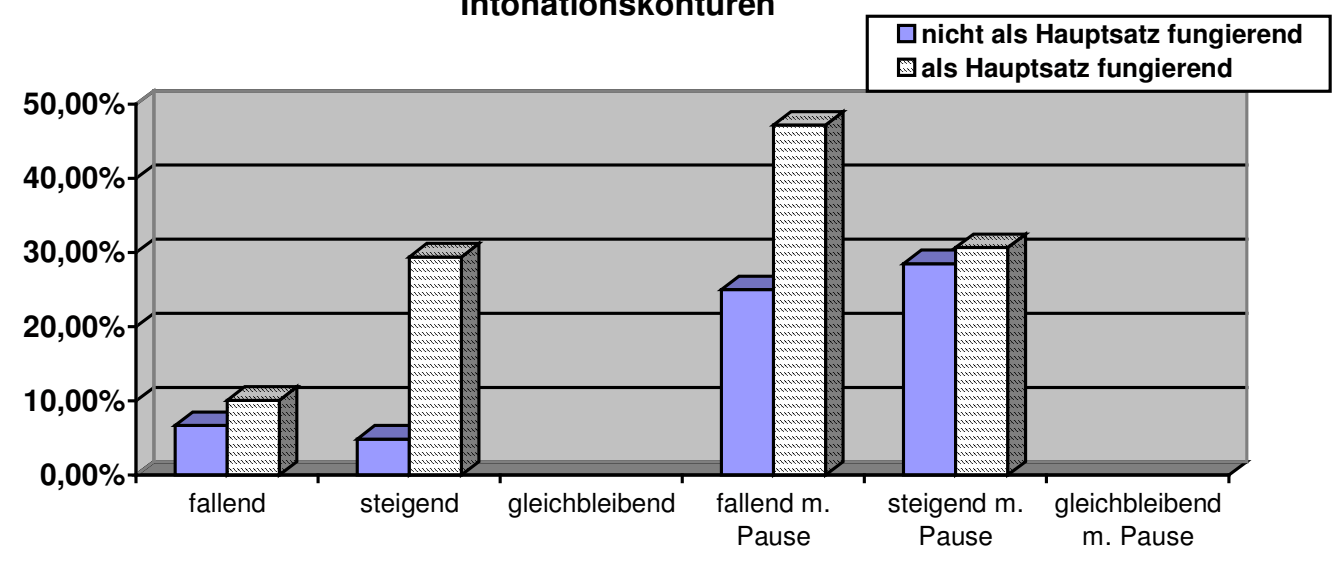

Sowohl bei Sätzen, die als Hauptsatz fungieren als auch bei Sätzen, die nicht als Hauptsatz fungieren, sind die Quoten der Hörersignale wie erwartet bei Intonationstypen mit Pause höher. Außerdem läßt sich eine Tendenz dahin gehend erkennen, daß Hauptsätze wesentlich höhere Quoten der Hörersignale (47,2\%) aufweisen als Sätze, denen kein Nebensatz untergeordnet ist (25\%). Das liegt daran, daß die Hauptsätze, denen abhängige Sätze untergeordnet sind, automatisch eine größere Informationsmenge und einen höheren Informationswert besitzen als Sätze, die keine abhängigen Sätze in sich tragen. Außerdem runden Hauptsätze oftmals eine größere Informationseinheit ab, die aus mehreren Sätzen besteht; dies ist vor allem bei als Hauptsatz fungierenden Vru-, Vte- und adversativen Sätzen der Fall; deren Abschluß kommt oft mit dem der Sinneinheit zusammen. Es kommt jedoch gelegentlich vor, daß adverbiale, attributive und Objektsätze ohne ihre Hauptsätze stehen. ${ }^{340}$ Am Ende solcher elliptischer Satzverbindungen wird die Wahrscheinlichkeit des Auftretens der Hörersignale erhöht.

Das steigende Tonmuster am Satzende mit Pause erzielt die zweithöchste Quote der Hörersignale. Die Begünstigung der Hörersignale in dieser linguistischen Umgebung ist ersichtlich: der Vollzug einer größeren Information, die im Anschluß an die Bestätigung des Hörers fortgesetzt werden soll. In bezug auf den Satzstatus der Sätze kann bei diesem Intonationstyp mit Pause nur eine geringfügige Erhöhung bei Hauptsätzen im Vergleich zu Sätzen, die nicht als Hauptsatz fungieren, festgestellt werden. Warum sich die Anzahl der

\footnotetext{
${ }^{340}$ Siehe Ôishi 1984, S. 47-48.
} 
Hörersignale bei Hauptsätzen nur so wenig erhöht, die an sich höhere Informationswerte als Nicht-Hauptsätze besitzen, läßt sich an dieser Stelle nicht klären. In bezug auf verschiedene Satzkategorien sind die Tendenzen nicht einheitlich.

Bei fehlender Pause nimmt die Häufigkeit der Hörersignale merklich ab, wie man am obigen Diagramm erkennen kann. Ein wichtiger Grund dafür ist, daß auf diese Intonationsvarianten keine Pausen folgen, die das Auftreten der Hörersignale begünstigen können. Bei fehlender Pause hat es der Hörer schwerer mit der rechtzeitigen Plazierung der Hörersignale und sieht außerdem keinen akuten Anlaß darin, sich verbal zurückzumelden, weil die Beendigung des betreffenden Satzes für den Sprecher keine große Bedeutung hat. Die Quote steigender Intonationstypen ohne Pause vor allem erhöht sich jedoch deutlich bei Hauptsätzen. Dies kann auf Folgendes zurückgeführt werden: Die Informationsmenge ist bei Hauptsätzen generell höher als bei Nicht-Hauptsätzen; außerdem bilden viele der Hauptsätze mit steigender Intonation den Abschluß der betreffenden Satzgefüge; dies veranlaßt den Hörer eher dazu, aus eigener Initiative Hörersignale an Satzgrenzen oder kurz danach einzusetzen.

\subsubsection{Die Frequenz der Hörersignale in Abhängigkeit von Sprechersignalen}

Sprechersignale, die sich in den japanischen Daten anhäufen, sind hauptsächlich satzletzte Postpositionen (slPP) wie ne (verstehst du), yo (es ist so, daß) und yone (es ist so, oder) Sie werden an das Verb bzw. das Hilfsverb der Höflichkeit angehängt.

Hinsichtlich der Intonationskonturen der Sprechersignale stellte sich heraus, daß 77,3\% aller Sprechersignale mit fallendem oder steigendem Tonhöhenverlauf mit Pause realisiert werden. Sprechersignale wie ne (nicht wahr) und yone (das ist so, verstehst du) wurden meistens steigend intoniert, hingegen sink die Stimme bei yo (das ist so, daß) in der Regel ab.

15,6\% aller Sätze enthalten eine oder zwei als Sprechersignale fungierende slPP. Sprechersignale sind bevorzugt in Vru-, Vte- und adversativen Sätzen distribuiert; die Quote der Sprechersignale ist insbesondere in Vru-Sätzen sehr hoch und liegt bei 56,1\%. Die Frequenz der Sprechersignale steigt ein wenig an, wenn an diese Sätze untergeordnete Sätze angeschlossen sind. Hingegen sind abhängige Sätze wie z.B. adverbiale, konditionale, attributive Sätze, gleich, ob sie gleichzeitig als Hauptsatz fungieren oder nicht, viel weniger mit Sprechersignalen versehen: 
Abbildung 19

Prozentualer Anteil der Sprechersignale

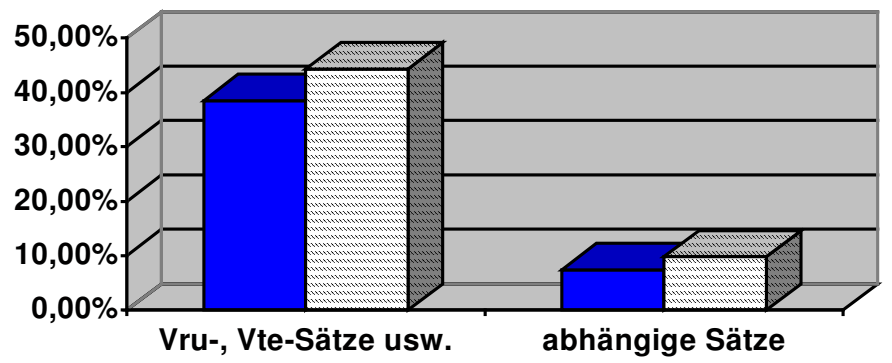

nicht als Hauptsatz

fungierend

@als Hauptsatz

fungierend

Das Diagramm zeigt deutlich, daß Sprechersignale den Abschluß einer Informationseinheit markieren, die sich syntaktisch und inhaltlich stärker von anderen Einheiten abgrenzt, was bei Vru-, Vte-, adversativen Sätzen oder generell bei Hauptsätzen der Fall ist. Hingegen treten bei abhängigen Sätzen, die keinen Hauptsatz darstellen, viel weniger Sprechersignale auf, weil sie sich in der Regel mitten in einem Satzgefüge befinden und daher für den Sprecher strategisch nicht von Bedeutung sind.

Sätze mit Sprechersignalen rufen mit Abstand mehr Hörersignale hervor als Sätze ohne Sprechersignale: Die Quote der Hörersignale, die nach Sprechersignalen beobachtet werden, beträgt 33,6\%, die Quote der Sätze ohne Sprechersignale hingegen 18,4\%. Demnach kann davon ausgegangen werden, daß Sprechersignale ebenso in den japanischen Daten einen effektiveren Auslöser der Hörersignale verkörpern als Intonationskonturen mit oder ohne Pause an Satzenden.

Hinsichtlich der Intonationstypen sind Sprechersignale mit steigender Intonation mit Pause am häufigsten: Ihre Quote beträgt 61,7\%. Außerdem wird steigende Intonation ohne Pause gelegentlich verwendet (18\% aller Sprechersignale); ebenso wie der Typ fallende Intonation mit Pause $(15,6 \%)$.

Von den Intonationsvarianten bewirken Sprechersignale mit steigender Intonation mit Pause am stärksten das Auftreten der Hörersignale: Die Quote der Hörersignale ist bei diesen Sprechersignalen höher als bei Sprechersignalen mit fallender Intonation mit Pause: Bei ersteren beträgt die Quote 48,1\%, bei letzteren 25\%. Die Verteilung der Hörersignale, die direkt nach dem letzten Inhaltswort des Satzes eingesetzt werden, ist umgekehrt, d.h. die 
Quote des fallenden Tonmusters mit Pause war höher als die des steigenden, pausierten Intonationstyps. Bei Sprechersignalen erzielt offenbar steigende Intonation mit Pause mehr Hörersignale als fallende Intonation mit Pause.

\subsubsection{Zusammenfassung}

Aus dem Vergleich zwischen den japanischen und den deutschen Daten ergibt sich Folgendes:

Die Gesamtquote der Hörersignale pro Satz ist wie erwartet in den japanischen Daten höher als in den deutschen Daten: 57,9\% der Sätze in den japanischen Daten sind mit Hörersignalen ausgestattet, während in den deutschen Daten die Quote 40,3\% beträgt. So geben also in meinen Daten japanische Hörer häufiger Hörersignale von sich als deutsche Hörer. Interessanterweise liegt der Unterschied zwischen den beiden Datengruppen nicht in der Frequenz der jeweiligen Hörersignale, die auf eine vergangene oder aktuell laufende Satzinformation bezogen sind, sondern in der Anzahl der Hörersignale, die sich nach einem kleineren Informationsträger wie dem eines Wortes oder einer Phrase richten, ${ }^{341}$ wie es sich im letzten Kapitel herausstellte. Die höhere Anzahl der Hörersignale mitten im Satz wird teils auf empirisch beobachtbare, linguistisch verankerte und teils auf kulturelle Ursachen zurückgeführt: Japanische Sprecher legen nach syntaktischen Einheiten in den VE (Verbergänzungen) häufiger Pausen ein oder dehnten die letzte Silbe solcher Einheiten. Außerdem scheinen japanische Hörer mehr als deutsche Hörer Wert darauf zu legen, nicht nur an Satzgrenzen, sondern zwischendurch mittels Hörersignalen den Sprecher zur Weiterführung des Turns zu motivieren.

Hörersignale, die sich meines Erachtens - sei es rechtzeitig, verspätet oder frühzeitig - auf eine Satzinformation beziehen, begleiten sowohl in den deutschen als auch in den japanischen Daten gut $40 \%$ aller Sätze. Obwohl man hier nicht von einer strikten Obligation sprechen kann, scheint beim Hörer ein gewisser Zwang zu bestehen, regelmäßig an bestimmten Stellen der Sprecheräußerungen verbal etwas zurückzumelden. Demnach kann man davon ausgehen, daß der Abschluß einer größeren Informationseinheit wie der eines Satzes in jedem Fall ein effektiver Einflußfaktor für das Auftreten der Hörersignale ist. 
In bezug auf die Satzkategorien erhalten in den deutschen Daten einfache, erweiterte und gleichkoordinierte Sätze am häufigsten Hörersignale: Die Quote der Hörersignale beträgt dabei 55\%. Das wird darauf zurückgeführt, daß mit dem Vollzug eines solchen Satzes eine größere Informationseinheit wie die eines Satzes abgeschlossen wird, die grammatisch komplettiert ist und mit einer anderen syntaktischen Einheit in keinem Abhängigkeitsverhältnis steht. Hingegen begünstigen Hauptsätze, adverbiale Sätze, Objektsätze sowie Infinitivkonstruktionen das Auftreten der Hörersignale weniger, was damit zusammenhängt, daß sie in meinen Daten des öfteren vorangestellt sind und die betreffenden Satzgefüge nicht beenden.

In den japanischen Daten weisen adversative Sätze die höchste Quote mit 56,8\% auf. Eine Erklärung dafür ist, daß sie einen möglichen Gegensatz andeuten. Dieser offene Abschluß einer Satzäußerung, die inhaltlich gesehen oft mit einem allein stehenden Satz (Vru-Satz) austauschbar ist, erweckt beim Hörer erhöhten Reaktionsbedarf. Außer in adversativen Sätzen sind die Quoten der Hörersignale bei Vru- und Vte-Sätzen relativ hoch. Bei diesen Sätzen ist ihr Vollzug an sich ein stärkerer Auslöser der Hörersignale, denn sie (vor allem Vru-Sätze) verkörpern wie einfache und erweiterte Sätze im Deutschen eine syntaktische Abgegrenztheit von anderen Einheiten. Hingegen bringen Vte-Sätze aufgrund ihrer Verbform einen konsekutiven Charakter zum Ausdruck. Dies bewirkt das Auftreten der Hörersignale (Fortsetzungssignale) in erhöhtem Maße. Abhängige Sätze sind verhältnismäßig weniger mit Hörersignalen versehen.

Bei Satzgefügen verteilen sich Hörersignale in den deutschen Daten deutlich stärker in nachgestellten Sätzen, die die betreffenden Satzgefüge beenden, als in vorangestellten Sätzen; deutsche Hörer tendieren dazu, mit verbalen Hörersignalen zu warten, bis die Satzgefüge vollbracht sind. Das heißt wiederum, daß auch bei Satzgefügen eine grammatische und inhaltliche Abgeschlossenheit einen wirksameren Stimulus der Hörersignale darstellt als der Vollzug einer Satzäußerung (wie abhängige Sätze), die sich inmitten eines Satzgefüges befindet.

\footnotetext{
${ }^{341}$ Die Befunde dieser Arbeit unterstützt Sawada (1991). Außerdem stellte sich bei Clancy et al. heraus, daß Hörersignale in den japanischen Daten häufiger mitten im Satz geäußert werden als in den amerikanischen Daten.
} 
Auch in den japanischen Daten zeigt sich zum Teil eine ähnliche Tendenz: Die Quoten der Hörersignale sind bei als Hauptsatz fungierenden Sätzen (Vru-, Vte- und adversativen Sätzen) höher als bei Sätzen derselben Kategorien, die jedoch keine abhängigen Sätze aufwiesen. Dies läßt sich ebenso auf die Erhöhung der Informationsmenge und den Abschluß einer satzübergreifenden Informationseinheit zurückführen. Ferner läßt sich interessanterweise feststellen, daß die Quoten in den adverbialen, attributiven und Objektsätzen, denen abhängige Sätze untergeordnet sind, insgesamt höher sind als in den deutschen Daten. Einige Erklärungen dafür sind: Erstens verkörpern diese Sätze eine Menge an Information, die etwa einem Satz entspricht; zweitens wird nach dem Vollzug dieser Sätze die Bedeutung der betreffenden Satzgefüge oftmals ohne die Hauptsätze transparent, so daß der Hörer trotz der Satzstellung Hörersignale sendet. Außerdem werden gelegentlich elliptische Konstruktionen mit solchen Sätzen beobachtet, die Hörersignale stimulierende Effekte haben.

In bezug auf die Verteilung der Hörersignale in Intonationstypen wird festgestellt, daß die Frequenz der Hörersignale bei Sätzen mit fallender und steigender Intonation ohne Pause viel niedriger ausfällt als bei Sätzen mit fallender und steigender Intonation mit Pause. Dies kann darauf zurückgeführt werden, daß der Sprecher mittels der Auslassung der Pause signalisiert, daß der Vollzug der betreffenden Satzäußerung für ihn keine strategische Relevanz hat; der Sprecher benötigt dabei keine verbale Reaktion vom Hörer.

Hingegen treten in den deutschen Daten wie erwartet viele Hörersignale an Satzenden auf, die durch fallende oder steigende Intonation mit Pause realisiert werden. Pausen regen den Hörer verstärkt dazu an, Hörersignale von sich zu geben, weil der Abschluß solcher Satzäußerungen vom Sprecher für die Weitergestaltung des Redeplans als relevant eingestuft wird. Von den beiden Intonationsvarianten mit Pause bringt fallender Tonhöhenverlauf mit Pause, die die Finalität einer für den Sprecher wichtigen Äußerungseinheit anzeigt, mehr Hörersignale mit sich als steigende Intonation mit Pause, die die Unabgeschlossenheit oder die Fortsetzung indiziert. Dies ist möglicherweise ein Indiz dafür, daß das Zusammenkommen von Pause und dem Vollzug einer größeren Informationseinheit mit konsekutivem Charakter einen weniger wirksamen Initiator für das Auftreten der Hörersignale darstellt als fallende Intonation (Finalität) mit Pause. Gleichbleibende Intonation ohne Pause, die die Progredienz und die Unvollendetheit anzeigt, wird nicht so oft von Hörersignalen begleitet: Ebenso gering ist die Quote der Hörersignale bei gleichbleibender Intonation mit Pause. Eine Erklärung dafür ist, daß Pausen bei diesen Sätzen eher Nachdenklichkeit und Schwierigkeiten mit dem Redeplan 
zum Ausdruck bringen; in solchen Momenten hält sich der Hörer mit Hörersignalen eher zurück.

In den japanischen Daten rufen ebenfalls Intonationstypen, die nicht durch Pausen begleitet werden, weniger Hörersignale hervor als Intonationsvarianten mit Pause. Als Begründung gilt Ähnliches wie in den deutschen Daten: Die Ankündigung einer Abgeschlossenheit oder einer Progredienz einer Satzäußerung motiviert den Hörer weniger zur verbalen Hörerrückmeldung, sondern der Sprecher muß signalisieren, daß er bei dem Vollzug jener Informationseinheit eventuell eine strategische Relevanz beimißt. Gleichbleibende Intonation ohne oder mit Pause wird in den japanischen Daten kaum beobachtet.

Insgesamt kann man die Tendenz erkennen, daß in den japanischen Daten Satzenden häufiger als in den deutschen Daten mit Pausen ausgestattet sind. Warum japanische Sprecher in meinen Daten an Satzenden häufiger als deutsche Sprecher Pausen einlegen, kann zum Teil dadurch erklärt werden, daß sie beim Reden dazu neigten, langsamer zu sprechen, indem sie häufig Pausen zwischen syntaktischen Einheiten einbauen oder die letzte Silbe einer Äußerungseinheit - sei es eine Phrase oder ein Satz - dehnen. Das deutet darauf hin, daß der japanische Sprecher mehr als der deutsche auf die Ratifizierung des Rederechts durch den Hörer angewiesen ist, um in der Rede fortzufahren, und daher zugleich dazu neigt, den Hörer auf seine Zuhörerschaft hin $\mathrm{zu}$ kontrollieren ${ }^{342}$ und sich des öfteren von diesem ein Einverständnis zum Weiterreden zu holen. ${ }^{343}$

In den deutschen Daten werden Sprechersignale wie ja, ne, na nicht, oder insgesamt bei 12,9\% der Sätze beobachtet; sie sind häufiger ans Ende eines Satzgefüges oder eines allein stehenden Satzes angehängt. So markieren Sprechersignale tendenziell den Abschluß einer satzübergreifenden Informationseinheit bzw. Sinneinheit. Sprechersignale sind überwiegend mit steigender Intonation mit Pause ausgestattet (59,8\%); außerdem wird auch steigende Intonation ohne Pause relativ oft produziert $(34,1 \%)$. Demnach liegt die Vermutung nahe, daß steigende Intonation mit oder ohne Pause im Zusammenhang mit Sprechersignalen für die Evozierung der Hörersignale prädestinierte Intonationstypen darstellen. Die Quote der

\footnotetext{
${ }^{342}$ Mizutani 1988, S. 98. Außerdem ist ebenfalls Maynard der Meinung (1986, S. 1104), daß die hohe Frequenz der Hörersignale bei den japanischen Teilnehmern mit der gegenseitigen Überwachung und der Kooperation zu tun hat.

${ }^{343}$ Mizutani (1988. S. 98), Clancy et al. (1996, S381), Maynard (1986, S. 1104) vertreten ähnliche Positionen.
} 
Hörersignale ist bei Sprechersignalen erwartungsgemäß etwas höher als bei Sätzen ohne Sprechersignale und liegt bei $24,4 \%$, wobei man dabei nicht davon ausgehen kann, daß Sprechersignale den Hörer dazu verpflichten, Hörersignale in jedem Fall zu senden. Nichtsdestotrotz sind Sprechersignale als Stimulus der Hörersignale wirksamer als Satzenden mit einer Intonationskontur mit oder ohne Pause.

In den japanischen Daten werden insgesamt 15,6\% aller Sätze von Sprechersignalen wie ne, yo, yone usw. begleitet. Sprechersignale folgen viel häufiger auf allein stehende und gleichkoordinierte Sätze als auf abhängige Sätze. Außerdem werden sie häufiger an Satzenden der Hauptsätze als am Ende der Sätze, die keine abhängigen Sätze aufweisen, beobachtet; dabei liegt der prozentuale Anteil der Sprechersignale bei als Hauptsatz fungierenden Vru-, Vte- und adversativen Sätzen viel höher als bei Sätzen anderer Satzkategorien. Daraus läßt sich die These ableiten, daß Sprechersignale eine größere Informationseinheit wie die eines Satzes oder eines Satzgefüges sowie eine Sinneinheit abrunden und deren Vollzug markieren.

Anders als in den deutschen Daten sind Sprechersignale in den japanischen Daten mit steigenden und fallender Intonation mit oder ohne Pause versehen. Das liegt daran, daß ne (nicht wahr) und yone (das ist so, oder) mit steigender Intonation mit oder ohne Pause realisiert wird, während yo (das ist so, daß) fallend intoniert wird. Der von Sprechersignalen besonders bevorzugte Intonationstyp ist wie in den deutschen Daten die steigende Intonation mit Pause, dessen Quote bei 61,7\% liegt. Steigende Intonation ohne Pause und fallende Intonation mit Pause werden viel weniger verwendet.

Sprechersignale bringen auch in den japanischen Daten merklich mehr Hörersignale als Sätze ohne Sprechersignale mit sich: Die Quote der ersteren beträgt 33,6\%, und die Quote der Sätze hingegen 18,4\%. Demnach stellen Sprechersignale ebenso in den japanischen Daten einen effektiveren Auslöser der Hörersignale dar als eine Intonationskontur mit oder ohne Pause am Ende. Vor allem begünstigen Sprechersignale mit steigender Intonation mit Pause das Auftreten der Hörersignale; ihr Einfluß auf das Auftreten der Hörersignale übertrifft sogar Sprechersignale mit fallender Intonation mit Pause. 


\subsection{Funktionen von Hörersignalen}

In diesem Kapitel werden Funktionen von Hörersignalen zusammengefaßt und exemplarisch erläutert. Als erstes sei ein Kapitel vorausgeschickt, in dem einige Beobachtungen und Überlegungen in bezug auf Funktionen von Hörersignalen aufgestellt werden; dies soll einen Überblick über die Komplexität der hier zu behandelnden Phänomene bieten und zugleich als Überleitung zu den nachfolgenden Kapiteln dienen.

\subsubsection{Vorbemerkungen zu Funktionen von Hörersignalen im Gespräch}

Derjenige, der sich in ein Gespräch begibt, hat bestimmte Erwartungen an seinen Gesprächspartner: Er hat ein Mitteilungsbedürfnis und möchte an die Reihe kommen, also den Turn übernehmen; dabei erwartet er, solange er den Turn innehat, daß der Hörer ihm zuzuhört, das Gesagte versteht und daß er darauf (positive) Reaktionen erhält. Hörersignale dienen dabei dem Hörer dazu, Ansprüche des Sprechers zum Teil zu erfüllen, indem in regelmäßigen Abständen Standardreaktionen wie z.B. Fortsetzungs- und Verstehenssignale auf das Gesagte gezeigt oder an geeigneten Stellen Einstellungen dem Gesagten gegenüber bekundet werden, ohne den Sprecher beim Reden zu stören.

Hörersignale werden nicht nur eingesetzt, um die Bedürfnisse des Sprechers zu befriedigen, sondern auch um Mitteilungsbedürfnisse des Hörers während des Turns des Gegenübers auszuleben; Hörersignale werden ebenso oft verwendet, um Zwischenergebnisse des Hörerplans, d.h. des Verstehensprozesses nach außen zu bringen oder Einstellungen des Hörers wie Überraschung, Begeisterung oder Skepsis dem Gesagten gegenüber zu übermitteln. Dabei stehen dem Hörer einige Verfahren zur feineren Nuancierung der Bedeutung der Hörersignale zur Verfügung: Dazu gehören z.B. die Auswahl und die Variation die Plazierungspositionen oder die Prosodie der Hörersignale.

Außerdem können Hörersignale bei der Regulierung der Sprecher- und Hörerrolle einen großen Beitrag leisten. In der Regel gilt in der Forschungsliteratur jede Satzgrenze als turnübergangsrelevante Stelle $;^{344}$ der Hörer setzt bekanntermaßen Hörersignale oft an solchen Stellen, an denen er dem Sprecher ankündigen will, daß der Sprecher mit dem Turn fortfahren soll, weil hörerseits keine Hindernisse zum Verstehen bestehen. ${ }^{345}$ Der Turnwechsel, der

\footnotetext{
${ }^{344}$ Siehe Sacks et al. 1974, S. 720.

${ }^{345}$ Schegloff 1982, S. 81.
} 
reibungslos und glatt durchgeführt wird, zeichnet sich dadurch aus, daß der Turn des neuen Sprechers ohne Verzögerung nach dem Turnende des vorigen Sprechers beginnt. ${ }^{346}$ Der Turnwechsel verläuft jedoch nicht immer reibungslos. Es kommt oft vor, daß die Gesprächsbeteiligten um den Turn ringen: Der Sprecher will seinen Turn fortsetzen, während der Hörer ebenfalls den Turn beansprucht. In solchen Fällen entsteht eine Weile simultanes Sprechen. Der Gesprächspartner, der kooperativ sein will, hört rechtzeitig oder ggf. sofort mit dem Kampf um das Rederecht auf und gibt dem Gegenüber den Vortritt; dabei kann derjenige, der sich zugunsten des anderen zurückzieht, mit Hilfe eines Hörersignals seine Zurücknahme signalisieren.

Drittens haben meine Daten oft gezeigt, daß der Hörer Hörersignale verwendet, um den vermeintlichen Abschluß der Verarbeitung einer Informationseinheit zu markieren. Der Hörer scheint seinerseits ebenso wie der Sprecher Sprecheräußerungen in inhaltlich enger zusammengehörende Teile zu untergliedern, um den Sprecherplan besser mental nachbilden zu können. Dies spiegelt sich in der Plazierungsposition der Hörersignale auf der Satz- sowie der satzübergreifenden Ebene wider.

Viertens kann angenommen werden, daß Hörersignale den Gesprächsverlauf steuernde Leistungen aufweisen. Hörersignale können z.B. den geplanten Fortgang des Sprecherturns erleichtern oder erschweren: Fortsetzungssignale, die an turnübergangsrelevanten Stellen eingesetzt werden, helfen dem Sprecher beim Weiterreden; hingegen können Hörersignale, die die Skepsis des Hörers oder Verstehensprobleme andeuten, den Turn kurzfristig unterbrechen und „side sequences“ einführen ${ }^{347}$ oder den Turn in eine andere Richtung lenken. Ferner kann der Hörer mittels Hörersignalen den Redebeitrag des Sprechers verlängern oder verkürzen: Hörersignale, die das Interesse am Thema bekunden oder umgekehrt Hörersignale, die gesendet werden, statt den Turn zu übernehmen, bewirken die Verlängerung des betreffenden Turns, während hingegen z.B. Verstehenssignale, die Ungeduld zum Ausdruck bringen, die Beendigung des Redebeitrags beschleunigen können.

Hörersignale können eine Auskunft darüber geben, wie der Hörer zum bestehenden Rollenverhältnis steht. In der Regel werden Hörersignale eingesetzt, um kenntlich zu machen, daß der Hörer weiterhin bei der Hörerrolle bleiben will; so gibt er dem Sprecher die

\footnotetext{
${ }^{346}$ Vgl. Henne/Rehbock (1982, S. 193)
} 
Erlaubnis, weiterhin einen Turn fortzusetzen. Ferner kommt es vor, daß der Hörer das Rederecht für sich beansprucht, oder daß simultanes Sprechen stattfindet. Bei Turnbeanspruchungen gibt der Hörer auf, seinen Willen durchzusetzen. Simultanes Sprechen wird hingegen gestoppt, wenn einer der Gesprächsteilnehmer seinen Anspruch zurücknimmt; in solchen Fällen kann er mittels Hörersignale signalisieren, daß er sich aus Rücksicht auf den anderen zurückzieht.

Des weiteren können Hörersignale bei der Regulierung der sozialen Beziehung zwischen den Gesprächsteilnehmern einen großen Beitrag leisten. Die Gesprächsbeteiligten, die sich in ein Gespräch mit einem Unbekannten begeben, bei dem sie sogar auf Tonband und/oder Video aufgenommen werden, sind in der Regel bestrebt, Konflikte mit ihrem Gesprächspartner möglichst gering zu halten; ihr Ziel besteht in solch einer Gesprächssituation eher darin, die Konversation so reibungslos wie möglich $\mathrm{zu}$ gestalten und sich und den anderen vor Gesichtsverlust zu schützen. Daher ist ihr Verhalten in erhöhtem Maße von Kooperationsbereitschaft und Rücksichtnahme geprägt, und dies dient dazu, eine konfliktarme, respektvolle Beziehung zueinander herzustellen. Ein Ausdruck kooperativer Verhaltensweisen des Hörers läßt sich darin finden, daß der Hörer in regelmäßigen Abständen auf Verlangen des Sprechers oder auf Eigeninitiative Hörersignale sendet und so seine Anteilnahme am Gespräch, sein Verstehen signalisiert. Außerdem ist es angemessen, an passenden Stellen seine (positiven) Einstellungen (wie Zustimmung, Bewertung) dem Gesagten gegenüber zu bekunden. Ferner wirken eine angemessene Art der Turnübernahme (z.B. an Satzgrenzen nach einer Sinneinheit) oder die Zurücknahme der eigenen Turnbeanspruchung zugunsten des anderen kooperativ und rücksichtsvoll.

Außerdem bestehen andere Mittel zur Herstellung einer angenehmen Gesprächsatmosphäre und der Aufrechterhaltung eines harmonischen Miteinanders: Die Betonung der Übereinstimmung durch Zustimmungssignale, die Aufwertung des Sprechers durch positive Bewertungen oder der Ausdruck der Empathie helfen dabei, die Sympathie und die Solidarität zwischen den Gesprächsbeteiligten zu stärken. Die wohlmeinenden emotionalen Hörerreaktionen verstärken dabei positive Effekte für die Beziehungsgestaltung zwischen den Gesprächsteilnehmern.

\footnotetext{
${ }^{347}$ Dazu siehe Jefferson (1972).
} 
Hingegen können weniger kooperative, negativ gestimmte Verhaltensweisen des Hörers die Beziehung zueinander verschlechtern. Allzu häufige Unterbrechungen durch die Turnübernahme an nicht turnübergangsrelevanten Stellen, das Insistieren auf der Hörerrolle oder eine offensichtliche Verweigerung der Turnübernahme haben eine Mißstimmung zur Folge. Außerdem erzeugt die Anhäufung von Hörersignalen, die den Sprecher vom ursprünglichen Sprecherplan ablenken können, bei diesem oft einen unangenehmen Eindruck.

Im folgenden werden die o.a. Beschreibungsebenen von Funktionen von Hörersignalen folgendermaßen zusammengefaßt: ${ }^{348}$

1. Signalisieren des Verstehensstandes des Hörers

2. Signalisieren des Wissensstandes des Hörers

3. Signalisieren von Stellungnahmen des Hörers dem Gesagten gegenüber (wie Zustimmung, Bewertung, Überraschung usw.)

4. Steuerung des Gesprächsverlaufs

5. Signalisieren des Wunsches auf die Beibehaltung bzw. die Änderung des bestehenden Rollenverhältnisses

6. Gliederung der Sprecheräußerungen

7. Gestaltung der zwischenmenschlichen Beziehung zwischen den Gesprächspartnern

In den kommenden Kapiteln werden Funktionen von Hörersignalen nach den jeweiligen Ebenen anhand von prägnanten Beispielen vorgestellt. ${ }^{349}$ Da Hörersignale jedoch gleichzeitig multiple Funktionen erfüllen, werden ebenfalls bei der Beschreibung der einzelnen Beispiele Funktionen, die auf den anderen Ebenen angesiedelt sind, erwähnt.

\subsubsection{Funktionen von Hörersignalen in den deutsche Daten}

\subsubsection{Hörersignale, die den Verstehensstand signalisieren}

Hörersignale, die sich auf den Verstehensstand des Hörers beziehen, lassen sich in folgende Gruppen unterteilen:

\footnotetext{
${ }^{348}$ Bei der Erstellung der Einteilung werden Wahmhoff/Wenzel (1979), Barba (1988), Horiguchi (1987) und Matsuda (1988) herangezogen.

${ }^{349}$ Für die Punkte 6 und 7 wird kein eigenes Kapitel eingerichtet, weil bei der Beschreibung der anderer Funktionen darauf eingegangen wird. Gliederung der Sprecheräußerungen
} 
- Fortsetzungs- und Verstehenssignale (sowie Anerkennungssignale ${ }^{350}$ ) und

- Hörersignale als Ausdruck von Verstehensproblemen oder zur Verständnissicherung.

\section{Fortsetzungs- und Verstehenssignale}

Es gibt sehr viele Hörersignale in meinen Daten, die in erster Linie als Verstehenssignale fungieren. Mit Verstehenssignalen wird angezeigt, daß der Hörer die Bedeutung des Satzes sowie die Sprecherintention verstanden hat. Dabei sind Verstehenssignale insofern direkt oder indirekt mit der „,continuer“-Funktion gekoppelt, als kein Turnwechsel nach diesen Signalen stattfindet. Wenn Verstehenssignale am Turnende des Sprechers gesendet werden, bevor man mit dem eigenen Turn beginnt, dann gelten sie nur als Verstehenssignale und dienen gleichzeitig dazu, als Anerkennungssignale den Sprecher für seine bisher ausgeführte Rolle zu honorieren. Im folgenden werden Verstehenssignale genauer charakterisiert:

- Sie werden sehr oft durch die Partikeln ja und $u \mathrm{hmhm}$ realisiert, die in der Regel mit einer fallend-steigenden Intonation ausgestattet sind; ja kann ebenfalls fallend intoniert werden.

- Sie treten bevorzugt im Satzendebereich (zwischen dem slV, slW und dem VVF oder dem VF) auf: Sie sind überwiegend an Satzgrenzen positioniert oder überlappen sich mit dem letzten Inhaltswort (d.h. slW bzw. slV) des Satzes.

- Sie beziehen sich auf eine größere Informationseinheit, die aus einem Satz oder mehreren Sätzen besteht.

- Sie sind in der Regel wenig emotional aufgeladen.

- Mit ihnen können außer Verstehen auch Einstellungen des Hörers wie Empathie, Interessenbekundung, Nachdenklichkeit usw. dem Gesagten gegenüber zum Ausdruck kommen. Dabei gibt die Prosodie der Hörersignale entscheidende Hinweise.

Im folgenden wird ein Beispiel für prototypische Verstehenssignale vorgeführt:

\footnotetext{
${ }^{350}$ Jefferson (1984) referiert auf „acknowledgement tokens“ am Turnende des Sprechers bzw. am Turnbeginn des neuen Sprechers.
} 
Gesprächskontext 24

Hanna und Alex unterhalten sich über die Anzahl der Professorinnen an einer Universität. Nachdem Alex Hanna gesagte hat, daß es in der Ethnologie viele Dozentinnen gibt, fängt Hanna an, Professorinnen in anderen Fächern aufzuzählen:

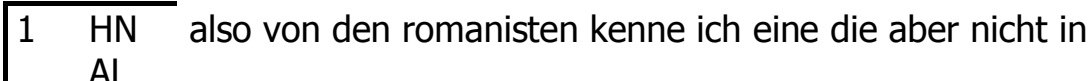

$2 \quad \mathrm{HN}$ göttingen angefangen hat sondern woanders sonst bei den $\mathrm{AL}$

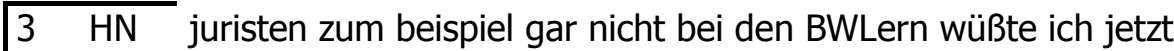
$\mathrm{AL}$

$4 \quad \mathrm{HN}$ auch niemanden politologen + fällt mir eine ein die $\mathrm{AL} \quad \Rightarrow u h m \downarrow h m \uparrow(m f)$

$\begin{array}{lll}5 & \mathrm{HN} & \text { war nicht professorin sondern nur lehrbeauftragte dann }\end{array}$

$\mathrm{AL} \quad \Rightarrow u h m \downarrow h m \uparrow(m f)$

$6 \quad \mathrm{HN}$ vielleicht so germanisten oder sowas das könnte sein na

$\mathrm{AL} \quad \Rightarrow j a \downarrow(m f)$

$7 \mathrm{HN}$

$\mathrm{AL}++$ weiß ich nicht $\mathrm{H}$ nur mal gehört daß glaube ich $+[\ldots .$.

uhmhm in Zeile 4 wird mit einer für Alex normal lauten Stimme (mf) fallend-steigend intoniert. Dieses Hörersignal läßt sich als Verstehenssignal deuten: Da sich Alex in den Fächern nicht gut auskennt, von denen Hanna erzählt, kann sie die Richtigkeit des Sachverhaltes weder bestätigen noch falsifizieren; außerdem fungiert dieses uhmhm gleichzeitig als Fortsetzungssignal, weil es keinen Turnwechsel einleitet; statt dessen markiert es den Abschluß eines Abschnittes innerhalb eines Sprecherturns.

In Zeile 5 und 6 sendet Alex zwei Hörersignale in kürzeren Abständen als dies beim ersten Hörersignal in Zeile 4 der Fall war und bestätigt dadurch ihr Verstehen. Das uhmhm in Zeile 5 ist ebenso als Fortsetzungssignal anzusehen. Diese Hörerreaktion indiziert darüber hinaus frühzeitiges Verstehen der Hörerin, was an der Überlappung mit der letzen Silbe des Satzes zu erkennen ist. Im weiteren wird dieses Signal anders als die beiden anderen Hörersignale, die zum Teil durch die Pause motiviert wurden, auf Eigeninitiative von Alex eingesetzt. 
Mit ja in Zeile 6 leistet die Hörerin eine zweifache Beziehungsarbeit: Zum einen stellt dieses ja eine Antwortreaktion auf die Vergewisserung der Sprecherin Hanna dar, und zum anderen honoriert sie damit vor dem Beginn des eigenen Turns den vorangegangenen Redebeitrag ihrer Gesprächspartnerin. Dabei markiert ja ebenfalls die Vollendung des Turns des anderen. Von allen drei Hörersignalen läßt sich behaupten, daß sie eine positive Einstellung der Hörerin (interessierte Kenntnisnahme der Information) dem Gesagten gegenüber zum Ausdruck bringen.

Verstehenssignale sind stets durch (diverse) Einstellungen des Hörers überlagert; eine überwiegende Mehrheit von Verstehenssignalen übermittelt dem Sprecher zusätzlich eine interessierte geistige Haltung des Hörers in bezug auf das Gesagte, wie im letzten Beispiel gezeigt wurde. In manchen Fällen jedoch kommen durch Verstehenssignale andere Einstellungen zum Ausdruck. Bei der Interpretation von überlagerten inneren Haltungen des Hörers ist vor allem die Prosodie der betreffenden Hörersignale von großer Bedeutung.

Gesprächskontext 25

Knut fragt Heinz, ob er Spaß daran habe, Japanisch zu lernen; Knut hat nämlich bereits ein Jahr lang einen Anfängerkurs, Japanisch I, an der Universität besucht und kennt sich darin sehr gut aus. Heinz fängt gerade damit an und ahnt im vorhinein, daß er mit dem Japanischkurs Schwierigkeiten haben wird, weil er sich nicht so viel Zeit zum Lernen nehmen kann:

$1 \mathrm{KN} \quad \operatorname{aja} \uparrow \downarrow(\mathrm{mf})$

$\mathrm{HZ}$ das macht echt spaß also: das problem ist bei mir nur $\mathrm{H}$ daß

$2 \mathrm{KN}$

$\mathrm{HZ}$ ich halt ähm:: mich da nicht zu sehr darauf so + fixieren kann

$3 \mathrm{KN}$

$\mathrm{HZ}$ und da: den ganzen tag jetzt lernen kann weil ich ja mit

$4 \mathrm{KN} \quad \Rightarrow h m:: m \downarrow$ (f)

$\mathrm{HZ}$ meinen anderen fächern ziemlich ++ ähm belastet bin [...]

uhmhm in Zeile 4 wird in der Mitte des letzten Satzes einer Sinneinheit eingesetzt; es bezieht sich meines Erachtens einerseits auf die ganze Sinneinheit und andererseits auf die Phrase: mit anderen Fächern. Diese Phrase bringt Knut die letzte entscheidende Information, die die Rekonstruktion des Sprecherplans ermöglicht. Er kann die Hörerreaktion frühzeitig zeigen, weil der Sachverhalt, auf den Heinz mit seiner Äußerung referiert, Knut bereits bekannt ist: Er 
befand sich nämlich vor einem Jahr in einer ähnlichen (schwierigen) Lage, so daß er nicht nur Japanisch lernen, was sehr zeitaufwendig ist, sondern auch gleichzeitig für sein Hauptfach arbeiten mußte. Darüber hinaus ist anzunehmen, daß er aufgrund der ähnlichen Erfahrung von der Sprecheräußerung betroffen ist; das könnte ihn dazu veranlaßt haben, das Hörersignal direkt nach dem Vollzug der Schlüsselinformation zu senden. So indiziert die Frühplazierung der Hörerrückmeldung in diesem Fall eine erhöhte Emotionalität des Hörers. In der Tat ist $h m:: m$ in Zeile 4 durch eine stark fallende Intonation und die laute Artikulation deutlich hervorgehoben, wodurch über das Verstehen hinaus das Verständnis für die Lage von Heinz und die Nachdenklichkeit zum Ausdruck gebraucht werden. Da das Hörersignal ziemlich früh plaziert wird, fungiert es meines Erachtens nur am Rande als Fortsetzungssignal, da der Sprecherturn weiter geführt wird.

Hörersignale als Ausdruck von Verstehensproblemen und zur Verständnissicherung

Verstehensprobleme resultieren aus unterschiedlichen Gründen: Die Ursachen können akustischer, semantischer oder pragmatischer Natur sein. ${ }^{351}$ Sie zwingen den Sprecher dazu, den Sprecherplan zu ändern oder ihn eine Weile zu suspendieren. Insofern steuern sie stärker als viele andere Hörersignale den Sprecherturn. Im folgenden wird ein Beispiel für NichtVerstehen präsentiert, das auf die Akustik zurückgeführt werden kann:

Gesprächskontext 26

Knut erwähnt nebenbei, daß er vor dem Studium eine Ausbildung als Berufsoffizier gemacht hat; dabei entstand ein Verstehensproblem, weil Knut einen Teil der Satzinformation undeutlich ausgesprochen hat:

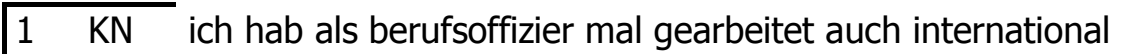
$\mathrm{HZ}$

$2 \quad \mathrm{KN}$ naja aber: ja:: in ???????? + das habe ich dann aber nicht $\mathrm{HZ} \quad \operatorname{echt\uparrow (f)}$

$3 \mathrm{KN}$ weiter gemacht äh::m in elmshorn wars $\mathrm{HZ} \quad \Rightarrow$ wo warst du noch mal؟ (f)

Die Nachfrage von Heinz in Zeile 3 beruht auf der leise, unklar ausgesprochenen Ortsangabe in Zeile 2, was für mich unverständlich war. Heinz wartet allerdings mit der Nachfrage, bis

${ }^{351}$ Hierzu Selting (1987). 
der Sprecher mit dem gerade laufenden Satz fertig ist, obwohl der nicht verstandene Informationsteil Bestandteil des vorigen Satzes war. Das kann ein Indiz dafür sein, daß der Hörer es im Vorliegen eines Verstehensproblems nicht sofort in Angriff nimmt, dieses zu beseitigen, sondern eine günstige Gelegenheit dazu abwartet. So wird diese Nachfrage wo warst du noch mal? (Zeile 3) erst an der Satzgrenze plaziert. Dies zeigt wiederum die Rücksicht auf den Sprecher, seine Rede nicht mittendrin zu stören. Da die Nachfrage den Sprecher unter die Obligation setzt, darauf zu reagieren, weil dadurch konditionale Relevanz geschaffen wird, bewirkt sie zwangsläufig die Kursänderung des Sprecherplans. Daher bringen Nachfragen eher dem Hörer Nutzen als für den Sprecher.

Im nächsten Beispiel war der Anlaß zur Nachfrage pragmatischer Natur, d.h. der Hörer interessierte sich von sich aus dafür, eine Information über einen bestimmen Sachverhalt zu erhalten, die der Sprecher von sich aus nicht gegeben hätte:

Gesprächskontext 27

Heinz erzählt, daß er noch nicht weiß, welchen Beruf er in Zukunft ausüben will. Eine Idee war, Graphikgestaltung zu machen, wobei er ein wenig Bedenken hat.

$1 \mathrm{KN}$

$\mathrm{HZ}$ aber das ist auch wieder äh: + so: $\mathrm{n}$ bißchen son son job den

$2 \mathrm{KN}$

$\mathrm{HZ}$ stellt man sich glaube ich auch immer kreativer vor als er ist $\mathrm{H}$

$3 \mathrm{KN}$

$\mathrm{HZ}$ wenn du s dann ah ich hab mal praktikum gemacht und das

$4 \mathrm{KN} \quad \Rightarrow$ wo denn $\uparrow(\mathrm{mf})$

$\mathrm{HZ}$ hat mich einigermaßen abgeschreckt $\mathrm{H}$ da bei äh ja so $\mathrm{n}$ büro

$5 \mathrm{KN} h m:: m \downarrow$ (mp)

$\mathrm{HZ} \quad \mathrm{H}$ und: ähm naja ich weiß nicht das war etwas trist und

$6 \mathrm{KN}$

$\mathrm{HZ} \quad \mathrm{H}$ man: man muß sich ja eigentlich ziemlich verkaufen + so mit

In diesem Fall liegt das Motiv der Nachfrage wohl an der Neugier des Hörers. Die Nachfrage wird etwas verspätet, d.h. erst während des Äußern des Satzes gestellt, der auf die Satzäußerung folgt, auf die das Hörersignal bezogen ist. Dabei wartet der Hörer nicht auf eine günstige Gelegenheit, sondern stellt die Frage mitten im Satz. Der Sprecher komplettiert 
seinen Satz noch; er wird jedoch gleich zur Kursmodifikation gezwungen, was eine weitere Verzögerung verursacht: Der Sprecher hat eine kurze Weile seinen Faden verloren und muß den Redeplan noch einmal restrukturieren, wie man dies in Zeile 5 verfolgen kann: Zuerst dehnt er und; dann macht er gefüllte Pause ähm; anschließend äußert er naja zur Einleitung des neuen Satzes, der aber nicht sofort in Angriff genommen wird, sondern erst nach einem Einschub. All dies wurde vermutlich dafür eingesetzt, um Zeit zur Reorganisation des Sprecherplans zu gewinnen.

\subsubsection{Hörersignale, die den Wissensstand des Hörers signalisieren}

Hörersignale können Hinweise auf den Wissensstand des Hörers geben. Mit manchen Hörersignalen wird indiziert, daß der propositionale Gehalt der betreffenden Sprecheräußerung für den Hörer neu bzw. unerwartet ist. Prototypischerweise werden dafür Kurzformen wie ach, achso, aha:, aja oder kombinierten Kurzformen wie achso achso, m::m, achso: ja, aha:: aha:: usw. verwendet. Je nach dem Grad der Diskrepanz zwischen den eigenen und den fremden Wissensbeständen oder Erwartungen in bezug auf den betreffenden Sachverhalt fällt die Emotionalität unterschiedlich aus. Die gefühlsmäßige Regung des Hörers kann auch an der Plazierung der Hörersignale festgemacht werden: In unmarkierten Fällen sind Hörersignale in meinen Daten meistens nach dem betreffenden Satz, d.h. an Satzgrenzen, im VVF oder im VF des nächsten Satzes zu finden; hingegen werden gefühlsbetonte Hörersignale oftmals gleich zum Zeitpunkt geäußert, an dem der Hörer zu verstehen beginnt, oder an dem die Schlüsselinformation geliefert wird. Das nächste Beispiel stellt einen unmarkierten Fall dar:

Gesprächskontext 28

Heinz war ein halbes Jahr in Japan und hat dort ein Praktikum gemacht; daraufhin fragt Knut, ob Heinz in Japan bereits Japanisch gelernt hat:

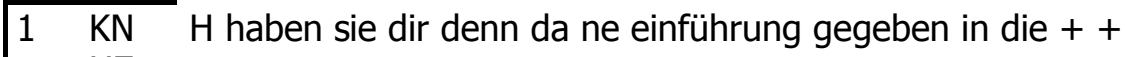
$\mathrm{HZ}$

$2 \mathrm{KN}$ japan oder was?

$\mathrm{HZ} \quad$ ja ich hab in japan japanischunterricht gehabt

$3 \mathrm{KN} \Rightarrow \operatorname{ach} \downarrow$ so $\uparrow(\mathrm{mf})$ ?????? $\quad$ pro woche ja

$\mathrm{HZ} \quad$ also einmal pro woche nur nicht viel aber:: ich 
achso in Zeile 3 wird geäußert, nachdem die gewünschte Antwort gegeben wird; Knut bestätigt damit, daß sein Wissensdefizit jetzt beseitigt ist. Achso markiert hier genauso den Abschluß einer Informationseinheit (d.h. eines Satzes), die für Knut von großem Interesse ist. Ob dieses Hörersignal gleichzeitig die Funktion erfüllt, den Fortgang des Turns von Heinz zu unterstützen, ist an dieser Stelle fraglich, weil Knut noch weiter kommentiert, dann aber schnell verstummt, nachdem Heinz seine Rede wieder aufgenommen hat. Knut zeigt hierbei ein rücksichtsvolles, kooperatives Verhalten, indem er sich zurücknimmt und Heinz weiterreden läßt.

Außer Kurzformen werden ebenfalls häufig Kombinationen von Kurzformen verwendet, um den Wissenstand des Hörers kenntlich zu machen; dabei kann man oftmals beobachten, daß Wissens- und Verstehensstand des Hörers nacheinander zum Ausdruck gebracht werden:

Gesprächskontext 29

Heinz erzählt von einem Journalisten, der Japanologie studiert hat; Knut, der Japanologie und Publizistik studiert, war daran interessiert, zu erfahren, in welchem Arbeitsfeld dieser Journalist jetzt tätig ist. Heinz verwechselt den Journalisten und seinen Freund, der auch Publizistik und Japanologie studiert. Knut merkt dies erst nach einer Weile:

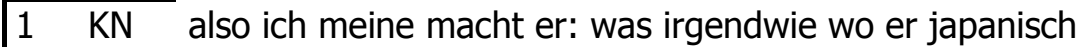
$\mathrm{HZ}$

$2 \mathrm{KN}$ gebrauchen kann? LACHEN ja:::::::

$\mathrm{HZ} \quad+$ er macht öh bis jetzt hat er hat er nicht so

$3 \mathrm{KN} \quad$ ja::.:.:.

$\mathrm{HZ}$ die sinnvolle kombination der wollte halt erstmal gucken was

$4 \mathrm{KN}$

$\mathrm{HZ} \quad$ ihn so interessiert jetzt im ersten semester der macht halt $\mathrm{H}$

$5 \quad \mathrm{KN} \Rightarrow a c h \downarrow$ so $9 a c h \downarrow s o \uparrow u:: m \downarrow u:: m \downarrow$ (ff)

HZ publizistik::::::::::::::::::::: japanologie und sport LACHEN

Die kombinierten Kurzformen achso achso $u:: m u:: m$ in Zeile 5 sind stark emotional aufgeladen, weil Knut zuerst nicht weiß, von wem Heinz redet. Erst in Zeile 5 kommt Knut darauf, daß Heinz von seinem Freund erzählt, aber nicht vom Journalisten, den er meinte. Aus der kurzen Verwirrung befreit, setzt Knut ein Hörersignal, das sich aus vier Kurzformen zusammensetzt, in dem Moment ein, in dem er versteht, worum es eigentlich geht. Die 
emotionale Regung von Knut läßt sich an der Prosodie, der Länge des Hörersignals und der Verdopplung von achso und $u: m$ erkennen. Die Wiederholung von $u: m$ deutet an, daß der Hörer jetzt alles richtig verstanden hat und keine Verstehensprobleme mehr hat, so daß der Sprecher seinen Turn fortsetzen kann. Diese Hörerrückmeldung hat keine den Sprecherbeitrag gliedernde, sondern eher eine den Gesprächsverlauf steuernde Funktion; dafür spricht, daß der Sprecher das Wort Publizistik so lange dehnte, bis das Hörersignal fertig ausgesprochen war. Verstehensprobleme können theoretisch auch durch die Auslassung von Verstehenssignalen signalisiert werden. In meinen Daten wurden jedoch keine Beispiele dafür gefunden.

\subsubsection{Hörersignale, die die Zustimmung signalisieren}

Hörersignale können auch dafür verwendet werden, diverse Einstellungen dem Gesagten gegenüber zu vermitteln. Zustimmungssignale werden in diesem Kapitel gesondert behandelt, weil sie sehr häufig in meinen Daten vertreten sind. Zustimmungssignale unterscheiden sich relativ eindeutig von Verstehenssignalen: in der Formenauswahl, der Position und der Prosodie. Erstere wirken häufig nachdrücklicher und intensiver als letztere und sind abwechslungsreicher in der Formenauswahl. Sie können z.B. durch Kurzformen, kombinierte Kurzformen oder satzförmige Äußerungen, die stärker an den aktuellen Kontext gebunden sind, realisiert werden. Ferner sind ihre Plazierungspositionen je nach Impulsivität des Hörers unterschiedlich. Zustimmungssignale können häufiger als Verstehenssignale die emotionale Regung des Hörers zum Ausdruck bringen. Nachfolgend wird ein Gesprächsabschnitt zitiert, in dem einige Zustimmungssignale enthalten sind, die mit Nachdruck geäußert werden. 
Gesprächskontext 30

Friedrich und Roby reden über das Fachgebiet Informatik, das im Vergleich zu den anderen Fachgebieten wie Jura oder Wirtschaft viel mehr Geld zur Verfügung hat. Roby nannte einige Gründe für die gute Finanzlage des Fachs Informatik.

$1 \quad \mathrm{FR}$

RB ich meine die haben natürlich auch was anzubieten na die

$\begin{array}{ll}2 & \mathrm{FR}\end{array} \Rightarrow j a: \downarrow+j a: \downarrow j a: \downarrow$ (ff)

$\mathrm{RB}$ machen ähn projekte und zusammenarbeiten mit

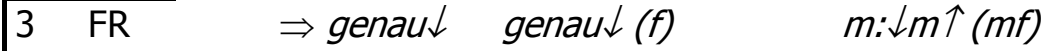

$\mathrm{RB}$ einem unternehmen irgendwie $\mathrm{H}$ dann lösen sie ein EDV

$4 \quad \mathrm{FR} \quad \Rightarrow$ das

RB problem und: dann kriegen sie entsprechend geld dafür

$5 \quad$ FR stimmt $\downarrow$ ja $(m f) \mathrm{H}$ na $\downarrow j a \uparrow(m f)$

RB also bei uns läuft das eher so: daß dann

Friedrich scheint genauso gut wie Roby über die finanzielle Lage der Informatiker an einer Universität Bescheid zu wissen. Daher können fast alle Hörersignale in diesem Beispiel als Zustimmungssignale aufgefaßt werden. Vieles spricht dafür: Die Formen, die hier ausgewählt werden, bestehen aus einer Kombination aus mehreren Kurzformen und sind abwechslungsreich; zweitens werden diese Hörersignale alle mit einer lauteren Stimme als sonst artikuliert; drittens werden sie relativ oft, d.h. in kürzeren Abständen gesendet; viertens werden sie alle in den unterschiedlichen Positionen des Satzes eingesetzt, wobei die Tendenz zu erkennen ist, daß Zustimmungssignale mit höherer Emotionalität spontaner geäußert werden als nüchterne Zustimmungssignale, die eher am Satzende oder kurz danach plaziert werden. Demnach kann angenommen werden, daß Zustimmungssignale, wenn sie vor allem stärker emotionalisiert sind, dem Hörer weniger dazu dienen, den Sprecherturn zu strukturieren oder zu steuern, sondern eher dazu, den Sprecher in der Richtigkeit seiner Äußerung zu bestätigen, das Mitteilungsbedürfnis des Hörers zu befriedigen und den Meinungskonsens mit dem Sprecher zu betonen. Daher tragen Zustimmungssignale sehr viel zur Herstellung einer angenehmen Gesprächsatmosphäre sowie einer guten, harmonischen Beziehung bei.

Zustimmungssignale werden in meinen Daten nicht nur durch Kurzformen oder Kombinationen von Kurzformen, sondern auch gelegentlich durch andere Typen wie 
satzförmige Höreräußerungen, Teil(Wiederholungen) usw. zum Ausdruck gebracht. Der nächste Gesprächsabschnit repärsentiert ein Beispiel für die die (Teil)wiederholung der vorangegangenen Sprecheräußerung.

Gesprächskontext 31

Hanna und Alex unterhalten sich darüber, wie wenig Frauen in Stellen der Universität vertreten sind. Hanna hat einige Vermutungen, wie es dazu geführt haben könnte.

$1 \quad \mathrm{HN}$ ja als das vergeben wurde waren wahrscheinlich auch nur $\mathrm{AL}$

2 HN männliche bewerber und die wurden auch denke ich $\mathrm{AL}$

$3 \quad \mathrm{HN}$ vorgezogen und die müssen erstmal wieder rauskommen $\mathrm{AL} \quad j a \downarrow(m f)$

$4 \quad \mathrm{HN} \quad+$ sie sitzen jetzt alle auf ihren plätzen $\mathrm{AL} \operatorname{genau} \downarrow(\mathrm{mf}) \quad \Rightarrow j a: \downarrow$ sie sitzen

$5 \mathrm{HN} \quad$ uhmhm würde ich auch gerne

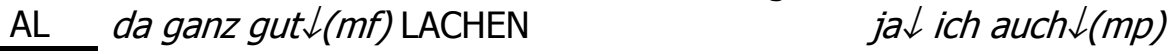

Das satzförmige Hörersignal in Zeile 4-5 ist eine fast gänzliche Wiederaufnahme der vorangegangenen Sprecheräußerung, die dazu dient, die Übereinstimmung der Sichtweise in bezug auf den betreffenden Sachverhalt zu signalisieren. Diese Höreräußerung wird mit etwas lachender, sanfter Stimme artikuliert, die den sachlichen Konsens zwischen beiden zusätzlich auf der emotionalen Ebene unterstreicht. Dadurch entsteht ein harmonisches, solidarisches Moment zwischen beiden Gesprächsbeteiligten.

Die Funktion von ja in Zeile 3 läßt sich verglichen mit den anderen hier präsentierten Hörersignalen nicht eindeutig bestimmen; es ist meines Erachtens nur schwach zustimmend und kann vielmehr als Verstehenssignal betrachtet werden. Ja markiert außerdem wie genau in Zeile 4 den Vollzug einer Sinneinheit des Redebeitrags Hannas. Die Phrase in Zeile 5: ja ich auch hingegen fungiert sowohl als Zustimmung als auch kurze Meinungskundgabe der Hörerin. 
4.5.2.4 Hörersignale, die diverse Einstellungen des Hörers dem Gesagten gegenüber signalisieren

In diesem Kapitel werden Hörersignale vorgestellt, die Bewertungen, Überraschungen usw. zum Ausdruck bringen.

$\underline{\text { Hörersignale, die Bewertungen signalisieren }}$

Außer Verstehens- und Zustimmungssignalen finden sich in meinen Daten relativ oft Hörersignale, die Informationen darüber vermitteln, wie der Hörer den dargestellten Sachverhalt bewertet. Viele von ihnen werden in den deutschen Daten durch satzförmige Hörersignale wie das ist ja interessant realisiert, die für die Bewertung prädestiniert sind. Sie sind bevorzugt an Satzgrenzen oder in der Position, die darauf folgt, wie die Position des VVF bzw. des VF plaziert. Anders als Verstehenssignale werden sie des öfteren erst nach dem Vollzug des betreffenden Satzes gesendet. Die Emotionalität ist bei Bewertungssignalen eher höher als Verstehenssignale oder Zustimmungssignale.

Gesprächskontext 32

Klara erzählt Frauke von ihrer Fortbildung, die sie gerade macht. Die Prüfungen der Fortbildung werden flexibel gehandhabt: Sie erfolgen nicht am Ende der Fortbildung, sondern bereits nach der ersten Hälfte der Fortbildung.

$\begin{array}{ll}1 & \mathrm{KA} \\ \mathrm{F}\end{array}$ also ich hab jetzt an eine woche dann im frühjahr im april FK

$2 \mathrm{KA}$ ist das dann irgendwann im sommer herbst nächstes jahr noch FK

$\begin{array}{ll}3 & \mathrm{KA} \\ & \mathrm{FK}\end{array}$ $\mathrm{FK} \quad j a \downarrow(\mathrm{mp})$

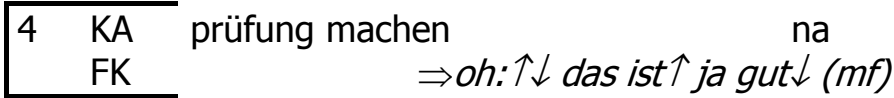

Frauke gibt in Zeile 4 eine bewertende Äußerung von sich, mit der sie Klara zu erkennen gibt, daß auch sie das Prüfungssystem dieser Fortbildung gut findet. Dabei ist der Grad der Emotionalität höher als sonst, was zum Teil an der Verwendung von oh: erkennbar ist: Frauke ist positiv überrascht, daß die Prüfungen so flexibel abgelegt werden können. In diesem Beispiel wird außerdem anhand des $n a$ in Zeile 4 besonders deutlich, daß beide Gesprächspartnerinnen eine bejahende Beurteilung in bezug auf denselben Sachverhalt teilen; 
sie bestätigen sich somit gegenseitig noch einmal den bestehenden Konsens; dies betont die Gemeinsamkeit und verstärkt die Sympathie zwischen beiden.

Als nächstes wird ein Beispiel für die Bewertung, die durch eine Kurzform realisiert wird, angeführt, was in meinen Daten nicht so häufig wie satzförmige Äußerungen vorkommt:

Gesprächskontext 33

Klara und Frauke unterhalten sich über ihre Erfahrungen mit Bewerbungen. Klara beginnt über ihre gerade geschriebene Bewerbung zu schildern.

$1 \mathrm{KA}$ da habe ich heute die bewerbung geschrieben $\mathrm{H}$ und zwar ist FK

2 KA es am: deutschen zentrum für altersforschung gesagt $\mathrm{H}$ in FK $\quad a h \uparrow: n \downarrow$ (mf)

$3 \quad \mathrm{KA}$ berlin $\mathrm{H}$ die machen ach ah einiges für die bundesregierung FK

$\begin{array}{ll}4 & \mathrm{KA}\end{array}$ an arbeiten zur forschungsarbeiten und erstellen jetzt wohl FK

$5 \quad \mathrm{KA}$ auch den $\mathrm{H}$ altenplan der bundesregierung na + dafür suchen FK $\Rightarrow w a \uparrow:$

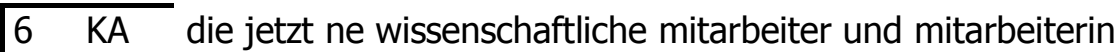

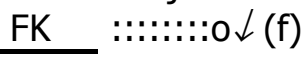

$\begin{array}{lll}7 & \mathrm{KA} & \text { da habe ich mich jetzt beworben }\end{array}$

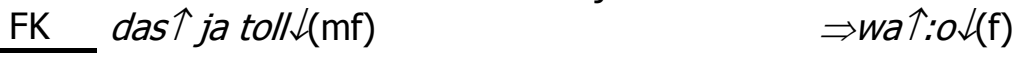

Mit Hilfe der letzten drei Hörersignalen zwischen Zeile 5 und 7 bringt Frauke ihre Bewunderung zum Ausdruck. Ihre starke emotionale Regung kann man auch an der Auswahl der Hörersignale, der Lautstärke von wa::o, der Dehnung sowie der Erhöhung der Anzahl der Hörersignale erkennen. Die satzförmige Bewertung in Zeile 7 und das darauf folgende wa:o sind an Satzgrenzen plaziert und üben dadurch eine die Turnkonstruktionseinheiten strukturierende Funktion aus. Die Anhäufung der positiv bewertenden Hörerrückmeldungen mit erhöhter Emotionalität leistet ebenfalls ein effektives „,face-work“, denn sie werten damit nicht nur das Gesagte oder die Handlung, von der die Rede ist, sondern letztendlich auch den Gesprächspartner als Person auf, wodurch wiederum die Sympathie des Sprechers dem Hörer 
gegenüber erhöht und damit auch die Beziehung zueinander verbessert wird. Bewertungen spielen also eine zentrale Rolle bei der Beziehungsgestaltung.

\section{Hörersignale, die Überraschungen signalisieren}

Hörersignale, die Überraschungen anzeigen, sind in meinen Daten relativ häufig anzutreffen. Prototypisch werden sie durch Kurzformen wie ja, nee und echt mit stark steigender Intonation realisiert. Dabei signalisieren sie in der Regel eine starke emotionale Regung des Hörers. Erhöhte Emotionalität ist meines Erachtens darauf zurückzuführen, daß das Gesagte weit von der Erwartung des Hörers abweicht, so daß er seine Verwunderung darüber aussprechen muß.

Gesprächskontext 34

Heinz und Knut sind der Meinung, daß man nicht unbedingt studieren muß; viele beginnen nach dem Abitur eine Berufsausbildung. Knut gehörte auch zu denjenigen, die nicht sofort angefangen haben zu studieren:

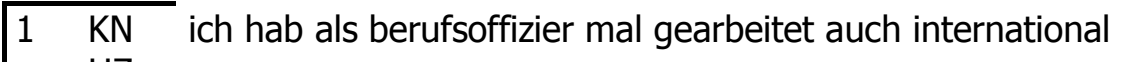
$\mathrm{HZ}$

$2 \quad \mathrm{KN}$ naja aber: ja:: in ???????? + das habe ich dann aber nicht $\mathrm{HZ} \Rightarrow \operatorname{echt\uparrow (f)~}$

Da die Ausbildung als Berufsoffizier vor dem Studium nicht dem Standard entspricht, war diese Tatsache für Heinz sehr überraschend. Dabei liefern die Lautstärke und die steil steigende Intonation einen Beleg für die starke Emotionalität.

Außer den Standardformulierungen gibt es ebenfalls Hörersignale, die mit dem aktuellen Kontext verbunden sind, d.h. kontextuelle Bezüge auf den vorangegangenen Satz aufweisen; dabei wird eine Ein-Wort-Äußerung verwendet: 
Gesprächskontext 35

Heinz erzählt von seinem Freund, der noch nicht weiß, was er studieren soll; dieser Freund probiert verschiedene Fächer (Publizistik, Sport, Sonderpädagogik usw.), um herauszufinden, was er will. Jetzt kam er auf die Idee, Flugzeugmechaniker zu werden.

$1 \mathrm{KN}$

$\mathrm{HZ} \quad$ er überlegt halt wieder ne ganz andere richtung flugzeug-

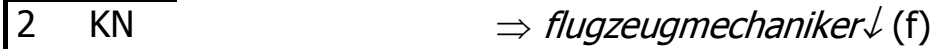

$\mathrm{HZ}$ mechaniker zu machen ja:: weil er so $\mathrm{n} \mathrm{H}$ ah

$3 \mathrm{KN}$

$\mathrm{HZ}$ flugzeugmodell baut für die ???????? das schon richtig lange

$4 \mathrm{KN}$

$\mathrm{HZ}$ gemacht und jetzt überlegt er halt sowas im großen sozusagen

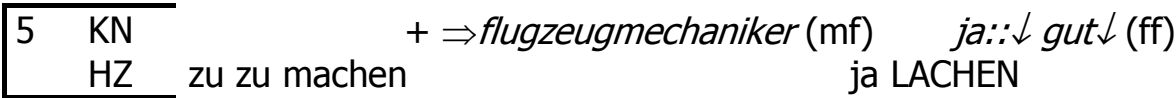

$6 \quad \mathrm{KN}$ das ist $H$ das wäre was ganz anders $\downarrow$ ne $\uparrow(\mathrm{mp})$ $\mathrm{HZ}$

Knut hatte etwas Schwierigkeiten, die Beweggründe des betreffenden Freundes zu verstehen, warum der Freund plötzlich Flugzeugmechaniker werden will, obwohl er jetzt für Publizistik, Sport und Japanologie eingeschrieben ist. Die Verwunderung Knuts wird durch die Lautstärke bei der ersten Ein-Wort-Äußerung flugzeugmechaniker in Zeile 2 und die Wiederholung in Zeile 5 unüberhörbar zum Ausdruck gebracht. Später macht Knut es mit seiner Satzäußerung in Zeile 6 explizit, womit er Probleme hat: Er kann den Sprung von den Studienfächern (Publizistik, Japanologie usw.) zum Flugzeugmechaniker nicht nachvollziehen. Die erste EinWort-Äußerung des Hörers veranlaßt den Sprecher dazu, die Richtigkeit des Sachverhalts mit ja noch einmal zu bestätigen. Dabei wird der Sprecherturn von dieser Höreräußerung nicht sehr beeinträchtigt, denn Heinz beginnt bereits mit der nächsten Turneinheit (dem Kausalsatz), bevor Knut das Hörersignal komplettiert hat.

Hörersignale, die Mitleid, Empathie, Dissens usw. signalisieren

Einstellungen, die durch Hörersignale signalisiert werden, beschränken sich nicht nur auf Zustimmungen, Bewertungen oder Überraschungen, sondern es gibt auch andere Haltungen des Hörers, die durch Hörersignale zum Ausdruck gebracht werden. Im folgenden wird ein Beispiel mit oh zitiert: 
Gesprächskontext 36

Hanna erzählt, daß sie einmal eine Geschäftsreise nach Japan absagen mußte, weil sie eine Magen- und Darminfektion hatte, die man normalerweise in drei Tagen überstehen kann. Die Krankheit erwies sich bei ihr jedoch als wesentlich schlimmer:

$1 \mathrm{HN}$ vor allem normalerweise ist so ein magen darm infekt echt in $\mathrm{AL}$

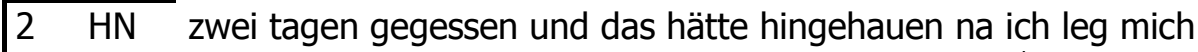
$\mathrm{AL} \quad$ ja: $\downarrow$ ( $m f)$

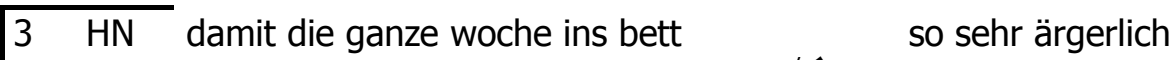
$\mathrm{AL} \quad \Rightarrow o h::: \downarrow \downarrow \uparrow(f)$ LACHEN::::::::::::::

Mit dem lang gedehnten, fallend-steigend intonierten oh kommt zum Ausdruck, daß Alex Mitleid mit Hanna empfindet. Diese Höreräußerung wirkt jedoch durch darauf folgendes Lachen kaum ernsthaft, sondern eher gespielt. Da dieser Abschnitt zu einem langen Turn der Sprecherin gehört, in dem über den beruflichen Werdegang Hannas auf eine lustige Art und Weise erzählt wird, bildet eine ebenso theatralische Äußerung der Hörerin oh in Zeile 3 ein Gegenstück zur Sprecheräußerung, auf die diese Hörersignal bezogen ist. Das ist ein harmoniestiftendes Zusammenspiel zwischen der Sprecherin und der Hörerin, was die angenehme Gesprächsatmosphäre und die Solidarität zwischen beiden verstärkt. Aufgrund der Plazierungsposition gliedert $o h$ gleichzeitig den Sprecherturn; in diesem Fall wird dadurch die Beendigung des Redebeitrags der Sprecherin Hanna markiert.

Hörersignale, die das Interesse des Hörers für das Thema bekunden

Hörersignale, die Interesse des Hörers für das Thema bekunden, können den Turn des Sprechers verlängern, indem sie den Sprecher dazu motivieren, das Thema in Detail auszuführen oder auszuweiten. Wie der Hörer dem Sprecher bei der Entfaltung eines Gesprächsthemas hilft, kann am besten in längeren Gesprächsabschnitten veranschaulicht werden; darin sind in der Regel Hörersignale enthalten, die diverse Einstellungen des Hörers kenntlich machen: Verstehens- und Zustimmungssignale, Belustigung, Bewertungen, Empathieäußerungen, Überraschung usw. Darüber hinaus finden sich viele Hinweise, die auf eine erhöhte Emotionalität hindeuten. Nachfolgend wird eine längere Passage eines Turns vorgestellt. 
Gesprächskontext 37

Hanna erzählt von ihrem Nebenjob bei einer Firma, bei der sie später angestellt werden soll. Hanna ist jetzt jedoch etwas ängstlich geworden und befürchtet, daß sie die Stelle doch nicht bekommt, denn sie mußte einmal eine wichtige Geschäftsreise absagen, weil sie krank wurde. Der Chef könnte sie nämlich durch jemand anderen ersetzen.

\begin{tabular}{lll}
\hline 1 & $\mathrm{HN}$ & aber ich hab mich entsprechend geärgert weil ich \\
& $\mathrm{AL}$
\end{tabular}
\begin{tabular}{|ll}
\hline 2 & $\mathrm{HN}$ \\
& $\mathrm{AL}$
\end{tabular}

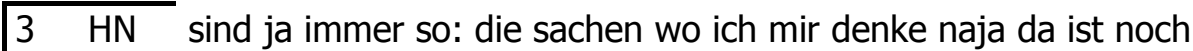
$\mathrm{AL}$

$4 \quad \mathrm{HN}$ ein risiko dabei es kann doch noch sein daß er sich jemand $\mathrm{AL}$

$5 \mathrm{HN}$ anderen einstellt na

$\mathrm{AL} \quad j a+$ aber da kannst du ja wirklich nichts

$6 \quad \mathrm{HN} \quad$ nee er war auch nicht böse ich konnte $\mathrm{AL}$ dafür wenn du krank bist ( $\mathrm{mf}$ )

$7 \quad \mathrm{HN}$ echt nichts dafür na die reise ist einmal versch einmal

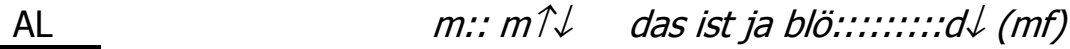

$8 \mathrm{HN}$ verschoben worden weil in japan taifun war und dann vierzehn $\mathrm{AL} \quad m:: m \downarrow \uparrow(m f)$

9 HN tage später hatte ich magen darm infekt und schüttelfrost und AL

$10 \mathrm{HN}$ fieber $\mathrm{H}$ wann hat man dann sowas schon mal na LACHEN::::::

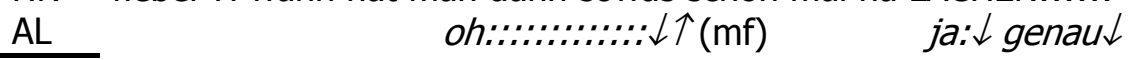

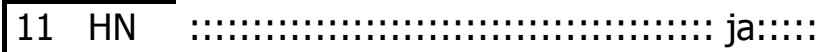

$\mathrm{AL} \quad$ LACHEN immer nur an solchen momenten $\downarrow$ LACHEN (mf)

In diesem Beispiel ist ersichtlich, daß sich die Hörerin sehr aktiv am Gespräch beteiligt und sich der Sprecherin einfühlsam zuwendet: Zum einen sind Hörersignale formal sehr abwechslungsreich: Kurzformen wie $o h, m:: m$, Kombinationen von Kurzformen wie ja klar, ja genau und satzförmige Äußerungen werden verwendet; dabei verkörperen die Satzäußerungen Verschiedenes: Ergänzungen zum Redebeitrag (Zeile 11), Bewertung (Ziele 7) und eine ausführlich begründete Zustimmung (Zeile 5). 
Außerdem übten die Hörersignale in diesem Beispiel unterschiedliche Funktionen aus: Zustimmung (Zeile 2, 7, 10), Verstehenssignale (Zeile 8), Bewertung (Zeile 7), Mitleidsäußerung (Zeile 5,10), Ausdruck des Verständnisses (Zeile 11) usw. Ferner zeichnen sich einige Hörersignale durch erhöhte Emotionalität aus (Zeile 7, 10, 11).

Ferner überlappen sich einige Hörersignale in dieser Passage auf eine relativ ungewöhnliche Art und Weise mit den Sprecheräußerungen: Die Hörersignale das ist ja blöd in Zeile 7 und oh in Zeile 10, die sich auf die vorangegangenen Äußerungen beziehen, wurden beide mitten im nächsten Satz (in der RL und im VF) eingesetzt. Nicht zuletzt trägt viel Lachen dazu bei, die Gesprächsstimmung zu erheitern.

\section{Hörersignale, die Dissens anzeigen}

In meinen Daten sind Dissens in Ansichten oder Bewertungen kaum vertreten; statt dessen wird die Nichtübereinstimmung häufiger indiziert; dabei geht es um Sachverhalte, die bestätigt oder falsifiziert werden können.

Gesprächskontext 38

Knut redet über das Publizistikstudium an der Hamburger Uni; er weiß jedoch nicht genau, wo der NC dort liegt und will als Vergleich den NC der Göttinger Uni heranziehen. Heinz dagegen widerspricht den von ihm angegebenen Information:

$1 \quad \mathrm{KN}$ ich weiß nicht wo der NC liegt aber $\mathrm{H}$ also die haben doch $\mathrm{HZ} \quad$ eins $\downarrow$ und $\downarrow$ (mf)

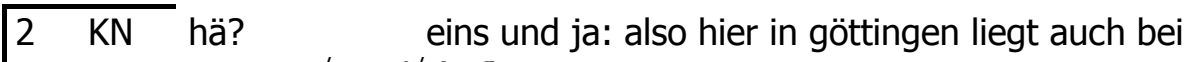
$\mathrm{HZ} \quad$ eins $\downarrow$ und $\downarrow$ (mf)

$3 \quad$ KN eins + neun oder so:: wahrscheinlich $\mathrm{HZ} \quad \Rightarrow$ der heiko ist mit zwei sieben reingekommen $\downarrow$

$4 \quad \mathrm{KN}$ ja? achso naja ich dachte na: $\mathrm{H}$ ich weiß nicht $\mathrm{H}$ weil die: $\mathrm{HZ}$ (f) also ja LACHEN

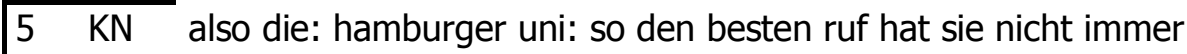
$\mathrm{HZ}$

Die Tatsache, daß ein Freund von Heinz mit der Abiturnote von 2,7 zum Publizistikstudium zugelassen wurde, stimmt mit den NC-Werten, die Knut angibt, nicht überein. Dieser 
Einwand lenkt den Sprecher vom ursprünglichen Redeplan ab; er nimmt die widersprüchliche Information vorerst so an, aber will dann seine Information noch einmal unterstreichen, was aber nicht mehr zu Ende geführt wird. Knut gibt also schnell damit auf, der der Richtigkeit seiner Vermutung zu bestehen (Zeile 4) und läßt die Frage ungeklärt. Damit entgeht er der Konfrontation mit dem Hörer und kommt zu seinem Thema (Zeile 5) zurück. So ist an diesem Beispiel ersichtlich, daß bei der Nichtübereinstimmung der Gesprächsverlauf nicht unversehrt bleibt; eventuell kann der Sprecherturn in eine gänzlich andere Bahn gelenkt werden.

\section{Hörersignale, die Desinteresse des Hörers für das Thema bekunden}

Ebenso können Verhaltensweisen des Hörers auf Desinteresse hindeuten. Dies läßt sich besser in Redebeiträgen, die sich länger hinzogen, beobachten. Beim subtilen Ausdruck einer weniger engagierten Hörerhaltung kann der Sprecherturn ebenso verlängert werden.

Gesprächskontext 39

Das Projekt, an dem sich Roby beteiligt, soll dazu dienen, ein Konzept für die regionale Entwicklung zu erstellen. In der Regel erstreckt sich ein solches Projekt auf mehrere Jahre, weil die Beteiligten zuerst abwarten, ob das Projekt erfolgreich erscheint.

$1 \quad$ FR

RO Ah aber an sich beruht es eigentlich auf der idee äh so ne +

2 FR

RO sozusagen win win situation daß man irgendwie alle versucht

$3 \quad F R$

RO An einen tisch zu kriegen und alle ein bißchen davon

$4 \quad \mathrm{FR} \quad m: \downarrow(m p)$

$\mathrm{RO}$ profitieren und deswegen mitmachen na $\mathrm{H}$ ah::n wie gesagt

$5 \quad \mathrm{FR}$

RO Da man da meistens erstmal vorarbeit leisten muß und so

$6 \quad \mathrm{FR}$

RO $\mathrm{H}$ ah:n versucht man da am anfang noch versuchen

$7 \quad F R$

RO Die beteiligten am anfang ihre einsätze möglichst gering zu

$8 \quad \mathrm{FR}$

$\mathrm{RO}$ halten und wenn dann $\mathrm{H}$ die sache angelaufen ist und auch 
$9 \quad \mathrm{FR}$

RO erfolgsversprechend scheint dann steigt man da etwas mehr

$10 \mathrm{FR} \quad h m \uparrow(m p)$

RO Ein na und wie gesagt sowas vollzieht sich dann auch

11 FR

RO wenn es dann administrativ abgestimmt werden muß und so

12 FR

RO weiter $\mathrm{H}$ un deshalb kann sich das schnell über drei bis sechs

13 FR $m:: m \downarrow(\mathrm{mp})+m: m \downarrow \uparrow(m p)$

RO jahre erstrecken + wie gesagt na

14 FR $\quad j a: \downarrow+j a: \uparrow(m p)$

RO das geht aber irgendwie nicht so schnell na

15 FR

RO ist aber auch: spannend ja da hat man sich also $\mathrm{H}$ äh:n

16 FR

RO zielvorgaben das ist halt dieses un dreieck ökonomie ökonomie

\begin{tabular}{|ll}
17 & FR \\
& RO
\end{tabular} und soziales na $m: h m \downarrow \uparrow(m p)$

Der o.a. Abschnitt befindet sich in der mittleren Phase eines von Roby geführten Turns, der knapp drei Minuten lang andauert. Dabei erzählt Roby ausführlich über sein Projekt, für das Friedrich inzwischen das Interesse verloren hat: Dies kommt im mittleren Abschnitt (zwischen Zeile 4 und 12) deutlich zum Ausdruck: Diese Passage ist dadurch gekennzeichnet, daß Hörersignale überwiegend aus unauffällig intonierten Verstehenssignalen wie aus hm:m bestehen, die kaum emotionale Regung des Hörers anzeigen. Dabei sind die Verstehenssignale sehr variationsarm in der Formenauswahl: Es gab z.B. keine Hörersignale, die auf eine interessierte, involvierte Einstellung des Hörers dem Gesagten gegenüber hindeuten.

Für das Desinteresse des Hörers spricht ferner, daß die Anzahl der Hörersignale in den anfänglichen Sequenzen des Beispiels (Zeile 1 bis 10) trotz der Übermittlung von mehreren substantiellen Informationen merklich zurückgeht. Die Frequenz erhöht sich zwar in der mittleren Phase, aber die betreffenden Hörersignale werden fast nur auf Verlangen des Sprechers eingesetzt (Zeile 4, 10, 13, 14, 17): So werden z.B. Hörersignale kurz nach der 
Pause an Satzgrenzen oder nach Sprechersignalen gesendet; es gibt jedoch keine Hörersignale, die aus eigener Initiative gesendet werden; dieses Verhalten Friedrichs läßt sich eher als Ausdruck seiner passiven Haltung interpretieren und weniger als eine aktive Anteilnahme. Insgesamt spielt Friedrich in den o.a. Sequenzen einen zurückgezogenen, höflichen Hörer, der geduldig auf einen günstigen Zeitpunkt zur Beendigung des Sprecherturns wartet. Dies wirkt sich auf die Beziehungsgestaltung eher negativ aus. ${ }^{352}$

4.5.2.5 Hörersignale, die die Beibehaltung bzw. die Änderung des bestehenden Rollenverhältnisses anzeigen

In der Regel wird die bestehende Sprecher- und Hörerrollenverteilung mittels Hörersignalen verschiedener Funktionen, mit denen kein Turn übernommen wurde, gleichzeitig bestätigt. Und umgekehrt wird das alte Rollenverhältnis durch den Sprecherwechsel in ein anderes überführt. Außerdem finden sich Hörersignale, die indizieren, daß der Hörer den eigenen Wunsch nach Rederecht zugunsten des anderen zurücknimmt. Dazu gehören auch Turnbeanspruchungen. Nachfolgend wird ein Beispiel für eine Turnbeanspruchung des Hörers dargelegt.

Gesprächskontext 40

Alex erzählt, daß sie zuerst die USA nicht mochte; aber seitdem sie sich als Au-Pair-Mädchen in den USA aufgehalten hatte, mag sie die USA.

$1 \mathrm{HN}$

AL also die au pair programm nicht so gut das war irgendwie nicht

$2 \mathrm{HN}$

AL so: wie ich mir das vorgestellt hab na O.K. dann gehe ich doch

$3 \mathrm{HN} \quad \Rightarrow$ aber

AL nach amerika also in die USA und jetzt ich meine LACHEN also

$\begin{array}{cc}4 & \mathrm{HN} \\ & \mathrm{AL}\end{array}$ ???????????????? $\Rightarrow$ das klingt echt nicht schlecht???

$\mathrm{AL}$ ich mag das total gerne + ja

$5 \mathrm{HN}$ ???????

$\mathrm{AL}$ doch ganz toll $++[\ldots]$

\footnotetext{
${ }^{352}$ Roby gab später zu, daß er nur wenig motiviert war, sich im Gespräch zu öffnen, weil er keinen Zugang zu seinem Gesprächspartner fand. Friedrichs Gesprächsverhalten wirkte auf Roby zu defensiv und verschlossen.
} 
Hanna versucht in Zeile 3 den Turn zu übernehmen, um wohl einen Dissens einzuleiten; sie verstummt jedoch schnell. Ebenso deutet die Äußerung von Hanna in Zeile 4 an, daß sie eventuell den eigenen Turn der bewertenden Äußerung anschließen will. Hanna stellt jedoch beide Male ihre Turnbeanspruchung zurück und läßt Alex weiter reden. So respektiert die Hörerin das Mitteilungsbedürfnis der Sprecherin und zeigt damit ihre Kooperationsbereitschaft. Die Plazierung der Höreräußerungen deutet auf die Rückssichtsnahme Hannas Alex gegenüber hin; sie wartet nämlich, bis die jeweiligen Satzäußerungen (Zeile 3 und 5) vollzogen sind. Der Turnbeginn nach dem Hörersignal wie es in Zeile 4 versucht wird, ist in meinen Daten oftmals festzustellen.

\subsubsection{Hörersignale, die den Gesprächsverlauf steuern}

Hörersignale steuern den Sprecherturn auf verschiedenen Ebenen: Hörersignale, die sich an Satzgrenzen befinden, fördern den Übergang eines Satzes in die nächste syntaktische Einheit; dabei sind sie oft an Enden von allein stehenden Sätzen und Satzgefügen plaziert und erleichtern so dem Sprecher den Beginn der nächsten Satzäußerung.

Innerhalb eines Satzes steuern Hörersignale den betreffenden Satz auf das Ende hin: Hörersignale, die sich mit Satzelementen im Mittelfeld oder mit dem letzten Wort des Satzes überlappen, bewirken die schnelle Beendigung des Satzes, weil durch überlappte Hörersignale signalisiert wird, daß der Hörer die Satzbedeutung vermeintlich frühzeitig erschlossen hat.

Ferner können Hörersignale wie Nachfragen, Kommentare usw. den Sprecher dazu zwingen, den Redeplan zu modifizieren, der Sprecher muß dann vom Turn abschweifen und auf Nachfragen antworten oder auf Kommentare gewisse Reaktionen zeigen.

In bezug auf die Distribution von Hörersignalen in längeren Gesprächsabschnitten kann die Vermutung angestellt werden, daß Hörersignale zum Teil dazu eingesetzt werden, den Sprecherturn in die Länge zu ziehen. Dabei kann der Hörer dies aus Interesse für das aktuelle Thema tun oder weil er sich hinter der Hörerrolle verstecken will. Hingegen können Hörersignale dazu dienen, um den Redebeitrag des anderen schnell zum Abschluß zu bringen, weil man selbst den Turn übernehmen will. In manchen Fällen wird der Wunsch nach der Turnübernahme mittels Hörersignalen im voraus angekündigt. Im folgenden Beispiel handelt 
es sich um eine Aufeinanderfolge von Hörersignalen, die eine Beendigung des Sprecherturns bewirken soll.

Gesprächskontext 41

Roby erzählt Friedrich sehr ausführlich von einem Projekt, an dem er gerade beteiligt ist. Friedrich versucht dreimal vergeblich, den Turn des Sprechers zu stoppen. Beim vierten Mal setzt er ein deutliches Zeichen für seinen Überdruß und strengt sich an, das Rederecht zu übernehmen. Im folgenden wird ein Abschnitt aus einem fast dreiminütigen Turns vorgeführt, der auf den o. a. Abschnitt vom Beispiel 20 folgt:

$1 \quad$ FR

RO weil erstmal müssen die kommunen naja ähn + naja gewisse

$2 \quad \mathrm{FR} \quad \Rightarrow m: m \downarrow$ (pp)

RO egoismen überwinden und: + zusammen + arbeitsbereitschaft

$3 \quad \mathrm{FR} \quad \Rightarrow m: m \downarrow$ (pp) + + na klar na klar naja (mf) H willst du

RO zeigen na ja m:m

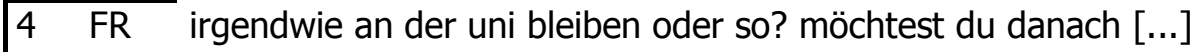
RO

Friedrich verlor Interesse für das Thema nach einer $\mathrm{zu}$ ausführlichen Erklärung über das Projekt, an dem sich Roby beteiligt. Am Ende sendet er Hörersignale eher aus Höflichkeit, was z.B. durch die leise artikulierten $m:: m$ s in Zeile 2 und 3 signalisiert wird. Sehr auffällig ist eine Kombination von Hörersignalen na klar na klar naja in Zeile 3 und stellt bei Friedrich ein typisches Zeichen für den Wunschen zur Beendigung des Themas dar: Er setzt des öfteren vor dem Turnwechsel Kombinationen aus Kurzformen wie in diesem Beispiel ein, um den Sprecherwechsel herbeizuführen, sowie um das Thema $\mathrm{zu}$ wechseln. Die kombinierten Kurzformen in Zeile 3 zeigen an, daß der Hörer das Gesagte sehr gut verstanden hat und keine weiteren Ausführungen zum aktuellen Thema benötigt. Damit bezweckt der Hörer zum einen die Anerkennung des Turns und zum anderen die Beendigung des Turns sowie die Einleitung des eigenen Turns; naja dient hierbei dazu, das alte Thema abzurunden und den bevorstehenden Themawechsel anzukündigen. Dieses wurde in diesem Beispiel durch eine neue Frage eingeführt. 


\subsubsection{Funktionen von Hörersignalen in den japanischen Daten}

\subsubsection{Hörersignale, die als Fortsetzungssignale fungieren}

In den japanischen Daten findet sich eine Reihe von Hörersignalen, die in der Satzmitte positioniert sind und nicht auf den ganzen Satz oder die Satzbedeutung, sondern auf die einen Satz konstruierende Elemente (Phrasen, Wörter) bezogen sind. Solche Hörersignale werden in diesem Kapitel von Verstehenssignalen, die sich nach einer größeren Informationseinheit, die aus einem oder mehreren Sätzen besteht, richten, abgesondert und als Fortsetzungssignale behandelt. Diese lassen sich folgendermaßen charakterisieren:

- Sie sind in der Pause nach einem Wort oder einer Phrase plaziert oder mit einem Wort oder einer Postposition überlappt.

- Dabei sind sie auf kleinere Informationseinheiten wie Wörter oder Phrasen bezogen.

- Sie markieren somit den Vollzug von Teilinformationen, die für den Verstehensprozeß des Hörers relevant sind.

- Sie signalisieren den Empfang und das Verstehen des betreffenden kleineren Informationsträgers und fördern zugleich den Fortgang des Sprecherturns.

- Mit ihnen können außerdem die Emotionalität oder diverse Einstellungen des Hörers dem Gesagten gegenüber zum Ausdruck gebracht werden.

- Formal gesehen werden Fortsetzungssignale oft durch um und $e$ : oder deren Wiederholung wie e:e:e:, umumum usw. realisiert.

Fortsetzungssignale finden sich viel häufiger in den japanischen als in den deutschen Daten. Viele von diesen sind mehr oder minder emotional aufgeladen und bekunden (großes) Interesse für die Aufnahme weiterer Informationen; dies regt den Sprecher zur Weiterführung des Turns, also des betreffenden Satzes, an.

Als erstes wird ein Beispiel für ein Hörersignal mit der Partikel $e$ : angeführt, das stärkere emotionale Regung des Hörers zum Ausdruck bringt. 
Gesprächskontext 42

Momoru, der Politologe ist, erzählt von den heutigen Wahlkampf-Strategien. Dabei ist er der Meinung, daß das Image der Partei gegenüber dem Parteiprogramm bevorzugt wird. ${ }^{353}$

\begin{tabular}{|cccc}
\hline 1 & MR & yoku iwarete iru no wa e:: sono $\mathrm{H}$ hoshu to kakushin to no \\
& & Was oft behauptet wird, ist daß ah: also zwischen den Konservativen und den Progressiven \\
& TY & & $\Rightarrow e: \downarrow$
\end{tabular}

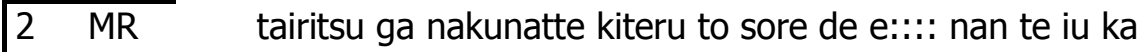
Unterschiede immer weniger geworden sind. Und dann äh:: Wie sagt man!? TY

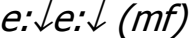
$e: \downarrow(m f)$

$3 \quad$ MR senkyosen nanka demo moppara imêjisensen ga senkô suru bei der Wahl oder so nur der Imagekampf wird bevorzugt TY $h m: m \downarrow(m p)$

$\left.\begin{array}{lll}4 & \text { MR } & \text { to }\end{array} \ldots . ..\right]$

Das Hörersignale $e: e$ : $e$ : in Zeile 1-2 wird nach dem Vollzug des Nomens kakushin (die Progressiven) eingesetzt, das eine der wichtigen Informationen des Satzes enthält. Dabei überlappt es sich mit der adnominalen Postposition no (von), die auf dieses Nomen folgt. Die o.a. Rückmeldung ist eindeutig auf beide adnominale Phrasen hoshu to kakushin to no (zwischen den Konservativen und den Progressiven) ausgerichtet. Damit zeigt der Hörer, daß er einen wichtigen Informationsteil verarbeitet hat und wartet, daß der Turn (oder der Satz) weiter geführt wird. $e: e: e$ : ist formal eine Verdreifachung von $e$ :, wobei alle $e$ : wie Stakkato betont und stark fallend intoniert wurden; außerdem wurde es mit relativ lauter Stimme artikuliert. Dies alles indiziert, daß der Hörer das bereits Gesagte sehr interessant findet und auf die kommenden Informationen gespannt ist. Dies motiviert den Sprecher bei der Fortführung des Turns.

Das nächste Beispiel steht für ein Fortsetzungssignal, das noch emotionalisierter wirkt und daher im erhöhten Maße den Sprecher zur Weiterrede ermuntert.

\footnotetext{
${ }^{353}$ Hier meine Übersetzung: Heuzutage wird oft behauptet, daß die Unterschiede zwischen den Konservativen und den Progressiven verloren gegangen sind, und daß beim Wahlkampf mehr Wert auf das Image der Partei gelegt wird.
} 
Gesprächskontext 43

Haruyo erzählt Sanako, daß sie bereits einmal in Deutschland war; sie besuchte mit einer Delegation aus ihrer Universität zusammen ein Herderinstitut in Ostdeutschland. ${ }^{354}$

1 HR H kyûhigashidoitsu wa: gêteinsutichût to narande ano Im ehemaligen Ostdeutschland ähnlich wie Goetheinstitut SN $e: \therefore:: \cdot(p p)$

\begin{tabular}{|cccc}
\hline 2 & HR & headâinstichût tte iu no ga aru n desu yo $\begin{array}{c}\text { H de sore:: ni i } \\
\text { Und daran }\end{array}$ \\
& gibt es sog. ein Herderinstitut & ho:::: $\rightarrow(\mathrm{mp})$
\end{tabular}

$3 \quad \mathrm{HR}$ ano ga daigaku no chiba daigaku: no sono dantai to iu ka also unserer Universität, von Universität Chiba die
SN $::: \cdot m)(m p)$

$4 \quad$ HR ikkaime de itte zum ersten Mal gefahren und $\mathrm{SN} \Rightarrow e:: e:: e:: e: \downarrow \downarrow \downarrow \downarrow(m f)$

In Zeile 4 wird ein Fortsetzungssignal aus einem vierfach wiederholten $e$ : nach dem Vollzug einer komplexen Phrase: daigaku no chiba daigaku: no sono dantai to iu ka (eine Gruppe von unserer Universität oder von der Universität Chiba oder so) eingesetzt. Ähnlich wie im letzten Beispiel wird $e$ : viermal nachdrücklich akzentuiert und stark fallend intoniert. Damit bezweckt die Hörerin Sanako, den Empfang der ganzen Phrase zu bestätigen und damit die Relevanz der vorangegangenen Information zu unterstreichen. Zum anderen dient dieses Hörersignal dazu, den Fortgang des Turns zu erleichtern, weil es sehr emotional eine interessierte Haltung der Hörerin dem Gesagten gegenüber mitteilt. Sie begleitet sogar die nächste Phrase der betreffenden Satzäußerung, indem sie die Hörerrückmeldung $e: e$ : $e: e$ : dem Mora-Akzent der Phrase `ik kai`me`de (zum ersten Mal) angeglichen hat; dadurch stand das betreffende Signal im musikalischen Einklang mit der Sprecheräußerung, was letztendlich eine Harmonie oder das Einssein zwischen dem Sprecher und dem Hörer symbolisch herstellt. Diese Art längerer Überlappung ist in meinem japanischen Datenmaterial des öfteren anzutreffen.

\footnotetext{
354 Hier meine Übersetzung: Im ehemaligen Ostdeutschland gibt es ein Herderinstitut ähnlich wie das Goetheinstitut; dorthin ist die Gruppe von unserer Universität, also von der Universität Chiba zum ersten Mal gefahren, und...
} 
Als letztes wird ein Fortsetzungssignal herangezogen, das verhältnismäßig wenig Emotionalität zum Ausdruck bringt. „Nüchterne“ Fortsetzungssignale sind in meinen Daten ebenfalls relativ oft vertreten.

Gesprächskontext 44

Satoru erzählt Shigeru über sein Fachgebiet „Planung der sozialen Umwelt", in dem er als Assistenzprofessor in Japan tätig ist. Er hat dort als Jurist einen Lehrstuhl; außerdem gibt es in seinem Fach Dozenten, die aus den naturwissenschaftlichen Bereichen stammen ${ }^{355}$.

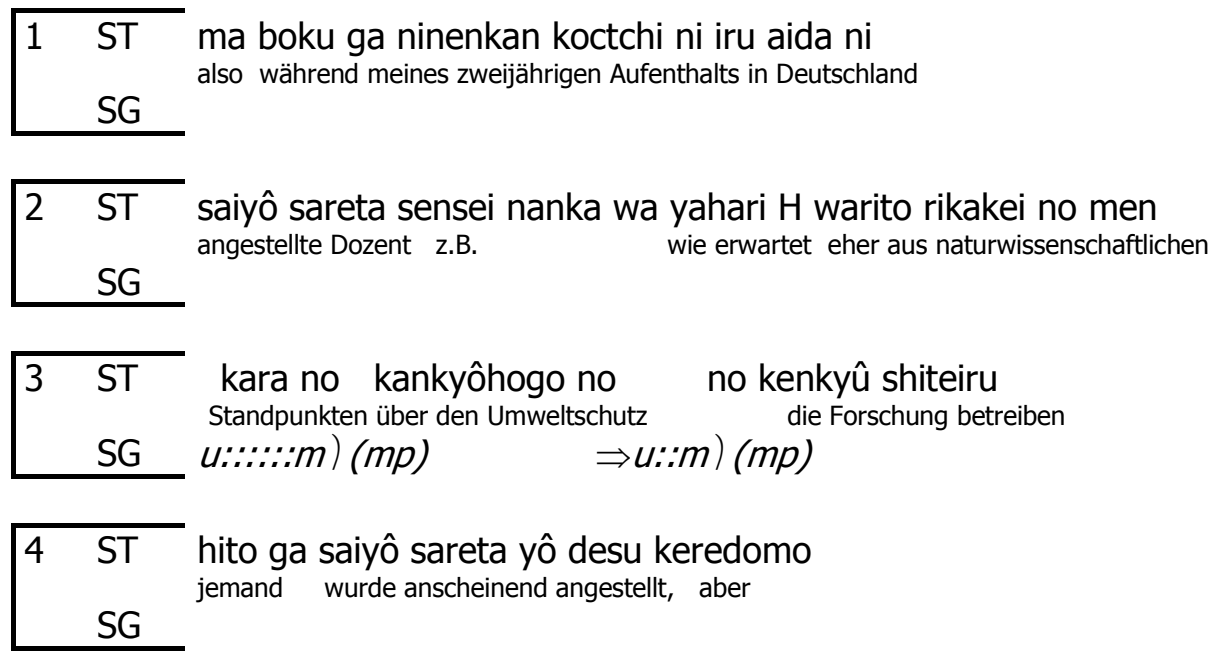

In Zeile 3 sind zwei Hörersignale zu beobachten, die als Fortsetzungssignale fungieren: Beide werden mitten im Satz geäußert, in dem für das Verstehen wichtige Teilinformationen bereits geliefert sind, ohne daß die Satzbedeutung schon transparent ist. Sie übermitteln das Verstehen des bereits geäußerten Teils und zugleich die Bereitschaft zur weiteren Informationsaufnahme. Dabei wird ebenfalls der Vollzug einer wichtigen, kleineren Informationseinheit markiert. Ferner kommt durch die Dehnung und die leicht fallende Intonationskontur beider Hörersignale eine innere Haltung des Hörers zum Ausdruck, die dafür spricht, daß der Hörer das Gesagte ernst nimmt und darüber nachdenkt.

\subsubsection{Hörersignale, die den Verstehensstand signalisieren}

Als Verstehenssignale gelten in diesem Kapitel Hörersignale, die durch folgende Merkmale gekennzeichnet sind: 
- Sie werden durch die Partikeln um, e:, ha:, hai oder deren Wiederholung wie $e$ : $e: e$;, um um um, hai hai hai usw. realisiert; Verstehenssignale setzen sich des öfteren aus mehrfach aneinander gereihten Kurzformen zusammen.

- Verstehenssignale sind häufiger als Fortsetzungssignale gefühlsbetont und mit diversen Einstellungen wie Interesse, Empathie, Verständnis des Hörers dem Gesagten gegenüber versehen: Dies kann man vor allem an der Lautstärke, der Dehnung, der Akzentuierung, der Intonationskontur und der Anzahl der Wiederholungen von um, e: usw. festmachen.

- Sie sind in der Regel im Satzendebereich positioniert; sie treten jedoch ab und an vor diesem Bereich auf und kündigen vermeintliches frühzeitiges Verstehen der betreffenden Satzäußerung an.

- Sie zielen auf größere Informationseinheiten wie einen Satz, ein Satzgefüge oder eine Sinneinheit aus mehreren Sätzen.

Im nächsten Beispiel werden verschiedene funktionale Aspekte von Verstehenssignalen auf einmal illustriert.

Gesprächskontext 45

Shigeru erzählt Satoru, warum er vor dem Studium in Göttingen einmal Deutschland besucht hat: Er hatte in Japan sehr oft gehört, daß Norddeutsche gefühlskalt sind oder daß sie nicht antworten, wenn man sie nach etwas fragt usw. Daraufhin wurde er ein wenig ängstlich und wollte selber in Erfahrung bringen, ob all diese Vorurteile in bezug auf Norddeutsche der Wahrheit entsprechen. ${ }^{356}$

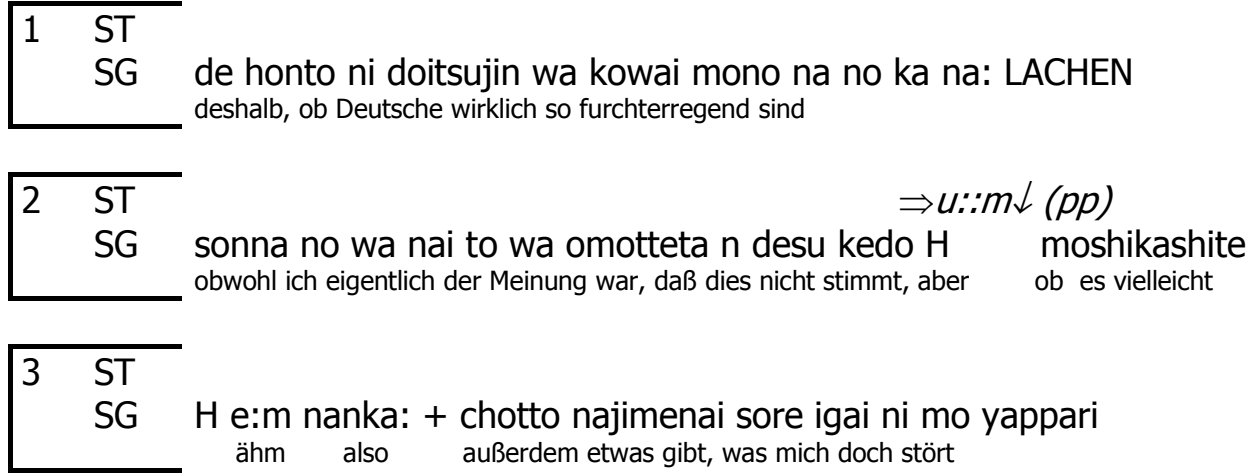

355 Die Übersetzung: Der Dozent, der während meines zweijährigen Aufenthalts in Deutschland angestellt wurde, erforscht den Umweltschutz aus naturwissenschaftlichen Standpunkten.

356 Übersetzung: Da ich in Erfahrung bringen wollte, ob Deutsche wirklich so furchterregend sind, oder ob es außerdem noch eventuell Mentalitäten oder Sitten und Gebräuche gibt, an die ich mich nicht gewöhnen kann, bin ich einmal hierher gekommen, obwohl ich eigentlich dachte, daß sie (Deutsche) nicht so sind. Dann fand ich Deutschland doch toll. 


\begin{tabular}{|c|c|c|}
\hline 4 & $\begin{array}{l}\text { ST } \\
\text { SG }\end{array}$ & $\begin{array}{l}\qquad \Rightarrow u::: m \downarrow(p) \\
\text { najimenai bubun toka: seikatsushûkan toka ga aru no ka na } \\
\text { ob schlecht annehmbare Eigenschaften oder Sitte und Gebräuche existieren }\end{array}$ \\
\hline 5 & $\begin{array}{l}\text { ST } \\
\text { SG }\end{array}$ & 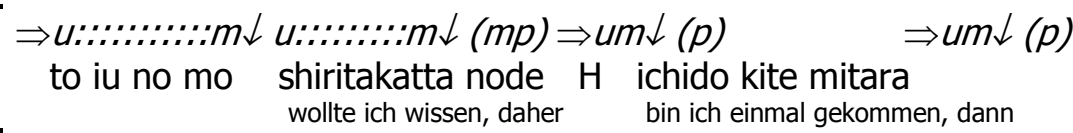 \\
\hline 6 & $\begin{array}{l}\text { ST } \\
\text { SG }\end{array}$ & \begin{tabular}{ll}
\multicolumn{4}{c}{$\Rightarrow u m \downarrow(p) \Rightarrow u m \downarrow(p)$} & $\Rightarrow u m \downarrow(p)$ \\
$\begin{array}{l}\text { yappari ii na: to } \\
\text { daß es doch toll ist }\end{array}$ & $\begin{array}{c}\text { omoimashite } \\
\text { dachte ich }\end{array}$
\end{tabular} \\
\hline
\end{tabular}

In Zeile 2 bestätigt Satoru das Verstehen eines Satzgefüges, was zugleich als Fortsetzungssignal fungiert, denn dort wird kein Turnwechsel durchgeführt. Dieses um kann als Reaktion auf die Pause des Sprechers angesehen werden; der Hörer zeigt sich hierbei kooperativ mit dem Sprecher.

Das nächste um in Zeile 4 hingegen wurde nach der Phrase des Bezugsnomens eingesetzt, der auf einen Attributsatz folgt. Damit bezweckt der Hörer nicht nur das Verstehen anzuzeigen, sondern auch den Sprecher zum Weiterreden zu ermutigen oder besser den Turn in Gang zu bringen, denn Shigeru hatte anfänglich Anlaufschwierigkeiten: Eine gefüllte Pause, eine Phrase zur Zeitgewinnung und eine Pause ähm nanka: + (ähm also) und die anschließende Präzision der bereits angefangenen Äußerung: sore iga ni mo yappari najimenai bubun (außerdem etwas, was mich stören könnte). Ebenso sind Verstehenssignale in Zeile 5 und 6 stärker mit einer „continuer“-Funktion gekoppelt. An den Stellen, an denen diese Hörerrückmeldungen positioniert sind, sind die jeweiligen Satzgefüge noch nicht komplettiert oder auf eine „offene“ Art und Weise vorläufig beendet (Vte-Satz).

In Zeile 5 signalisiert die Hörerreaktion erhöhte Emotionalität und Zuwendung des Hörers; um wird gedehnt und verdoppelt; ferner wird dieses Hörersignal lauter als sonst intoniert; drittens wird es vor dem Hauptsatz to iи no mo shiritakatta node (weil ich wissen wollte, daß), d.h. frühzeitig positioniert, und überlappt sich fast mit dem ganzen Hauptsatz (außer node (weil)). Diese Plazierung von um bezeugt, daß der Hörer oftmals in der Lage ist, die Sprecherientention schneller mental zu verarbeiten, als die betreffende Äußerung vollzogen ist, und gleichzeitig diese Sprecheräußerunge jeweils nach dem zum Verstehen weniger relevanten und bedeutenderen Teil zu gliedern. Außerdem kommt dabei der Wunsch des Hörers zum Vorschein, die Sprecherrede wie ein Baßinstrument rhythmisch zu begleiten und 
mit ihm in einem harmonischen Einklang zu sein. So kann der Hörer auf eine andere Art als der Sprecher das Gespräch gemeinsam mit ihm gestalten.

Nach der (längeren) Überlappung wird noch ein Hörersignal direkt nach dem Vollzug des Satzgefüges zusätzlich gesendet (Zeile 5), was in den japanischen Daten oftmals vorkommt: Dadurch möchte der Hörer dem Sprecher womöglich versichern, daß er das Gesagte trotz der Überlappung gut verstanden hat. Diese Art Verstehenssignale findet sich außer in Zeile 5 auch in Zeile 6 (das zweite $u m$ ).

Die erhöhte Anzahl der Verstehenssignale in der letzten Hälfte der Zeilen läßt sich in diesem Fall als Ausdruck der (sehr) aktiven Beteiligung und der Interessenbekundung des Hörers interpretieren. Ein Grund dafür ist, daß der Hörer nach diesem Beispiel keinen Turn übernahm oder versuchte, das Thema zu ändern. Außerdem verhielt sich Satoru oftmals in vergleichbaren Gesprächskontexten ähnlich, in den sein Hörerverhalten darauf hindetet, daß er Interesse am Thema hat.

Nachfolgend wird ein Verstehenssignal präsentiert, das besonders emotionalisiert ist. In meinen Daten bilden emotional aufgeladene Verstehenssignale keine Ausnahme.

Gesprächskontext 46

Nachdem Ayumi nicht begründen konnte, warum sie nach Deutschland gekommen ist, um Indologie zu studieren, erzählt Mako über die Gründe für ihren Aufenthalt in Deutschland. ${ }^{357}$

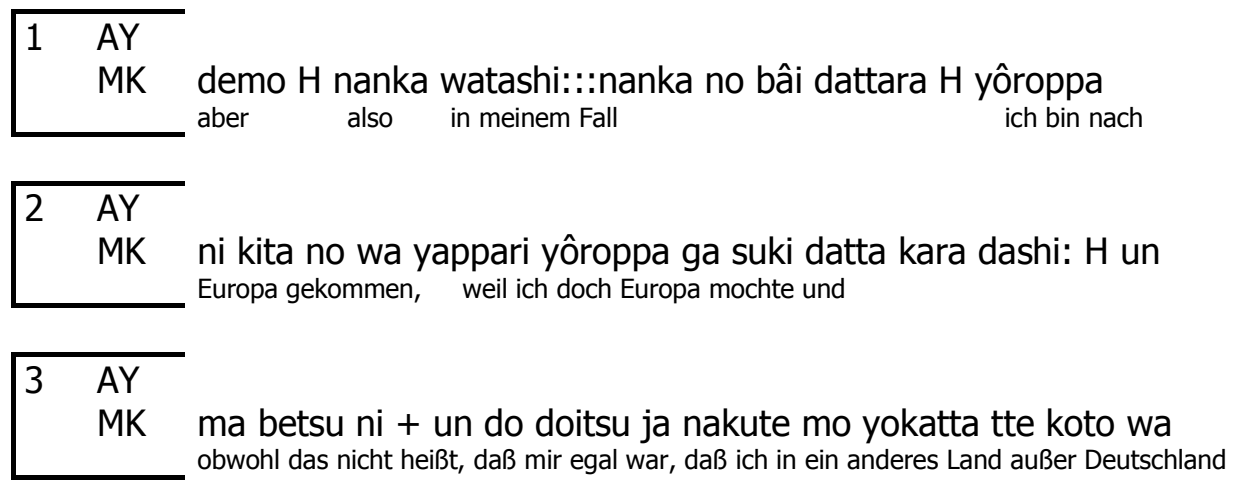




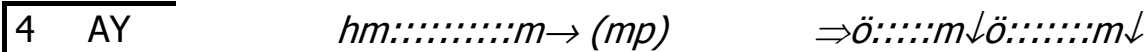

MK nai kedo ma tamatama doitsu ni en ga atta kara doitsu ni

gegangen wäre; aber ich hatte zufällig eine Schicksalsverbindung nach Deutschland, daher bin ich nach Deutschland

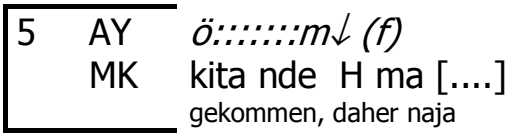

um in Zeile 4-5 überlappt sich mit dem Verb atta (bestanden); offensichtlich ist es auf die Phrasen doitsu-ni en-ga (mit Deutschland eine Schicksalsverbindung) gezielt, wobei an jener Stelle die Satzbedeutung ohne weiteres erschließbar ist. Die Plazierung dieser Hörerreaktion indiziert, daß diese Phrase die Hörerin Ayumi angesprochen hat, weswegen sie spontan den Vollzug dieses Informationsteils markiert hat. Die dreifache Wiederholung von um bezeugt darüber hinaus starke emotionale Regung der Hörerin; außerdem wird diese Höreräußerung relativ laut ausgesprochen und mit großem Nachdruck akzentuiert; die Intonationskontur ist dabei sanft fallend. Im weiteren spricht die länger hingezogene Überlappung für die erhöhte Emotionalität der Hörerin. Mittels dieses Hörersignals wird bekundet, daß Ayumi Makos Begründung sehr gut nachvollziehen kann, und daß sie auch aus ähnlichen Gründen nach Deutschland gekommen ist. Womöglich ist durch Makos Äußerung bei Ayumi „ein Licht aufgegangen“ und sie weiß plötzlich, daß sie ihre Gründe für ihr Studium in Deutschland nur so erklären kann.

Außer diesem Beispiel lassen sich eine Reihe von Verstehenssignalen beobachten, die mehr oder minder stark emotionalisiert sind oder diverse Einstellungen des Hörers in bezug auf den dargestellten Sachverhalt subtil zum Ausdruck bringen. Häufig werden Interesse am Thema, die Empathie, die Nachdenklichkeit usw. des Hörers angezeigt.

Hörersignale, die Verstehensprobleme anzeigen oder zur Verständnissicherung dienen, sind in den untersuchten Abschnitten der japanischen Daten nicht vertreten. Anscheinend ist der Hörer in den japanischen Daten mit Nachfragen vorsichtig, weil er befürchtet, dadurch den Sprecherturn durcheinander zu bringen. Diese Vermutung läßt sich jedoch aufgrund einer geringen Datenmenge weder bestätigen noch verwerfen.

\footnotetext{
${ }^{357}$ Übersetzung: Was mich angeht, bin ich nach Europa gekommen, weil ich Europa mochte; das heißt nicht, daß ich lieber in ein anderes Land als Deutschland gegangen wäre. Aber ich hatte zufällig die Gelegenheit, nach Deutschland zu kommen.
} 


\subsubsection{Hörersignale, die den Wissensstand des Hörers signalisieren}

Hörersignale, die die Wissensdivergenz zwischen dem Sprecher und dem Hörer anzeigen, weisen folgende Merkmale auf: Sie zeigen an, daß die betreffende Information für den Hörer neu oder unerwartet ist. Dabei wird oft signalisiert, daß der Hörer den dargestellte Sachverhalt langsam zu verstehen beginnt oder die in Vergessenheit geratene Information gerade aus der Erinnerung zurückgeholt hat. Man könnte den inneren Verstehens- oder Erinnerungsvorgang folgendermaßen paraphrasieren: ,jetzt, wo Du es sagst, verstehe ich Dich langsam bzw. erinnere ich mich langsam daran“.

Hörersignale der betreffenden Kategorie werden vor allem durch folgende Formen der Hörersignale realisiert:

- Kurzformen $a$ : (langsam oder jetzt verstehe ich) oder die mehrfache Wiederholung von $a$ : wie $a: a: a:$

- Kombinationen aus $a$ : und einer oder mehreren Kurzformen wie $a$ : sô (achso, aja), $a$ : naruhodo (aja ich kann jetzt Dich verstehen),

- Kombination aus $a$ : und einer satzförmigen Höreräußerung wie $a$ : sô desu ka (ach, so ist das).

Solche Hörersignale werden ähnlich wie Verstehenssignale überwiegend im Satzendebereich, vor allem erst nach dem Vollzug des Satzes plaziert. Außerdem sind sie wie Verstehenssignale oftmals mit Einstellungen des Hörers dem Gesagten gegenüber und/oder hoher Emotionalität versehen. Gefühlsbetonte Hörersignale können spontan mitten in der Satzäußerung auftreten.

Nachfolgend wird ein Beispiel vorgeführt: 
Gesprächskontext 47

Tsuyoshi nennt einige Gründe für die niedrige Konjunktur der japanischen Wirtschaft. Ein Grund dafür ist, daß sich das Konsumverhalten der Japaner in verschiedenen Hinsichten geändert hat. ${ }^{358}$

\begin{tabular}{|c|c|c|}
\hline & $\begin{array}{l}\text { MR } \\
\text { TY }\end{array}$ & 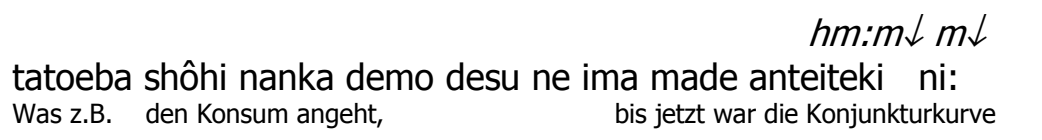 \\
\hline 2 & $\begin{array}{l}\mathrm{MR} \\
\mathrm{TY}\end{array}$ & 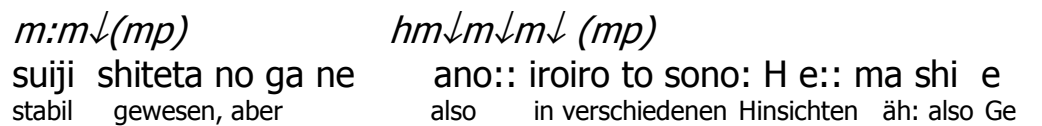 \\
\hline 3 & $\begin{array}{l}\mathrm{MR} \\
\mathrm{TY}\end{array}$ & $\begin{array}{l}\Rightarrow a:: i \downarrow(m f) \\
\text { shikô mo kawatte kite ne ano mukashi dattara sannen ka } \\
\text { der Geschmack änderte sich langsam also, früher } \quad \text { im drei oder }\end{array}$ \\
\hline 4 & $\begin{array}{l}\text { MR } \\
\text { TY }\end{array}$ & $\begin{array}{l}\text { yonnen no shûki de ureta mono ga urenaku natteru toka tte } \\
\text { vier Jahrenzyklus } \quad \text { verkaufte Sachen } \quad \text { nicht mehr gekauft werde }\end{array}$ \\
\hline 5 & $\begin{array}{l}\text { MR } \\
\text { TY }\end{array}$ & $\begin{array}{l}\qquad h m: m \downarrow h m \downarrow h m \downarrow(m p) \\
\text { iu no ga arimasu shi: } \quad \text { ma ano:: [...] } \\
\text { oder so was gibt es und }\end{array}$ \\
\hline
\end{tabular}

In Zeile 3 drückt $a$ : aus, daß die Information der vorangegangenen Satzäußerung für den Hörer neu war, daß er daran nicht gedacht hat. Ferner zeigt dieses Hörersignal an, daß die Wissensdivergenz zwischen dem Sprecher und dem Hörer in bezug auf den geäußerten Sachverhalt nivelliert wird, weil er diese Neuigkeit in sein Wissenssystem eingliedert. Durch die Prosodie kommt zusätzlich zum Ausdruck, daß der Hörer jedoch diese Neuigkeit mit großem Interesse aufnahm. Die reibungslose, interessierte Kenntnisnahme dieses neuen Wissensstandes wurde durch die sanft fließende Intonationskontur dieses Hörersignals wiedergegeben; außerdem deuten die lautere Stimme (mf) und die steigend-fallende Intonation darauf hin, daß der Hörer von der Sprecheräußerung angetan war.

Als nächstes wird ein Beispiel für ein hoch emotionales Hörersignal angeführt.

\footnotetext{
${ }^{358}$ Übersetzung: Was den Konsum angeht, war die Konjunkturkurve bis jetzt stabil, und man konnte Sachen alle drei oder vier Jahre auswechseln, aber jetzt hat er sich der Geschmack der Konsumenten geändert, so daß sich die Waren nicht mehr in dieser Periode verkaufen lassen.
} 
Gesprächskontext 48

Mako erzählt, daß sie, als sie zum ersten Mal nach Europa kam, viele Vorurteile hatte: Zum Beispiel glaubte sie, daß Europäer nicht so bescheiden sind. Sie machte jedoch in Europa eine andere Erfahrung: Europäer sind auch nicht so taktlos, wie sie vorher dachte. ${ }^{359}$

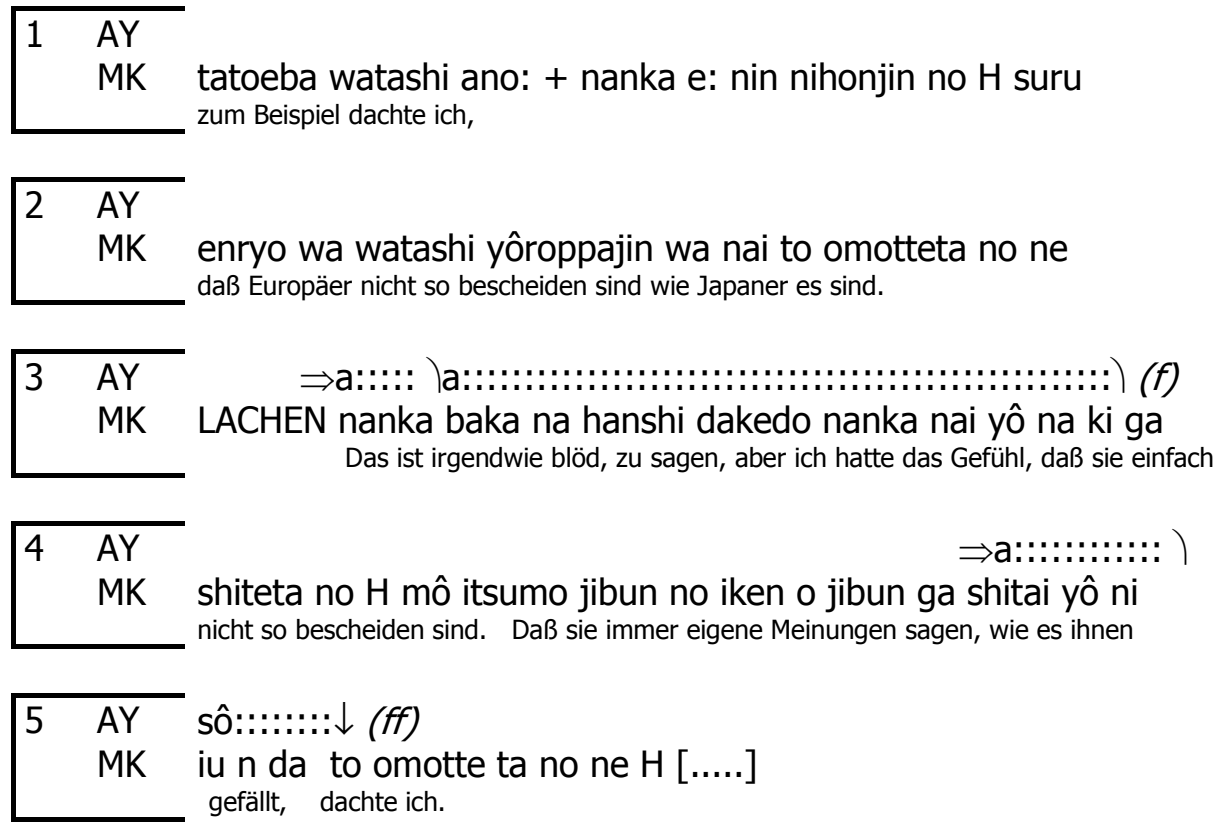

$a$ : in Zeile 3 ist in mehreren Hinsichten sehr stark markiert: Die laute Stimme, die lange Überlappung trotz der Weiterführung des Turns Makos, die sanft steigende Intonationskontur signalisieren, wie emotional gerührt Ayumi ist, als sie die vorangegangene Satzäußerung von Mako hörte. Es kommt Ayumi wohl langsam bekannt vor, was Mako erzählt. Womöglich erinnert sich Ayumi, daß sie selbst ähnliche Vorurteile hatte oder sie konnte zumindest Makos Vorurteile sehr gut nachvollziehen. Die starke Emotionalität unterstreicht die Konvergenz im Wissen oder in den Ansichten zwischen beiden Gesprächsteilnehmerinnen sowohl auf der Sach- als auch auf der emotionalen Ebene.

In Zeile 4-5 wurde $a$ sô direkt nach einer Phrase eingesetzt; Ayumi wartete vor Begeisterung nicht auf die Beendigung des Satzes, sondern plazierte dieses Hörersignal direkt nach den Phrasen, die ihr das Verstehen ermöglichen. Dies signalisiert die emotionale Regung Ayumis, die darauf zurückzuführen ist, daß sie sich an eine in Vergessenheit geratene Information

\footnotetext{
359 Übersetzung: Zum Beispiel habe ich gedacht, daß Europäer nicht rücksichtsvoll sind. Das ist zwar blöd zu sagen, aber ich habe geglaubt, daß sie keine Rücksicht kennen und immer ihre eigenen Meinungen sagen, wie es ihnen paßt.
} 
durch die Gesprächspartnerin plötzlich erinnert hat. In diesem Beispiel fungiert $a$ sô gleichzeitig als Zustimmung.

\subsubsection{Hörersignale, die als Zustimmungssignale fungieren}

Ebenso wie Fortsetzungs- und Verstehenssignale sind eine Reihe von Zustimmungssignalen in meinen Daten vertreten. Zustimmungssignale haben folgende Merkmale gemein:

- Sie drücken die Konvergenz zwischen dem Sprecher und dem Hörer in bezug auf die Ansichten oder die Richtigkeit der Sachverhalte aus; mit anderen Worten: Der Hörer stimmt den Ansichten oder den Bewertungen des Sprechers zu oder bestätigt die Richtigkeit des Gesagten.

- Dabei läßt sich die unterschiedliche Einstufung des Sicherheitsgrades des Hörers feststellen: sehr sicher - sicher - wenig sicher.

- Sie werden überwiegend im Satzendebereich positioniert; es gibt jedoch gelegentlich frühzeitig plazierte Zustimmungssignale.

- Sie sind oftmals mit der zum Teil heftigen emotionalen Regung des Hörers versehen, was an der Form, der Prosodie, der Plazierung und der Überlappungslänge usw. festgemacht werden kann.

- Außer Zustimmung oder Bestätigung können ebenfalls durch Zustimmungssignale andere Einstellungen des Hörers synchron übermittelt werden.

- Formal können sie durch Kurzformen wie um, e:, sô (ja so ist das), kombinierte Kurzformen wie $e: e$ : $e$ :, hai hai hai hai oder satzförmige Höreräußerungen, die protoypisch oder stark mit dem aktuellen Kontext verbunden sind, konkretisiert werden.

Nachfolgend werden drei Zustimmungssignale präsentiert, die eher neutral wirken. 
Gesprächskontext 49

Shigeru hat zuvor erzählt, daß er in Deutschland studieren und promovieren will, um Wissenschaftler im Bereich Umweltschutz zu werden. Da er jedoch später in Japan leben möchte, hat er vor, während des Studiums in Deutschland Kontakte zu japanischen Wissenschaftlern zu knüpfen. Satoru findet dies gut und gibt Shigeru Tips. ${ }^{360}$

\begin{tabular}{|c|c|c|}
\hline 1 & $\begin{array}{l}\text { ST } \\
\text { SG } \\
\end{array}$ & $\begin{array}{l}\text { ano nihon ni kuraberu to doitsu wa kankyôhogo ga susunderu } \\
\text { also mit Japan verglichen daß in Deutschland der Umweltschutz fortschrittlicher }\end{array}$ \\
\hline 2 & ST & 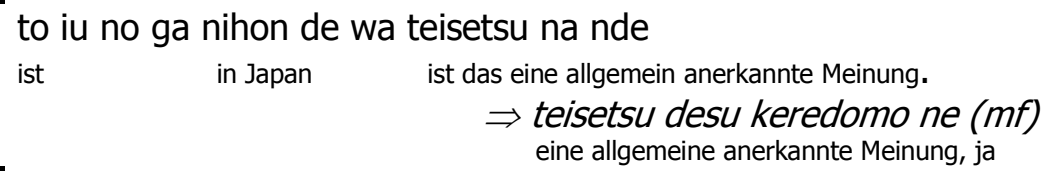 \\
\hline 3 & $\begin{array}{l}\text { ST } \\
\text { SG }\end{array}$ & 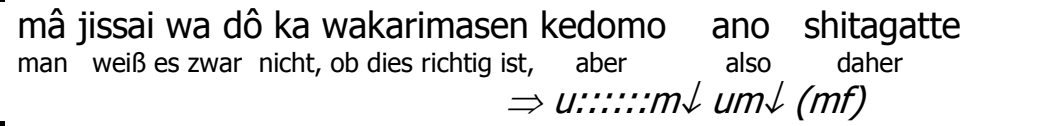 \\
\hline 4 & $\begin{array}{l}\text { ST } \\
\text { SG } \\
\end{array}$ & $\begin{array}{l}\text { nihon kara: shisatsu ni kuru toka: iu hito ippai iru to omou n } \\
\text { daß es viele Leute gibt, die aus Japan zur Besichtigung kommen, denke ich. }\end{array}$ \\
\hline 5 & $\begin{array}{l}\text { ST } \\
\text { SG }\end{array}$ & $\begin{array}{l}\text { desu ne dakara tatoeba tsûyaku shitari annai shitari toka } \\
\text { daher, wenn Sie für solche Leute übersetzen, für sie die Führung machen }\end{array}$ \\
\hline 6 & $\begin{array}{l}\text { ST } \\
\text { SG }\end{array}$ & $\begin{array}{l}\text { setsumei shitari toka } \mathrm{H} \text { suru to sono nihon de no } \\
\text { oder erklären, } \\
\text { dann würde also }\end{array}$ \\
\hline 7 & $\begin{array}{l}\text { ST } \\
\text { SG }\end{array}$ & $\begin{array}{l}\text { ko konekushon tte iu no wa sono ni tsuyoku nihon ni iru yori } \\
\text { die Verbindung zu Japan }\end{array}$ \\
\hline 8 & $\begin{array}{l}\text { ST } \\
\text { SG }\end{array}$ & $\begin{array}{l}\begin{array}{l}\text { mo tsuyoku naru } n \text { ja nai ka to } \\
\text { stärker wird }\end{array} \\
\Rightarrow u:: m \downarrow \begin{array}{l}\text { so omo denke ich, aber } \\
\text { in Bezug auf diesen Bereich ja }\end{array}\end{array}$ \\
\hline
\end{tabular}

Die satzförmige Höreräußerung: teisetsu desu keredomo ne (ja, das ist eine gängige Meinung, ja) in Zeile 2 ist die Wiederholung der Sprecheräußerung und unterstreicht den Konsens zwischen dem Sprecher und dem Hörer, wobei diese Hörerreaktion keine starke Betroffenheit

\footnotetext{
360 Übersetzung: Es ist eine gängige Meinung, daß Deutschland verglichen mit Japan im Umweltschutz fortschrittlicher ist, obwohl man es eigentlich nicht weiß, ob dies stimmt. Daher gibt es viele Japaner, die zur Besichtigung kommen. Wenn man sie führt, für sie übersetzt oder ihnen etwas erklärt, dann wird die Verbindung zu Japan stärker, als wenn man in Japan ist, denke ich.
} 
des Hörers indiziert. Hier stellt sich die Frage, ob es sich bei diesem Hörersignal um einen mißglückten Versuch einer Satzvollendung handelt; der Hörer erfaßt womöglich die Sprecherintention bereits zu diesem Zeitpunkt und äußert die Reste des Satzes, bevor der Sprecher dies tut. Dafür spricht einiges: die Plazierung direkt nach dem Schlüsselwort, die formale Übereinstimmung mit der Sprecheräußerung und der Wissensstand des Hörers gegenüber der gängigen Meinung in Japan in bezug auf den Umweltschutz. In diesem Fall stellt die Höreräußerung eine sehr überzeugte Zustimmung des Hörers dar.

$u:: m$ um in Zeile 3 überlappt sich mit dem satzletzten Wort keredomo (aber) und endete mit dem ersten Wort des nächsten Satzes; so überbrückt dieses Hörersignal zwei Sätze. Damit teilte der Hörer dem Sprecher mit, daß er den gleichen Meinungen ist, wobei diese Hörerrückmeldung eher „nüchtern“ wirkt; es läßt sich also keine starke Emotionalität dabei feststellen. Ähnliches gilt ebenso für das dritte Zustimmungssignal in Zeile 8. Inhaltlich gesehen stellt es zugleich eine Ergänzung zur Sprecheräußerung dar.

Im nächsten Beispiel wird ein Gesprächsabschnitt vorgestellt, in dem sich emotional aufgeladene Zustimmungssignale anhäufen.

Gesprächskontext 50

Ayumi hat zuvor über eine Bekannte geredet, die Mako auch kennt. Sie ist begeistert über die Fürsorge und die Hilfsbereitschaft dieser Bekannten. Jetzt fängt auch Mako an, über ihre Erfahrung mit dieser netten Bekannten zu erzählen ${ }^{361}$.

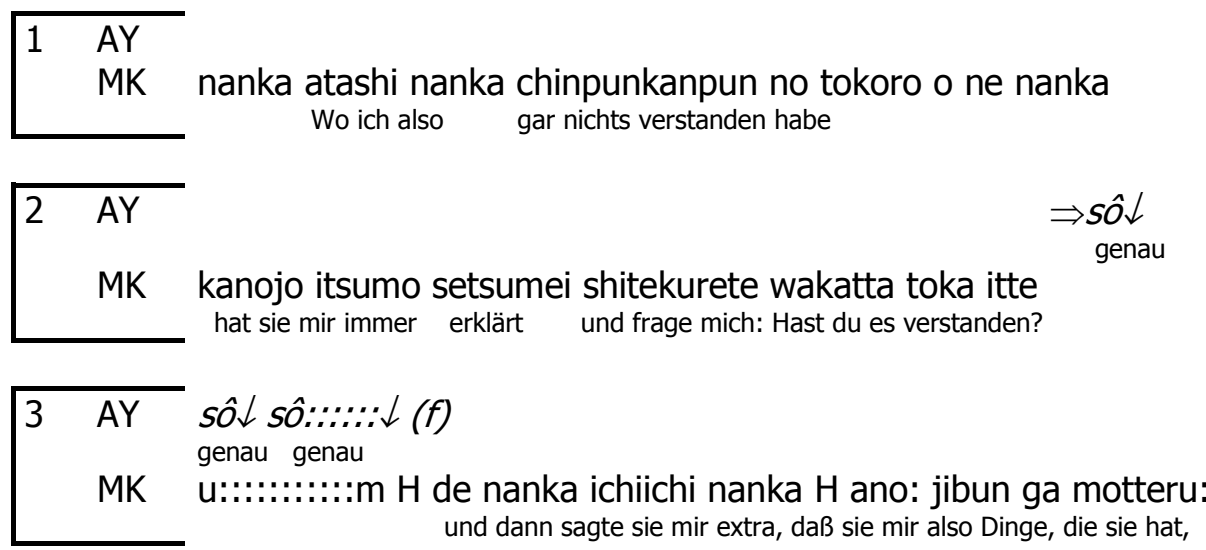




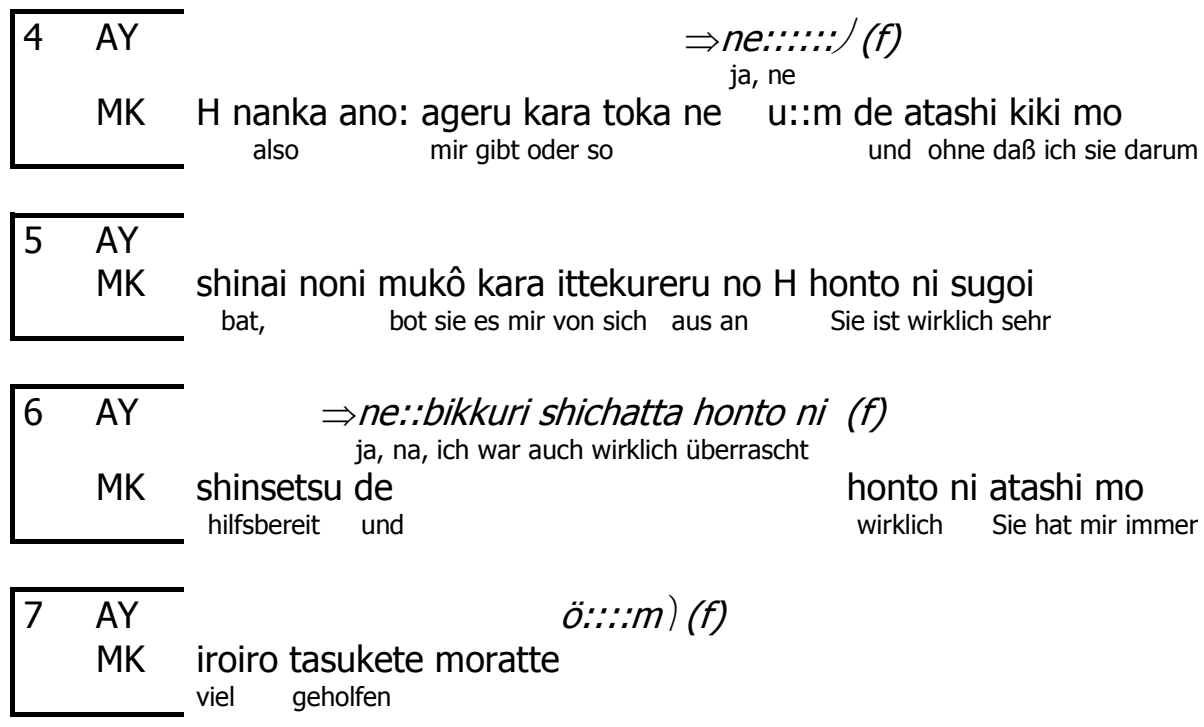

In Zeile 2 kann Ayumi Makos Äußerung mit hoher Überzeugung bestätigen, weil sie eine ähnliche Erfahrung mit derselben Bekannten gemacht hat. Die Lautstärke, die stark fallende Intonationskontur, die Formenauswahl (sô), die dreimalige Wiederholung von sô (ja, so ist das) indizieren die gesteigerte Emotionalität Ayumis; sie ist offenbar begeistert von der Persönlichkeit dieser Bekannten. Während Ayumi damit die Pause der Sprecherrede füllt, erwidert Mako die Hörerreaktion mit $u:: m$, was eine sprecherseitige Bestätigung auf die durch das Hörersignal übermittelte Mitteilung darstellt. So vergewissern sich beide Gesprächsbeteiligten ihres Konsenses noch einmal gegenseitig.

ne: (nicht wahr) in Zeile 4, das mit aufgeregter, begeisterter Stimme sanft-steigend intoniert wird, ist ebenso ein Mittel zur doppelten Bestätigung der Meinungskonvergenz: Ne: bestätigt die Sprecheraussage und evoziert zugleich vom Sprecher eine bejahende Reaktion. Ne: bikkuri shichatta honto ni (ja, na, ich war wirklich überrascht) in Zeile 6 ist als Steigerung von ne: in Zeile 4 anzusehen. Durch den zusätzlichen Kommentar wird expliziert, was genau die Einstellung der Hörerin mit dem dargestellten Sachverhalt beinhaltet.

In dieser Passage bestätigen beide Gesprächsteilnehmerinnen mehrmals ihre Erfahrung mit der betreffenden Bekannten und vergewissern sich gegenseitig ihrer positiven Bewertung ihr gegenüber. Die Betonung des Konsens auf der Sach- und emotionalen Ebene schafft eine gute

\footnotetext{
${ }^{361}$ Da die Übersetzung im Trankript gut verständlich ist, wird auf die Übersetzung in der Fußnote verzichtet; dies gilt für weitere Beispiele.
} 
Gesprächsatmosphäre und trägt zur Aufrechterhaltung der harmonischen Beziehung zwischen beiden bei.

4.5.3.5 Hörersignale, die diverse Einstellungen des Hörers dem Gesagten gegenüber signalisieren

In diesem Kapitel werden Hörersignale zusammengefaßt, die verschiedene Einstellungen signalisieren. In meinen Daten sind überwiegend Hörersignale vertreten, die (positive) Bewertung, (angenehme) Überraschung oder interessierte Aufnahme in bezug auf die übermittelte Information zum Ausdruck bringen.

Diverse Einstellungen des Hörers dem Gesagten gegenüber können zusätzlich als Fortsetzungs-, Verstehens- und Zustimmungssignale fungieren, wie dies in den letzten Kapiteln gezeigt wurde; es gibt jedoch im Japanischen einige Hörersignale, die dafür prädestiniert sind, Überrasschungen oder Bewertungen zu realisieren: Dazu gehören z.B. he: (unerwartet, interessant), ho: (unerwartet, interessant), sugoi (toll), sore wa $\hat{\imath}$ desu ne (das ist ja gut) usw.

$\underline{\text { Hörersignale, die angenehme Überraschung mit interessierter Kenntnisnahme signalisieren }}$ Im folgenden werden Beispiele für he: und ho: herangezogen. Sie dienen zum Ausdruck einer angenehmen Überraschung und einer interessierten Informationsaufnahme.

Nachfolgend wird ein Gesprächsabschnitt vorgestellt, in dem sich die Hörerin sehr begeistert zeigt. Ihre erhöhte Emotionalität ist deutlich an der Dehnung, der Intonation, der Lautstärke, der Überlappungslänge usw. erkennbar: 
Gesprächskontext 51

Mako erzählt über ihre erste Reise nach Europa; dabei hat sie zwei Wochen lang bei einer deutschen Familie mit Menschen anderer Nationalitäten (Europäern) zusammengewohnt. Sie stellte begeistert fest, daß Europäer genauso wie Japaner Rücksicht auf andere nehmen, denn sie dachte vorher, daß sich Europäer immer verhalten, wie sie wollen und nicht so zurückhaltend sind.

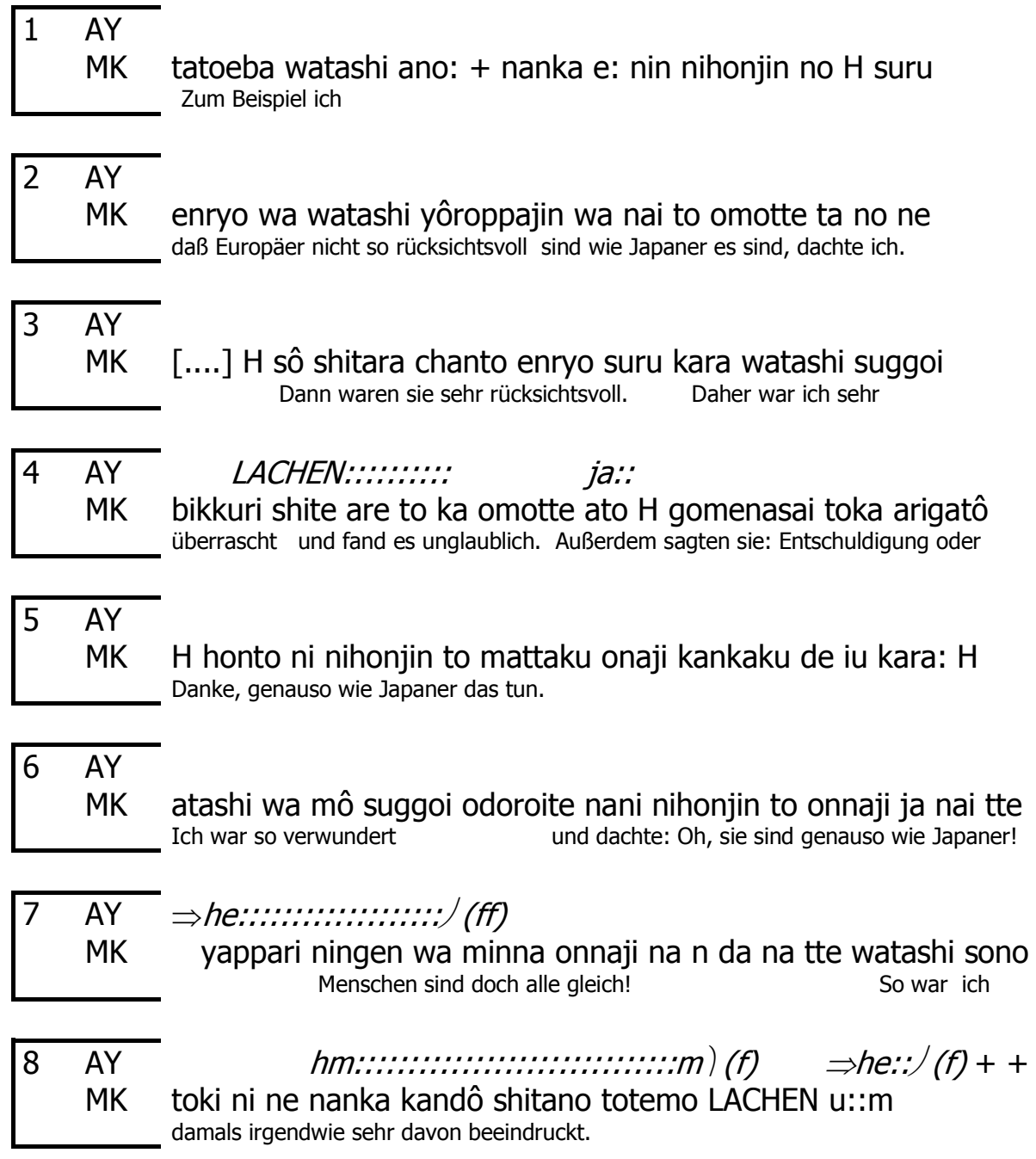

he: in Zeile 7 wird mit lauter Stimme artikuliert und außerdem stark gedehnt. Ferner wird in Zeile 8 nach dem Vollzug eines Satzgefüges zum zweiten Mal he: eingesetzt. Dies zeigt deutlich, wie unglaublich Makos Erfahrung Ayumi vorkommt. Dabei hat he: einen positiven Beigeschmack; die Hörerin findet die Mitteilung der Sprecherin unerwartet oder neu, nimmt sie aber angenehm überrascht an. Interessanterweise wurde he: in meinen Daten nur von Frauen verwendet. $^{362}$

\footnotetext{
${ }^{362} \mathrm{He}$ : gehört jedoch im Japanischen nicht zur Frauensprache, sondern wird auch von Männern benutzt.
} 


\section{Hörersignale, die Überraschung signalisieren}

Beispiele für Überraschungssignale finden sich nicht so oft in meinen Daten. Prinzipiell können sie jedoch durch Kurzformen wie $e$ !, ee: $\uparrow$ (stark steigend), Ein-Wort-Äußerungen wie honto: $\uparrow$ (wirklich?) oder satzförmige Äußerungen wie shinjirarenai (es ist unglaublich!) usw. konkretisiert werden. Der Grad der Verwunderung wird ebenfalls durch verschiedene Mittel (vor allem Prosodie) markiert. Es folgt ein Beispiel für ein Überraschungssignal mit großer Emotionalität.

Gesprächskontext 52

Haruyo erzählt, was sie in absehbarer Zukunft vorhat. Daraufhin fragt Sanako, was Haruyo studiert. Anschließend verrät Sanako, daß ihre Geschwister auch an der Universität Haruyos studiert haben. Als Haruyo dies erfährt, ist sie sehr überrascht.

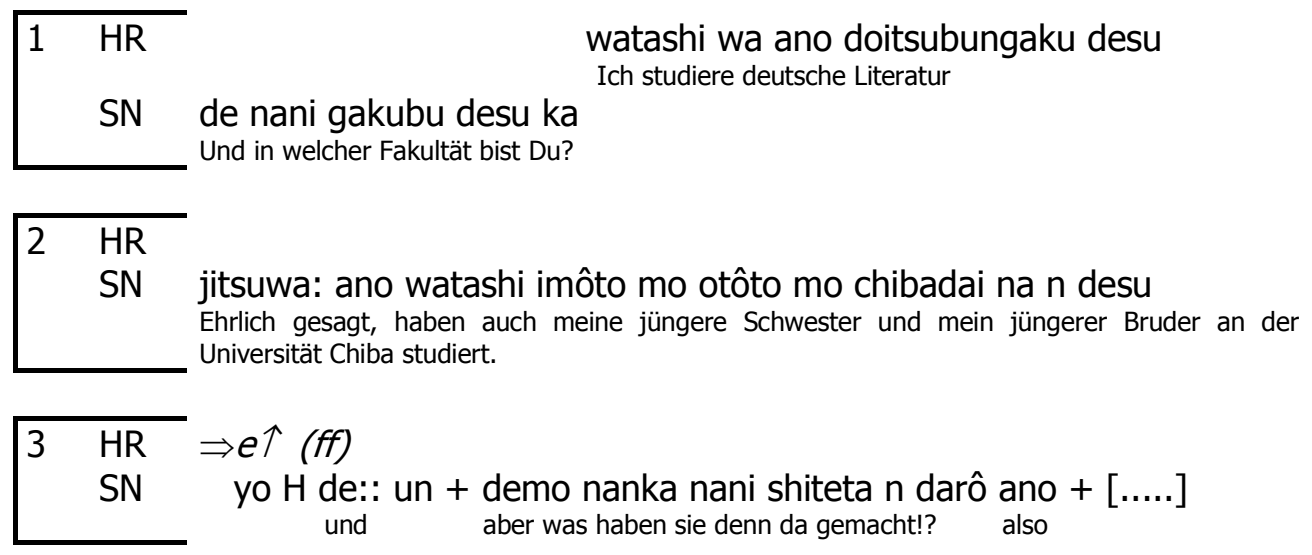

$e$ ! in Zeile 3 überlappt sich mit der satzletzten Postposition yo (das ist so, daß). An jener Stelle versteht Haruyo die Satzbedeutung und setzte vor Überraschung spontan dieses Hörersignal ein. Außerdem wird durch die kurzatmige, schnell und stark steigende Intonation sowie die Lautstärke (ff) deutlich, wie unerwartet die neue Information für Haruyo ist.

$\underline{\text { Hörersignale, die positive Bewertung anzeigen }}$

Positive Bewertungen können durch Kurzformen wie wa: (toll), sugoi (toll, super), suteki (schön) oder konventionalisierte oder stärker kontextgebundene satzförmige Höreräußerungen realisiert werden. Im kommenden Beispiel wird eine kontextgebundene Höreräußerung zitiert. 
Gesprächskontext 53

Haruyo und Sanako unterhalten sich über die Sprachschwierigkeiten in Deutschland. Sanako hat kaum Gelegenheit, Deutsch zu sprechen. Haruyo, die in einem Wohnheim wohnt, erzählt, daß die deutschen Mitbewohner dort sehr nett sind, weil sie viel mit unterschiedlichen Ausländern zu tun haben.

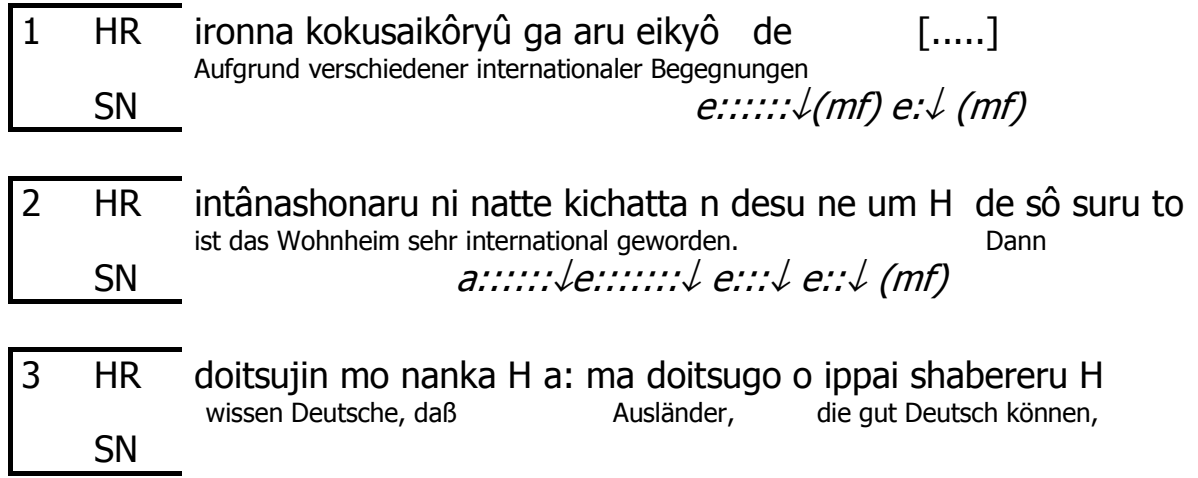

2 HR intânashonaru ni natte kichatta $n$ desu ne um $\mathrm{H}$ de sô suru to ist das Wohnheim sehr international geworden. Dann

SN

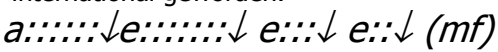

$3 \quad \mathrm{HR}$ doitsujin mo nanka $\mathrm{H}$ a: ma doitsugo o ippai shabereru $\mathrm{H}$ SN wissen Deutsche, daß Ausländer, die gut Deutsch können,

$4 \quad$ HR gaikokujin to sô de nai gaikokujin ga ite um sô suru to

SN und Ausländer, die nicht so gut können, existieren. Und dann

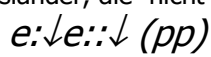

5 HR doitsujin mo a nanka $\mathrm{H}$ a: shaberenai hito mo iru no ne tte denken Deutsche, daß es doch Leute gibt, die nicht gut Deutsch sprechen,

SN

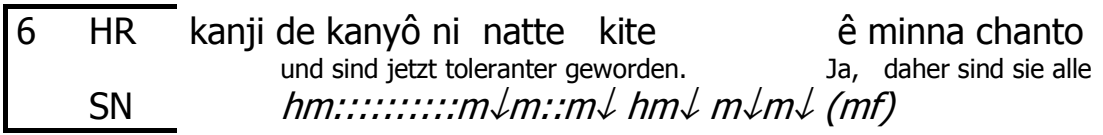

$7 \quad$ HR sugoku shinsetsu ni shitekureru shi

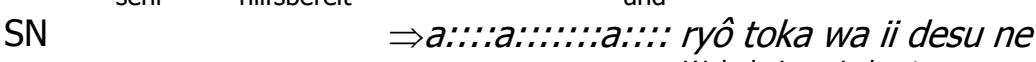
Wohnheime sind gut

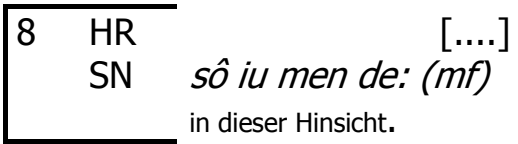

Durch das Hörersignal in Zeile 7-8 ryô toka wa ii desu ne sô iu men de (Wohnheime sind gut in dieser Hinsicht) kommt zum Ausdruck, daß Sanako es sehr gut findet, in einem Wohnheim zu wohnen, weil man dort viel Deutsch sprechen kann. Diese Äußerung ist nicht hoch emotionalisiert, aber klingt sehr wohlmeinend und positiv gestimmt. Diese Interpretation stützt sich auch auf mehrere Hörersignale, die dieser Äußerung vorausgegangen sind: In Zeile 2 wird ein Hörersignal aus $a: \because$ gesendet, das eine begeisterte Kenntnisnahme einer neuen Information indiziert. Außerdem übermittelt das Verstehenssignal in Zeile 6 eine positive 
Bewertung des dargestellten Sachverhaltes mit erhöhter Emotionalität, was die Sprecherin Haruyo sehr aufbaut.

Als nächstes wird ein Beispiel für eine für eine positive Bewertung prädestinierte Kurzform angeführt.

Gesprächskontext 54

Ayumi erzählt Mako über ihr Indologiestudium. Man lernt dort zuerst die Sprache; später kann man den Buddhismus studieren.

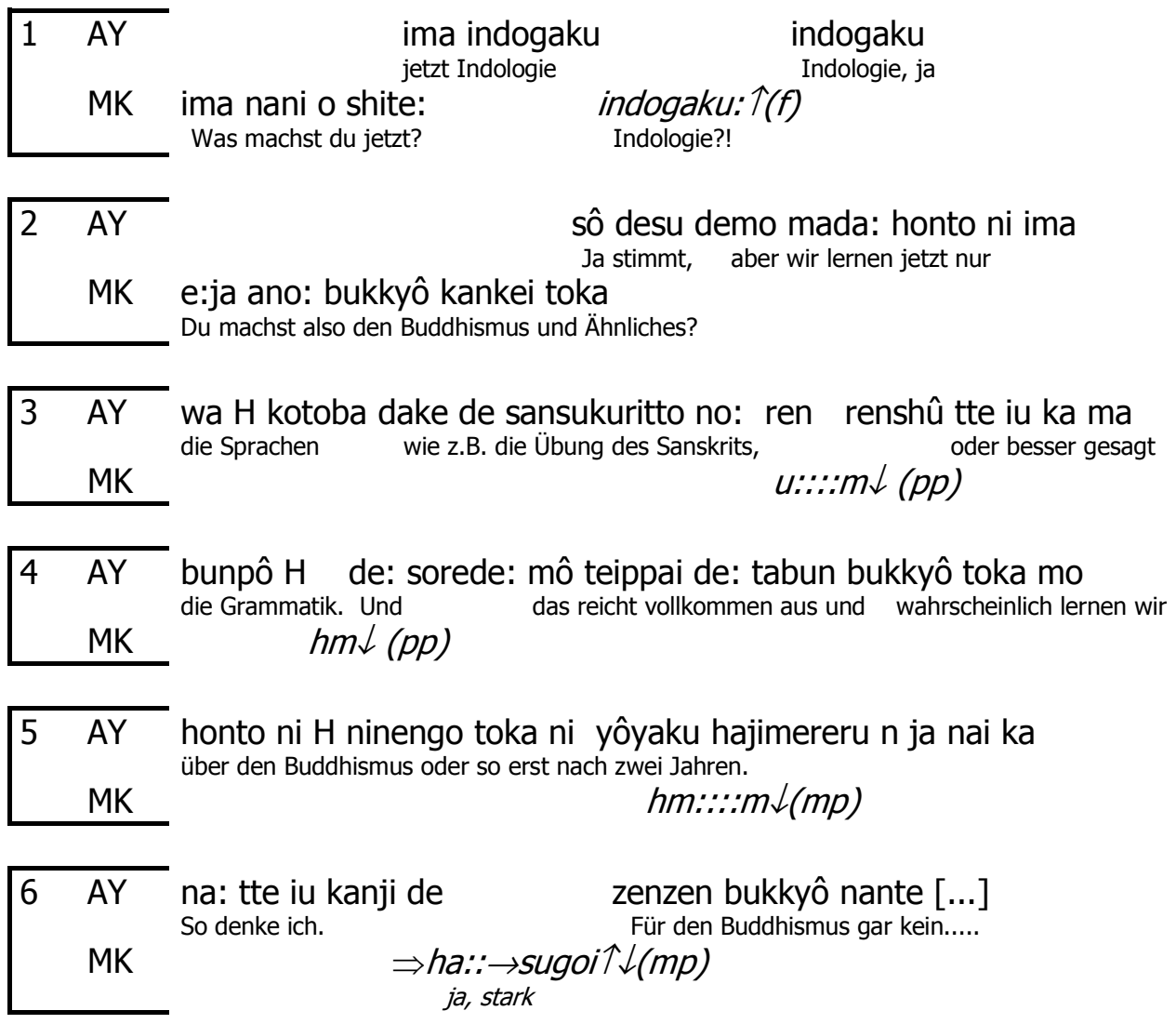

In Zeile 6 läßt Mako durch die Kombination von Kurzformen ha: sugoi (ja, stark) durchblicken, daß sie es sehr hoch schätzt, den Buddhismus zu studieren. Diese Hochachtung hängt womöglich damit zusammen, daß es selten Studenten gibt, die sich wissenschaftlich mit dem Buddhismus beschäftigen, was man an der Verwunderung Makos über das Studienfach Ayumis in Zeile 1: indogaku: (Indologie?!) festmachen kann. 


\section{Hörersignale, die Zweifel oder Skepsis anzeigen}

Hörersignale, die Zweifel oder Skepsis anzeigen, können durch konventionalisierte Mittel wie e: demo (ja aber), iya iya (nee nee), to iu ka (oder) sore wa aru kamo shiremasen ga (vielleicht hast du recht, aber) usw. ausgedrückt werden. In meinen Daten sind jedoch keine Hörersignale $\mathrm{zu}$ registrieren, die Nichtübereinstimmung oder Zweifel andeuten. Beim Vorliegen des Dissens usw. findet viel eher der Turnwechsel statt, der des öfteren mit iya (nee), demo (aber) eingeleitet wird.

\subsubsection{Satzvollendungen bzw. Vorwegnahmen}

Satzvollendungen oder Vorwegnahmen werden in den japanischen Daten viel häufiger als in den deutschen Daten beobachtet. Viele von ihnen werden an Satzgrenzen oder danach, d.h. in den präverbalen Positionen des nächsten Satzes (wie und, dann, also usw.) plaziert und begleiten den Turn des Sprechers solange, bis der betreffende Satz komplettiert ist. Formal betrachtet können Satzvollendungen und Vorwegnahmen aus Phrasen oder Sätzen bestehen.

Satzvollendungen und Vorwegnahmen können den Konsens zwischen dem Sprecher und dem Hörer verstärken und stellen ein harmonisches Moment her. Außerdem haben sie oft den Effekt, die Stimmung zu erheitern; dies ist vor allem der Fall, wenn der Sprecher darauf mit erhöhter Emotionalität reagiert. Ferner kann der Hörer mit Satzvollendungen dem Sprecher bei der Wortfindung helfen. So kann der Einsatz von Satzvollendungen oft eine positive Beziehungsgestaltung auf der Sach- und emotionalen Ebene bewirken.

Im folgenden Beispiel wird eine satzvollendende Äußerung des Hörers gezeigt, die gleichzeitiges Sprechen zwischen dem Sprecher und dem Hörer verursachte. 
Gesprächskontext 55

Nachdem Tsuyoshi dafür plädiert, daß Japan föderalistischer werden sollte, äußert Mamoru Bedenken, ob der Föderalismus in Japan überhaupt möglich ist, denn viele behaupten zwar Ähnliches, aber handeln nicht danach.

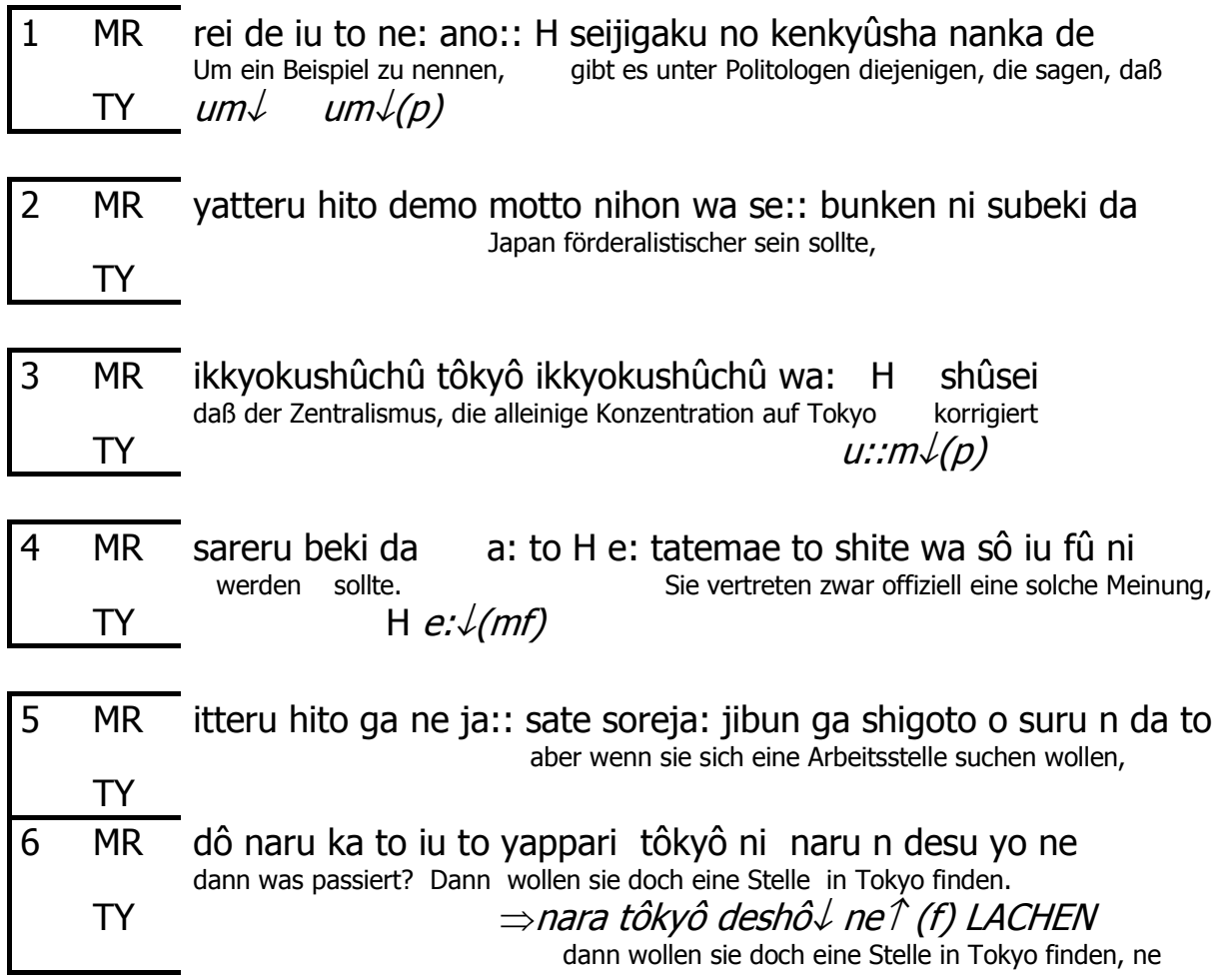

Die Satzvollendung in Zeile 6 beginnt fast gleichzeitig mit dem Hauptsatz: yappari tôkyô ni naru $n$ desu yo ne (sie wollen dann doch eine Stelle in Tokyo finden) und läuft parallel zur Sprecheräußerung desselben Inhalts. Da der Sprecher hierbei den Hauptsatz fortführt, ohne eine Pause einzulegen, entsteht dadurch eine Weile gleichzeitiges Sprechen. Die betreffende Vorwegnahme signalisiert die Aufmerksamkeit und schnelles Verstehensvermögen des Hörers; außerdem gilt sie als Zustimmungssignal mit hoher Überzeugung, denn es wird nicht erst nach der betreffenden Satzäußerung geäußert, sondern bevor der Sprecher sie ausgesprochen hat. In diesem Beispiel reagiert der Sprecher jedoch wenig auf die Vorwegnahme des Hörers; er führt dann seinen Turn weiter, als ob nichts geschehen wäre, was in meinen Daten selten der Fall war; der Sprecher zeigt in der Regel gewisse Reaktionen darauf. Im folgenden Beispiel nimmt die Sprecherin die Vorwegnahme der Hörerin begeistert engegen. 
Gesprächskontext 56

Sanako ist der Meinung, daß man oft verletzende Erfahrungen in Deutschland macht, wenn man Deutsch versteht, aber nicht sprechen kann. Sie fängt an, von einem Erlebnis im Bibliothekscafe, zu erzählen.

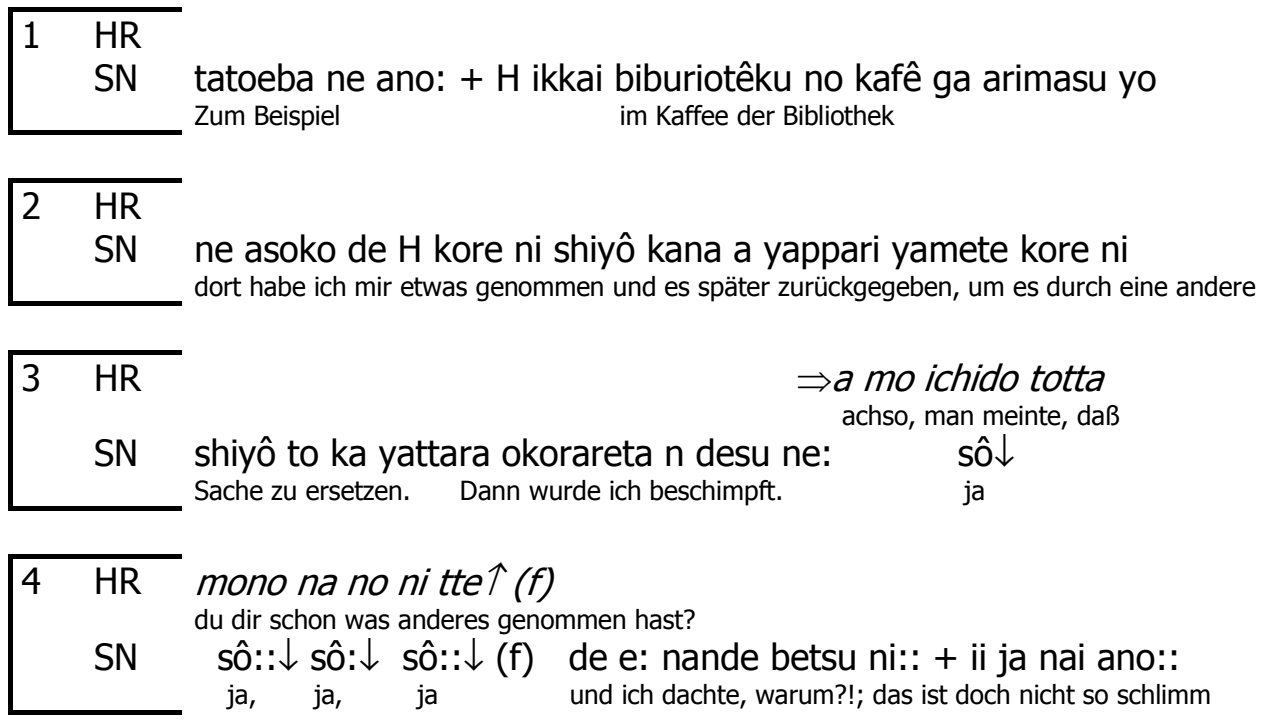

Die Satzvollendung in Zeile 3 wird dazu eingesetzt, den Sprecherbeitrag zu ergänzen; im Vergleich zum obigen Beispiel kann man hierbei nicht sicher sein, ob die Sprecherin vollzieht, die Äußerung mit demselben Inhalt wie diese Satzvollendung auszuführen. Haruyo vollzieht nicht nur den Sprecherplan sehr gut, sondern auch denkt weiter. Sie liefert an dieser Stelle sogar eine Erklärung für die Beschimpfung. Die Sprecherin reagiert begeistert auf die Vorwegnahme der Hörerin (sô sô sô sô in Zeile 4). In diesem Moment wird die Konvergenz im Wissen in bezug auf das Gesagte zwischen beiden zusätzlich auf der emotionalen Ebene unterstrichen, was auch durch die Überlappung symbolisiert wird. Vorwegnahmen oder Satzvollendungen in diesem Beispiel präsentieren am deutlichsten, daß der Sprecher und der Hörer einander ergänzen und beim Zustandekommen des Turns kooperativ zusammenarbeiten. Dies setzt nicht nur gutes Verstehensvermögen des Hörers, sondern auch viel Gemeinsamkeiten im Wissen und in den Erwartungen oder Ansichten zwischen beiden Gesprächsbeteiligten voraus.

4.5.3.7 Hörersignale, die die Beibehaltung bzw. die Änderung des bestehenden Rollenverhältnisses anzeigen

In den untersuchten Abschnitten der japanischen Gespräche sind insgesamt sehr wenig Beispiele für Turnbeanspruchungen zu finden. Das japanische Datenmaterial erweckt den 
Eindruck, daß der Hörer bei der Turnübernahme meistens geduldig wartet, bis der Sprecher dem Hörer das Rederecht übergeben will. In der Tat findet der Turnwechsel in den japanischen Daten auf eine gelassene, friedliche Art und Weise statt: Beim Sprecherwechsel entstehen des öfteren kurze oder längere Pausen, jedoch kaum Sequenzen, die den Kampf um das Rederecht andeuten. Im folgenden wird ein Beispiel für eine Turnbeanspruchung vorgeführt.

Gesprächskontext 57

Mamoru und Tsuyoshi unterhalten sich über Parlamentsreden deutscher und japanischer Politiker. Tsuyoshi ist beeindruckt von überzeugenden Parlamentsreden einiger deutscher Politiker. Mamoru begründet die rhetorische Gewandtheit deutscher Politiker durch die Tradition der Streitkultur in Deutschland.

1 MR iya nan to itte mo doitsujin ano:: $\mathrm{H}$ e: giron suru no ga suki de

TY also, wie dem auch sei, mögen Deutsche also diskutieren und

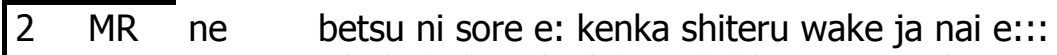

das heißt aber nicht, daß sie sich dabei streiten, sondern TY $\quad u: \because m \downarrow(m f)$

$u: m \downarrow(m f)$

$3 \quad$ MR nichijôteki ni: yatteru wake na $\mathrm{n}$ de ne e: ma: e::

sie tun das ja alltäglich und TY

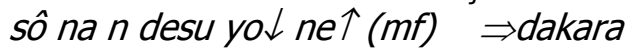
ja so ist das, ja daher

$4 \quad$ MR sô um chîsai chi chîsai kodomo no toki kara sô iu fû na: TY ja, von Kin, Kindheit an sind sie gewöhnt,

5 MR jibun no kangae o o::: matomete a::: hito to giron shite to TY die eigene Meinung bilden und diskutieren mit anderen.

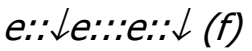

Eine Turnbeanspruchung läßt sich in Zeile 3 beobachten. Tsuyoshi will im Anschluß an das Zustimmungssignal sô desu yo ne (ja, du hast Recht, ja) den Turn übernehmen. Bei Tsuyoshi sind die Formulierungen wie sô desu yo ne usw. ein Indiz für den Wunsch nach der Turnübernahme, denn er hat im Gespräch mehrere Male mit einer solchen Höreräußerung den Turn eingeleitet. 


\subsubsection{Pausenfüller-Funktionen von Hörersignalen}

In den japanischen Daten findet sich eine Reihe von Hörersignalen, die gleichzeitig die Funktion ausüben, Sprechpausen zu füllen. Alle Hörersignale, die in der Pause plaziert sind oder Hörersignale, die sich mit Elementen des Satzes überlappen, aber durch die Pause hindurch hinziehen, erfüllen die Pausenfüller-Funktion. Dabei können Hörersignale aus einer Kurzform oder einer mehrfachen Wiederholung von einer Kurzform wie um um um um bestehen. Sie können mehr oder minder emotional sein, wobei die Tendenz erkennbar ist, daß emotionalisierte Pausenfüller länger werden, wie dies das nachfolgende Beispiel veranschaulicht.

Gesprächskontext 58

Tsuyoshi erzählt, warum die Wirtschaftskonjunktur Japans so lange im Tief ist. Er ist der Meinung, daß alles jetzt zusammenkam, so daß die Konjunktur nicht nach oben steigen kann.

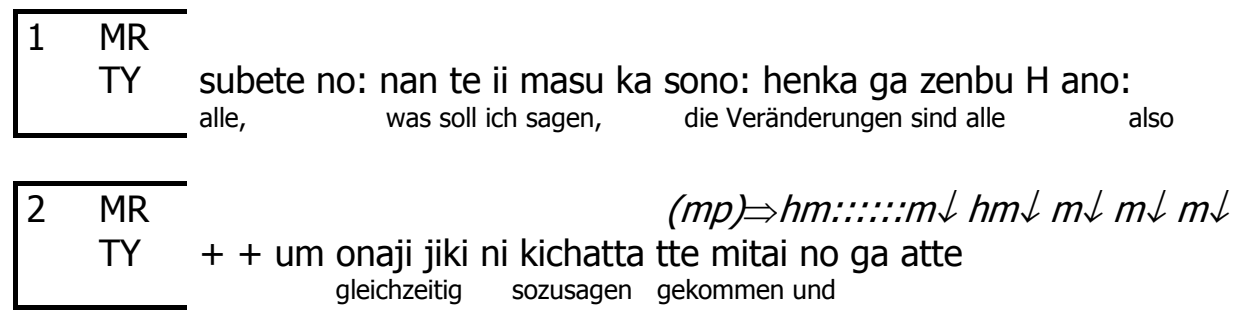

In Zeile 2 setzt Mamoru ein nachdrückliches Verstehenssignal. Die mehrmalige Wiederholung von um macht deutlich, daß der Hörer die Erklärung von Tsuyoshi als sehr einsichtig und nachvollziehbar ansieht. Außerdem fungiert dieses Hörersignal als Pausenfüller und führt während der Pause der Sprecheräußerung den Rhythmus fort. Dadurch bleibt der Sprecher im Takt und kann in den nächsten Satz leichter einsteigen. 
Gesprächskontext 59

Tsuyoshi schildert die Zeit nach dem „big bang" der japanischen „bubble"-Wirtschaft. Da die Wirtschaftskonjunktur dort noch im Tief liegt, ändert sich langsam das alte japanische System der Anstellungsbedingungen. ${ }^{363}$

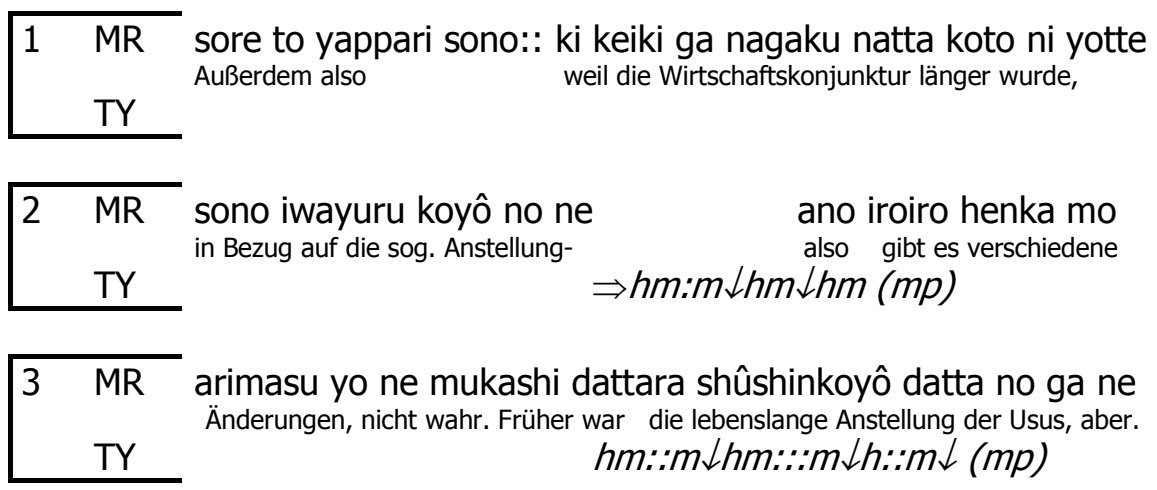

In Zeile 2 sendet der Hörer nach einer adnominalen Phrase: koyô no ne (die Anstellunegs-) ein Hörersignal hm: $\mathrm{hm} \mathrm{hm}$, das sehr intensiv und sehr stark dreimal fallend intoniert wird. Damit füllt der Hörer, den Rhythmus skandierend, die Pause in der Sprecherrede und überbrückt dadurch zwischen zwei Phrasen des Satzes. Ebenso kommt bei dieser Hörerrückmeldung auch durch ihre Prosodie die erhöhte Emotionalität und die Erwartung des Hörers in bezug auf die bevorstehenden Informationsteile zum Ausdruck, wobei der Eindruck an dieser Stelle nicht zu leugnen ist, daß der Hörer seinerseits im voraus ahnt, was kommen wird. In diesem Fall übt dann hm: $\mathrm{hm} \mathrm{hm}$ eine dramatisierende Wirkung aus: Es baut in der Satzmitte die Spannung auf, die beim Vollzug des Satzes den Höhepunkt erreichen soll; dadurch soll am Ende der Satzäußerung der bestehende Konsens zwischen dem Sprecher und dem Hörer umso deutlicher hervorgehoben werden.

\subsubsection{Hörersignale, die den Gesprächsverlauf steuern}

Hörersignale können ebenso wie in den deutschen Daten in den japanischen Daten den Gesprächsverlauf steuern. Im folgenden werden Hörersignale unter diesem Aspekt charakterisiert.

Fortsetzungssignale, die in der Satzmitte verstreut werden, haben den Effekt, den Sprecher zum Weitereden zu ermutigen. Insbesondere können emotionalisierte Fortsetzungssignale mit

\footnotetext{
${ }^{363}$ Übersetzung: Außerdem also, dadurch, daß die Wirtschaftskonjunktur länger im Tief ist, gibt es die Änderung in den sog. Anstellungsbedingungen. Früher war die lebenslange Anstellung der Normalfall.
} 
der Pausenfüller-Funktion die Spannung im Gespräch erzeugen oder erhöhen, indem sie während der Pause weiterhin den Takt angeben und dadurch den Beginn der neuen syntaktischen Einheit erleichtern.

Verstehenssignale beschleunigen ebenso den Fortgang des Turns, weil sie signalisieren, daß keine Hindernisse zum Verstehen vorliegen. So kann der Sprecher seinen ursprünglichen Sprecherplan weiter fortführen. Dies gilt vor allem bei Hörersignalen, die sich länger mit Sprecheräußerungen überlappen, wodurch indiziert wird, daß der Hörer die Sprecherintention vermeintlich für sehr gut erschlossen hält. Gefühlsmäßige Verstehenssignale mit oder ohne Pausefüller-Funktion motivieren den Sprecher zusätzlich zur Fortsetzung des Turns.

Ebenso fördern Zustimmungssignale den Gesprächsverlauf, weil der Hörer mit diesem Mittel zu erkennen gibt, daß er das Gesagte nicht nur gut verstanden hat, sondern auch die Meinungen teilt oder die Richtigkeit des Gesagten bestätigt, d.h. es gibt für den Sprecher nichts weiter $\mathrm{zu}$ erläutern oder $\mathrm{zu}$ erklären. Satzförmige, kontextgebundene Zustimmungssignale können hingegen oft die Modifikation des Sprecherplans bewirken, weil dabei etwas Substantielles behauptet wird, das den Sprecher mehr als prototypische Zustimmungssignale zu einer gewissen Reaktion veranlassen kann.

Positive Bewertungen, die durch konventionalisierte Mittel realisiert werden, bewirken keine Verzögerung des Sprecherturns; der Sprecher setzt dabei in der Regel seinen Turn fort, ohne darauf einzugehen. Hingegen geben kontextgebundene (positive) Bewertungen dem Sprecher Anlaß zur Erwiderung. Positive Bewertungen erhöhen das Image des Sprechers und vermittelt ihm ein gutes Gefühl beim Reden.

Überraschungen des Hörers setzen den Sprecher tendenziell mehr unter Reaktionszwang: Der Sprecher bestätigt das Gesagte noch einmal oder erläutert den Sachverhalt genauer usw., wobei solche Hörersignale weniger den Turnfortgang hemmen als Dissens oder Zweifel, die den Kurs des Sprecherplans stärker einlenken können.

Im folgenden wird eine Stelle herangezogen, an der der Sprecher nach dem Hörersignal, das die Ungewißheit zum Ausdruck bringt, anfing, genauer die Wetterlage des letzten Jahres zu schildern. 
Gesprächskontext 60

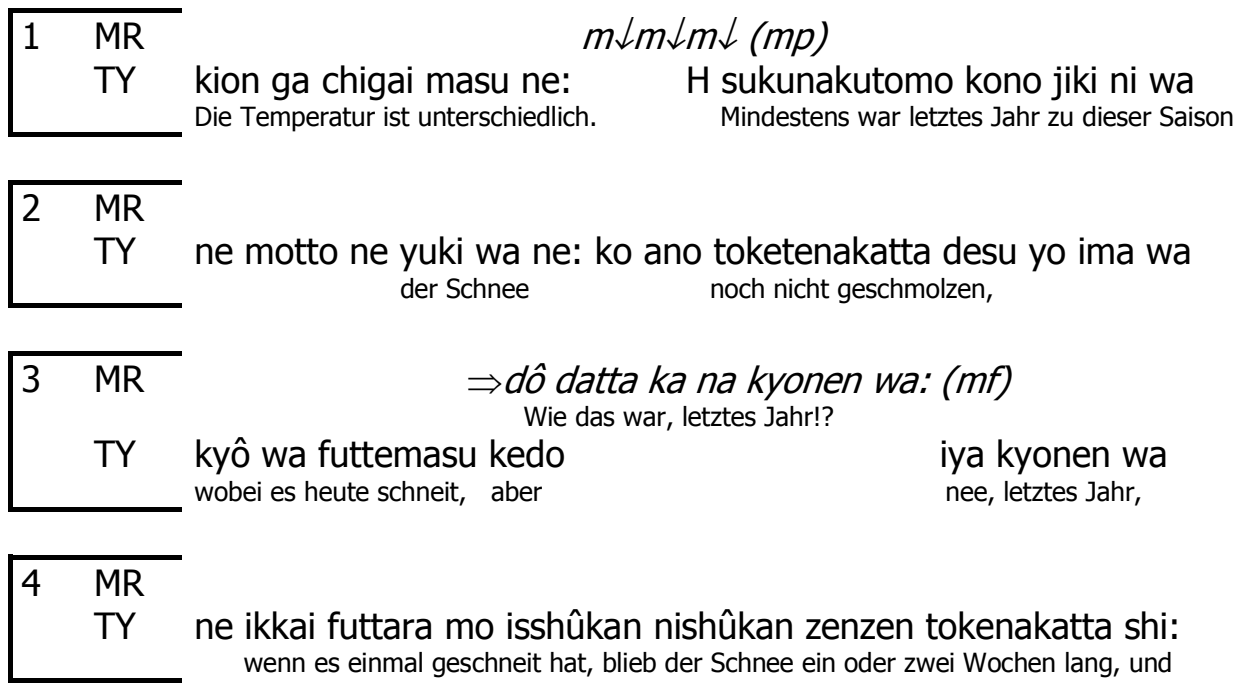

In Zeile 3 äußert der Hörer seine Unsicherheit: Er weiß nicht genau, wie das Wetter letztes Jahr war. Daraufhin beginnt der Sprecher, die Wetterlage des letzten Jahres ausführlicher darzustellen, um den Hörer zu überzeugen.

\subsubsection{Zusammenfassung}

Hörersignale üben multiple Funktionen gleichzeitig aus, die auf verschiedenen Ebenen angesiedelt werden können -: Signalisieren des Verstehens- oder des Wissensstandes, diverse Einstellungen dem Gesagten gegenüber, turnsteuernde, gliedernde Funktionen und die Sprecher- und Hörerrolle sowie die soziale Beziehung zwischen beiden regulierende Funktionen -.

Dabei stellt sich heraus, daß Hörersignale in den deutschen wie in den japanischen Daten trotz einiger Unterschiede im großen und ganzen ähnliche Funktionen erfüllen. Vor allem Verstehenssignale und Zustimmungssignale sind in beiden Datengruppen zahlreich vertreten, ${ }^{364}$ weil Hörersignale beider Kategorien bei der Turnorganisation und bei der Beziehungsgestaltung eine wichtige Rolle spielen.

Verstehenssignale werden in den deutschen Daten häufig durch Kurzformen wie ja, uhmhm und in den japanischen Daten durch Kurzformen wie e: um oder deren mehrfache

\footnotetext{
${ }^{364}$ Dieses Ergebnis ist mit den Befunden bei Hartung (1998, S. 108) übereinstimmend.
} 
Wiederholungen wie um um um realisiert. Sie werden sowohl in den japanischen als auch in den deutschen Daten meistens nah an Satzgrenzen eingesetzt und übermitteln dem Sprecher, daß der Hörer die Satzäußerung empfangen und verstanden hat und der Sprecher den Turn weiterführen soll. So fördern Verstehenssignale den Fortgang der Sprecherrede. Verstehenssignale können außer Verstehen auch diverse Einstellungen des Hörers wie Interesse, Empathie, Nachdenklichkeit, Begeisterung usw. zum Ausdruck bringen. Solche Verstehenssignale verstärken Solidarität und Sympathie zwischen den Gesprächspartnern in erhöhtem Maße im Vergleich zu „,neutralen und nüchternen“ Verstehenssignalen. Insgesamt wirken Verstehenssignale in den japanischen Daten interessierter und empatischer; außerdem sind sie oftmals emotional aufgeladener als in den deutschen Daten. Dabei liegt die Betonung im japanischen Datenmaterial nicht nur darin, Verstehen auf der kognitiven Ebene anzukündigen, sondern auch darin, darauf emotionalen Beistand zu leisten. ${ }^{365}$

Zustimmungssignale werden in den deutschen Daten durch verschiedene Formen Kurzformen wie ja, genau, kombinierte Kurzformen wie ja genau, ja stimmt oder kontextgebundene satzförmige Äußerungen - realisiert; in den japanischen Daten werden dabei häufig Kurzformen wie $u m, e:$, sô, deren Wiederholungen wie $e: e: e$ : oder $s \hat{o}-$ Kombinationen wie sô desu ne (ja, so ist das) verwendet. Zustimmungssignale werden verglichen mit Verstehenssignalen nachdrücklicher und intensiver intoniert und verkörpern eine stärkere emotionale Anteilnahme des Hörers ans Gespräch, was man an der Auswahl der Formen, der Prosodie und der Überlappungslänge - dies gilt allerdings nur für die japanischen Daten - festmachen kann. Da Zustimmungssignale den Konsens zwischen den Gesprächsbeteiligten im Wissen und in den Ansichten bekunden, verringern sie dabei die Distanz zwischen Sprecher und Hörer und bewirken eine persönliche Annäherung. Je nachdrücklicher oder gefühlsmäßiger sie geäußert werden, desto mehr schaffen sie Nähe und Verbundenheit zwischen den beiden Partnern. Die Emotionalität der Zustimmungssignale ist ebenfalls in den japanischen Daten viel ausgeprägter als in den deutschen Daten; dabei zielen sie darauf, nicht nur die Konvergenz zwischen den Gesprächsbeteiligten auf der kognitiven Ebene zu ermöglichen, sondern auch auf der emotionalen Ebene herauszustreichen. Vor allem symbolisieren Zustimmungssignale, die sich lange mit Sprecheräußerungen überschneiden,

\footnotetext{
${ }^{365}$ In der japanischen Kommunikation liegt die Betonung eher auf dem Ausdruck des Verständnisses als auf dem Meinungsaustausch. Hörersignale, die indizieren, daß der Hörer die Empfindung oder die Denkweise des Sprechers sehr gut verstanden hat, genügen, um die Harmonie zwischen Sprecher und Hörer zu verstärken. Daher sind „einfühlsame Verstehenssignale“ in Gesprächen unter Japanern von großer Bedeutung.
} 
darüber hinaus auch die Einigkeit und die Harmonie zwischen den Gesprächspartnern auf der sprachlichen Ebene: ${ }^{366}$ Hörersignale gleichen sich der prosodischen Struktur der Sprecherrede an und begleiten so den Turn eine Weile.

Hörersignale, die den Wissensstand zwischen Sprecher und Hörer anzeigen, finden sich sowohl in den deutschen als auch in den japanischen Daten relativ oft. Dabei werden in den deutschen Daten oft Kurzformen wie achso, aja, aha: oder Kombinationen von Kurzformen wie achso ja verwendet. In den japanischen Daten werden dafür die Kurzform $a$ : oder satzförmige Äußerungen wie a sô-Variationen wie a sô desu $k a$ (achso) präferiert. Durch diese Hörersignale wird Folgendes angezeigt: Wissensstände und Erwartungen des Hörers in bezug auf bestimmte Sachverhalte weichen von denen des Sprechers ab, aber der Hörer konnte die neue, unerwartete oder vergessene Information ohne weiteres annehmen und sie neu oder erneut in seine Wissens- oder Erwartungssysteme eingliedern. Die betreffenden Hörersignale dienen ähnlich wie Verstehenssignale dazu, den Sprecherturn voranzutreiben, solange Hindernisse beim Verstehensprozeß zum Zeitpunkt des Vollzugs der Problemäußerung beseitigt werden. Hörerrückmeldungen, die durch Verstehensschwierigkeiten verspätet gesendet werden, können den reibungslosen Verlauf des Turns hemmen. Die Emotionalität der Hörersignale dieser Kategorie hängt zum Teil vom Grad der Unerwartetheit der betreffenden Information ab; der Hörer reagiert tendenziell aufgeregter, wenn er für die Verarbeitung des neuen oder unerwarteten Sachverhaltes längere Zeit benötigt oder sich langsam wieder an das erinnert, was in Vergessenheit geraten ist.

Hörersignale, die eine positiv bewertende Haltung des Hörers dem Gesagten gegenüber signalisieren, sind ebenfalls relativ häufig in meinen Daten vertreten. Vor allem in den deutschen Daten finden sich einige Formen, die dafür prototypisch sind (wie z.B. das ist ja interessant, super usw.). Bewertungen, die das Gesagte positiv beurteilen (z.B. wa:o, das ist ja toll), erhöhen das Image (das Gesicht) des Sprechers und geben ihm ein gutes Gefühl. Hörersignale, die indizieren, daß der Hörer die Bewertung des Sprechers in bezug auf einen Sachverhalt teilt oder eine empatischen Haltung des Hörers gegenüber dem Gesagten (z.B. schade) offenbaren, stiften das Solidaritätsgefühl und die Sympathie zwischen den Gesprächsbeteiligten. Diese Effekte sind bei Bewertungssignalen mit größerer Emotionalität

\footnotetext{
366 Harmonie gilt als eine der wichtigsten japanischer Kommunikationsmaximen. Dies wird von vielen Japanforschen angenommen: Nagatomo (1986, S. 56), Matsuda (1988, S. 64), Maynard (1986, S. 1104), LacCastro (1987, S. 110-111).
} 
größer als bei weniger emotionalen Bewertungssignalen. Bewertungen wirken in den japanischen Daten insgesamt gefühlsbetonter als in den deutschen Daten.

Hörersignale, die Überraschung signalisieren, sind in meinen Daten insgesamt nicht so oft anzutreffen. Überraschungen werden in den deutschen Daten oft durch die Kurzformen wie ja?, echt?, kurze kontextgebundene Äußerungen (wie z.B. Flugzeugmechaniker!?, so viel!?) versprachlicht; in den japanischen Daten werden sie überwiegend durch Kurzformen wie $e$ ?! zum Ausdruck gebracht. Überraschungssignale sind in den beiden Datengruppen oft in erhöhtem Maße emotional aufgeladen, da wohl für den Hörer die Divergenz im Wissen oder in den Erwartungen in bezug auf die betreffende Information sehr groß ist, so daß er darauf spontan Reaktionen zeigen muß. Überraschungen können aufgrund ihrer Emotionalität einen (kurzen) Stimmungswechsel im Gespräch herbeiführen und somit die Gesprächsatmosphäre erheitern.

Hörersignale, die Verstehensprobleme oder Nichtverstehen ankündigen, finden sich in meinen Daten kaum; in den japanischen Daten werden meines Erachtens Verstehensprobleme nicht explizit ausgehandelt; ${ }^{367}$ einige wenige Beispiele stammen aus den deutschen Daten, wobei meistens Nachfragen angewendet werden, um Unklarheiten zu beseitigen oder Informationen zu erhalten, die der Hörer gerne hätte, obwohl der Sprecher sie von sich aus nicht gegeben hätte. Da Nachfragen aufgrund ihres Fragecharakters oftmals den Sprecherplan zur Kursänderung zwingen oder den Turn stärker als sonst beeinträchtigen können, werden sie relativ sparsam eingesetzt.

Hörersignale, die Dissens zum Ausdruck bringen, lassen sich in meinen Daten kaum beobachten. Es besteht sowohl in den deutschen als auch in den japanischen Daten weitgehend die Tendenz, Konflikte möglichst zu vermeiden. Eine Erklärung dafür liegt wohl in der Gesprächssituation: Die Gesprächsteilnehmer wurden sowohl auf Band als auch auf Video aufgenommen; außerdem kannten sie sich vorher nicht bzw. nur flüchtig. ${ }^{368}$ Ferner ist aus Studien verschiedener Wissenschaftsbereiche bekannt, daß Japaner in der

\footnotetext{
${ }^{367}$ Es ist im allgemeinen bekannt, daß Japaner aus Rücksicht auf den Sprecher oder wegen der Gesichtswahrung Verstehensprobleme nicht so oft anzeigen; dies ist vor allem der Fall, wenn man sich mit einer sozial höher stehenden Person unterhält (Sugitani 1994, S. 93).

${ }^{368}$ Eine der Gesprächsteilnehmerinnen sagte mir nach dem Gespräch, daß sie sich bemüht hatte, höflich zu sein und ihre Gesprächspartnerin während der Rede nicht zu unterbrechen; außerdem gab ein Gesprächsbeteiligter
} 
zwischenmenschlichen Kommunikation auf die Konfliktvermeidung sehr viel Wert legen, um eine harmonische Beziehung nicht $\mathrm{zu}$ gefährden. ${ }^{369}$ Interessanterweise sind solche Hörersignale in den untersuchten Abschnitten der japanischen Daten weniger als in den deutschen Daten registriert; dies könnte dafür sprechen, daß Hörer in den japanischen Daten mehr als Hörer in den deutschen Daten dafür sorgen, das Gespräch reibungslos bzw. konfliktarm zu gestalten.

Ein großer Unterschied zwischen den deutschen und den japanischen Daten besteht in der Frequenz der Fortsetzungssignale; Fortsetzungssignale sind fast nur in den japanischen Daten vertreten. In der Regel werden sie durch um oder $e$ : oder bei größerer emotionaler Aufgeladenheit des Hörers durch die Wiederholungen von Kurzformen wie z.B. $e$ : $e$ : $e$ : realisiert. Fortsetzungssignale sind mitten im Satz plaziert und bestätigen somit Empfang und Verstehen der unmittelbar vorangegangenen Teilinformation des betreffenden Satzes. Dabei können außerdem auch diverse Einstellungen des Hörers dem Gesagten gegenüber (vor allem eine interessierte oder empatische Haltung) übermittelt werden. Fortsetzungssignale, die intensiver und nachdrücklicher intoniert sind, können eine starke Involviertheit des Hörers ins Geschehen bekunden und so die Spannung erhöhen, so daß der Sprecher in erhöhtem Maße dazu ermuntert wird, seinen Turn (in diesem Fall den Satz) fortzusetzen.

So unterstützt der Hörer in den japanischen Daten mittels Fortsetzungssignalen den Sprecher tatkräftig bei der Beendigung des betreffenden Satzes.

Die hohe Frequenz der Fortsetzungssignale in den japanischen Daten kann empirisch darauf zurückgeführt werden, daß sich der Sprecher von sich aus bemüht, beim Hörer Hörersignale mitten im Satz zu evozieren; er dehnt z.B. oft die letzte Silbe eines Wortes wie daigaku ni (Nomen-pp) (zur Uni) oder einer darauf folgenden Postposition wie daigaku ni (Nomen-pp) (zur Uni) und baut anschließend eine Pause ein. So scheint der Sprecher in den japanischen Daten bei der Turnproduktion in höherem Maße auf den Hörer angewiesen zu sein als in den deutschen Daten, was die folgende These der Forschungsliteratur unterstützt: Der Sprecher neigt dazu, seinen Turn Stück für Stück fortzuführen, indem er beim Hörer verbale

nachher zu, daß er sich mit seinem Gesprächspartner nicht sehr wohl fühlte, aber das Gespräch möglichst reibungslos gestalten wollte.

${ }^{369}$ Vgl. Matsuda (1988, S. 64), Okabe (1989, S. 47), Maynard (1986, S. 1104); Nagatomo (1986, S. 100) nennt die Strategie der Konfliktvermeidung „kotonakare shugi“ (Hauptsache, keine Konflikte, keine Auseinandersetzung); dieses Prinzip betrachtet er als Kennzeichen für die allgemeine Mentalität der Japaner. 
Reaktionen evoziert, um den Verstehens- und Interessenstand des Hörers immer wieder überprüfen zu können. ${ }^{370}$ Auf der anderen Seite strengt sich der Hörer ebenso an, kooperativ zu sein und den Sprecher bei der Ausführung des Turns zu helfen. Diese aktive Anteilnahme des Hörers am Gespräch wird in der japanischen Kommunikationskonversation gut geheißen. ${ }^{371}$ Dies trifft auf den Sprecher in den deutschen Daten nicht gleichermaßen zu; der Sprecher benötigt in den deutschen Daten anscheinend kaum das Einverständnis des Hörers für die Beibehaltung des Rederechts während der Durchführung eines Satzes oder eines Satzgefüges. Fortsetzungssignale können als Ausdruck der Kooperations- und Hilfsbereitschaft des Hörers sowie der Interdependenz zwischen Sprecher und Hörer in der Gesprächsführung angesehen werden. ${ }^{372}$ In den deutschen Daten könnte die Anhäufung von Fortsetzungssignalen sogar die Beziehung verschlechternde Effekte haben, weil sich der Sprecher durch sie gestört und irritiert fühlen könnte. ${ }^{373}$

Satzvollendungen und Vorwegnahmen sind nur in den japanischen Daten zu registrieren. Sie kommen dadurch zustande, daß der Hörer dem Sprecher einen Satz oder einen Satzteil vorwegnimmt, bevor der Sprecher diesen geäußert hat. Satzvollendungen o.ä. indizieren den Konsens zwischen den Gesprächsbeteiligten im Wissen, in der Erwartung, in der Beurteilung oder in der Ansicht stärker als sonst. Damit wird die Einigkeit zwischen beiden auf der kognitiven Ebene unterstrichen. Wenn auf Satzvollendungen eine begeisterte Reaktion des Sprechers (d.h. Bestätigung) folgt, entsteht dabei eine heiterte Stimmung, die die Annäherung zwischen den Gesprächspartnern auf der emotionalen Ebene fördert. Satzvollendungen und Vorwegnahmen demonstrieren am deutlichsten das Zusammenwirken zwischen Sprecher und Hörer im Gespräch: Beide konstruieren gemeinsam einen Satz oder ein Satzgefüge. So stellen

\footnotetext{
${ }^{370}$ Hierbei habe ich einige Textstellen bei Mizutani zusammengefaßt (1988a, S. 8-10). Außerdem betrachtet Maynard (1986, S. 1104) die extrem hohe Frequenz der Hörersignale in ihren japanischen Daten als Indiz dafür, daß die Gesprächspartner sich gegenseitig kontrollieren (,mutual monitoring“).

${ }^{371}$ Vgl. Mizutani 1988a, S. 10.

372 Die unterschiedlichen Stile der Gesprächsgestaltung, die in meinen Daten festgestellt werden, können eventuell auf das Selbstkonzept von Japanern oder Deutschen zurückgeführt werden: Nach Doi, einem japanischen Psychologen, ist ein Grundmuster der japanischen zwischenmenschlichen Beziehung eine MutterKind-Beziehung, die sehr stark auf die Abhängigkeit zwischen beiden ausgerichtet ist (1973, S. 7). Sugitani (1996) geht davon aus, daß Japaner ein Selbstmodell aufweisen, das kein von anderen klar abgegrenztes Selbstbild darstellt (Individualismus), sondern ein enger verbundenes soziales Umfeld als Teil vom Selbst einbezieht (Kollektivismus). Ihrer Meinung nach sind Deutsche eher „Individualisten“, während Japaner zu den Kollektivisten gehören. Auch Mae (1985, S. 139) vertritt die Ansicht, daß Japaner sich ihre eigene Existenz in der gegenseitigen Beziehung mit ihren Nächsten bewußt machen und ihre eigene Identität gerade in der Beziehung finden und sich selbst darin verobjektivieren; Europäer hingegen besitzen ein starkes Selbstbewußtsein und wollen nach ihrem eigenen Urteil und mit Verantwortung freie Willensentscheidungen treffen sowie aus eigener Kraft handeln.

${ }^{373}$ Diese These stützt sich auf Alltagserfahrungen.
} 
beide wirksame Mittel zur Verstärkung der gegenseitigen Abhängigkeit und zur Ergänzung in der Gestaltung des Turns dar; diese Art der Gesprächsführung wird von Mizutani (1988a) „kyôwa“ genannt und dem Konzept des „Dialogs“ gegenübergestellt. ${ }^{374}$

Pausenfüller finden sich ebenso viel häufiger in den japanischen Daten als in den deutschen Daten. Als Pausenfüller fungieren alle Hörersignale, die in der Pause oder auch vor dem Beginn der Pause (d.h. überlappt mit Sprecheräußerungen) plaziert werden und die Pausen zwischen zwei syntaktischen Einheiten überbrücken. Charakteristisch dabei ist, daß Pausenfüller während der Pause der Sprecherrede den Takt angeben und so dem Sprecher die Fortsetzung des Turns, d.h. den Übergang in die neue syntaktische Einheit erleichtern. Pausenfüller sind wiederum Beispiele für das Zusammenspiel und die Kooperation zwischen Sprecher und Hörer bei der Turnweiterführung und führen zur Stärkung der Interdependenz zwischen Sprecher und Hörer in der Gesprächsführung.

Längere überlappende Hörersignale, die sich oft in den japanischen Daten finden, sind ebenso ein Mittel, Harmonie zwischen Sprecher und Hörer auf der sprachlichen Ebene zu realisieren; sie passen sich den prosodischen Gegebenheiten der Sprecherrede an und begleiten so die Sprecheräußerung; dabei stehen Hörersignale und Sprecheräußerungen miteinander in Einklang wie Akkorde. ${ }^{375}$

Hörersignale können sowohl in den deutschen als auch in den japanischen Daten auf verschiedenen Ebenen turnstrukturierende Funktionen ausüben. Sie kennzeichnen den Moment, in dem der Verstehensprozeß des Hörers vermeintlich beendet ist. So markieren z.B. Hörersignale, die an Satzgrenzen plaziert sind, den Abschluß einer Phrase, eines Satzes, eines Satzgefüges, einer Sinneinheit aus mehreren Sätzen oder eines Turns. Hörersignale, die vor dem Vollzug des betreffenden Satzes plaziert sind, gliedern die betreffende Äußerung des Sprechers nach dem für das Verstehen des Hörers relevanten (Informationen vor der Plazierung) und dem weniger relevanten Teil (Informationen nach der Plazierung). Ähnliches

\footnotetext{
374 Nach Mizutani (1988a, S. 10-11) basiert „Kyôwa“ darauf, daß die Gesprächsteilnehmer gemeinsam einen Turn oder ein Thema komplettieren, während im Dialog die Gesprächsteilnehmer einen Turns oder ein Thema selbständig ausführen. Ähnliches stellt Hayashi (1990) in ihren Daten (Geschäftsmeetings) der japanischen Geschäftsleute fest; bei einem Geschäftsmeeting zwischen amerikanischen Geschäftsleuten hingegen werden die einzelnen Themen des Meetings tendenziell von einem Gesprächsteilnehmer initiiert, entwickelt und beendet.

${ }^{375}$ Nach Nagatomo (1986, S. 56) ist das Prinzip der Harmonie ,eine soziale Denk- und Verhaltensweise, ein Gefühl der Gemeinschaftszugehörigkeit, das bis hin zur heutigen japanischen Gesellschaft als geltender
} 
gilt vor allem in den japanischen Daten für die Satzelemente, die sich mit Hörersignalen überlappen; überlappte Informationsträger besitzen für den Hörer weniger Relevanz für das Verstehen.

Hörersignale steuern den Verlauf des Redebeitrags des Sprechers: Fortsetzungssignale, die mitten im Satz plaziert werden, können die betreffende Satzäußerung vorantreiben. Dies läßt sich besonders oft in den japanischen Daten beobachten. Ebenso beschleunigen Hörersignale, die nah oder an Satzgrenzen eingesetzt werden, die Beendigung des Satzes und unterstützen den Übergang in die nächste Satzeinheit. Ferner können Hörersignale den Turn auf das Ende hin steuern (in meinen Daten kaum beobachtet). Darüber hinaus können sie den Sprecherturn aus verschiedenen Gründen verlängern: Der Hörer, der wenig Interesse für das aktuelle Thema hat, kann sich sehr zurückhaltend verhalten und den Sprecher dazu zwingen, den Turn länger als geplant zu führen; hingegen kann der interessierte Hörer aufgrund seiner aktiven Hörerrückmeldungen den Sprecher dazu zu ermutigen, den Turn länger auszuführen. Im weiteren können einige Hörersignale (wie Nachfragen, Zweifel, Dissens) den Sprecherplan stärker in eine bestimmte Richtung steuern: Bei Nachfragen wird der Sprecher unter eine Antwortobligation gesetzt; Dissens oder Zweifel können den Sprecher dazu veranlassen, den betreffenden Sachverhalt genauer zu erläutern oder zu erklären.

Prinzipiell bestätigen alle Hörersignale, die keinen Turn einleiten, die bestehende Sprecherund Hörerrolle. In den japanischen Daten versucht der Sprecher häufiger als in deutschen Daten, das Einverständnis des Hörers für die Weiterführung des Turns zu erhalten. Turnbeanspruchungen oder gleichzeitiges Sprechen sind wiederum eher in den deutschen Daten zu beobachten als in den japanischen Daten. In solchen Fällen zieht sich in der Regel einer der Gesprächsteilnehmer zugunsten des anderen zurück und verzichtet auf das Rederecht. In den japanischen Daten wird der Turnwechsel viel „gelassener“ und „friedlicher" gehandhabt.

Hörersignale regulieren die soziale Beziehung zwischen Sprecher und Hörer. Da beziehungssteuernde Leistungen der Hörersignale bereits mehrmals erwähnt wurden, werden im folgenden einige Punkte aufgelistet:

Grundakkord zu betrachten ist“. Dieses Prinzip findet in den japanischen Daten im Gespräch eine tatsächliche 
Hörersignale müssen sowohl in den deutschen als auch in den japanischen Daten zwar nicht in jedem hörerreaktionsrelevanten Moment (d.h. an jeder Satzgrenze), aber an Stellen, die für den Sprecher für die Organisation seines Redeplans relevant sind, gesendet werden. Es wirkt sich negativ auf die Beziehung zwischen den Gesprächspartnern aus, wenn Hörersignale in längeren Sequenzen ohne erkennbare Gründe wie Lachen, etwas trinken usw. ausgelassen werden. Dies kann vom Sprecher als Zeichen für Desinteresse ausgelegt werden und ihm die Motivation nehmen, weiter $\mathrm{zu}$ reden. Bewußtes Unterlassen von Fortsetzungs- und Verstehenssignalen kann die Beziehung ggf. soweit verschlechtern, daß der Sprecher den Verdacht hegt, daß der Hörer ihn gar nicht leiden kann. ${ }^{376}$

Außerdem verringert das Insistieren auf der Hörerrolle und damit die Verweigerung der Turnübernahme oft die Sympathie zwischen den Gesprächsbeteiligten; ein gut gelungenes Gespräch zeichnet sich oft durch eine gleichmäßige Verteilung der Sprecher- und Hörerrolle zwischen den Gesprächsbeteiligten ab. Ferner schafft die Anhäufung von Verstehenssignalen mit geringer Emotionalität eher Distanz und führt zu einer kühlen Beziehung, die nur aus Höflichkeit funktioniert. ${ }^{377}$

Tendenziell haben Hörersignale, die interessierte, empatische, zustimmende, positiv bewertende Haltungen des Hörers dem Gesagten gegenüber bekunden, positivere Effekte auf die Beziehung zwischen Sprecher und Hörer als „,neutral wirkende Hörersignale“; erstere verstärken in erhöhtem Maße die Sympathie oder die Solidarität zwischen den Gesprächspartnern und erleichtern ihnen die persönliche Annäherung. In den japanischen Daten ist der Hörer darin mehr bemüht, explizit eine engagierte Anteilnahme am Gespräch zu signalisieren als der Hörer in den deutschen Daten.

Emotional aufgeladene Hörersignale scheinen zumindest in den japanischen Daten wirksame Mittel darzustellen, die zur Herstellung einer angenehmen Gesprächsstimmung sowie eines harmonischen Miteinanders auf der emotionalen Ebene beitragen. In den deutschen Daten sind Hörersignale insgesamt abgesehen von einigen wenigen Momenten - z.B. bei

\footnotetext{
Realisierung.

${ }^{376}$ In einer japanischen Zeitung wurde ein Leserbrief veröffentlicht; darin stand, daß eine Schwiegermutter den Kontakt zu ihrer Schwiegertochter abgebrochen hat, weil ihre Schwiegertochter bei Telefongesprächen kaum Hörersignale von sich gegeben hat. Für die Generation der Schwiegermutter ist es Usus, daß man häufiger Hörersignale während der Telefongespräche sendet; die Schwiegermutter war sehr beleidigt und traurig (Asahi 3.11.2000).
} 
Überraschungen und in wenigen Abschnitten, in denen Erlebnisse auf lustige Art und Weise erzählt werden - eher reservierter.

Die Tendenz, Konflikte zu vermeiden, ist in beiden Datengruppen stark zu spüren; dies läßt sich zum Teil dadurch erklären, daß es sich dabei um eine „offene Aufnahme“ handelte und die Gesprächsteilnehmer sich vorher kaum kannten. In einer solchen Gesprächssituation möchte man eher sich und dem Gesprächspartner das Gesicht wahren und nicht in eine unangenehme Situation bringen. Nichtsdestotrotz kann vor allem in den deutschen Daten gelegentlich „der Kampf ums Rederecht“ beobachtet werden: Der Sprecher will seinen Turn noch nicht abgeben, während der Hörer den Turn beansprucht und zu reden beginnt; so lassen sich in den Gesprächen unter Deutschen gelegentlich Konkurrenzsituationen (d.h. simultanes Sprechen) beobachten, in denen die Gesprächsbeteiligten um ihren Turn miteinander ringen und Konkurrenz und Kooperation miteinander aushandeln müssen. In den deutschen Daten scheint Konkurrenz bei der Turnübernahme unproblematischer zu sein als in den japanischen Daten, in denen der Turnwechsel friedlicher verläuft, weil die Gesprächsteilnehmer womöglich versuchen, Unstimmigkeiten bei der Turnübernahme möglichst zu minimieren.

Langes Insistieren auf der Hörerrolle statt Übernahme des Turns wirkt sich eher negativ auf die Beziehung aus; sowohl in den deutschen als auch in den japanischen Daten ist es angemessen, daß die Sprecher in bestimmten Abständen einander abwechslen. Vor allem in den deutschen Daten ist der Redebeitrag des neuen Sprechers für den neuen Hörer in dem Sinne relevant, daß der Turn eventuell verrät, wie gut der neue Sprecher dem Gegenüber zugehört hat, als jener vorher die Hörerrolle ausgeübt hat. Der thematisch kohärente Beitrag des neuen Sprechers ist eine Bedingung für eine gute soziale Beziehung zwischen den Gesprächsbeteiligten, denn auch so kann der neue Sprecher das Gesagte des vorherigen Sprechers honorieren. In den japanischen Daten, in denen die inhaltliche Konsistenz weniger gegeben ist, ist es wichtiger, Interesse und Engagement des Hörers gleich an der betreffenden Stelle zu zeigen.

${ }^{377}$ Jene Passage wurde bereits zuvor als Beispiel herangezogen. 


\section{Zusammenfassung und Schlußbemerkung}

Ziel der Arbeit war, zum einen Formen, Positionen sowie Funktionen von Hörersignalen sowohl in den deutschen als auch in den japanischen Daten zu untersuchen und dadurch die Regularitäten bzw. die Systematik in der Auswahl der Formen, in der Positionierung und in der Verwendung von Hörersignalen aufzuzeigen. Außerdem war angestrebt, Faktoren zu ermitteln, die das Auftreten der Hörersignale steuern. Dabei wurde davon ausgegangen, daß einerseits Auslösestrukturen in Sprecheräußerungen existieren, die Hörersignale in erhöhtem Maße hervorrufen können, d.h. der Sprecher versucht, seinerseits Hörersignale zu evozieren. Andererseits werden Hörersignale bewußt vom Hörer eingesetzt, um den Verstehensprozeß zu erleichtern oder eigenen Mitteilungsbedürfnissen nachzukommen. Drittens bestand das Erkenntnisinteresse dieser Arbeit darin, Ähnlichkeiten und Unterschiede zwischen den deutschen und den japanischen Daten herauszufinden und diese möglichst aus linguistischer (vor allem aufgrund der Syntax) und empirischer (beruhend auf den Befunden aus den Daten) Sicht zu erklären und ggf. mit kulturellen Werten in Verbindung zu setzen.

Um die o.a. Ziele zu erreichen, wurde teils quantitativ und teils qualitativ vorgegangen: Zur Darlegung der Regularitäten der Formen und der Positionen der Hörersignale sowie der Auslöser der Hörersignale wurde die prozentuale Verteilung der Hörersignale nach bestimmten Aspekten errechnet; dabei bildeten die Ergebnisse der Berechnungen die Grundlage der Beschreibung der zu analysierenden Phänomene. Anschließend wurden die Befunde interpretiert und erklärt. Bei der Erläuterung der Funktionen der Hörersignale wurde hingegen eine qualitative Methode angewandt, d.h. die jeweiligen Hörersignale wurden nicht einer Berechnung unterzogen, sondern in bezug auf ihren Verwendungskontext sowie auf die Befunde der vorangegangenen Kapitel nach ihren möglichen Funktionen beschrieben, und ihre Interpretationen wurden dabei von empirischen und linguistischen Standpunkten begründet.

Bei der Analyse und Charakterisierung des Untersuchungsgegenstandes wurde nicht von vorn herein als Ziel gesetzt, Kulturunterschiede zwischen den deutschen und den japanischen Daten ausfindig zu machen, sondern es wurde darauf Wert gelegt, vorerst Phänomene zu finden, die in den Daten wiederholt und gehäuft auftreten, um die Befunde der beiden Datengruppen miteinander vergleichen zu können. Wenn die Ergebnisse der beiden Sprachgruppen merklich voneinander abwichen, wurde versucht, diese Unterschiede zuerst 
linguistisch oder auf den Befunden der Daten beruhend $\mathrm{zu}$ begründen; kulturelle Wertvorstellungen, die dem Sprachsystem sowie dem Sprachverwendungssystem zugrunde liegen könnten, wurden dann herangezogen, wenn die betreffenden Phänomene allein durch linguistische Aspekte nicht ausreichend erklärt werden konnten.

Da die kleine Datenmenge sowie die Heterogenität des Datenmaterials dieser Arbeit es nicht erlaubt, statistisch fundierte Aussagen in bezug auf Hörerverhalten von Japanern oder Deutschen zu machen, konnten nur Vermutungen und Tendenzaussagen aufgestellt werden, die auf den Ergebnissen meiner Daten beruhen. Daher stellt die Aufstellung der Thesen in dieser Arbeit keinen allgemeinen Gültigkeitsanspruch. Alle Annahmen und Vermutungen gelten primär nur für meine Daten.

Im Kapitel 2 wurde die Forschungslage in bezug auf das Thema Hörerverhalten bzw. Hörersignale ausführlich dargestellt. Der Zweck dabei war, den Lesern einen guten Überblick über die betreffende Thematik zu geben und die Leser zugleich in die Fragestellung meiner Arbeit einzuführen. Da es bislang im deutschsprachigen Raum nur sporadisch Studien über Hörerverhalten gibt, also keine umfangreiche Veröffentlichungen darüber, war es angebracht, die Forschungsliteratur anderer Ländern vorzustellen und damit Interesse für dieses Thema bei deutschsprachigen Forschern zu erwecken.

Aufgrund der Befunde der Forschungsliteratur sind folgende Thesen aufgestellt worden:

- Hörersignale können in verschiedene Kategorien unterteilt werden; dabei wird die Klasse kurzsilbiger sprachlicher oder tonaler Hörersignale wie ja, uhmhm, e:, um usw. viel häufiger als andere Kategorien verwendet. Innerhalb der Kurzformen gibt es wiederum solche, die besonders oft zum Einsatz kommen.

- Hörersignale treten angehäuft an Satzgrenzen oder nah an Satzgrenzen (überlappt mit der letzten Silbe des Satzes) auf; im Japanischen jedoch werden Hörersignale außerdem verhältnismäßig häufig mitten im Satz geäußert; dies stellt einen der großen Unterschiede zwischen dem Deutschen und dem Japanischen dar.

- Pausen, Sprechersignale, Intonationskonturen (fallend oder steigend) usw. können als Auslöser der Hörersignale fungieren, wobei der Hörer nicht jede Auslösestruktur der Sprecherrede verbal erwidern muß. 
- Viele der Hörersignale werden dazu verwendet, Verstehen oder Zustimmung des Hörers dem Gesagten gegenüber zu signalisieren. Funktionen von Hörersignalen sind an sich jedoch komplexer Natur; Hörersignale können gleichzeitig verschiedene Funktionen ausüben, so können diverse Einstellungen (Emotionen, Ironie, Skepsis usw.) beim Äußern eines Verstehenssignals oder Zustimmungssignals gleichzeitig zum Ausdruck gebracht werden.

- Außerdem dienen Hörersignale zur Gesprächssteuerung, Gesprächsgliederung oder der Regulierung der Sprecher- und Hörerrollen sowie der sozialen Beziehung zwischen den Gesprächspartnern.

- Ein großer Unterschied zwischen Deutschen und Japanern liegt darin, daß in Gesprächen unter Japanern mehr Aufmerksamkeits- und Fortsetzungssignale mitten im Satz gesendet werden, während Deutsche dazu tendieren, Hörersignale erst am Satzende einzusetzen. Insgesamt legen japanische Hörer sehr viel Wert auf die Aufrechterhaltung einer harmonischen Beziehung und die Schaffung einer angenehmen Gesprächsatmosphäre; daher bemühen sie sich, ihren Sprechern gegenüber rücksichtsvoll, kooperativ, empathisch, konsensorientiert bzw. konfliktvermeidend zu sein.

Im Kapitel 4.2 wurden Formen von Hörersignalen in den deutschen und den japanischen Daten thematisiert und charakterisiert. Dabei stellte sich Folgendes heraus:

Hörersignale können zwar prinzipiell durch einzelne Wörter, Phrasen und Sätze zur Sprache gebracht werden, werden jedoch meistens durch kurze Äußerungen aus einem Wort (einer Partikel, einer Interjektion, einem Wort anderer Wortarten) realisiert. Sowohl in den deutschen als auch in den japanischen Daten werden über $80 \%$ der Hörersignale durch Wörter realisiert. Hörersignale sind also tatsächlich wenig raumeinnehmend und stören den Verlauf des Sprecherturns geringfügig.

Zweitens ist die Auswahl der Hörersignale hochgradig standardisiert; der Hörer schöpft beim Einsatz der Hörersignale meistens aus dem Reservoir konventionalisierter Mittel; sowohl in den deutschen als auch in den japanischen Daten werden beim Akt der Hörerrückmeldung „prototypische Hörersignale“ viel häufiger verwendet als „nicht-prototypische Hörersignale“: 88,6\% aller Hörersignale in den deutschen Daten und 91,3\% in den japanischen Daten. 
Die Standardisierung des Gebrauchs der Formen der Hörersignale scheint in den japanischen Daten fortgeschrittener zu sein als in den deutschen Daten ${ }^{378}$. Ein Argument dafür ist, daß die Anzahl der als Hörersignale verwendeten Formen in den deutschen Daten größer ist als in den japanischen Daten (fünfzig vs. vierzig Hörersignale). Eine ähnliche Tendenz ist ebenso bei den einzelnen Gesprächsteilnehmern zu erkennen: In den japanischen Daten variieren die Formen der Hörersignale je nach Benutzern geringer als in den deutschen Daten, d.h. gleiche Formen werden mit unterschiedlicher Frequenz verwendet. Hingegen ist die Anzahl und damit die Variationsbreite der Formen der Hörersignale in den deutschen Daten je nach den Personen unterschiedlich. ${ }^{379}$

Ferner läßt sich in den japanischen Daten deutlicher als in den deutschen Daten das „Phänomen der Männer- und Frauensprache“380 im Formengebrauch beobachten. Gedehnte, sanft steigend intonierte $h e:, n e$ : usw. wurden nur von Frauen verwendet.

Prototypische Hörersignale lassen sich sowohl in den deutschen als auch in den japanischen Daten nach Kurzformen, kombinierten Kurzformen und phrasen- und satzförmigen Höreräußerungen einteilen. Kurzformen (Hörersignale aus einem Wort) werden als Hörersignale am stärksten präferiert, was sowohl für die deutschen $(65,8 \%)$ als auch für die japanischen Daten $(78,4 \%)$ gilt. kombinierte Kurzformen werden in den deutschen Daten relativ oft gebraucht $\left(17,3 \%\right.$ aller Hörersignale). ${ }^{381}$ In den japanischen Daten kommen „aizuchi“-Sätze wie a sô desu ka (achso) am zweithäufigsten zum Einsatz (8,4\%).

Von den Kurzformen gibt es wiederum welche, die besonders oft verwendet werden, diese sind die Kurzformen ja, uhmhm in den deutschen Daten (zusammen 54,6\%) und e:, um in den japanischen Daten (zusammen 66,6\%), wobei die Frequenz beider Formen je nach

\footnotetext{
${ }^{378}$ Miller (1991, S. 119) stellte in ihrer Untersuchung fest, daß Japaner die Formen der Hörersignale weniger als Amerikaner variieren; das hat in ihrer Untersuchung tatsächlich zu interkulturellen Mißverständnissen geführt.

${ }^{379} \mathrm{Ob}$ dieses Ergebnis auf die zwischen Deutschland und Japan unterschiedliche kulturelle Betonung wie „Individualismus“ vs. „Kollektivismus“ oder „Differenzbetonung“ vs. „Konformitätsstreben“ usw. zurückgeführt werden kann, sei noch dahin gestellt; dazu Sugitani (1996), Hayashi (1990), usw.

${ }^{380}$ Es sollen ebenso in den deutschen Daten geschlechterspezifische Unterschiede im Gebrauch von Formen der Hörersignale erkennbar sein: Manche meiner deutschen Freunde sind der Meinung, daß wao, boa eher von Frauen und richtig eher von Männern gebraucht werden.

${ }^{381}$ In den deutschen Daten werden Kombinationen von Kurzformen tendenziell von männlichen Teilnehmern präferiert.
} 
Teilnehmern unterschiedlich ist. ${ }^{382}$ Dieses Ergebnis unterstützt die o.a. These, daß der Gebrauch der Hörersignale in hohem Maße normiert ist.

Funktionen von Kurzformen können zum Teil aus dem semantischen Gehalt oder den typischen Verwendungsweisen der als Hörersignale fungierenden Wörter oder Sätze bereits erahnt werden: Verstehen (ja, e:), Zustimmung (genau, sô), Kenntnisnahme einer neuen Information (a:ja, a:), Überraschung (ja?, ee!), Bewertung (toll, sugoi), Vergewisserung (ja?, echt?, honto?) usw.

Im Vergleich zu Kurzformen können Kombinationen von Kurzformen aufgrund ihrer Form (ja ja, ja genau, e: e:, sô sô) deutlicher und nachdrücklicher Einstellungen des Hörers dem Gesagten gegenüber zum Ausdruck bringen; außerdem sind sie oft eingesetzt, mehrere Funktionen gleichzeitig zum Ausdruck bringen zu können: z.B. das stimmt ja naja, a:so naruhodo (achso ja verstehe).

Satzäußerungen, die in den deutschen Daten oftmals als Hörersignale aufgetreten sind, sind hauptsächlich solche, die Bewertungen wie das ist ja blöd, das klingt gut usw. anzeigen. Hingegen sind in den japanischen Daten eine Reihe von standardisierten Satzäußerungen aus sô-Varianten wie sô desu ne (ja, so ist das), a sô desu ka (achso) registriert, die entweder die Wissensdivergenz oder den Konsens im Wissen oder in Ansichten und Erwartungen zwischen Sprecher und Hörer kennzeichnen.

Hörersignale, die meines Erachtens keine für Hörerrückmeldungen typischen Formen darstellen, finden sich in meinen Daten relativ wenig.

Ein-Wort-Äußerungen sind oft gänzliche oder Teilwiederholungen der Sprecherrede; der Hörer bezweckt dabei verschiedenes: Sie können zum Ausdruck der Überraschung, zur Verständnissicherung (Fragen oder Selbtvergewisserung) oder als Denkanstoß zum weiteren Nachdenken dienen; außerdem können sie einen inhaltlich-thematisch ergänzenden Beitrag zum Gesagten des Sprechers leisten. In den japanischen Daten finden sich ebenso einige EinWort-Äußerungen, die ähnlich wie diejenigen in den deutschen Daten fungieren. Darüber

\footnotetext{
${ }^{382}$ Einige Gesprächsteilnehmer verwenden entweder $u h m h m$ oder ja häufiger; außerdem gibt es andere, die beide Formen fast gleich oft einsetzen.
} 
hinaus gibt es solche, die Worthilfen oder Vorwegnahmen verkörpern, was in den deutschen Daten nicht beobachtet werden kann.

Phrasen- oder satzförmige Höreräußerungen, die kontextgebunden sind, üben ähnliche Funktionen wie Kurzformen oder Kombinationen von Kurzformen aus; außerdem stellen sie Kommentare, inhaltliche Ergänzungen zum Gesagten oder Wiedergaben des Gesagten mit eigenen Worten dar. Dies trifft auf Satzäußerungen sowohl in den deutschen als auch in den japanischen Daten zu. Ferner können Phrasen oder Sätze als Satzvollendungen fungieren und so Verstehen oder Zustimmung besonders stark signalisieren. Interessanterweise sind Satzvollendungen nur in den japanischen Daten registriert. Satzvollendungen können zum Teil als Ausdruck der Zusammenarbeit zwischen Sprecher und Hörer beim Zustandekommen des Sprecherturns und als Ausdruck der gegenseitigen Abhängigkeit betrachtet werden.

Im Kapitel 4.3 wurde thematisiert, wo im Satz Hörersignale positioniert werden.

Hörersignale konzentrieren sich in den deutschen Daten auf den Satzendbereich, der die Positionen zwischen dem slW und dem NF, die darauf folgende Pause eingeschlossen, umfaßt; die Position, in der Hörersignale am häufigsten auftreten, ist die Pause nach dem letzten Inhaltswort des Satzes; außerdem befinden sich Hörersignale relativ häufig in der Position des slW oder slV und im NF sowie in bzw. nach der Pause des NF. Die Anhäufung der Hörersignale um das Satzende ist zum einen dadurch erklärbar, daß dort die Satzbedeutung sowie die Sprecherintention transparent werden, weil der betreffende Satz (fast) $\mathrm{zu}$ Ende gegangen ist; zweitens begünstigen Pausen im Satzendbereich oder Sprechersignale (NF) usw. zusätzlich das Auftreten der Hörersignale.

Auch in den japanischen Daten befinden sich Hörersignale sehr häufig im Satzendbereich, d.h. in der Verbposition sowie in der Pause nach der kjPP bzw. der PP des Zitates. Die Verteilung der „aizuchi“ im postverbalen Bereich ist jedoch zum Teil von Satzkategorien abhängig: Bei Sätzen mit der kjPP oder Objektsätzen treten ,aizuchi“ zwar am häufigsten in der Pause nach der kjPP oder der PP des Zitates, aber auch öfters in der Position der betreffenden PP oder des Verbs auf. Hingegen konzentrieren sich Hörersignale bei Vte-Sätzen in der Verbposition sowie in der darauf folgenden Pause. In bezug auf attributive Sätze sind Hörersignale zu beobachten, die sich mit dem Verb oder dem Bezugsnomen überlappen. Bei Vru-Sätzen sind Hörersignale am häufigsten in der Pause nach der slPP anzutreffen. Diese 
Verschiebung der bevorzugten Position der Hörersignale je nach Satzkategorie wird darauf zurückgeführt, daß der Hörer im voraus die betreffende Satzkategorie herauszufinden versucht, um dann Hörersignale an geeigneten Stellen (Pause oder kurz vor der vermuteten Pause) rechtzeitig plazieren zu können.

Außerdem gibt es Hörersignale, die sich vor dem Satzendbereich befinden. In den deutschen Daten verteilen sich Hörersignale relativ häufig im ME und gelegentlich im VVF oder VF. Hörersignale, die sich mit Elementen des VVF oder VF überlappen, zielen überwiegend auf den vorangegangenen Satz, während die meisten Hörersignale im MF auf den aktuell laufenden Satz bezogen sind. Die Plazierungsposition der Hörersignale gibt uns Hinweise darüber, wann der Hörer vermeintlich den Sinn des Satzes für erschlossen hält. In den japanischen Daten dagegen sind viel mehr Hörersignale mitten im Satz (vor allem in der VE) vertreten als in den deutschen Daten; sie sind unter anderem auf einen kleineren Informationsträger wie der eines Wortes oder einer Phrase bezogen. Dies ist einer der großen Unterschiede zwischen den deutschen und den japanischen Daten: Japanische Hörer unterstützen ihre Sprecher bei der Fortführung des Satzes eifriger als deutsche Hörer, die vielmehr den Empfang und das Verstehen des betreffenden Satzes bestätigen. ${ }^{383}$

Hörersignale werden sowohl in den deutschen als auch in den japanischen Daten nicht nur in der Pause plaziert, sondern überlappen sich mit Sprecheräußerungen. Die Überlappungsquoten sind sogar höher als die Quoten der Pausenplazierung: 52,5\% der Hörersignale in den deutschen Daten und $57,3 \%$ in den japanischen Daten. Daraus ist zu schließen, daß die Überlappung keinen (großen) Störfaktor im Gespräch darstellen kann, sondern bis zu einem gewissen Grad toleriert wird. ${ }^{384}$ Hörersignale überlappen sich vor allem mit dem letzten Inhaltswort des Satzes; ein Grund dafür ist, daß der Hörer in der Regel beim letzten Inhaltswort des Satzes die Satzbedeutung bereits ohne weiteres erschließen kann; daher sind die Reste des Satzes für den Hörer informativ gesehen nicht mehr hochwertig, so daß sie überlappt werden können.

\footnotetext{
383 Es wird des öfteren von Deutschen, die sich gut in Japan auskennen, berichtet, daß Japaner viel zu oft Hörersignale senden, was für Deutsche zum Teil störend wirkt; andererseits hört man oft von Japanern, die nicht so lange in Deutschland leben, daß sie beim Reden unsicher werden, weil deutsche Hörer nicht so häufig Hörersignale einsetzen.

${ }^{384}$ Zur gleichen Schlußfolgerung kommt auch Barba (1988, S. 58).
} 
Wenn Hörersignale gänzlich in die Pause hineinpassen, dann kann dies als ein Indiz für die Kooperationsbereitschaft des Hörers und die geschickte Koordination zwischen Sprecher und Hörer angesehen werden: Der Hörer erwidert mittels verbaler Hörersignale auf den Wunsch des Sprechers, ein explizites Signal von sich zu geben; der Sprecher hingegen wartet, bis Hörersignale fertig geäußert werden. Außerdem ist diese Art der Pausenplazierung ein harmoniestiftendes Moment, in dem Sprecher und Hörer quasi musikalisch in Einklang stehend das Gespräch kooperativ gestalten: Hörersignale füllen Lücken (Pausen) in der Sprecherrede, wie der Gegenschlag des Hammers den Hammerschlag des anderen erwidert; diese Metaphorik gilt für die beiden Sprachgruppen.

Bezüglich der Überlappung lassen sich zwischen den deutschen und den japanischen Daten Unterschiede erkennen: Hörersignale in den deutschen Daten sind eher punktuell plaziert, und es kommt kaum vor, daß sie sich länger mit Sprecheräußerungen überlappen. Hingegen gibt es in den japanischen Daten des öfteren längere Überlappungen, die sich sogar auf einen oder zwei Sätze des Sprecherturns erstrecken. Die Betonung der überlappten Hörersignale passen sich der Betonung der Sprecheräußerungen an und bilden somit einen Einklang auf der „musikalischen Ebene“. Dieses Phänomen der längeren Überlappung läßt sich zum Teil auf die Satzstruktur des Japanischen zurückführen: Im Japanischen kann sich der Satzendbereich häufig aus mehreren verschiedenen Elementen wie Verb, Hilfsverben, konjunktionale Postposition oder satzletzte Postpositionen konstruieren. Der Hörer, der die Satzinformation bereits beim Vollzug des Verbs verstanden hat, hat die Gelegenheit, Hörersignale beim Verb zu plazieren und die Reste des Satzes damit zu begleiten. Ebenso können Hörersignale bei Satzgefügen bereits nach dem Vollzug des abhängigen Satzes geäußert werden, wodurch die gänzliche Überlappung mit dem betreffenden Hauptsatz, der stets dem abhängigen Satz nachgestellt ist, ermöglicht wird. Die Tendenz der längeren Überlappung in den japanischen Daten läßt sich zum Teil durch den Harmoniewunsch des Hörers mit dem Sprecher in Zusammenhang erklären.

Im Kapitel 4.4 wurde analysiert, welche Merkmale an Satzenden das Auftreten der Hörersignale begünstigen.

Als erstes (im Kapitel 4.4.1) wurde überprüft, ob der Abschluß eines Satzes als Auslöser der Hörersignale fungiert, weil aus den Ergebnissen des Kapitels 4.3 hervorging, daß Hörersignale sowohl in den deutschen als auch den japanischen Daten sehr häufig nah am 
Satzende auftreten. Ein weiterer Zweck dieser Analyse bestand darin, eine vergleichbare Basis für die Untersuchung darüber zu schaffen, in welcher der beiden Sprachgruppen häufiger Hörersignale gesendet werden.

Dabei stellte sich heraus, daß japanische Hörer insgesamt mehr Hörersignale von sich geben als deutsche Hörer: In den japanischen Daten werden 57,9\% aller Sätze von Hörersignalen begleitet, wohingegen in den deutschen Daten 40,3\% der Sätze mit Hörersignalen versehen sind. Der Unterschied in der Frequenz resultiert daraus, daß in den japanischen Daten etwa ein Drittel der Hörersignale nicht auf eine Satzäußerung, sondern auf eine kleinere Informationseinheit wie die eines Wortes oder einer Phrase ausgerichtet sind. Dieses Phänomen läßt sich darauf zurückführen, daß der Sprecher in den japanischen Daten nicht nur an Satzenden, sondern auch mitten im Satz Reaktionen vom Hörer evozieren und dadurch den Hörer häufig auf die Zuhörerschaft hin kontrollieren will. Der kooperative Hörer erfüllt diesen Wunsch des Sprechers und bestätigt das Verstehen der betreffenden syntaktischen Einheit. Außerdem wird angenommen, daß der japanische Hörer seinerseits darum bemüht ist, den Sprecher beim Weitereden möglichst zu unterstützen und das Gespräch voranzutreiben; darin spiegelt sich meines Erachtens eine kulturelle Betonung auf die gegenseitige Abhängigkeit zwischen Sprecher und Hörer wider. ${ }^{385}$

Außerdem kann man davon ausgehen, daß der Vollzug einer Satzäußerung als wirksamer Auslöser der Hörersignale fungiert; sowohl in den japanischen als auch in den deutschen Daten sind gut $40 \%$ der Sätze mit Hörersignalen versehen, die auf den aktuellen oder vorangegangenen Satz ausgerichtet sind. ${ }^{386}$ Jedoch scheint der Hörer nicht dazu verpflichtet zu sein, sich nach jedem Satz verbal zurückzumelden.

Von den verschiedenen Satzkategorien rufen in den deutschen Daten allein stehende und gleichkoordinierte Sätze häufiger Hörersignale hervor als Haupt- und Nebensätze; eine Erklärung dafür ist, daß erstere zu keinen anderen Sätzen im Abhängigkeitsverhältnis stehen

\footnotetext{
385 Yamada (1990) stellt fest, daß in ihren Gesprächsdaten Japaner in Geschäftsmeetings dazu neigen, Themen gemeinsam mit den anderen Teilnehmern zu entwickeln und zu gestalten, während Amerikaner tendenziell das selbst initiierte Thema selbst bis zum Ende durchführen. Daraus zieht sie die Schlußfolgerung, daß die japanische Art der Themenführung die Gruppenzugehörigkeit stärkt, während der amerikanische Stil die Autonomie und Unabhängigkeit fördert (S. 291).

${ }^{386}$ In den japanischen Daten gibt es außerdem einige Hörersignale, die sich auf kleinere Informationseinheiten wie die eines Wortes oder einer Phrase beziehen. Insgesamt ist die Quote der Hörersignale in den japanischen Daten wesentlich höher.
} 
und so in sich abgeschlossene syntaktische Einheiten darstellen, während letztere den anderen Sätzen über- oder untergeordnet sind und zusammen eine größere syntaktische Ordnung konstituieren.

Ebenso weisen in den japanischen Daten allein stehende und gleichkoordinierte Sätze (Vru-, Vte- und adversative Sätze) generell höhere Quoten von Hörersignalen auf als abhängige Sätze (adverbiale, attributive und Objektsätze). Vru-Sätze können meines Erachtens deswegen viele Hörersignale mit sich bringen, weil sie aufgrund ihrer Verbform anzeigen, daß sie in sich syntaktisch abgeschlossen und einem anderen Satz nicht untergeordnet sind. Vte- und adversative Sätze implizieren hingegen Fortsetzung oder einen möglichen Gegensatz; gerade dieses „offene Ende“ dieser Sätze bewirkt in hohem Maße das Auftreten der Hörersignale. Vor allem stellen adversative Sätze eine Äquivalenz zu Vru-Sätzen dar, d.h. letztere lassen sich oft durch erstere austauschen, ohne die Satzbedeutung zu verändern; der Unterschied liegt darin, daß adversative Sätze aufgrund ihres offenen Endes weniger bestimmt klingen als entsprechende Vru-Sätze und eine gewisse Zurückhaltung erkennen lassen.

Die Frequenz der Hörersignale hängt bei Haupt- und Nebensätzen (wie Relativ-, Objekt- und adverbialen Sätzen) in den deutschen Daten von der Satzstellung ab; nachgestellte Sätze der Satzgefüge sind viel häufiger mit Hörersignalen ausgestattet als vorangestellte Sätze der Satzgefüge. Daraus läßt sich die These ableiten, daß eine grammatische Vollständigkeit bei Satzgefügen ebenso ein wichtiger Faktor für das Auftreten der Hörersignale ist: Der Hörer hält sich solange damit zurück, Hörersignale zu senden, bis das betreffende Satzgefüge komplettiert wird, weil er sonst den Sprecher bei der Durchführung des Redeplans stören würde. Das ist auch ein Zeichen für die Rücksichtnahme des Hörers auf den Sprecher.

Ebenso kann man in den japanischen Daten eine ähnliche Tendenz bei den Satzgefügen feststellen: Nachgestellte Sätze, d.h. Hauptsätze - im Japanischen sind übergeordnete Sätze stets den abhängigen Sätzen nachgestellt - erhalten viel mehr Hörersignale als vorangestellte Sätze (abhängige Sätze); der Hörer ist also bei Satzgefügen auch in den japanischen Daten aus ähnlichen Gründen vorsichtig damit, Hörersignale nach dem Vollzug des vorangestellten Satzes einzusetzen. Nichtsdestotrotz sind die Quoten der vorangestellten Sätze in den japanischen Daten etwas höher als in den deutschen Daten, dies steht damit im Zusammenhang, daß manche Satzgefüge elliptisch verwendet werden, so daß bei 
vorangestellten Sätzen die Hauptsätze weggelassen werden; gerade diese elliptische Konstruktion von Satzgefügen erweckt beim Hörer stärker als sonst das Bedürfnis, dem Sprecher mitzuteilen, daß er das Satzgefüge trotz der Unvollständigkeit des Satzes verstanden hat.

Im Kapitel 4.4.2 wurden Satzenden der sechs Intonationstypen zugeordnet: fallende, steigende und gleichbleibende Typen mit oder ohne Pause, und es wurde überprüft, welcher Intonationstyp wie häufig Hörersignale auslöst.

Dabei stellte sich heraus, daß in den deutschen Daten Pausen entscheidend beeinflussen, ob an Satzenden Hörersignale auftreten oder nicht; Hörersignale folgen bei Satzenden mit steigender oder fallender Intonation viel häufiger auf Satzenden mit Pausen als ohne Pausen. Dies ist darin begründet, daß Pausen in meinen Daten vielerorts an strategisch wichtigen Stellen der Sprecherrede gesetzt werden, an denen der Sprecher für die Bildung seines Redeplans vom Hörer eine Bestätigung erhalten möchte; diesen Wunsch gibt er dem Gegenüber mittels der Pause zu erkennen. Welche der Intonationstypen fallende oder steigende Intonation mit Pause mehr Hörersignale auslösen, kann an dieser Stelle nicht beantwortet werden, obwohl in meinen deutschen Daten der fallende Intonationstyp mit Pause, die auf eine Finalität hindeutet, eine höhere Quote der Hörersignale erzielt als die steigende Intonationsvariante mit Pause, die eine Unabgeschlossenheit indiziert. Dies bedarf einer genaueren Untersuchung. Gleichbleibende Intonation ohne Pause, die eine vage Fortsetzung indiziert, oder gleichbleibende Intonation mit Pause, die in meinen Daten Nachdenklichkeit oder Formulierungsschwierigkeiten andeuten, evozieren genauso wenig verbale Hörerrückmeldungen wie ein fallender oder steigender Tonhöhenverlauf ohne Pause.

In den japanischen Daten zeichnet sich ebenfalls eine den deutschen Daten ähnliche Tendenz ab: Pausen sind auch in den japanischen Daten in jedem Fall ein wirksamer Stimulus der Hörersignale. Ob fallende Intonation mit Pause mehr Hörersignale hervorrufen kann, kann an dieser Stelle nicht eindeutig bejaht werden, denn Sätze mit steigender Intonation mit Pause rufen fast genauso viel Hörersignale hervor; außerdem ist die Quote der Hörersignale bei Sätzen mit steigender Intonation ohne Pause höher als bei Sätzen mit fallender Intonation ohne Pause. Gleichbleibende Intonation wird in den japanischen Daten kaum produziert. 
Sprechersignale stehen in beiden Sprachgruppen zur Verfügung. In den deutschen Daten werden Sprechersignale wie ja, ne, na, nicht, oder häufig verwendet und markieren oftmals den Abschluß der allein stehenden Sätze oder der Satzgefüge. In der Regel werden sie mit steigender Intonation mit oder ohne Pause realisiert. In den japanischen Daten werden ne, yo, yone als Sprechersignale verwendet; sie sind häufiger allein stehenden Sätzen oder als Hauptsatz fungierenden Vru-, Vte- und adversativen Sätzen angeschlossen als abhängigen Sätzen. Anders als in den deutschen Daten sind Sprechersignale in den japanischen Daten mit steigenden und fallenden Intonationstypen mit oder ohne Pause versehen; ne (nicht wahr) und yone (das ist so, oder) werden mit steigender Intonation mit oder ohne Pause, und yo (das ist so, daß) wird fallend intoniert. Vor allem wird wie in den deutschen Daten steigende Intonation mit Pause bevorzugt verwendet.

Sprechersignale werden eingesetzt, um explizit beim Hörer verbale Hörerreaktion zu evozieren; sie erweisen sich sowohl in den deutschen als auch in den japanischen Daten als effektiverer Auslöser als Satzenden ohne Sprechersignale: Die Quote der Hörersignale liegt in den deutschen Daten bei Sätzen mit Sprechersignalen bei $24,4 \%$ und ist erwartungsgemäß höher als bei Sätzen ohne Sprechersignale (17,5\%). Auch in den japanischen Daten bringen Sprechersignale merklich mehr Hörersignale als Sätze ohne Sprechersignale mit sich: Die Quote der ersteren beträgt 33,6\%, die Quote der letzteren hingegen 18,4\%. Dabei begünstigen Sprechersignale mit steigender Intonation mit Pause das Auftreten der Hörersignale. Trotz der erhöhten Quoten kann man jedoch nicht davon sprechen, daß Sprechersignale den Hörer dazu verpflichten, Hörersignale von sich zu geben; sie erhöhen lediglich die Wahrscheinlichkeit des Auftretens der Hörersignale.

Im Kapitel 4.5 wurden Funktionen von Hörersignalen exemplarisch dargestellt und erklärt.

Die deutschen und die japanischen Daten unterscheiden sich wenig in den Funktionen der Hörersignale. $^{387}$ Hörersignale in den beiden Datengruppen können gleichzeitig multiple Funktionen ausüben, die auf verschiedenen Ebenen angesiedelt werden können: Signalisieren des Verstehensstandes des Hörers (Fortsetzungssignale, Verstehenssignale und Nachfragen)

\footnotetext{
${ }^{387}$ Sawada (1991, S. 72) ist ebenso der Meinung, daß Hörersignale im Deutschen und im Japanischen ähnliche Funktionen ausüben; in bezug auf das Englische und das Japanische behauptet Maynard Ähnliches (1986, S. 1079).
} 
Signalisieren des Wissensstandes des Hörers, der Stellungnahmen des Hörers dem Gesagten gegenüber (wie Zustimmung, Bewertung, Überraschung usw.), Gliederung der Sprecheräußerungen, Steuerung des Gesprächsverlaufs, Signalisieren des Wunsches nach Beibehaltung bzw. Änderung des bestehenden Rollenverhältnisses sowie Gestaltung der zwischenmenschlichen Beziehung zwischen den Gesprächspartnern. ${ }^{388}$

Fortsetzungssignale, die sich mitten im Satz befinden und das Verstehen der kleineren Informationseinheit wie die eines Wortes oder einer Phrase bestätigen, sind viel häufiger in den japanischen Daten registriert als in den deutschen Daten. Formal gesehen sind sie oft durch Kurzformen wie um, $e$ : realisiert; gelegentlich werden sie nachdrücklicher intoniert und mehrfach wiederholt (z.B. um um um). Solche Fortsetzungssignale bekunden ein großes Interesse des Hörers für das Thema; außerdem erzeugen sie aufgrund ihrer prosodischen Struktur mehr Spannung und fördern den Gesprächsfluß des Sprechers.

Viele der Hörersignale fungieren in meinen Daten als Verstehenssignale. Verstehenssignale sind zum großen Teil an oder nah an Satzgrenzen plaziert; sie geben dem Sprecher dabei zu erkennen, daß er seinen Turn fortführen soll, weil der Hörer die betreffende Informationseinheit (wie die eines Satzes, eines Satzgefüges oder einer Sinneinheit) ohne weiteres verstanden hat. So ermutigt der Hörer den Sprecher zum Weiterreden; Verstehenssignale, die zusätzlich Interesse oder Empathie des Hörers für bzw. gegen das aktuelle Thema bekunden, sind noch motivierender als „nüchterne, neutrale“ Verstehenssignale. Das kooperative und rücksichtsvolle Verhaltens des Hörers, das den Fortgang des Turns fördert und die Motivation des Sprechers erhöht, hat positive Konsequenzen für die soziale Beziehung zwischen beiden. Verstehenssignale in den japanischen Daten zeigen stärker einfühlsame, emotionale Zuwendung des Hörers dem Sprecher gegenüber als in den deutschen Daten.

Verstehensprobleme sind in meinen Daten wenig zu registrieren; vor allem finden sich in den japanischen Daten keine Hörersignale, die Verstehensschwierigkeiten andeuten. Ein Grund dafür könnte sein, daß der Hörer sein Image wahren will; er möchte also nicht als jemand erscheinen, dem das Verstehen schwerfällt. Außerdem könnte dabei Rücksicht des Hörers auf den Sprecher eine Rolle spielen, denn die Ankündigung von Verstehensproblemen

${ }^{388}$ Dieser Aspekt wird bei der Beschreibung der Hörersignale, die Verstehensstand, Wissensstand und diverse 
beeinträchtigt den reibungslosen Verlauf des Gesprächs mehr oder minder. In der Forschungsliteratur wird berichtet, daß in bestimmten Situationen (z.B. im Gespräch mit dem Vorgesetzten) Nachfragen trotz des Nichtverstehens möglichst vermieden werden. ${ }^{389}$

Hörersignale, die wie achso, aja, a sô desu ka, a sô usw. die anfängliche Wissens-, Erwartungs- oder Meinungsdivergenz anzeigen, sind ebenfalls relativ oft in meinen Daten vertreten. Der Hörer stuft dabei die gelieferte Information als neu oder unerwartet ein, nimmt sie aber wiederum ohne Stellungnahme als Tatsache hin. Die betreffenden Hörersignale sind des öfteren gefühlsbetonter, weil der Hörer, der anfänglich mit dem betreffenden Sachverhalt nichts anzufangen wußte, es jedoch mit der Zeit schaffte, das Neue oder Unerwartete in sein Wissenssystem einzuordnen.

Zustimmungssignale, die in meinen Daten ebenso oft wie Verstehenssignale eingesetzt werden, sind ebenfalls überwiegend nah oder an Satzgrenzen zu finden und bekunden, daß der Hörer die Ansichten in bezug auf den geäußerten Sachverhalt mit dem Sprecher teilt oder die Richtigkeit des Sachverhaltes bestätigt. Auf diese Weise wird die Gemeinsamkeit zwischen den Gesprächspartnern hervorgehoben. Emotional aufgeladene, nachdrücklich intonierte Zustimmungssignale können dabei die Distanz zwischen beiden in erhöhtem Maße abbauen und die Nähe und die Sympathie fördern. Im Vergleich zu Verstehenssignalen sind Zustimmungssignale sowohl in den deutschen als auch den japanischen Daten nachdrücklicher und werden in emotionalerer Form zum Ausdruck gebracht, wobei die zum Ausdruck gebrachte Emotionalität in den japanischen Daten noch erheblich stärker ist als die in den deutschen Daten. Das spricht dafür, daß in den japanischen Daten eine emotionale Annäherung zwischen den Gesprächsteilnehmern eine große Bedeutung hat.

Bewertungen werden in meinen Daten gelegentlich geäußert. In den deutschen Daten werden sie meistens durch konventionalisierte Formulierungen wie das ist ja gut konkretisiert. Bewertungen, die die Handlungen des Sprechers gut heißen, wirken sich sehr positiv auf die Beziehung zwischen dem Sprecher und dem Hörer aus, weil das Ansehen des Sprechers dadurch erhöht wird. Außerdem finden sich bewertende Höreräußerungen, die Verständnis,

Einstellungen des Hörers dem Gesagten gegenüber anzeigen, behandelt.

389 Siehe Sugitani (1994, S. 248). Nach Sugitani vermeiden Japaner Nachfragen im Gespräch mit dem Vorgesetzten; man versucht, Verstehensprobleme mit Hilfe von kontextuellen Zusammenhängen selbst zu beseitigen, statt direkt bei dem Vorgesetzten nachzufragen. 
Mitgefühl oder Bedauern in bezug auf den darstellten Sachverhalt anzeigen; diese stärken die Solidarität und die Sympathie zwischen den Gesprächsbeteiligten.

Dissens oder Zweifel werden sowohl in den deutschen als auch in den japanischen Daten nur selten durch Hörersignale realisiert. Vielmehr führen Nichtübereinstimmungen den Turnwechsel herbei. Dieses Ergebnis läßt sich auf die Konfliktvermeidungsstrategie der Gesprächsteilnehmer in den beiden Sprachgruppen zurückführen; dieses ist zum Teil dadurch bedingt, daß es sich dabei um eine Aufnahmesituation handelte; konfliktäres Verhalten, das offen dokumentiert wird, bewirkt Verlust sowohl des eigenen als auch des fremden Images. Dieses Verhaltensprinzip ist besonders in den japanischen Daten wirksam, weil die Vermeidung der Konflikte oder Meinungskontroversen eine der japanischen Kommunikationsmaximen darstellt.

Satzvollendungen und Vorwegnahmen sind nur in den japanischen Daten vertreten. Dabei äußert der Hörer einen Satzteil oder einen ganzen Satz vorweg, bevor der Sprecher ihn zur Sprache bringt. So gestaltet der Hörer gemeinsam mit dem Sprecher einen Teil des Turns. Solche Höreräußerungen setzen gemeinsam geteilte Wissens- und Erwartungssysteme sowie Lebenserfahrungen voraus und dienen dazu, zum einen den Verlauf des Turns zu beschleunigen und zum anderen die Kooperation und die Abhängigkeit zwischen Sprecher und Hörer zu unterstreichen. Bestätigt der Sprecher die Satzvollendungen des Hörers begeistert, erheitert dies die Gesprächsatmosphäre und trägt zur emotionalen Annäherung zwischen den Gesprächspartnern bei.

Mit Pausenfüllern sind Hörersignale gemeint, die in der Pause zwischen zwei syntaktischen Einheiten oder auch vor dem Beginn der Pause (d.h. überlappt mit Sprecheräußerungen) eingesetzt werden und die Pausen zwischen ihnen überbrücken; Pausenfüller sind in den japanischen Daten häufig anzutreffen. Dabei klingen sie so, als ob man den Takt trommelte. So gibt der Hörer mittels Pausenfüllern den Takt an und hält während der Pause die Spannung aufrecht. Dies erleichtert dem Sprecher den Beginn des nächsten Satzes. Pausenfüller können wiederum als Widerspiegelung der stark auf die gegenseitige Kooperation und Ergänzung zwischen Sprecher und Hörer basierender Art der Gesprächsgestaltung betrachtet werden.

Hörersignale üben den Sprecherbeitrag gliedernde Funktionen aus: Sie können den Abschluß eines Satzes, eines Satzgefüges oder einer Sinneinheit aus mehreren Sätzen markieren. 
Außerdem dienen überlappende Hörersignale dazu, die Satzäußerung in zwei Teile zu zerlegen: den Teil, der für den Hörer relevante Informationen beinhaltet, und den Teil, der für den Verstehensprozeß weniger Wertigkeit besitzt.

Hörersignale steuern den Verlauf des Redebeitrags des Sprechers auf den verschiedenen Ordnungsebenen; Fortsetzungssignale fördern den Fortgang des betreffenden Satzes. Ebenso beschleunigen Hörersignale, die nah oder an Satzgrenzen eingesetzt werden, die Beendigung des Satzes und erleichtern dem Sprecher den Übergang in die nächste syntaktische Einheit. Hörersignale können auch den Turn auf das Ende hin steuern und den eigenen Turn einleiten. Ferner können Hörersignale die Länge des Turns beeinflussen: Sie können den Turn verlängern, indem sie Interesse des Hörers bekunden und dadurch den Sprecher nicht nur zur Weiterführung, sondern auch zur Ausführung eines aktuellen Themas anregen und unterstützen. Hörersignale (wie Nachfragen, Zweifel, Dissens) steuern den Sprecherplan stärker als viele andere Hörersignale in eine bestimmte Richtung: Bei Nachfragen ist der Sprecher dazu verpflichtet, eine Antwort darauf zu geben; Dissens oder Zweifel können den Sprecher z.B. dazu bringen, dagegen zu argumentieren oder seinen Standpunkt genauer zu erläutern, wodurch der Kurs des ursprünglichen Redeplans teilweise in eine andere Richtung gelenkt wird.

Hörersignale regulieren die Turnzuweisung, indem sie die bereits bestehende Sprecher- und Hörerrolle bestätigen oder im voraus die bevorstehende Turnübernahme ankündigen. Meine Daten zeigen jedoch, daß Hörersignale hauptsächlich verwendet werden, um die aktuelle Rollenverteilung zu legitimieren.

Nachfolgend soll der Hörerverhaltensstil sowohl in den deutschen als auch in den japanischen Daten thematisiert werden. Die japanischen Daten zeichnen sich durch Folgendes aus:

- Der Hörer ist rücksichtsvoll und kooperativ mit dem Sprecher; er hilft ihm bei der Turnweiterführung tatkräftig und motiviert ihn dazu (z.B. Fortsetzungssignale, Verstehenssignale, Pausenfüller); die Unterstützung des Hörers ist für den Sprecher, der in seiner Gesprächsführung relativ unsicher ist, unentbehrlich. ${ }^{390}$

\footnotetext{
${ }^{390}$ Dieses Phänomen läßt sich auf das japanische Konzept der Gesprächsführung, „kyôwa“ zurückführen, das womöglich den Verhaltensweisen der japanischen Hörer in meinen Daten zugrunde liegt. Demnach besteht in der japanischen Kommunikation generell die Tendenz, das Gespräch langsam voranzutreiben, indem der
} 
- Der Hörer bleibt während des Turns des anderen aktiv und im Vordergrund, indem er sich oftmals in die Turnproduktion des Sprechers einmischt und sogar einen Teil des Turns mitgestaltet (z.B. Satzvollendungen, Vorwegnahmen). Diese Art des Hörerverhaltens verwischt eher die klare Trennung zwischen dem Sprecher- und Hörerstatus und demonstriert eine Interdependenz zwischen beiden.

- Der Hörer ist stark darauf bedacht, Konflikte oder Auseinandersetzungen zu vermeiden und eine harmonische Beziehung mit dem Sprecher aufzubauen und aufrechtzuerhalten; er ist bemüht, die Divergenz zwischen Sprecher und Hörer im Wissen, in den Erwartungen oder Ansichten zu verringern und sich kognitiv und emotional dem Sprecher anzunähern; dazu werden z.B. Verstehenssignale, die eine empathische Haltung des Hörers deutlich zum Ausdruck bringen, oder Zustimmungssignale, die den sachlichen Konsens mit erhöhter Emotionalität unterstreichen, eingesetzt.

- Mittels längerer überlappender Hörersignale realisiert der Hörer sogar eine faktische Harmonie mit dem Sprecher; dies ist ein Beispiel dafür, wie sehr ein harmonisches Miteinander für den Hörer von Bedeutung ist.

- Der Hörer sorgt mit allen Mitteln dafür, daß im Gespräch eine gute, angenehme Gesprächsatmosphäre entsteht - Hörersignale, die Interesse, positive Überraschung, positive Bewertungen oder den Konsens in Ansichten oder Empfindungen bekunden und gleichzeitig emotional aufgeladen sind, sind sehr aufwertend und aufmunternd und verstärken die Sympathie zwischen Sprecher und Hörer.

- Der Hörer wirkt zum Teil zu überschwenglich und enthusiastisch, so daß der Eindruck entstehen kann, daß er eine aktive und emotionale Anteilnahme am Gespräch womöglich simuliert, ohne es damit ehrlich zu meinen.

In den deutschen Daten kann der Hörerverhaltensstil folgendermaßen charakterisiert werden:

- Der Hörer ist kooperativ mit dem Sprecher; der Hörer gibt in regelmäßigen Abständen, genauer gesagt an strategisch relevanten Stellen der Sprecherrede (vor allem an Satzgrenzen des allein stehenden Satzes, des Satzgefüges oder nach Sprechersignalen) Hörersignale von sich, um dem Sprecher den Turnfortgang zu erleichtern.

Sprecher ständig die Zuhörerschaft des Hörers kontrolliert und dabei auch das Einverständnis zur Weitererhaltung des Turns einholt. Der Hörer hingegen ist stets bestrebt, kooperativ zu sein, und gibt möglichst viele Hörersignale von sich, um den Sprecher tatkräftig zu unterstützen. Siehe Mizutani (1988a, S. 10). 
- Dennoch deutet das Hörerverhalten in den deutschen Daten auf eine andere Haltung des Hörers gegenüber dem Sprecher und der Gestaltung des Gesprächs als in den japanischen Daten hin: Der Hörer zieht sich während des Zuhörens eher in den Hintergrund zurück und überläßt dem Sprecher die Gesprächsführung weitgehend; der Sprecher ist offenbar sicherer im Besitz seines Turns und benötigt daher kaum Bestätigung des Hörers mitten im Satz oder im Satzgefüge, um seinen Redeplan weiterführen zu können. So wird in den deutschen Daten das Recht des Sprechers, die Rede bis zu einem gewissen Grad aus eigener Entscheidung gestalten zu können, vom Hörer respektiert und weniger angetastet. Aus diesem Grund wirkt der Hörer im deutschen Datenmaterial eher passiv und weniger präsent als im japanischen, während hingegen sich der Sprecher im ersteren umso mehr durch seine Präsenz auszeichnet.

- Obwohl die Tendenz, Konflikte zu vermeiden, auch in den deutschen Daten stark zu spüren ist, lassen sich dennoch einige Stellen (vor allem beim Turnbeginn und Turnende) finden, an denen man Konkurrenzverhalten zwischen den Gesprächspartnern (Turnbeanspruchungen oder simultanes Sprechen) festmachen kann. Konflikte oder Konfrontationen sind in den deutschen Daten in begrenztem Maße toleriert oder erlaubt. Die Betonung liegt nicht auf der Vermeidung von Unstimmigkeiten und Auseinandersetzung, sondern vielmehr auf dem ausgewogenen Balanceakt zwischen Kooperation und Konkurrenz.

- Der Hörer wendet sich in den deutschen Daten dem Sprecher weniger emotional zu, der emotionale Aspekt ist also in den deutschen Daten nicht in derart hohem Maße in den Vordergrund gestellt wie in den japanischen Daten; statt dessen wird mehr Wert darauf gelegt, den Konsens im Wissen oder in Ansichten auf der kognitiven Ebene zu unterstreichen. Die persönliche Annäherung zwischen den Gesprächspartnern beruht eher auf dem „nüchternen“ gegenseitigen Verstehen der Standpunkte anderer als auf der „überschwenglichen Einigkeitsstimmung“.

- Trotz des verbal zurückhaltenden Stils des Hörerverhaltens in den deutschen Daten kann man davon ausgehen, daß der Hörer dem Sprecher sehr gut zuhört; dies läßt sich in vielen Fällen daran erkennen, daß der neue Sprecher in seinem eigenen Turn auf den vorangegangenen Turn Bezug nimmt; die inhaltliche Konsistenz ist ein zuverlässigerer Beleg für gutes Zuhören und Verstehen als ein mögliches Simulieren des aktiven Zuhörens (vor allem durch Kurzformen) in den japanischen Daten. 
Als Resümee dieser Arbeit läßt sich feststellen, daß die Thesen, die aus der Forschungsliteratur entwickelt wurden, weitgehend bestätigt worden sind; das ist relativ erstaunlich, weil die Ergebnisse in der vorliegenden Arbeit auf einem Datenmaterial beruhen, das - wenn überhaupt - nur in einem sehr schmalen Bereich der Gesellschaft gelten kann. Dies ist wiederum ein Indiz dafür, daß Hörerverhalten in hohem Maße standardisiert ist, so daß eine kleinere Stichprobe ausreicht, um Tendenzaussagen zu treffen, die ggf. eine allgemeine Gültigkeit haben könnten. Nichtsdestotrotz lassen sich immer wieder Phänomene finden, die z.B. auf individuelle, geschlechterspezifische, generationsspezifische, situationsbedingte Unterschiede hindeuten. ${ }^{391}$ Es ist durchaus sinnvoll, Hörerverhalten daraufhin zu untersuchen. Ferner empfiehlt es sich, Regularitäten oder Steuerungsmechanismen der Hörersignale mittels eines statistisch fundierten Verfahrens genauer zu erforschen. Vor allem wäre es interessant, die Frequenz der Hörersignale in Abhängigkeit von multiplen, gleichzeitig auftretenden Merkmalen - lexikalisch, prosodisch, nonverbal usw. -, also multifaktoriell zu ermitteln. ${ }^{392}$ Außerdem können qualitativ verankerte Arbeiten über Hörerverhalten viele Aufschlüsse über die Interaktion zwischen Sprecher und Hörer auf der verbalen und nonverbalen Handlungsebene geben; sowohl in Deutschland als auch in Japan existieren bislang nur wenige solcher Studien.

\footnotetext{
${ }^{391}$ Man könnte z.B. überprüfen, ob man in den deutschen Daten geschlechterspezifische Unterschiede in bezug auf Formen feststellen kann; außerdem scheint es in den japanischen Daten Differenzen in der Frequenz der Hörersignale zwischen den jüngeren und älteren Teilnehmern zu geben: Die jüngeren Teilnehmer geben weniger Hörersignale von sich als die älteren.

${ }^{392}$ Umfangreiche statistische Untersuchungen fehlen insbesondere im deutschsprachigen Raum.
} 


\section{Literatur}

Barba, G. (1988) „Dialogsteuerung in Medieninterviews: Eine kontrastive Darstellung Deutsch-Rumänisch“. Diss. Freiburg 1988.

Basic Japanese-English-Dictionary (1993) Hrsg. von Japan Foundation. Bonjinsha. Toyko 1986.

Bergmann, J. R. (1988) „Ethnomethodologie und Konversationsanalyse“. Kurseinheit 1-3. Hrsg. von Fernuniversität Hagen.

Blau, A. (1986) „Communication in the back-channel: Social structure analysis of nonspeech/speech conversation". City University of New York.

Brinker, K./Sager, S. F. (1995) „Linguistische Gesprächsanalyse“. Berlin 1995.

Bublitz, W. (1980) „Hörersignale und Gesprächssteuerung im Englischen“. In: Perspektive: Texttexterne Akten des 14. linguistischen Kolloqiums Bochum 1979 Bd. 2. Hrsg. von G. Tschauder/W. Weigand. Tübingen 1980.

Bühler, K. (1927) „Die Krise der Psychologie“. Jena 1927.

Bünting, K.-D./Bergenholz, H. (1989) „Einführung in die Syntax“. Frankfurt a. M. 1989.

Clancy, M./Thompson, S. A./ Suzuki, R.,/Tao, H. (1996) „The conversational use of reactive tokens in English, Japanese, and Mandarin“. In: Journal of pragmatics 26, S. 355387.

Coulmas, F. (1981) „Routine im Gespräch: Zur pragmatischen Fundierung der Idiomatik“. Wiesbaden 1981.

Deppelmann, A. (1999) „Gespräche analysieren“. Opladen 1999.

Dittman, A.T./Llewellyn, L. (1968) „Relationship between vocalizations and head nods as listener response“. In: Journal of personality and social psychology 9/1. S. 79-84.

Doi, T. (1973) „Anatomy of dependence“. Kôdansha international. Tokyo 1973

Drach, E. (1973) „Grundgedanken der deutschen Satzlehre“. Frankfurt a. M. 1973.

Duncan, S. (1972) „Some signals and rules for taking speaking turns in conversations“. In: Journal of personality and social psychology 23, S. 283-292.

Duncan, S. (1973) „Toward a grammar for dyadic conversation“. In: Semiotica 9, S. 29-34.

Duncan, S. (1974) „On the structure of speaker-auditor interaction during speaking turns“. In: Language in society 2 , S. 161-180.

Duncan, S./Fiske, D. W. (1977) „Face-to-face interaction“. New York 1977.

Ehlich, K. (1979) „Formen und Funktionen von 'HM': Eine phonologische pragmatische Analyse“. In: Deutsche Sprachpartikeln. Hrsg. von H. Weydt, S. 503-515.

Ehlich, K. (1986) „Interjektionen“. Tübingen 1986.

Ehlich, K. (1989) „Hiat-Dos 2.2: Handbuch“. München 1989.

Erickson, F. (1979) „Talking down: Some cultural source of miscommunication in interracial interviews“. In: Nonverbal behavior. Hrsg. von A. Wolfgang, S. 99-126.

Erickson, F. (1988) „Listening and speaking“. In: Language and linguistics. Hrsg. von D. Tannen und E. Alatis, S. 294-319. 
Fries, C. C. (1952) „The structure of English: An introduction to the construction of English sentences“. New York 1952.

Goodwin, Ch. (1981) „Conversational organization: Interaction between speakers and hearers“. New York 1981.

Goodwin, Ch. (1984) „Notes on story structure and the organization of participation“. In: Structures of social action. Hrsg. von M. Atkinson/J. Heritage, S. 225-246.

Goodwin, Ch. (1986) „Between and within“. In: Human studies 9, S. 205-217.

Gudykunst, W. B. (1994) „Bridging Japanese/North American differences“. California 1994.

Günthner, S. (1993) „"Diskursstrategien in der interkulturellen Kommunikation: Analysen deutsch-chinesicher Gespräche. Tübingen 1983.

Hall, E. (1969) „Listening behaviour“. In: Phi Delta Kappen 50 (7), S. 379-380.

Hall, E. (1984) „kakureta sai (Verborgene Signale)“. Hrsg. von Gruner + Jahr AG \& Co. Stern. Hamburg 1984.

Hall, E. (1985) „Verborgene Signale“. Hrsg. von Gruner + Jahr AG \& Co. Anzeigenabteilung Stern. Hamburg 1985.

Hartung, M. (1998) „Ironie in der Alltagssprache“. Wiesbaden 1998.

Hayashi, H. (1990) ,Topic management and turn distribution in business meetings: American versus Japanese strategies“. In: Text 10, S. 271-295.

Hayashi, R. (1988) „Simultaneous talk“. In: World Englishes 7(3), S. 289-288.

Henne, H. (1978) „Die Rolle des Hörers im Gespräch“. In: Sprache und Pragmatik. Hrsg. von I. Rosengren. Malmö 1978, S. 122-134.

Henne,H./Rehbock, H. (1982) ,Einführung in die Gesprächsanalyse“. Berlin 1982.

Hinnenkamp, V. (1994) „Interkulturelle Kommunikation“. Heidelberg 1994.

Hinds, J. (1978) „Conversational structure: an investigation based on Japanese interview discourse“. In: Problems in Japanese syntax and semantics. Hrsg. von J. Hinds/I. Houward. Kaitakusha. Tokyo 1978.

Heritage, J. (1984) „A change-of-state token and aspects of its segmential placement”. In: Structures of social actions. Hrsg. von M. Atkinson/J. Heritage, S. 299-345.

Heath, Ch. (1984) "Talk and recipiency: Sequential organization in speech and body movement". In: Structures of social actions. Hrsg. von M. Atkinson/J. Heritage, S. 247-265.

Horiguchi, J. (1987) „Komyunikeishon ni okeru kikite kôdô“ (Hörerverhalten in der Kommunikation). In: Nihongokyôiku 64, S. 13-26.

Horiguchi, J. (1991) „Aizuchi kenkyû no shodankai to kadai (Analyseschritte bei der Erforschung von ,aizuchi“ und Aufgaben)“. In: Nihongogaku 10 (10), S. 31-41.

Japanisch-japanisches Wörterbuch (shinchô kokugo jiten) (1979) Shinchôsha. Tokyo 1979.

Jefferson, G. (1972) „Side sequences“. In: Studies in social interaction. Hrsg. von D. Sudnow, S. 294-338.

Jefferson, G. (1984) „Notes on a systematic development of the acknowledgement tokens 'yeah' and 'mm hm'“. In: Papers in linguistics 17, S. 17-216. 
Kasper, G./ Færch, F. (1984) „Ja und? - og hva'sa ${ }^{\circ}$-: A contrastive discourse analysis of gambits in German and Danish“. In: Contrastive linguistics. Hrsg. von J. Fisiak. Berlin 1984.

Katô, A./Saji, K./Morita, Y. (1990) „Nihongo gaisetsu (Einführung in die japanische Sprachwissenschaft)“. Ôfûsha. Tokyo 1990.

Kendon, A. (1967) „Some functions of gaze-directions in social interaction"“ In: Acta Psycology 26, S. 22-63.

Knapp, E./Knapp-Kotthoff, A. (1990) „Interkulturelle Kommunikation“. In: Zeitschrift für Fremdsprachenunterricht 1, S. 62-93.

Kotthoff, H. (1989) „Pro und Contra in der Fremdsprache“. Frankfurt a. M. 1989.

Koiso, H./Horiguchi, Y./Tutiya, S./Ichikawa, A./Den, Y. (1998) „An analysis of turn-taking and backchannels based on prosodic and syntactic features in Japanese map task dialogs“. In: Language and speech 41 (3-4), S. 295-321.

Kraut, E./Lewis, S. H./Swezey, L. W. (1982) „Interpersonal relations and group processes“. In: Journal of social science Vol. 43 (4), S. 718-731.

Kucharcik, K. (1989) „Sprecher- und hörerseitige Verwendungsweisen der Interjektion „HM““. In: Arbeitspapiere zur Linguistik 20. Zeitliche und inhaltliche Aspekte der Textproduktion, S. 169-191.

LcCastro, V. (1987) „Aizuchi: A Japanese conversational routine“. In: Discouses across cultures. Hrsg. von L. E. Smith. S. 101-113.

Labov, W. (1972) „Rules for ritual insults“. In: Studies in social experiences. Hrsg. von D. Sudnow. S. 120-169.

Lewin, B./Müller-Yokota, W./Fujiwara, M. (1984) „Einführung in die japanische Sprache“. Wiebaden 1984.

Lexikon der germanistischen Linguistik (1980) Hrsg. von H. Henne/H. E. Wiegand. Tübingen 1980, S. 314-318.

Mae, M. (1985) „Japanische Kommunikationsverhalten und sein sozialpsychologischer Hintergrund“. In: Interkulturelle Kommunikation und Neuorientierung von Mensch und Gesellschaft Bd 5. Hrsg. von W. Otte, S. 133-147.

Maibauer, J. (1999) „Pragmatik: Eine Einführung“. Tübingen 1999.

Matsuda, Y. (1988) „Taiwa no nihongokyôiku“ (Die Didaktik für Dialoge in der japanischen Sprache). In: Nihongogaku Vol. 7, Meijishoin, Tokyo 1988, S. 59-65.

Maynard, S. K. (1986) „On back-channel behaviour in Japanese and English casual conversation“. In: Linguistics 24/6, S. 1079-1108.

Maynard, S. K. (1989) „Japanese conversation: self contextualization through structure and intercultural management“. 1989 Norwood, NJ: Ablex.

Maynard, S. K. (1990) „Conversation management in contrast: listener response in Japanese and American English“. In: Journal of pragmatics. 14:3. S. 399-412.

Miller, L. (1991) „Verbal listening behavior in conversations between Japanese and Americans". In: The pragmatics of intercultural and international communication. Selected papers of the international pragmatics conferences Antwerp August 17-22. Vol.3 and the Ghent symposium on intercultural communication. Hrsg. von J. Blommaert/Verschueren, J. Amsterdam 1987. 
Minami, F. (1985) „Nihongo wa donna gengo ka (Was für eine Sprache ist das Japanische)“. In: Nihongo no tokushoku (Besonderheiten des Japanischen) 10. Hrsg. von Bunkachô. Tokyo 1985.

Miyachi, A. (1959) „Ukekotae“ (Reagieren und Erwidern). In: Kokugogaku 39 (Japanische Sprachwissenschaft). Hrsg. von Kokugogakkai (Kongreß der japanischen Sprachwissenschaft)

Mizutani, N. (1988) „Language behavior patterns“. In: hanashikotoba no komyunikeishon (die Kommunikation in der gesprochenen Sprache). Tokyo 1988. Bonjinsha, S. 86-108.

Mizutani, N. (1988a) „Aizuchiron“ (Über ,aizuchi“). In: Nihongogaku (Japanische Sprachwissenschaft) 7. Tokyo 1988. Meijishoin, S. 4-11.

Nagatomo, M (1986) „Die Leistung der Anrede- und Höflichkeitsformen in den sprachlichen Beziehungen: Ein Vergleich der soziativen Systeme im Japanischen und Deutschen“. Münster 1986.

Okabe, R. (1983) „Cultural assumptions East and West“. In: International and intercultural communication annual Vol. 7. Intercultural communication theory current perspectives. Hrsg. von W. B. Gudykunst, S. 21-44.

Ôhama, R./Yamataki, M./Nagata, R. (1998) „Michigiki danwa ni okeru aizuchi no kinô (Funktionen von ,aizuchi“ im Gesprächstyp „Wegauskünfte“)“. In: Nihongogaku 96. Tokyo 1998.

Ôishi, H. (1984) „Hanashi kotoba towa nani ka (was ist die gesprochene Sprache)“. In: Nihongo no tokushoku (Die Besonderheiten des Japanischen) 12. Hrsg. von Bunkachô (Kulturamt). Tokyo 1984.

Quasthoff, U. M. (1981) „Zuhöreraktivitäten beim konversationellen Erzählen“. In: Dialogsforschung. Hrsg. von P. Schröder und M. Steger, S. 287-313.

Quasthoff-Hartmann, U. M. (1986) „Zuhöreraktivitäten in der interkulturellen Kommunikation“. In: Aspekte einer interkulturellen Didaktik. Dokumentation eines Werkstattgespräches des Goethe Instituts München vom 16-17. Juni 1986. Hrsg. von J. Geringhausen/P. C. Seel. S. 104-133.

Rehbein, J. (1977) „Komplexes Handeln“. Stuttgart 1977.

Reid, J. (1995) „A study of gender differences in minimal responses“. In: Journal of pragmatics 24 , S. 489-512.

Sawada, M. (1991) „Hörersignale in deutschen und japanischen Telefonberatungsgesprächen“. In: Sohia Linguistica 30, S. 61-78.

Rath, R. (1979) „Kommunikationspraxis: Analysen zur Textbildung und Textgliederung im gesprochenen Deutschen“. Göttingen 1979.

Sacks, H. (1971) „Das Erzählen von Geschichten innerhalb von Unterhaltungen"“ In: Zur Soziologie der Sprache, S. 307-314.

Sacks, H./Schegloff, E./Jefferson, G. (1974) „A simplest systematics for the organization of turn-taking for conversation“. In: Language Vol. 50/4, S. 696-735.

Schank, G./Schoenenthal, G. (1976) „Gesprochene Sprache“. Tübingen 1976.

Schegloff, E. (1982) „Discourse as an interactional achievement: some issue of 'UH-HUH and other things that come between sentences". In: Analysing discourse: text and talk. Gorgetown University round table on language and linguistics, S. 71-93 
Schmidt, C. (1986) „Typisch weiblich - typisch männlich“. Tübingen 1986.

Schmidt, H. (1983) „Suprasegmentale Kommunikation: MHM. Der Anteil der Suprasegmentalia am Austausch von Rezipientensignalen in der gesprochenen französischen und deutschen Sprache“. Dissertation der Universität Konstanz 1983.

Schmidt, W, H. (1998) „Über Hörer, Hören und sich-sagen-Hören“. In: Vom Sprecher zum Hörer. Hrsg. von H.W. Schmidt. 1998 Münster.

Schwitalla, J. (1997) „Gesprochenes Deutsch“. Berlin 1997.

Schenkein, J. N. (1972) „Towards an analysis of natural conversation and the sense of heheh“. In: Semiotica 6, S. 344-377.

Schwitalla, J. (1976) „Dialogsteuerung: Vorschläge zur Untersuchung“. In: Berens u.a., S. 73-104.

Searle, R. J. (1971) „Sprechakte: Ein sprachphilosophischer Essay“. Frankfurt a. M. 1971.

Selting, M. (1987) „Reparaturen und lokale Verstehensprobleme“. In: Linguistische Berichte 108, S. 128-149.

Sugifuji, M. (1987) „Pôzu to intoneishon“ (Pausen und Intonation). In: Danwa kôdo no shoso (Verschiedene Aspekte des Gesprächsverhaltens). Hrsg. von Kokuritsukokugo kenkyûjo (Staatliches Institut für die japanische Sprache). Tokyo 1987, S. 107-138.

Sugitani, M. (1994) „Fortbildungsseminar für Japanischlehrer an Gymnasien, Gesamt- und Handelsschulen vom 3. bis 7. Oktober 1994 in Bad Liebenzell“. (unveröffentlicht).

Sugitani, M. (1996) „Kontextualismus als Verhaltensprinzip: „Kritisch“ erlebte Interaktionssituationen in der japanisch-deutschen Begegnung. In: Psychologie interkulturellen Handelns. Hrsg. von A. Thomas, S. 227-245.

Sugito, S. (1987) „Hatsuwa to uketsugi“ (Sprecheräußerungen und Sprecherwechsel). In: Danwa kôdô no shosô (verschiedene Aspekte des Gesprächsverhaltens). Hrsg. von Kokuritsukokugo kenkyûjo (staatliches Institut für die japanische Sprache). Tokyo 1987, S. 68-106.

v. Helmolt, K. (1993) ,Zur Relevanz der linguistischen Gesprächsanalyse für interkulturelle Trainingscurricula“. In: Interkulturelle Kommunikation und interkulturelles Training: Problemanalysen und Problemlösungen. Hrsg. vom Institut für Auslandsbeziehungen. Stuttgart 1993.

Takayama-Wichter, T. (1981) „Deutsch als Fremdsprache - Über die Lernersprache von Japanern -,,. Unveröffentlichte Magisterarbeit an der Ruhr-Universität Bochm.

Takayama-Wichter, T. (1993) „Japanische Deutschlerner und ihre Lernsprache im gesprochenen Deutsch. Untersuchungen“. Frankfurt a. M. 1993.

Thomlison, T. D. (1991) „Chapter four intercultural listening“. In: Listening in every day life. Hrsg. von D. Borisoff/M. Purdy. New York 1991. S. 88-137.

Wahmhoff/Wenzel (1979) „Ein HM ist noch lange kein HM - oder was heißt klientenbezogene Gesprächsführung?“. In: Konversationsanalyse. Hrsg. von J. Dittman. Darmstadt 1979.

Weinrich, H. (1993) „Textgrammatik der deutschen Sprache“.

Willkop, E-M. (1988) „Gliederungspartikeln im Dialog“. München 1988. 
White, S. (1986) „Functions of backchannels in English: A cross-cultural analysis of Americans and Japanese“. Gorgetown University 1986.

White, S. (1989) „Backchannel across cultures“. In: Language in society 18, S. 59-76.

Yngve, V. H. (1970) „On getting a word in edgewise“. In: Papers from the $6^{\text {th }}$ regional meeting of the Chicago linguistic society. Chicago 1970, S. 567-578 